On the role of soil organic matter for crop production in European arable farming

Renske Hijbeek 


\section{Thesis committee}

\section{Promotor}

Prof. Dr. Martin K. van Ittersum

Personal chair at the Plant Production Systems Group

Wageningen University \& Research

\section{Co-promotor}

Dr. Hein F. M. ten Berge

Senior researcher at Agrosystems Research

Wageningen University \& Research

\section{Other members}

Prof. Dr. Oene Oenema, Wageningen University \& Research

Dr. Julie Ingram, University of Gloucestershire, UK

Dr. Frank Verheijen, University of Aveiro, Portugal

Dr. Hans J. M. van Grinsven, Netherlands Environmental Assessment Agency (PBL), the Hague, the Netherlands

This research was conducted under the auspices of the C.T. de Wit Graduate School Production Ecology and Resource Conservation - PE\&RC. 


\title{
On the role of soil organic matter for crop production in European arable farming
}

\author{
Renske Hijbeek
}

Thesis

submitted in fulfilment of the requirements for the degree of doctor

at Wageningen University

by the authority of the Rector Magnificus

Prof. Dr. A.P.J. Mol,

in the presence of the

Thesis Committee appointed by the Academic Board

to be defended in public

on Wednesday 4 October 2017

at 1.30 p.m. in the Aula. 
Renske Hijbeek

On the role of soil organic matter for crop production in European arable farming 211 pages

$\mathrm{PhD}$ thesis, Wageningen University, Wageningen, the Netherlands (2017) With references, with summary in English

ISBN 978-94-6343-663-2

DOI https://doi.org/10.18174/421022 
"The management of organic matter for nutrient supply and soil improvement is as old as the history of arable agriculture itself. Yet science has been slow to provide the predictive understanding that will assist farmers to move beyond their own traditional knowledge based on centuries of empirical trial and error"

(Palm et al. 2001) 


\begin{abstract}
The aim of this thesis was to improve understanding of the role of organic inputs and soil organic matter (SOM) for crop production in contemporary arable farming in Europe. For this purpose, long-term experiments were analysed on the additional yield effect of organic inputs and savings in mineral fertiliser. In addition, a farm survey was conducted to find drivers and barriers for the use of organic inputs and to assess if arable farmers in Europe perceive a deficiency of SOM.

The findings in this thesis suggest that at least on the shorter term, on average, there seems to be no immediate threat from a deficiency of SOM to crop production in arable farming in Europe. The long-term experiments showed that with sufficient use of only mineral fertilisers, on average, similar yields could be attained over multiple years as with the combined use of organic inputs and mineral fertiliser. This was reflected in the farm survey, in which a large majority of farmers indicated not to perceive a deficiency of SOM. Analysis of long-term experiments also showed that more mineral fertiliser $\mathrm{N}$ was saved when using farmyard manure at high $\mathrm{N}$ rates (with mineral fertiliser application) than at low $\mathrm{N}$ rates (without mineral fertiliser application), based on comparisons at equal yield.
\end{abstract}

Specific crops and environments did benefit from organic inputs and more SOM in terms of crop production. Long-term experiments showed that organic inputs give benefit to crop production in wet climates and on sandy soils. In addition, farmers perceived a higher deficiency of SOM on steep slopes, sandy soils, wet and very dry climates. The additional yield effect of organic inputs was significant for potatoes. More in general, farmers who cultivated larger shares of their land with specialized crops (including potatoes, sugar beets, onions and other vegetables) than cereals perceived a higher deficiency of SOM. It seems that while the functions of SOM can be replaced with technical means to a large extent (e.g. tillage, use of mineral fertilisers), there are limits to this technical potential when environmental conditions are more extreme and crops are more demanding.

The farm survey revealed that farmers perceive a trade-off between improved soil quality on the one hand and increased pressures from weeds, pests and diseases and financial consequences on the other hand when using organic inputs. If policies aim to stimulate the maintenance or increase of SOM, more insight is needed into the conditions that regulate the pressures of weeds, pests and diseases in response to organic inputs. Financial consequences (at least on the short term) should also be accounted for. More importantly however, benefits from SOM for crop production cannot be taken for granted. Only in specific situations such benefits will exist. If European policies on SOM aim to include benefits for crop production, focus should be on areas with more extreme environmental conditions (very dry or wet climates, steep slopes, sandy soils), or cropping systems with more specialized or horticultural crops rather than cereals. 


\section{Contents}

$\begin{array}{lll}\text { Chapter } 1 \text { General introduction } & 1\end{array}$

Chapter 2 Do organic inputs matter - a meta-analysis of additional yield 13 effects for arable crops in Europe

Chapter 3 Nitrogen fertiliser replacement values for organic inputs 41 appear to increase with $\mathrm{N}$ application rates

Chapter 4 Drivers and barriers for arable farmers to use organic inputs 57 in six agro-ecological zones across Europe

Chapter 5 How are farmers' beliefs on soil organic matter related to 95 their use of organic inputs? A case study in the Netherlands

Chapter 6 Do farmers perceive a deficiency of soil organic matter? A 123 European and farm level analysis

Chapter 7 General discussion

List of references

Summary/ Samenvatting

Acknowledgements

About the author 206

List of publications 207

PE\&RC Education certificate 209

Financial support 


\section{Chapter 1. General introduction}

Soil organic matter (SOM) is known to improve many soil properties such as soil structure, water holding capacity and nutrient supply (Johnston et al. 2009). For this reason, SOM content is commonly seen as the main indicator for soil fertility (Reeves 1997). Yet there is surprisingly little scientific consensus on the exact relation between SOM and crop production. For such a generally accepted indicator this might seem rather strange at first. However, when the many pathways through which SOM affects soil productivity are considered, and how these may vary, depending on the prevailing environment and cultivation technologies, it becomes more understandable.

European agriculture benefits from a mostly temperate climate and has achieved relatively high yields through intensive use of external inputs and technologies. Nonetheless, concerns have been raised that SOM is declining in European soils (Morari et al. 2016; Toth et al. 2008). Therefore, proposals have been made to maintain SOM above 3.5\% SOM (EC 2011a) or increase SOM annually with 4\%o (UNFCCC 2015) to protect productive capacity of soils. It is currently unclear whether these concerns are justified. The aim of this thesis is to improve understanding of the role of organic inputs and SOM for crop production in contemporary arable farming in Europe. Effects of SOM on crop productivity are analysed in European soils and climates and with current degrees of intensification. In addition, perceptions of European arable farmers on the use of organic inputs and their SOM content are assessed using a farm survey.

In this chapter, I introduce my thesis by providing a short overview on SOM composition and the carbon cycle (Section 1.1). This should be considered background information and is not intended to be comprehensive. For further details, readers are advised to follow the references. Subsequently, an overview is given on the different functions SOM has in arable farming and how these relate to environmental conditions and farm management (Sections 1.2 to 1.5). This leads us to the research questions and outline of this thesis (Sections 1.6 and 1.7).

\subsection{SOM and the carbon cycle}

SOM is composed of plant or animal debris (including faeces) in various stages of decomposition to humus and includes the living organisms in soils (Oades 1988). Based on physical fractionation, SOM can be divided into a number of fractions based on either particle size, density class or aggregate size (Stockmann et al. 2013). Based on chemical 
fractionation, SOM is often divided into humic acids, fulvic acids, and humin (Stevenson 1994; Stockmann et al. 2013).

In contrast, for modelling purposes SOM is often divided into a number of arbitrary pools, based on decomposition rates rather than chemical or physical characteristics (Shibu et al. 2006). When these model pools were conceived, they were conceptual in nature and could not be directly related to measurable fractions (Zimmermann et al. 2007). Some authors have tried to relate SOM fractions to SOM pools used for modelling purposes (Dungait et al. 2012; Wander 2004; Zimmermann et al. 2007). In these cases, often three broad categories are used which can be denoted active, slow or passive SOM (for an example see Table 1.1). Besides chemical stabilization, SOM can also be physically stabilized through association with silt and clay particles (Feller \& Beare 1997; Six et al. 2002) or by forming micro and macro aggregates (Tisdall \& Oades 1982).

Table 1. 1 Mean residence time of SOM pools used in the Century model linked to chemical compounds (based on Dungait et al. 2012; Stockmann et al. 2013).

\begin{tabular}{|c|c|c|}
\hline & Mean residence time (yr) & Chemical compounds \\
\hline \multirow{3}{*}{ Active SOM } & \multirow[t]{3}{*}{ 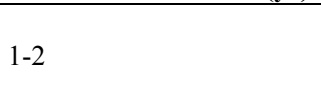 } & Living biomass \\
\hline & & Particulate organic matter \\
\hline & & Polysaccharides \\
\hline \multirow{3}{*}{ Slow SOM } & \multirow{3}{*}{$15-100$} & Lignified tissues \\
\hline & & Waxes \\
\hline & & Polyphenols \\
\hline \multirow{3}{*}{ Passive SOM } & \multirow{3}{*}{$500-5000$} & Humic substances \\
\hline & & Clay-OM complexes \\
\hline & & Biochar \\
\hline
\end{tabular}

Rice and MacCarthy (1991) have shown that elemental composition of SOM (carbon $[\mathrm{C}]$, hydrogen $[\mathrm{H}]$, oxygen $[\mathrm{O}]$, nitrogen $[\mathrm{N}]$ and sulphur $[\mathrm{S}]$ ) is very similar around the world, regardless of the origin. This suggests that a relatively narrow range of compositions exists for SOM, especially for C content. Conventionally the factor 1.72 is used between SOM and SOC (Pribyl 2010; Waksman \& Stevens 1930).

Despite the similarity in elemental contents, it is not possible to construct a molecular structure that fully describes a humic substance (MacCarthy 2001). In addition, no scientific consensus exists on how formation of SOM molecules takes place. Lehmann and Kleber (2015) identify four theoretical models on SOM formation: 1) classic humification; 2) selective preservation; 3) progressive decomposition and 4) soil continuum model. In classic humification, synthesis of decomposed and smaller molecules results in large macromolecules resistant to decomposition (Schulten et al. 
1991; Stevenson 1994). Selective preservation is similar to classic humification, with the difference that compounds can be labile or more recalcitrant and that the latter do not necessarily have to be large macromolecules (Baldock et al. 1992). In progressive decomposition, organic materials are degraded on an energetic downhill trajectory, as opposed to the classic humification model (Hedges et al. 2000; Lehmann \& Kleber 2015). Finally, in the soil continuum model, a continuum of organic fragments exists that are continuously processed towards smaller molecular sizes while at the same time opportunities for incorporation into aggregates increase (Lehmann \& Kleber 2015).

Carbon is an essential component of SOM and part of the global carbon cycle. In the global carbon cycle, three large reservoirs of carbon exist: sedimentary carbonates and kerogens (together $>60,000,000 \mathrm{Pg} \mathrm{C}$, Falkowski et al. 2000), ocean reservoirs $(38,400$ Pg C, Falkowski et al. 2000) and reservoirs of fossil fuels (mean estimation 1,972 Pg C, Ciais et al. 2013). Sedimentary carbonates and large parts of the ocean reservoirs are inorganic carbon. In addition to these reservoirs, smaller pools of carbon exist, of which size estimations differ. Generally, the soil carbon pool (around 1,500 $\mathrm{Pg} \mathrm{C}$ ) is thought to be roughly three times larger than the terrestrial vegetation carbon pool (500 Pg C) and two times larger than the carbon present in the atmosphere (currently around 829 Pg C, Ciais et al. 2013; Janzen 2004; Scharlemann et al. 2014).

Since the start of the industrial revolution (middle of the $18^{\text {th }}$ century) concentrations of atmospheric carbon dioxide $\left(\mathrm{CO}_{2}\right)$ have increased from around $280 \mathrm{ppm}$ to $400 \mathrm{ppm}$ in 2016 (Dlugokencky \& Tans 2017; Eggleton 2013). This increase in $\mathrm{CO}_{2}$ concentration is mainly caused by the burning of fossil fuels and to a lesser extent cement production and land use change (Le Quéré et al. 2012).

\subsection{SOM content of arable fields}

Between 1765 and 2005, 6.6-6.8 million $\mathrm{km} 2$ of forest land has been converted into crop land (Meiyappan \& Jain 2012). Conversion from natural vegetation - especially forests - to agriculture almost always causes a decrease in SOM content (Poeplau \& Don 2015) due to non-permanent vegetation, export of biomass and consequently reduced amounts of organic inputs. It has been estimated that the global soil carbon pool has decreased $78 \pm 12 \mathrm{Pg}$ between 1850 and 1998 due to land use change and soil cultivation (Lal 2004a). If SOM content could be increased in arable lands, this would be a potential global carbon sink (Lal 2004b). Therefore, a number of initiatives exist to promote soil carbon sequestration, such as the recent 4/1000 initiative (UNFCCC 2015). 
Increasing SOM content in arable fields is however strongly limited by environmental conditions and inherent SOM dynamics (Ingram \& Fernandes 2001). SOM content is a balance between rates of inputs (composition) and rates of outputs (decomposition). This balance is affected by three environmental factors (soil texture, temperature and precipitation) and management (Burke et al. 1989; Haynes \& Naidu 1998; Kätterer et al. 1998; Krull et al. 2001; Leiros et al. 1999; Miller et al. 2004; Motavalli et al. 1995).

Which crops a farmer cultivates and the achieved yields determine together the amounts of available crop residues that can be returned to the soil. Amounts of crop residues can be increased by cultivating green manures within a crop rotation, including more cereals or returning crop residues such as straw which otherwise would have been sold. If available, a farmer can also import organic inputs from other fields or livestock farms. In addition, a number of crop management choices such as drainage or tillage systems and crop protection or erosion prevention measures influence the actual SOM content of a field.

On a given arable field, a farmer can thus increase SOM content by: 1) increasing organic inputs, ii) reducing tillage or iii) reducing drainage (Verheijen 2005b). The effect of reducing tillage on SOM depends on soil texture, with more effects shown on clay soil than on sandy soils (Chivenge et al. 2007). Reducing tillage might only increase stratification of SOM in the surface soil horizons, while reducing SOM content below, with no net change as a result (Baker et al. 2007; Luo et al. 2010).

\subsection{Benefits of SOM for soil fertility}

SOM content is known to improve soil fertility by stabilizing soil structure, increasing nutrient availability and improving water holding capacity (Johnston et al. 2009; Watts $\&$ Dexter 1997). Despite these positive attributes, crop yields do not always increase with higher SOM contents (Loveland \& Webb 2003). This discrepancy between improvements in soil quality and lack in yield response has been explained by De Haan (1977) and Janssen (2002). They assert that apparently sometimes factors improved by adding organic matter are not the yield limiting ones.

Crop yield factors can be divided into three categories: water, nutrients and pests and diseases (Fig. 1.1, arrows 8 to 10; van Ittersum \& Rabbinge 1997). SOM contents affects yield factors in a number of ways such as by increasing the cation exchange capacity, improving aggregate stability or changing soil microbial mass (Fig. 1.1, arrows 1 to 6). Farmers might profit from SOM content if yields are increased (Fig. 1.1, arrow 11) or if 
improved workability of the soil leads to more flexibility in their working schedule (Fig. 1.1 , arrows 7 and 12).

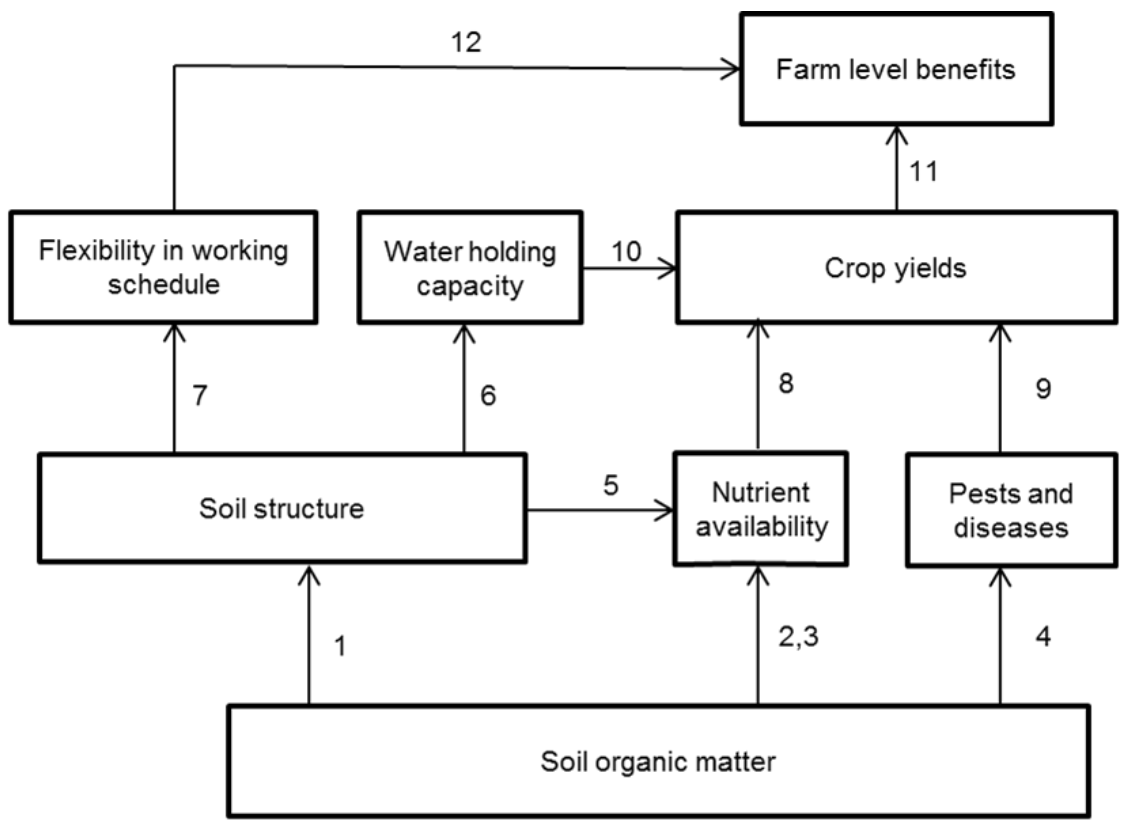

\section{Direct effects on soil fertility: \\ 1. Aggregate stability \\ 2. Increase of cation and anion exchange capacity}

3. Year-round release of $\mathrm{N}, \mathrm{P}, \mathrm{S}$ and some trace elements

4. Increase or change in soil microbial biomass
Indirect effects on soil fertility:

5. Ease of root penetration

6. Increase of adhesive forces due to aggregation of mineral particles

7. Stabilization of soil structure

\section{Effects on yield limiting Effects at farm factors: \\ Level: \\ 8. Reducing nutrients as 11 . Increase in a yield limiting factor crop \\ 9. Reducing pests and production diseases as yield 12. Reduction in reducing factors \\ 10. Reducing water as a yield limiting factor machinery costs}

Fig 1. 1: Schematic overview of the different functions of SOM and relations with crop yields and farm level benefits.

During the last century, different technical replacements have been developed which replace some of the functions of SOM (Fig. 1.2, van Noordwijk et al. 1997). Mineral fertilisers can complement nutrient supply, irrigation can complement water holding capacity and an array of pest control methods have been developed (chemical or biological) which can replace or complement these functions of SOM. The degree of intensification often determines the extent to which a cropping system relies on SOM or on technical replacements to provide the functions mentioned. 
In traditional agricultural systems, SOM content is maintained either by importing organic inputs from other fields or by rotating cultivated land (e.g. slash-and-burn agriculture or using a ley-arable cropping system). Slash-and-burn agriculture is hereby a typical example of a cropping system that primarily relies on SOM for all the functions. Hydroponic horticulture is a typical example in which SOM has been completely replaced by technical means. Most other cropping systems fall somewhere in between (horizontal axis Fig. 1.2).

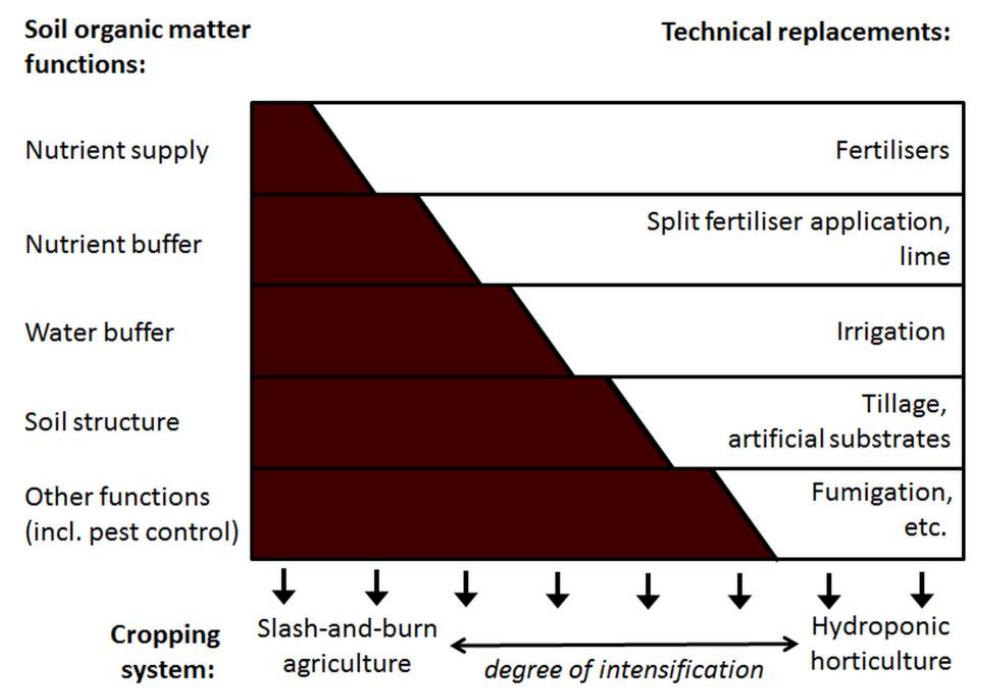

Fig 1. 2: Schematic overview of the existing technical replacements of SOM (van Noordwijk et al. 1997).

For nutrient supply, using a combination of both mineral fertilisers and organic inputs has been recommended, in what is framed as integrated soil fertility management (Richards et al. 2016; Vanlauwe et al. 2010). N in organic inputs is released more slowly than $\mathrm{N}$ in mineral fertilisers, mainly depending on the $\mathrm{C} / \mathrm{N}$ ratio (Flavel \& Murphy 2006). Therefore, $\mathrm{N}$ in organic inputs must be carefully matched with mineral fertiliser $\mathrm{N}$ application to make sure that sufficient $\mathrm{N}$ is available for crop growth while avoiding leaching. One manner in which this can be done is to characterize organic inputs by their Nitrogen Fertiliser Replacement Value (NFRV, Jensen 2013). NFRV is defined as the amount of mineral fertiliser $\mathrm{N}$ saved when using organic input- $\mathrm{N}(\mathrm{kg} / \mathrm{kg})$, while attaining the same crop yield (Herron \& Erhart 1965).

It is often difficult to disentangle the different functions of SOM as they are interdependent. Janssen (2002) made a division between effects of SOM through the 
provision of macro-nutrients (N, P and $\mathrm{K}$ ) and other effects. Any effect of organic inputs or SOM on crop yield not related to macro-nutrients is called "the additional yield effect of SOM"'Janssen 2002). De Haan (1977) made an investigation into the additional yield effect of farmyard manure (FYM) in two experiments in the Netherlands. After around 20 years he found a positive additional yield effect for potatoes and sugar beets, but no effects on cereals. As his analysis was only based on two experimental sites with FYM, it's not clear to which extent these results are valid for different types of organic inputs across different climates and soil types.

\subsection{Threshold values for SOM}

With a decrease in SOM content, most soil properties change along a continuum (Karlen et al. 2001). This continuous change is one of the factors which makes it difficult to define a critical or desirable SOM content for farmers (Sparling et al. 2003). Even so, for the percentage of SOM to be a useful indicator for productive capacity, target values need to be specified. Sparling et al. (2003) argue in favour of a minimum or threshold soil C value: "below which there would be loss of desirable soil characteristics, productive capacity and ecological functions that were not readily restored within an acceptable timeframe".

A number of authors have tried to specify minimum or threshold values for SOM for crop production (also called critical levels), using a range of approaches such as information from soil surveys, literature reviews, soil organic carbon modelling, expert opinions or a combination of these (Aune \& Lal 1997; Körschens et al. 1998; Loveland $\&$ Webb 2003; Sparling et al. 2003). Proposed threshold values range between 1 to $5.1 \%$ SOM ( 0.6 to $3 \%$ SOC). None of the authors of these studies asked farmers for their views whilst farmers are the group of stakeholders with the longest and most practical exposure to SOM of their fields. Farmers would therefore be well suited to asses SOM in view of their local context.

\subsection{Management of SOM by farmers}

When managing their farm, farmers need to balance SOM management with different objectives such as profit maximization or labour use efficiency (Mandryk 2016). In a recent farm survey in Denmark, Case et al. (2017) found low costs an important driver for the use of organic inputs. Glenk et al. (2017) however found that organic inputs have mixed effects on farm gross margin. In two different areas in Europe (Scotland and 
Spain), incorporation of straw was found to have a negative effect on farm gross margin, cultivation of green manure a small negative or neutral effect and the application of animal manure had a positive effect on farm gross margin. This study relied on an economic model which only included effects on crop yields and input costs. Farmers might have a larger number of drivers and barriers for using certain measures, beyond effects on yields and input costs, such as seasonal labour or machinery requirements. Glenk et al. (2017) note that farmers' behaviour may be motivated by factors which are not directly economic such as perceived workability of the soil, or soil health for future generations.

Similarly, Van den Putte et al. (2010) argue that farmers often have too few incentives to use soil conservation measures because productive capacities of farms are not affected by soil degradation in the short term (and thus not included in economic models). Simple cost-benefit models do not capture the complexity of farmers' behaviour and attitudes (Lynne et al. 1988). Therefore, Burton (2004) argues that using the theory of planned behaviour (Ajzen 1991) might improve our understanding of farmers' willingness to adopt certain management practices.

According to the theory of planned behaviour, farmers will base their SOM management on three main constructs: 1) their attitude, 2) their subjective (social) norm and 3) the degree of perceived behavioural control. The attitude refers to the expected impact or outcome of SOM management. The subjective norm is the social pressure to manage SOM in a certain way. Perceived behaviour control reflects past experiences and anticipated impediments and obstacles for SOM management. This theory can be used to find drivers and barriers for farmers to use specific measures (such as specific types of organic inputs) or to understand farmers' intention to increase SOM content of their soils.

\subsection{Research questions}

My aim in this thesis is to improve understanding of the role of organic inputs and SOM for crop production in contemporary arable farming in Europe. The adjective term contemporary relates to the current level of agricultural intensification in Europe (relatively high yields and intensive use of external inputs and technologies), placed more to the right on the horizontal axis of Fig. 1.2. The following research questions are addressed: 
- What is the additional yield effect of organic inputs for arable crops in Europe? (Chapter 2)

- Do mineral fertiliser savings from organic inputs depend on total $\mathrm{N}$ supply? (Chapter 3)

- What are currently the main drivers and barriers for arable farmers to use organic inputs? (Chapter 4)

- How are farmers' beliefs on SOM related to their use of organic inputs? (Chapter 5)

- Do farmers perceive a deficiency of SOM? (Chapter 6)

This thesis uses data form field and farm level to answer the research questions. To answer the first two research questions, data from long-term experiments were analysed. To answer the last three research questions, a large farm survey was conducted in six European countries (the Netherlands, Belgium, Austria, Spain, Italy and Germany).

\subsection{Outline of the thesis}

This thesis consists of this introductory chapter, five research chapters and a discussion chapter. Each of the research chapters answers a research question. In Fig. 1.3 an overview is given of the research questions, outcomes and the relationships between the different components of this thesis.

The effect of SOM on crop production will depend on the measure used to maintain or increase SOM content. My research focuses on the use of organic inputs as a measure to maintain or increase SOM content. As mentioned, organic inputs can be crop residues, green manures, compost or animal manures (also called organic fertilisers, organic amendments, organic manures or organic resources). In Chapters 2 to 5, relationships between the use of different types of organic inputs and crop production are analysed. In Chapters 2, 5 and 6, the relationships between SOM and crop production are analysed (Table 1.2). 


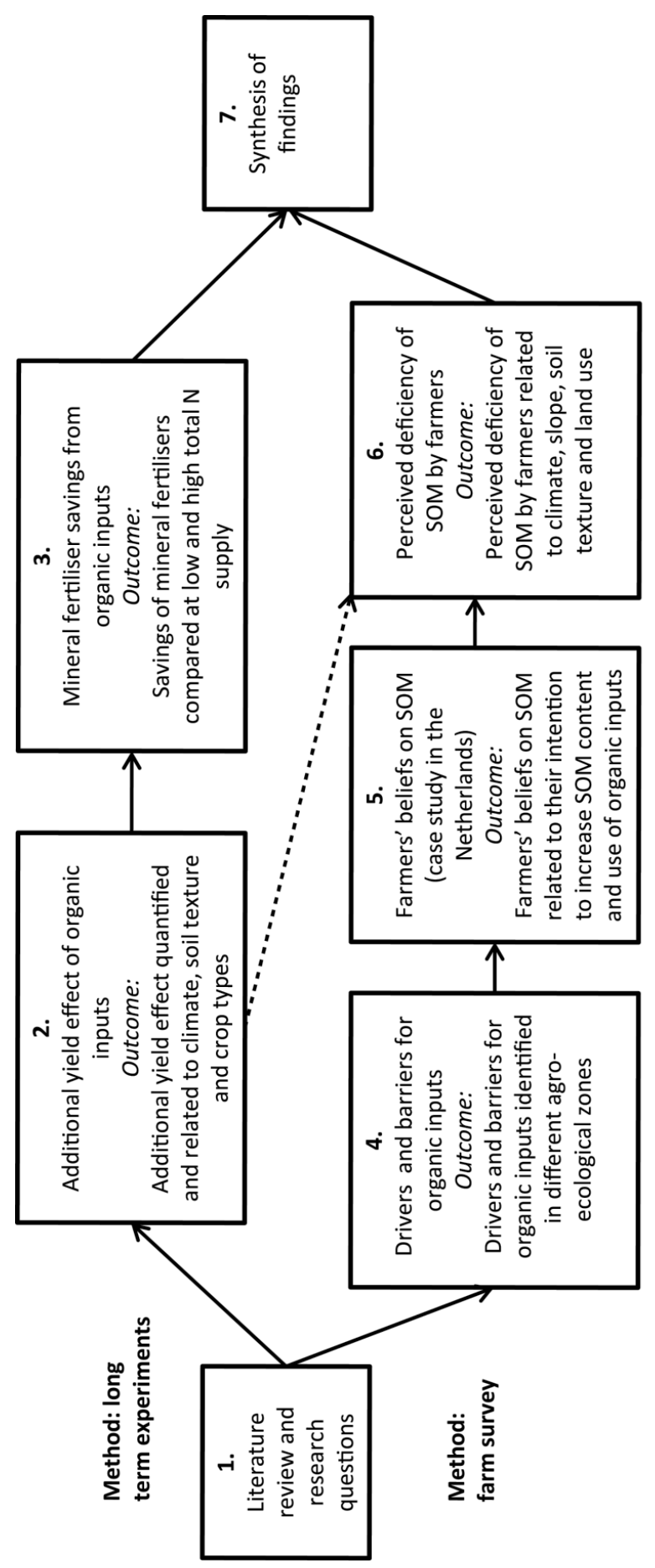

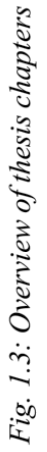


Table 1. 2: Focus on either SOM or on the use of organic inputs in each research chapter

Subject of investigation:

\begin{tabular}{lcc} 
& Organic inputs & SOM \\
\hline Chapter 2. Additional yield effects of organic inputs & $\mathrm{X}$ & $\mathrm{X}$ \\
Chapter 3. Mineral fertiliser savings from organic inputs & $\mathrm{X}$ & $\mathrm{X}$ \\
Chapter 4. Drivers and barriers for organic inputs & $\mathrm{X}$ & $\mathrm{X}$ \\
Chapter 5. Farmers' beliefs on SOM (case study in the Netherlands) & & $\mathrm{X}$ \\
Chapter 6. Perceived deficiency of SOM by farmers & & \\
\hline
\end{tabular}

I hypothesize that the contribution of SOM to crop production on arable farms depends on environmental conditions and crop types cultivated. Where possible, analyses therefore include effects of environmental factors (slope, soil texture and climate) and types of crops cultivated on the relation between SOM and crop production (Table 1.3).

Table 1. 3: Overview of environmental factors and land use included as co-variables in each chapter

\begin{tabular}{|c|c|c|c|c|}
\hline & Climate & Slope & $\begin{array}{c}\text { Soil } \\
\text { texture }\end{array}$ & $\begin{array}{l}\text { Crop } \\
\text { type }\end{array}$ \\
\hline Chapter 2. Additional yield effects of organic inputs & $\mathrm{X}$ & & $\mathrm{X}$ & $\mathrm{X}$ \\
\hline Chapter 3. Mineral fertiliser savings from organic inputs & & & & \\
\hline Chapter 4. Drivers and barriers for organic inputs & $\mathrm{X}$ & $\mathrm{X}$ & $\mathrm{X}$ & \\
\hline Chapter 5. Farmers' beliefs on SOM (case study in the Netherlands) & & & $\mathrm{X}$ & \\
\hline Chapter 6. Perceived deficiency of SOM by farmers & $\mathrm{X}$ & $\mathrm{X}$ & $\mathrm{X}$ & $\mathrm{X}$ \\
\hline
\end{tabular}

Chapter 2 differentiates the additional yield effect for climate, soil texture and crop type. Chapter 4 differentiates drivers and barriers for organic inputs by agro-ecological zones, which are based on climate, slope and soil texture. In a case study in the Netherlands, Chapter 5 differentiates farmers' intention to increase SOM content by soil texture. Chapter 6 differentiates perceived deficiency of SOM by farmers by climate, slope, soil texture and crop types cultivated.

In Chapter 2, a meta-analysis was performed to find the additional yield effect of organic inputs and SOM. Using data from 20 long-term experiments, yield response curves to mineral fertiliser-N were calculated, with and without organic inputs (and with sufficient $\mathrm{P}$ and $\mathrm{K}$ supply). The additional yield effect of organic inputs was calculated by taking the difference between the maxima of the yield response curves. The size of the additional yield effect was related to clay content, aridity, crop types and SOM content of the fields.

In Chapter 3, yield response curves to mineral fertiliser-N were calculated, with and without organic inputs (and with sufficient $\mathrm{P}$ and $\mathrm{K}$ supply). Using data from eight long- 
term experiments, savings in mineral fertiliser $\mathrm{N}$ from organic inputs were compared at low and high total $\mathrm{N}$ supply.

In Chapter 4, the theory of planned behaviour was used to analyse drivers and barriers for the use of organic inputs (incorporation of straw, cultivation of green manures or cover crops, FYM and compost). A farm survey was held among 1180 arable farmers in six agro-ecological zones in four European countries (the Netherlands, Belgium, Austria and Italy). Drivers and barriers were based on underlying beliefs of farmers and classified into nine main categories (soil type \& climate, soil quality, crop protection, land use, technical, financial, environmental impact, legal and social). Drivers and barriers were compared per type of organic input and agro-ecological zone.

To assess how farmers' underlying beliefs on SOM are related to their intention to increase SOM content and use of organic inputs, a case study was done in the Netherlands (Chapter 5). In an online survey, 435 arable farmers were asked questions to understand their attitude (perceived benefits), subjective norm (social pressure) and perceived behavioural control (anticipated impediments and obstacles) related to management of SOM. Farmers' answers were compared to their intention to increase SOM content, reported use of organic inputs and perceived increase in SOM content.

A risk indicator for SOM deficiency is proposed in Chapter 6 based on environmental factors (climate, slope and soil texture) and agricultural land use. The proposed risk indicator was tested using a farm survey among 1452 farmers in five European countries (Belgium, Germany, Austria, Spain and Italy). Threshold values for SOM content were developed by comparing perceived deficiency of SOM to reported SOM contents by farmers.

Chapter 7 summarizes and integrates the various chapters. First, an answer is given to each research question. Then, the influence of environmental factors and crop types on the relation between SOM and crop production on arable farms in Europe is discussed. Following, attention is given to synergies and trade-offs with other ecosystems services and limitations of the study. Finally, implications of the findings are presented. 


\section{Chapter 2.}

\section{Do organic inputs matter - a meta-analysis of additional yield effects for arable crops in Europe}

Renske Hijbeek ${ }^{1}$, Martin K. van Ittersum ${ }^{1}$, Hein F.M. ten Berge ${ }^{2}$, Gerrit Gort ${ }^{3}$, Heide Spiegel $^{4}$, and Andy P. Whitmore ${ }^{5}$

${ }^{1}$ Plant Production Systems, Wageningen University and Research, Wageningen, the Netherlands.

${ }^{2}$ Plant Research International, Wageningen University and Research, Wageningen, the Netherlands.

${ }^{3}$ Biometris, Wageningen University and Research, Wageningen, the Netherlands.

${ }^{4}$ Institute for Sustainable Plant Production, Austrian Agency for Health and Food Safety, Vienna, Austria.

${ }^{5}$ Sustainable Soils and Grassland Systems, Rothamsted Research, Harpenden, UK

Plant and Soil (2017) 411: 293-303 


\begin{abstract}
Organic inputs have a positive effect on the soil organic matter balance. They are therefore an important asset for soil fertility and crop growth. This study quantifies the additional yield effect due to organic inputs for arable crops in Europe when macronutrients are not a limiting factor.

A meta-analysis was performed using data from 20 long-term experiments in Europe. Maxima of yield response curves to mineral fertiliser nitrogen were compared, with and without organic inputs, under abundant $\mathrm{P}$ and $\mathrm{K}$ supply.

We were surprised to find that, across all experiments, the mean additional yield effect of organic inputs was not significant (+ 1.4 percent $\pm 1.6-95 \%$ Confidence Interval). In specific cases however, especially for root and tuber crops, spring sown cereals, or for very sandy soils or wet climates, organic inputs did increase attainable yields. A significant correlation was found between increase in attainable yields and increase in soil organic matter content.
\end{abstract}

Aggregating data from 20 long-term experiments in Europe, this study shows that organic inputs and/or soil organic matter do not necessarily increase yields, given sufficient nutrients are supplied by mineral fertilisers. Results show the relevance of some environmental factors for additional yield effect of organic inputs, but no simple relation between organic inputs and crop growth.

Keywords: soil fertility, soil organic matter, organic inputs, crop yield, food security, soil carbon sequestration
Abbreviations
C carbon
$\mathrm{K}$ potassium
$\mathrm{N}$ nitrogen
P phosphorus
SOC soil organic carbon
SOM soil organic matter 


\subsection{Introduction}

Soil organic matter (SOM) is often considered the most important indicator of soil fertility (Johnston et al. 2009; Reeves 1997). It contributes to each of fertility's three dimensions: the physical (structure, aeration, water retention), the biological (biomass, biodiversity, nutrient mineralisation, disease suppression) and the chemical (nutrient supply) dimension. On this basis, maintaining SOM is an important strategy to maintain crop productivity (Lal 2004a). SOM contains about 50\% organic carbon (Pribyl 2010), making it's increase a potential means to mitigate greenhouse gas emissions (Smith 2016). Because of this positive contribution to climate change mitigation and food security, a voluntary action plan has been proposed at COP21 to increase SOM in all soils, called "the 4/1000 initiative: Soils for Food security and Climate"(UNFCCC 2015).

In some cases however, yield effects of SOM seem smaller than expected. Reviewing the literature, Loveland and Webb (2003) found it difficult to establish a critical level of SOM for temperate regions. They also did not find evidence for an adverse effect on crop yields where SOM contents in the soils of England and Wales were reduced. Similarly, comparing potential yields of winter wheat and spring barley across a large range of SOM contents in Denmark, Oelofse et al. (2015) found no significant effect on yields of winter wheat and only a small effect on yields of spring barley.

The mentioned studies compared the effect of actual SOM content, they did not assess specific management practices used to increase SOM. In arable soils, SOM can be increased by increasing organic inputs or reducing organic outputs (Freibauer et al. 2004). Increasing organic inputs can be done by increasing returned biomass (roots, litter) via higher yields or adding additional organic inputs such as compost, animal manure or crop residues. Decreasing organic outputs can be done by changing the moisture content of the soil or by using reduced or no tillage, although the effect of the latter two remain disputed (Govaerts* et al. 2009). Actual increase in SOM depends on a number of factors, such as the current amount of SOM, type of organic input, and environmental factors such as temperature, soil texture, and humidity (Smith et al. 1997).

Studies assessing the effects of organic inputs on crop yields show mixed results. A recent meta-analysis of 32 long-term experiments in China compared the combined use of organic inputs and fertilizers with either only organic inputs or only fertilisers (Wei et al. 2016). The average yield increase of combining organics and fertilizers on wheat, 
maize and rice was found to be $8 \%$ compared to using only fertilizers. In a different case however, Dawe et al. (2003) found no improvement in grain yield trends with application of either manure or straw in intensive rice systems.

How do these contrasting insights compare? Although previous research has found a positive effect of either organic inputs or SOM on crop yields (Monreal et al. 1997; Wei et al. 2016), it has been argued that in these studies the effect of nutrients is seldom separated from other effects (Oelofse et al. 2015). In fact, Wei et al. (2016) mention this as the largest limitation of their study.

To circumvent this limitation, we have assessed the effect of organic inputs in a system without macro-nutrient limitation. In such a system, any effect of organic inputs on yield can be attributed to improved soil structure or soil life (the other two components of soil fertility). In our study, effects of organic inputs (also called organic fertilisers, organic manures or organic inputs) on attainable crop yields were examined in 20 long term experiments across a variety of soils and climates in Europe. To exclude the effects of macro-nutrients, the yield effect was analysed under abundant phosphorus (P) and potassium $(\mathrm{K})$ supply and varying rates of nitrogen $(\mathrm{N})$. Using this approach, we answer the following research question: Do organic inputs increase attainable yields? Previously, any effect of organic inputs or SOM on crop yield which are not related to macro-nutrients has been called the "additional yield effect"(Janssen 2002). Our objective is: to find the additional yield effect of organic inputs, beyond the nutrients supplied.

\subsection{Materials and methods}

\subsubsection{Literature search}

To find data on long term experiments in Europe, two databases with metadata were used: the EuroSOMNET metadata on 110 long-term experiments and a database compiled in a recent European research project called CATCH-C, containing 377 longterm experiments. Promising experiments were selected and publications were searched using online search engines (Google scholar, ISI Web of knowledge). When more publications were available for one treatment, only yield data from the most recent publication was included.

The following selection criteria were used to select experiments: (1) at least 4 increasing levels of $\mathrm{N}$ applications without organic inputs; (2) at least 4 increasing $\mathrm{N}$ application 
levels with organic inputs; (3) P and $\mathrm{K}$ applied in ample amounts on all fields; (4) at least 5 years of yield data; (5) if crops are cultivated in rotation, yield data available for at least 2 rotations; (6) yield data reported for individual crop types (mean yield values averaged over rotation were excluded).

Data from 20 experiments was found adhering to these selection criteria (Fig. 2.1 and Table 2.1). Following, 107 distinct data sets were created, each representing a single combination of experiment location, crop type and organic input type, covering a number of years of yield observations. All data were processed in R 3.0.0.

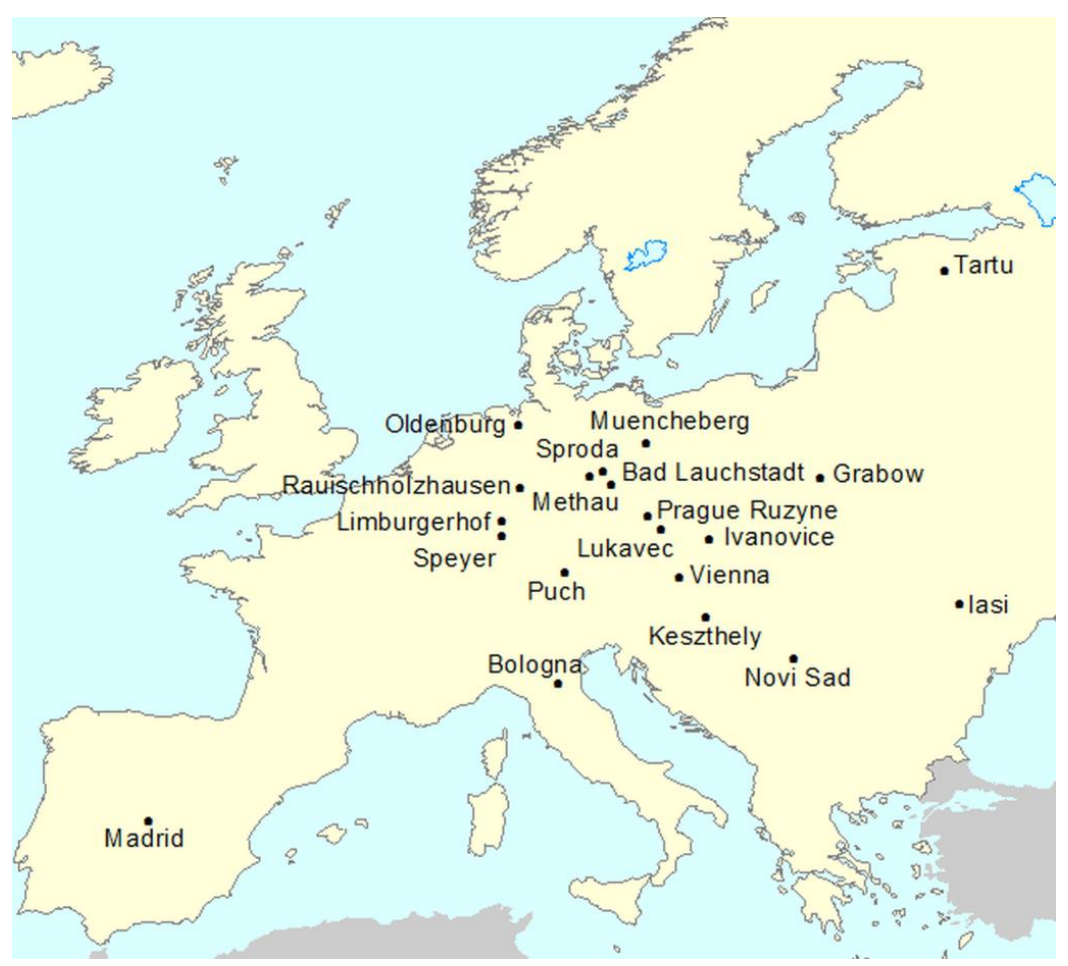

Fig 2. 1: Overview of locations of long term experiments included in the meta-analysis $(N=20)$. 


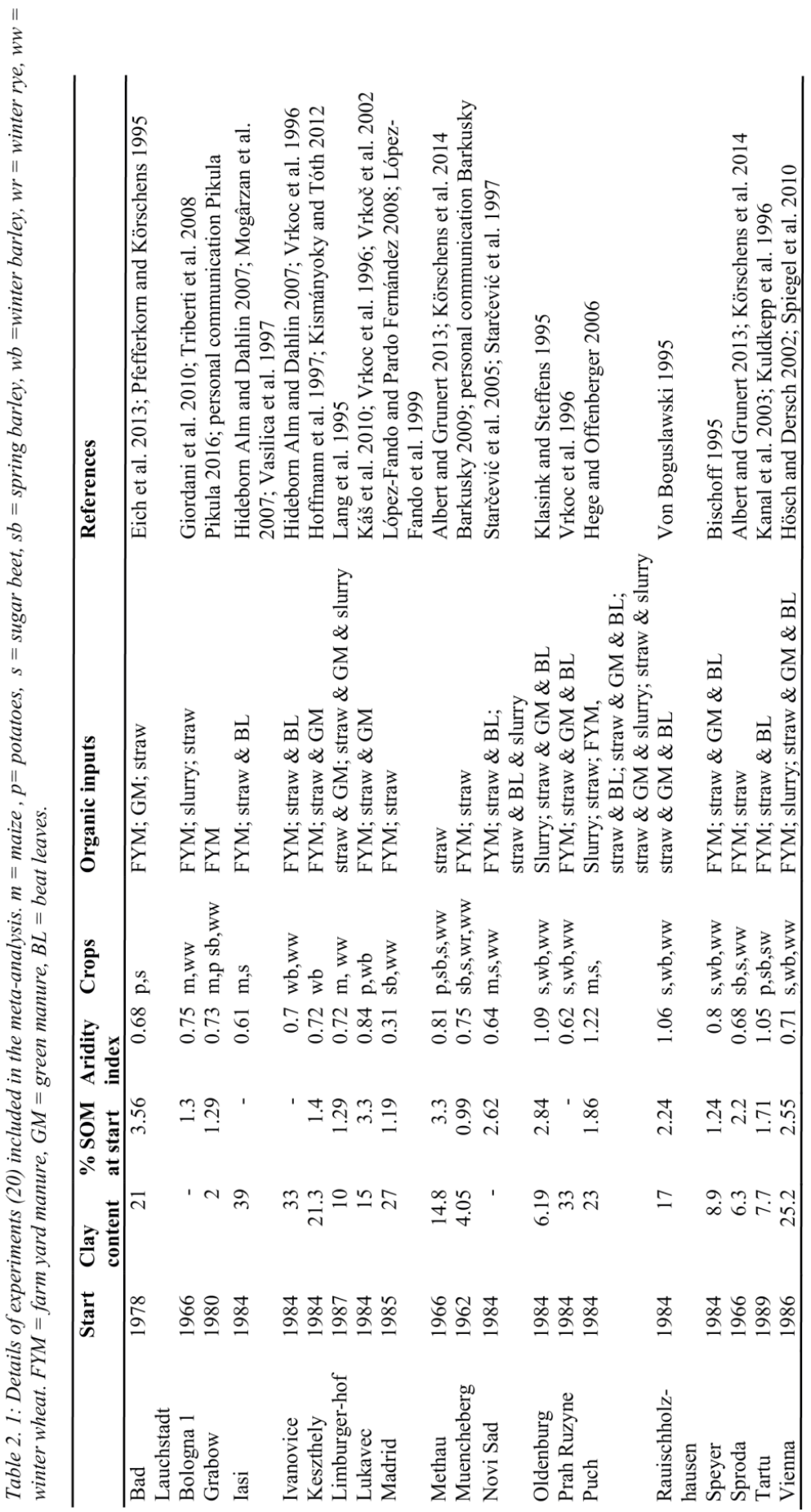




\subsubsection{Calculating additional yield effect of organic inputs for each set of data}

Crop yields are known to steeply increase at lower levels of $\mathrm{N}$ application while levelling off or slightly decrease at high levels of $\mathrm{N}$ application. When yields are known at different levels of $\mathrm{N}$ application, response curves can be fitted (Cerrato \& Blackmer 1990). For each set of data in our meta-analysis, two yield response curves were drawn: one with and one without organic inputs (Fig. 2.2a). To fit the curves, the following equation was used (George 1984):

yield $=a+B * 0.99^{N}+c * N+\varepsilon$

In Equation 2.1, $\mathrm{N}$ is nitrogen added as mineral fertiliser ( $\mathrm{kg} \mathrm{N} / \mathrm{ha}$ ), a, b and c are parameters to be fitted and $\varepsilon$ is the error term. The maximum of each curve was calculated by setting the first-order derivative equal to zero and inserting the optimal $\mathrm{N}$ rate in Equation 2.1. As $\mathrm{P}$ and $\mathrm{K}$ were applied in ample amounts, at the maximum of each curve N, P and K (the macro-nutrients necessary for crop growth) are not a limiting factor for crop yields. Accordingly, the maximum of each curve was regarded as the attainable yield for local environmental conditions and management. The additional yield effect of organic inputs was calculated by taking the difference between the attainable yield with and without organic inputs (Fig. 2.2b).
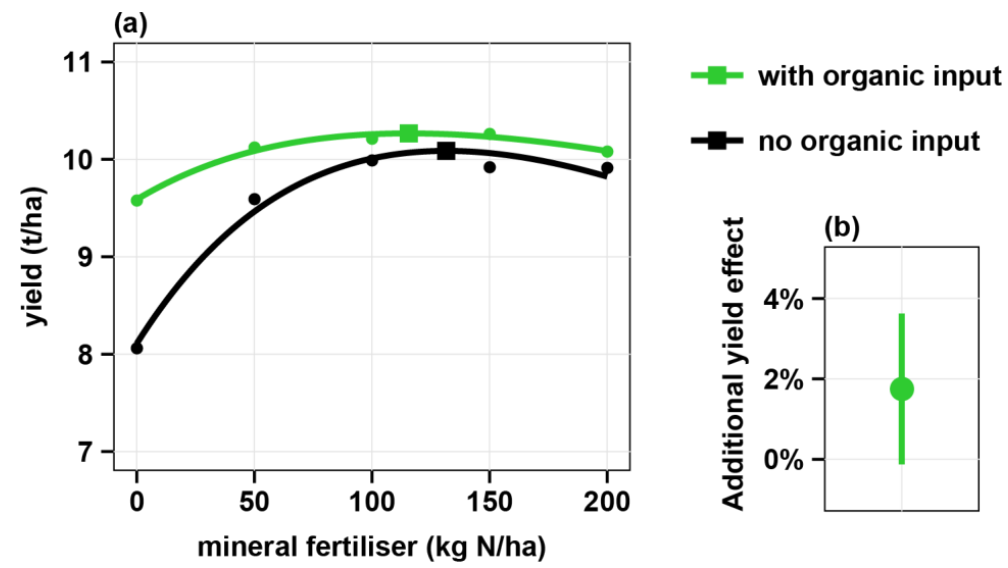

Fig 2. 2: Example of yield response curves to mineral fertiliser- $N$ under sufficient $P$ and $K$ supply with and without organic inputs. a) Black line is the response curve without organic inputs. Green line is the response curve with organic inputs. Squares indicate the maximum of each curve. The vertical difference between the two maxima is due to the additional yield effect of organic inputs. b) Green circle is the relative difference between the two maxima. Green line indicates the 95\% confidence interval due to the goodness of fit of the two curves. Yield data is from maize grown in Novi Sad between 1996 and 2003, with and without farmyard manure. 
For each data set, response curves might fit the data points better or worse, creating an error in the estimation of the additional yield effect. To correct for the goodness of fit of each curve, the delta method (Oehlert 1992) was used, giving a variance for each data set. The inverse of the variance was used as a weighting factor for the calculated additional yield effect of each data set. To enable comparisons among crops, the relative difference was chosen as the response variable in the meta-analysis, expressing the additional yield effect of organic inputs as percentage of attainable yield with only mineral fertiliser.

Supplementary Fig. 2.1 to 2.4 show the individual response curves, while Supplementary Fig. 2.5 gives the additional yield effect and related $95 \%$ confidence interval for each data set (pages 30 to 35 ).

\subsubsection{Removing of outliers}

Sizes of the additional yield effects were checked for outliers by assessing the point cloud across different variables and constructing a funnel plot. If a data point was located outside the point cloud and $\mathrm{P}$ and $\mathrm{K}$ could not be excluded as yield limiting factors in the treatment without organic inputs, the data was removed from the meta-analysis (this was only necessary in one case).

\subsubsection{Assessing influence of co-variates}

To assess the influence of environmental conditions, crop characteristics or type of organic input, a number of factors and co-variables were identified. Two grouping factors were used: type of organic input and crop type. In some cases, a combination of organic inputs was used, for example straw and slurry, where one of year straw was applied and the next year slurry. Each combination of organic inputs was included as a separate category.

In addition, for each dataset the following information was obtained from the literature: clay content, percentage of SOM content at the beginning of each experiment, amount of carbon (C) in organic input, SOM change during each experiment and duration of each experiment. When numbers were given in percentage of soil organic carbon (SOC), they were multiplied with the conventional factor 1.724 ((Pribyl 2010; Waksman \& Stevens 1930). Duration of each experiment was multiplied with yearly C applied to give the total $\mathrm{C}$ added over the years. Geographical coordinates of each experiment were used to find the CGIAR-CSI Global Aridity Index (Trabucco \& Zomer 2009). 
To assess the effect of the grouping factors and co-variates, a mixed effects model with a hierarchical structure (Konstantopoulos 2011) was used. Mixed effect models allow for incorporation of random effects, which is important when observations are not from a stratified or random sampling design as is typical in meta-analyses (Gurevitch \& Hedges 1999). The following two random effects were incorporated in the analysis: (1) Experiment: As a single experiment may produce multiple data sets, experiment was used as a random factor. (2) Treatment without organic inputs: Within a single experiment, multiple treatments with organic inputs can exist (for example one treatment with farmyard manure and one with crop residues) which are all compared to the same treatment without organic inputs (with only mineral fertiliser).

Group means for crop type and type of organic input were estimated with R-package lsmeans (Lenth 2015). To find the marginal effect of each co-variate on the additional yield effect of organic inputs, a separate model was made for each co-variate using the function lme (linear mixed-effects model) of package nlme (Pinheiro et al. 2015). Within these models, log-likelihood was maximized and yield effects were weighted by the inverse of the variance. Interaction between crop type and co-variate were checked on significance. Only SOM change had a significant interaction with crop type.

\subsubsection{Model selection}

To assess which combination of co-variates and factors could best explain the difference in the additional yield effect of organic inputs, multi-model dredging was performed using the dredge function in the R-package MuMin (Barton 2015). This function constructs a list of models by combining the given co-variates and then gives a ranking according to the corrected Akaike Information Criteria (AICc), an indicator commonly used to assess model fit (Bozdogan 1987).

Two model selections were run. In the first model selection, only data from experiments was included for which information on both percentage of clay and SOM content was available (15 out of 20). For the second model selection, only experiments were included for which data on SOM change was available (8 out of 20).

\subsubsection{Sensitivity analysis}

For some sets of data, maximum yield was not reached within the $\mathrm{N}$ applications of the experimental set-up. These maxima had to be estimated beyond the experimental setup, resulting in a higher uncertainty. When analysing the data, these points could be 
either included or excluded, with each choice having its own advantage. Excluding these data points gives a dataset with more certainty on each individual estimate, but including them increases the size of the total dataset. Because a greater uncertainty results in a larger variance, meaning a smaller weight is given to a yield effect which is calculated with a maximum yield outside the experimental setup, we chose to include these data sets in the meta-analysis. To see the effect of including or excluding the maxima outside the experimental set-up, a sensitivity analysis was done on the main results.

\subsection{Results}

The mean additional yield effect of organic inputs across all 107 data sets is not significant in this meta-analysis (1.4 percent $\pm 1.6-95 \% \mathrm{CI})$. When excluding maxima estimated outside the experimental set-up, the mean yield effect is slightly higher: 1.9 percent $\pm 2.0(95 \%$ CI. $)$, yet still not significant.

\subsubsection{Additional yield effect across type of organic inputs, crop types and time of sowing}

Comparing different types of organic inputs, the yield effect is roughly similar, but only the mean additional yield effect of farmyard manure is significantly positive (2.2 percent $\pm 1.8-95 \%$ CI, Fig. 2.3a). Yet we did find effects on specific crops. For potatoes the mean yield increase is 7.0 percent $\pm 4.9(95 \% \mathrm{CI})$. In addition, our results show that maize, a crop with a less developed root system than wheat or barley, also benefits significantly from organic inputs (mean yield effect of 4.0 percent $\pm 3.7-95 \%$ CI, Fig. $2.3 b)$.

Across the 20 experiments, cereals sown in winter do not benefit form organic inputs in our meta-analysis (Fig. 2.3c). On the other hand, spring sown cereals do benefit (3.4 percent \pm 2.6 - 95\% CI). Spring sown crops have a shorter time frame to develop their root system which is needed to acquire sufficient nutrients and water (Johnston et al. 2009). Organic inputs, by improving soil structure, might facilitate this process, resulting in larger yields. 


\section{A. Type of organic input}

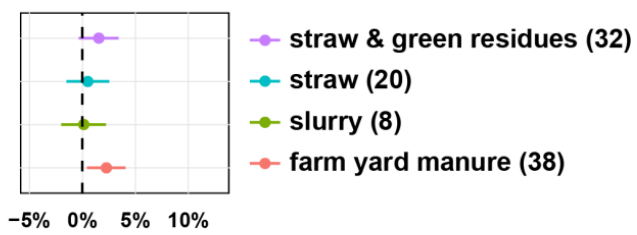

\section{B. Crop type}

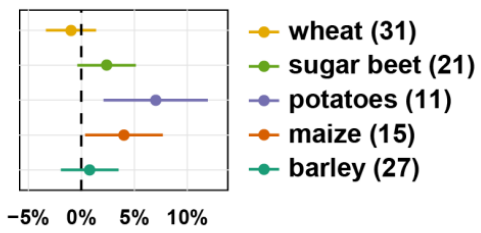

\section{Time of sowing}

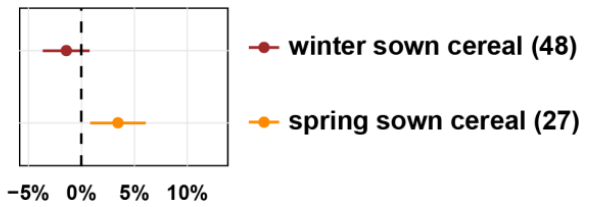

Additional yield effect of organic input

Fig 2. 3 Influence of type of organic input (a), crop type (b) and time of sowing (c) on the additional yield effect of organic inputs. Circles are mean additional yield effects, lines the 95\% confidence interval. Numbers in brackets are the number of data sets in each group. Only groups with at least 8 data sets are shown. Green residues are either green manures or beet leaves. Groups with less than 8 data sets and results of the sensitivity analysis are shown in Supplementary Fig. 2.6.

\subsubsection{Influence of soil, climate and amount of $\mathrm{C}$ added}

Crops grown on more sandy soils show a positive yield effect of organic inputs, while more clayey soils show neutral or negative yield effects (Fig. 2.4a). Relatively sandy soils normally have a poorer soil structure, which can be improved by adding organic inputs. Soils with low SOM content would also be expected to benefit more from organic inputs, but this is not apparent in our results (Fig. 2.4b).

For each experiment, climate was expressed in terms of aridity using the CGIAR-CSI Global Aridity Index (Trabucco \& Zomer 2009). Lower values indicate lower temperatures with more rainfall while higher numbers indicate higher temperatures with 
less rainfall. In our study, crops grown in wetter climates benefit more from organic inputs (Fig. 2.4c).
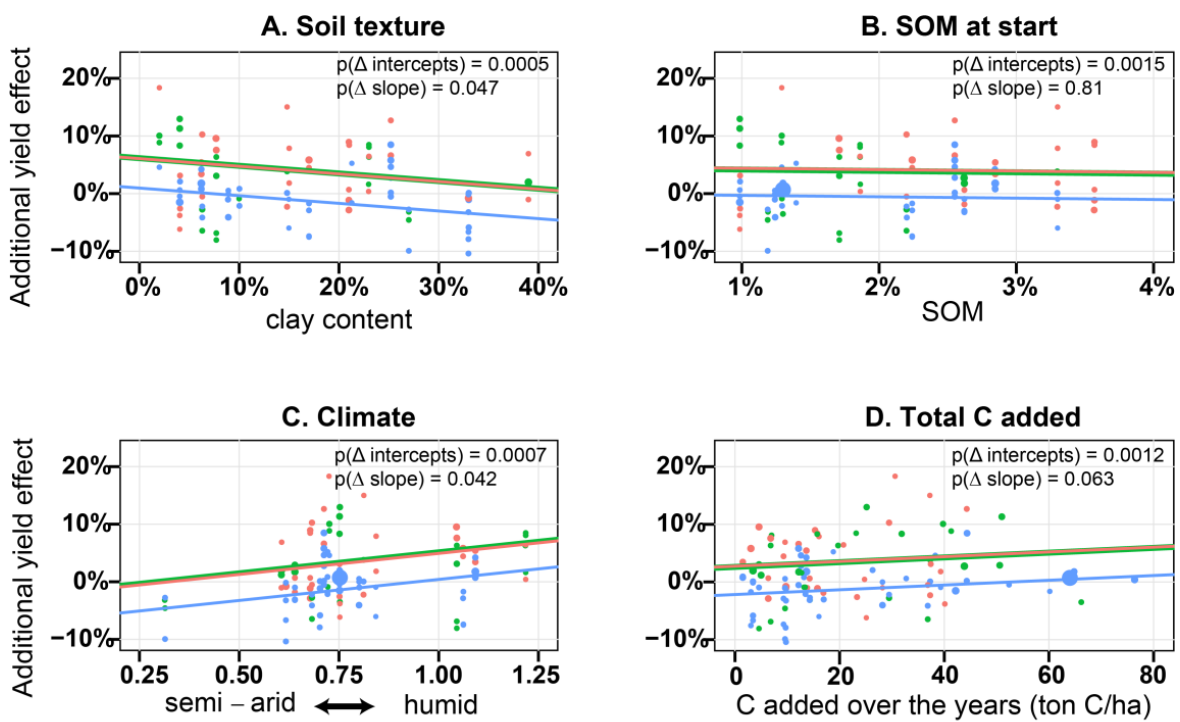

$\because$ root or tuber crop $\approx$ spring sown cereal $\multimap$ winter sown cereal

Fig 2. 4: Influence of soil texture (a), SOM content at the start of the experiment (b) climate (c) and amount of C applied over the years (d) on the additional yield effect of organic inputs. Clay content is expressed as the percentage of particles $<2 \mu \mathrm{m}$ in the soil. Climate is expressed as the CGIAR-CSI Global Aridity Index. Larger points have a smaller variance and therefore a higher weight. $P$ ( $\Delta$ intercepts) is the probability for the intercepts to be equal. $P$ (slope) is the probability the common slope is equal to zero.

Experiments differ in the type and the amounts of organic inputs applied annually, and in their duration. After converting all organic inputs to total $\mathrm{C}$ (tonnes $\mathrm{C} / \mathrm{ha}$, cumulated over the years), no significant relation was found between total $\mathrm{C}$ input and the yield effect (Fig. 2.4d).

\subsubsection{Relative increase in SOM}

For a subset of experiments, percentage increase in SOM during the experiment could be calculated. When running a model selection, combining the relative increase in SOM content with crop type gives the largest explanation of variance in the additional yield effect of organic inputs (Supplementary Tables 2.2 and 2.3, pages 37-38). The magnitude of the effect is shown in Fig. 2.5a. 


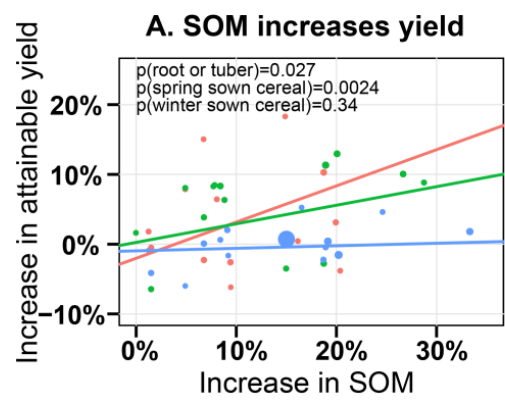

$\sim$ root or tuber crop

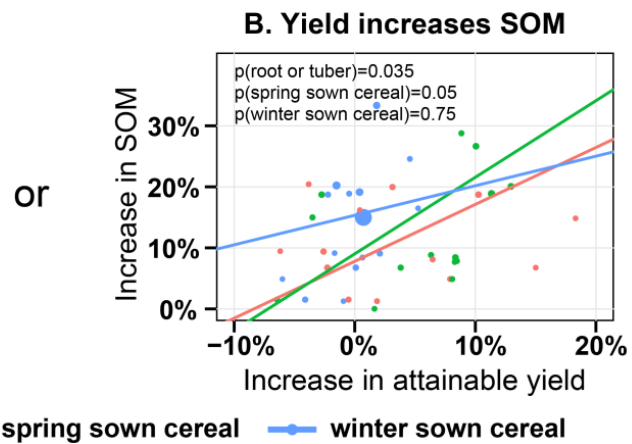

B. Yield increases SOM

$?$

Fig 2. 5 Relation between increase in SOM and yield increase. a) Increase in yield related to increase in SOM. $x$ axis: increase in SOM between the treatment with only mineral fertiliser and the treatment with organic inputs added. y-axis: difference in maximum yield between the treatment with only mineral fertiliser and the treatment with organic inputs added. b) axes vice versa from a. Larger points have a smaller variance and therefore a higher weight. P ( $\Delta$ intercepts) is the probability for the intercepts to be equal. $P(\Delta$ slope) is the probability for the slopes to be equal.

\subsection{Discussion}

When discussing possible benefits of organic inputs and SOM beyond nutrients supplied, it has been suggested that root or tuber crops might benefit more than cereals (De Haan 1977; Verheijen 2005a). The reason being that root and tuber crops depend more on soil structure for their successful cultivation and harvesting. Our study confirms this suggestion with a mean yield increase for potatoes of 7 percent.

Crops grown in both very dry or very wet conditions could potentially benefit from organic inputs as SOM increases water holding capacity in dry climates (Díaz-Zorita et al. 1999) and prevents soil compaction in wet climates (Soane 1990). In our study, crops grown in wetter climates do benefit more from organic inputs. As expected for a metaanalysis over Europe, most of our experiments (16) however have a humid climate (index $>0.65$ ), with three experiments having a dry sub-humid climate (index 0.5-0.65), one a semi-arid climate $(0.2-0.5)$ and none arid or hyper arid climates (index $<0.2)$. As very dry climate were not included, this could be the reason why we could not confirm whether organic inputs have additional yield effects in dry climates.

Very weathered soils, mostly occurring in tropical regions, were also not included in our meta-analysis. Weathered soils often have very low cation exchange capacity (Palm et al. 1997) and lack a number of micro nutrients necessary for crop growth (Gupta et al. 2008). On weathered soils therefore, yield effect of organic inputs could be larger when related to treatments with only $\mathrm{N}, \mathrm{P}$ and $\mathrm{K}$ supplied. A recent global database suggests 
experimental set-ups as used in our meta-analysis do not exist outside temperate regions (ISCN 2015), establishment of such long term experiments would therefore be recommended.

Before analysis, percentage of SOM at the start of each experiment was expected to be the largest influencing factor. Yet, no significant difference was found comparing experiments with different SOM contents (Fig. 2.4b). There is however uncertainty associated with comparing SOM contents across 20 experiments. When available, measurements of the upper soil layer or plough layer (often $24-30 \mathrm{~cm}$ ) were included in the analysis, yet depth of measurement was not always explicitly stated. In addition, measurements of SOM are known to deviate, depending on methods used (Hoogsteen et al. 2015). Even though some error in SOM measurements might be involved, our finding does correspond well with a recent study in Denmark comparing yields of winter wheat across a large range of SOM contents (Oelofse et al. 2015), with similarly no effects found.

Fig. 2.5a seems to indicate that more so than the total SOM at start (Fig. 2.4b) or the total C added (Fig. 2.4d), it is the percentage of fresh SOM in the soil which makes a difference. If so, this finding corresponds well with suggestions of (Loveland \& Webb 2003 ) that the proportions of fresh SOM is more important than the total pool of SOM. On the other hand, higher yields also have an effect on SOM by returning more crop, root and stubble residues (Glendining \& Powlson 1995). One could therefore question if larger yields in our analysis are the result of the increased SOM content (Fig.2.5a), or vice versa (Fig. 2.5b)? In practice, both possibilities might be true and - if so - can be mutually reinforcing: in some cases more SOM gives somewhat higher yields, which adds more organic matter to the soil which in turn gives higher yields, which then again gives more SOM.

\subsubsection{Limitations of study and broader contextualization}

This meta-analysis did not find a significant mean additional yield effect of organic inputs. When assessing the use of organic inputs on a farm or regional level however, other aspects might also be relevant. Organic inputs can promote the buffering function of soil in years with less favourable conditions, thereby reducing yield variability (Pan et al. 2009). In our experiments, variability in attainable yields was not lessened with organic inputs (data not shown), but this could be tested further under more extreme climates. 
Using organic inputs can also have environmental effects. Soils with higher SOM contents for example might create a more flourishing habitat for soil biota (Chang et al. 2007). Maintaining SOM contents can therefore contribute to biodiversity conservation. Combining organic inputs with mineral fertilisers can decrease the demand for mineral fertilisers which can have positive effects such as a decrease in demand for fossil fuels (Wood \& Cowie 2004). In our meta-analysis, the savings of mineral fertiliser $\mathrm{N}$ with organic inputs are substantial (Supplementary Fig. 2.7 and Table 2.4, page 39). The savings in mineral fertiliser $\mathrm{N}$ however do not outweigh the total $\mathrm{N}$ in the organic inputs and the occasionally added mineral fertiliser $\mathrm{N}$ for growth of green manures or decomposition of straw. Consequently, organic inputs might affect the extend of nitrate leaching, nitrous oxide or ammonia emissions. For nitrate leaching, both positive (Leclerc et al. 1995) and negative cases (Basso \& Ritchie 2005; Oelofse et al. 2015) are known. It has been suggested that the number of years of application is crucial and that over the long-term, if nutrients are applied attuned to crop requirements, organic inputs have no significant effect on nitrate leaching (Maeda et al. 2003).

Even though the mean additional yield effect across all data sets was not significant, a large variance exists between data sets (additional yield effects ranged between -10 to $+18 \%$; supplement Fig. 2.5). Using grouping factors (crop type, type of organic input) and co-variates (clay content, aridity), some variance was explained, but large parts remained unknown. In some individual cases, organic inputs did increase attainable yield significantly. In others, organic inputs might have had little effects on soil structure, either because soil structure was already very good or because it was beyond simple repair. These type of nuances can be tackled in-depth in single experiments, but are difficult to disentangle when aggregating larger data sets. Combining meta-analysis with more in-depth studies is therefore vital for more thorough understanding of processes and mechanisms involved.

\subsection{Conclusions}

Using organic inputs to increase SOM is often seen as a win-win situation for food security and climate change mitigation, such as in the recently proposed "4/1000 initiative" at COP21 (UNFCCC 2015). Using organic inputs to sequester carbon might be a viable option to buy time for developing technologies for reducing industrial emissions (IGBP 1998), this meta-analysis however shows that benefits for crop yields cannot be assumed to follow directly. On sandy soils, in wet climates and for certain crops (some root or tuber crops and spring sown cereals) organic inputs can increase 
yields beyond the nutrients they supply. In those cases, increases in attainable yields vary mostly between 3 to $7 \%$. In the majority of cases however, supplying only mineral fertiliser gives similar yields.

\subsection{Acknowledgments}

We thank all who set up, maintained and shared data from long-term experiments in Europe through their publications. We thank Dietmar Barkusky (ZALF), Matthias Wendland (Bayern LFL), Guido Baldoni (University of Bologna) and Dorota Pikuła (IUNG) for providing additional data. We acknowledge Margaret Glendining for providing an overview on long term experiments in Europe and sharing her network. We thank Jan Verhagen and Bert Janssen for suggestions on methodology and Steve McGrath and Ken Giller for reviewing the text. 


\section{Supplement Chapter 2}

Supplementary Fig. 2.1 Response curves of root and tuber crops 30

Supplementary Fig. 2.2 Response curves of spring sown cereals 31

Supplementary Fig. 2.3 Response curves of winter sown cereals $\quad 32$

Supplementary Fig. 2.4 Response curves of winter sown cereals 33

Supplementary Fig. 2.5 Additional yield effect and 95\% confidence $\quad 34$ interval for each data set.

Supplementary Table 2.1 Legend for Supplementary Fig. 2.4 35

Supplementary Fig. 2.6 Sensitivity analysis for including or excluding 36 estimations of maximum yield outside the experimental set-up

Supplementary Table 2.2 Results of model selection including all experiments with data available on both percentage of clay and SOM content

Supplementary Table 2.3 Results of model selection including all experiments with data available on on SOM change

Supplementary Fig. 2.7 Illustration of difference in mineral fertiliser N application rate needed to reach equal crop yield with and without organic inputs.

Supplementary Table 2.4 Comparing mineral fertiliser $\mathrm{N}$ needed to achieve equal yields with and without organic inputs 


\section{Response curves of root and tuber crops}
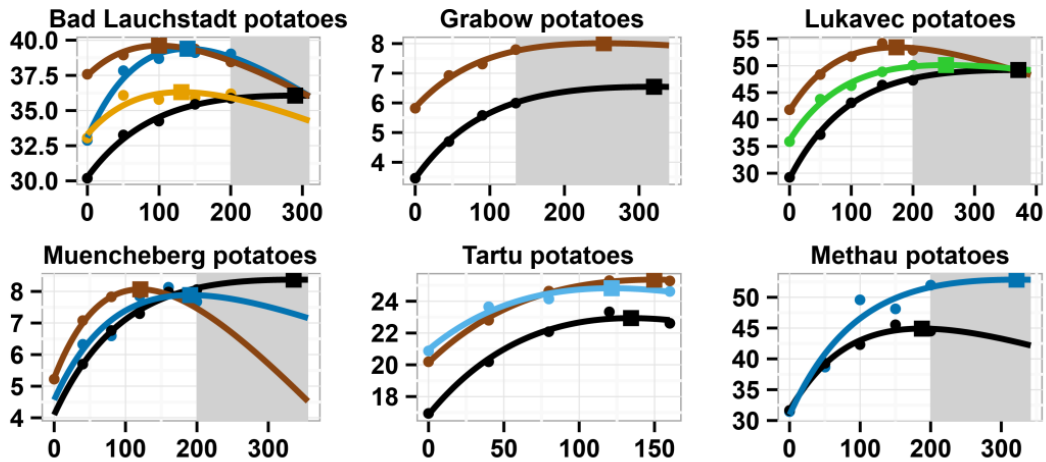

Bad Lauchstadt sugar beet
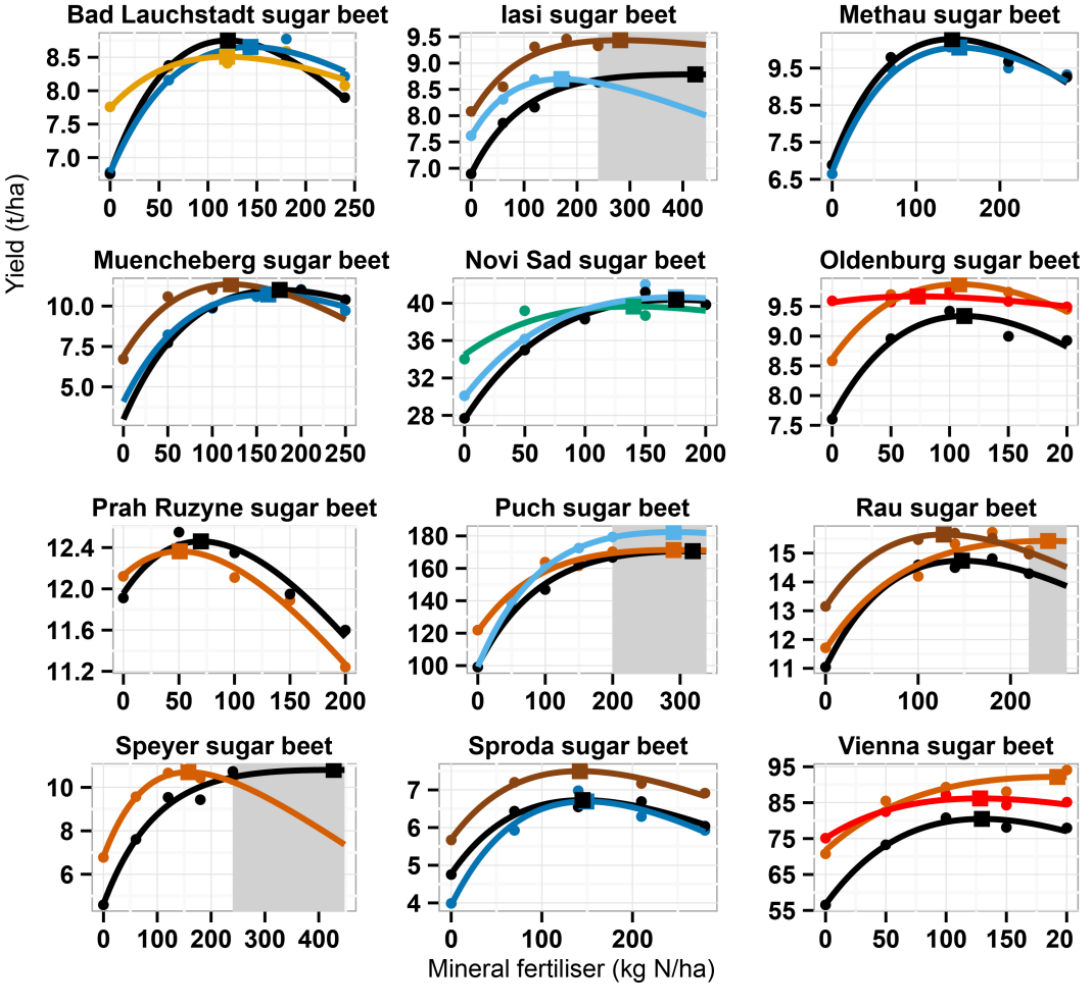

$$
\begin{aligned}
& =\text { farm yard manure } \\
& =\text { straw \& beet leaves } \\
& =\text { straw \& green manure }
\end{aligned}
$$

$$
\text { - straw \& slurry green manure straw \& green manure \& slurry straw \& green manure \& beet leaves }=\text { straw }
$$

no organic input $=$ straw \& beet leaves \& slurry

Supplementary Fig. 2. 1: Yield response curves of root and tuber crops to mineral fertiliser with and without organic inputs. X-axes are mineral fertiliser applied in $\mathrm{kg} \mathrm{N/ha}$. Y-axes are crop yield in tonnes/ha. Colours indicate types of organic input. Squares indicate the maximum of each curve. Shaded areas lie outside the experimental set-up. 


\section{Response curves of spring sown cereals}
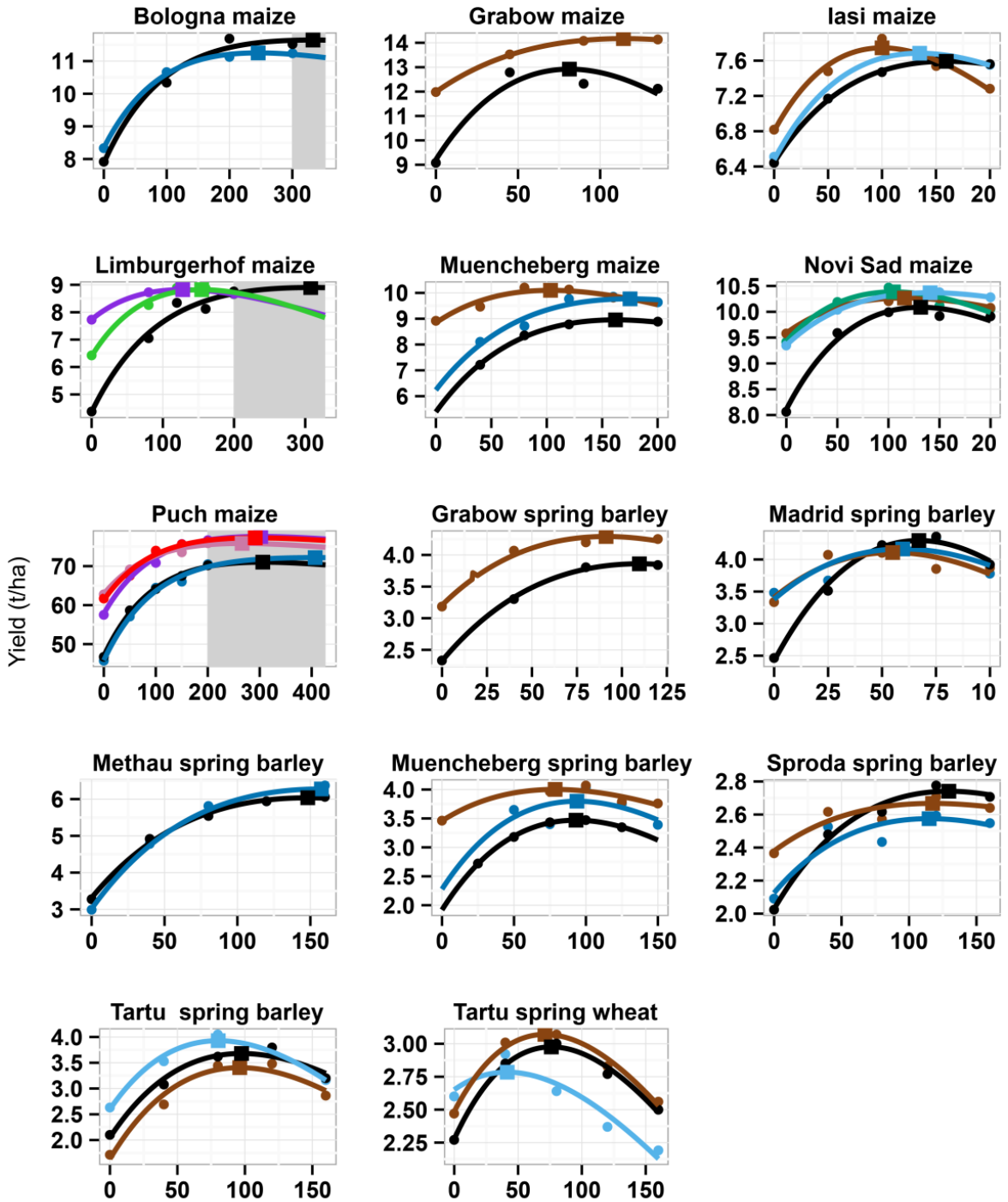

Mineral fertiliser (kg N/ha)

$=$ farm yard manure slurry $=$ straw \& slurry $=$ straw \& green manure \& slurry $=\begin{gathered}\text { no organic } \\ \text { input }\end{gathered}$
$=$ straw \& green manure $=$ straw $=$ straw \& beet leaves $=$ straw \& beet leaves \& slurry

Supplementary Fig. 2. 2: Yield response curves of spring sown cereals to mineral fertiliser with and without organic inputs. X-axes are mineral fertiliser applied in $\mathrm{kg} \mathrm{N/ha}$. Y-axes are crop yield in tonnes/ha. Colours indicate types of organic input. Squares indicate the maximum of each curve. Shaded areas lie outside the experimental set-up. 


\section{Response curves of winter sown cereals}
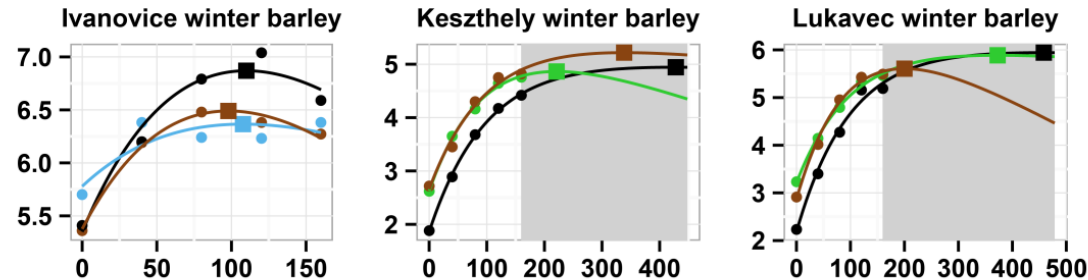

Oldenburg winter barley

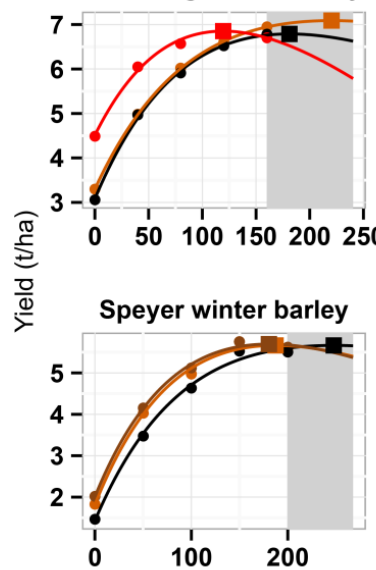

Prah Ruzyne winter barley

Rauischholzhausen winter barley
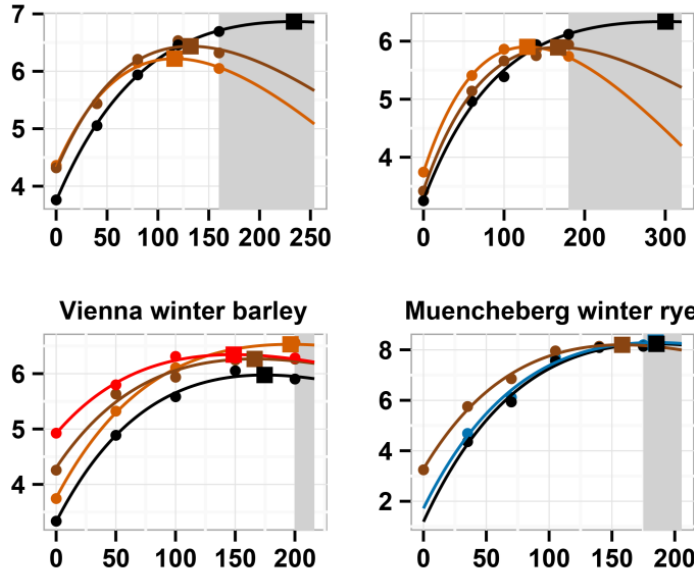

\section{Muencheberg winter rye}

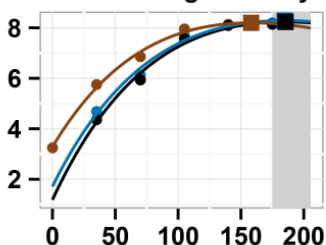

Bologna winter wheat
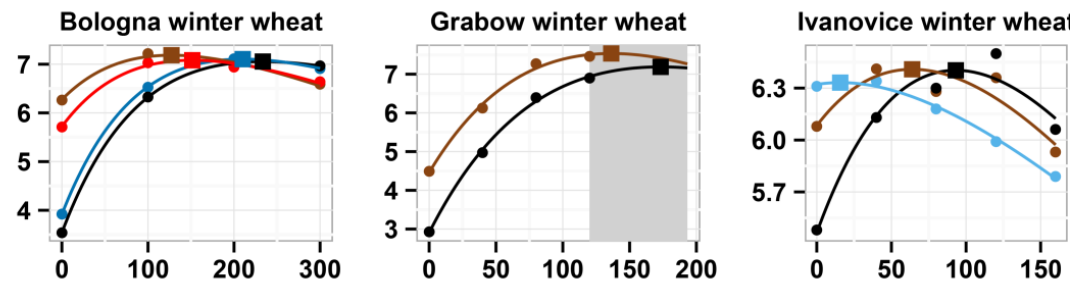

Mineral fertiliser ( $\mathrm{kg} \mathrm{N} / \mathrm{ha}$ )

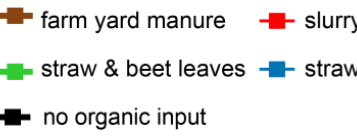

- straw \& green manure \& slurry

- straw \& beet leaves \& slurry

- straw \& green manure \& beet leaves

- straw \& green manure

Supplementary Fig. 2. 3: Yield response curves of winter sown cereals to mineral fertiliser with and without organic inputs. X-axes are mineral fertiliser applied in $\mathrm{kg} \mathrm{N/ha.} \mathrm{Y-axes} \mathrm{are} \mathrm{crop} \mathrm{yield} \mathrm{in} \mathrm{tonnes/ha.} \mathrm{Colours}$ indicate types of organic input. Squares indicate the maximum of each curve. Shaded areas lie outside the experimental set-up. 

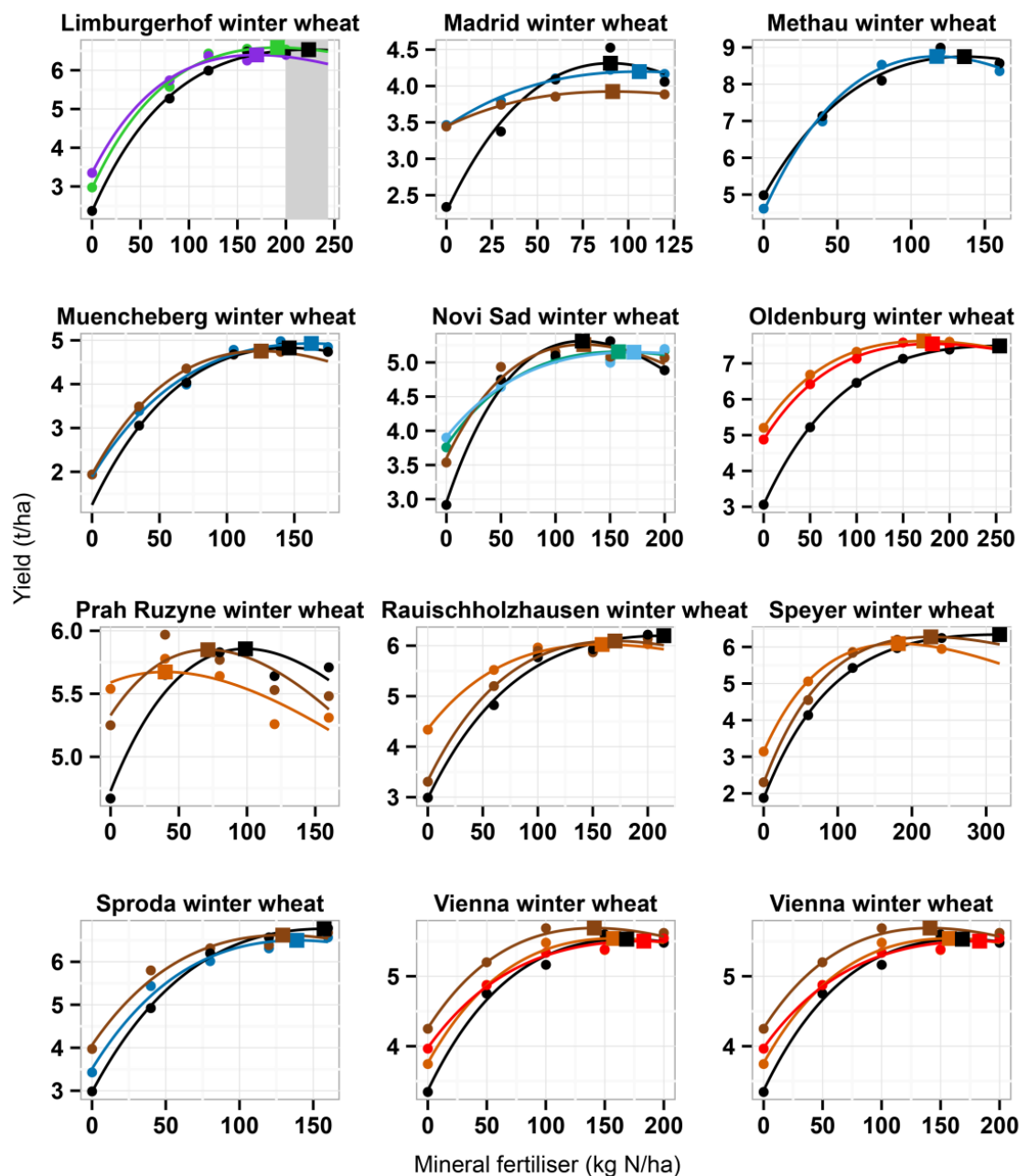

\footnotetext{
- farm yard manure

- straw \& beet leaves - straw

- no organic input
}

Mineral fertiliser ( $\mathrm{kg} \mathrm{N} / \mathrm{ha}$ )

Supplementary Fig. 2. 4: Yield response curves of winter sown cereals to mineral fertiliser with and without organic inputs. $X$-axes are mineral fertiliser applied in $\mathrm{kg} \mathrm{N} / \mathrm{ha}$. Y-axes are crop yield in tonnes/ha. Colours indicate types of organic input. Squares indicate the maximum of each curve. Shaded areas lie outside the experimental set-up. 


\section{Additional yield effect for all data sets}

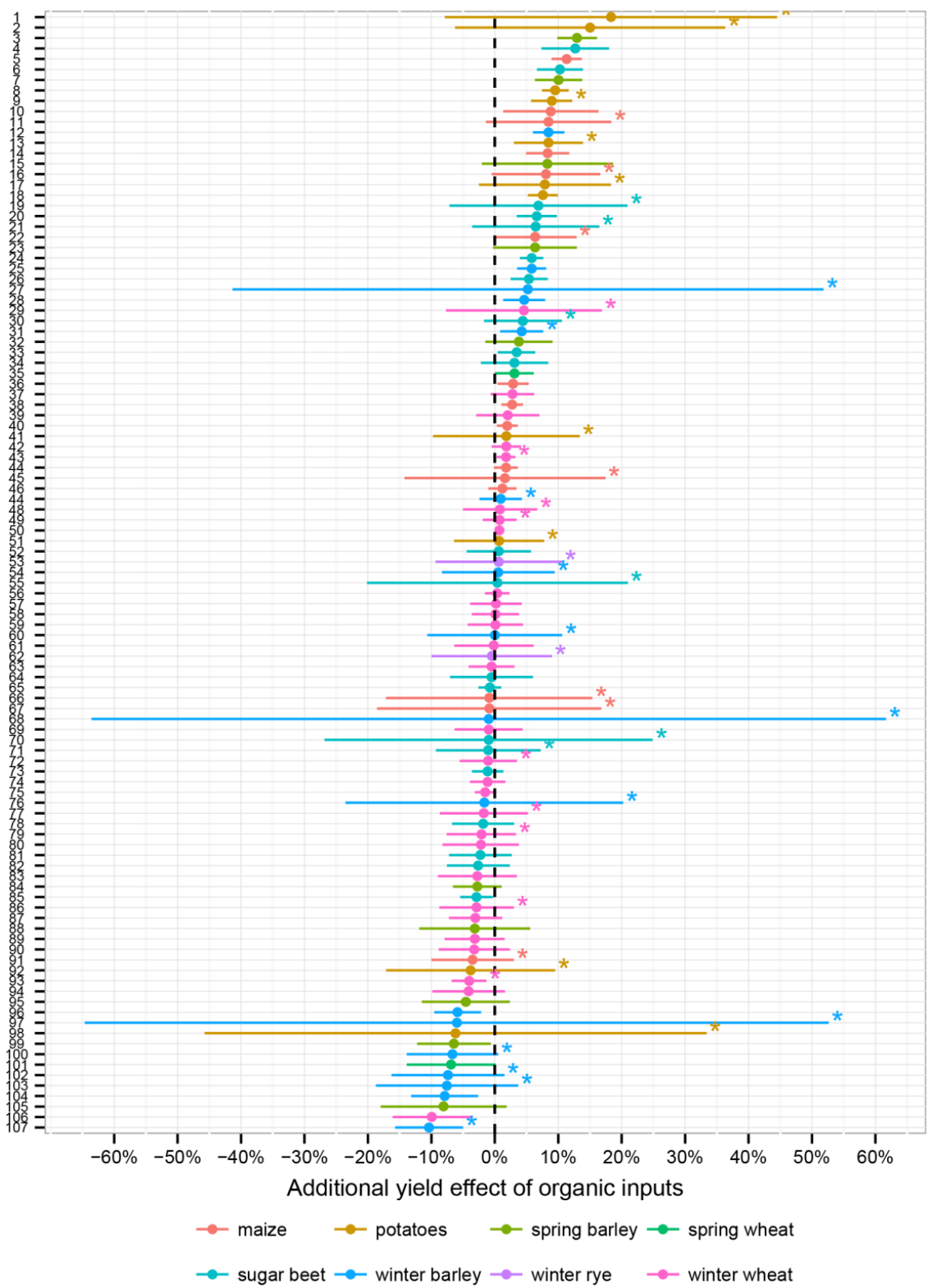

Supplementary Fig. 2. 5: Additional yield effect of organic inputs across experiments, crops and types of organic input. Lines indicate $95 \%$ confidence interval. * indicates maximum yield was estimated outside the experimental set-up. Numbers of data sets are explained in Supplementary Table 2.1 
Supplementary Table 2. 1: Explanation of dataset numbers of Supplementary Fig. 2.4. $m=$ maize; $p=$ potatoes; $s$ = sugar beet; $s b=$ spring barley; $w b=$ winter barley; $w r=$ winter rye; $w w=$ winter wheat; $s w=$ spring $w$ heat. $F Y M=$ farm yard manure, $G M=$ green manure, $B L=$ beat leaves.

\begin{tabular}{|c|c|c|c|}
\hline 1 & Grabow: p with FYM & 55 & Puch: s with straw \& GM \& BL \\
\hline 2 & Methau: $p$ with straw & 56 & Bologna 1: ww with slurry \\
\hline 3 & Muncheberg: sb with FYM & 57 & Vienna: ww with straw \& GM \& BL \\
\hline 4 & Vienna: s with straw \& GM \& BL & 58 & Ivanovice: ww with FYM \\
\hline 5 & Muncheberg: m with FYM & 59 & Methau: ww with straw \\
\hline 6 & Sproda: s with FYM & 60 & Speyer: wb with straw \& GM \& BL \\
\hline 7 & Grabow: sb with FYM & 61 & Prah Ruzyne: ww with FYM \\
\hline 8 & Tartu: p with FYM & 62 & Muencheberg: wr with FYM \\
\hline 9 & Bad Lauchstadt: $\mathrm{p}$ with FYM & 63 & Vienna: ww with slurry \\
\hline 10 & Grabow: m with FYM & 64 & Sproda: s with straw \\
\hline 11 & Puch: m with straw \& GM \& slurry & 65 & Prah Ruzyne: s with straw \& GM \& BL \\
\hline 12 & Vienna: wb with straw \& GM \& BL & 66 & Limburgerhof: $m$ with straw \& GM \& slurry \\
\hline 13 & Bad Lauchstadt: $\mathrm{p}$ with straw & 67 & Limburgerhof: $m$ with straw \& GM \\
\hline 14 & Muencheberg: $\mathrm{m}$ with straw & 68 & Lukavec: wb with straw \& GM \\
\hline 15 & Muencheberg: sb with straw & 69 & Novi Sad: ww with FYM \\
\hline 16 & Puch: m with slurry & 70 & Speyer: s with straw \& GM \& BL \\
\hline 17 & Lukavec: p with FYM & 71 & Iasi: s with straw \& BL \\
\hline 18 & Tartu: $p$ with straw \& BL & 72 & Speyer: ww with FYM \\
\hline 19 & Iasi: s with FYM & 73 & Bad Lauchstadt: s with straw \\
\hline 20 & Vienna: s with slurry & 74 & Ivanovice: ww with straw \& BL \\
\hline 21 & Puch: s with straw \& BL & 75 & Muencheberg: ww with FYM \\
\hline 22 & Puch: m with straw \& slurry & 76 & Keszthely: wb with straw \& GM \\
\hline 23 & Tartu: sb with straw \& BL & 77 & Rau: ww with FYM \\
\hline 24 & Rau: s with FYM & 78 & Novi Sad: s with straw \& BL \& slurry \\
\hline 25 & Vienna: wb with slurry & 79 & Limburgerhof: ww with straw \& GM \& slurry \\
\hline 26 & Oldenburg: s with straw \& GM \& BL & 80 & Sproda: ww with FYM \\
\hline 27 & Keszthely: wb with FYM & 81 & Methau: s with straw \\
\hline 28 & Vienna: wb with FYM & 82 & Muencheberg: s with straw \\
\hline 29 & Grabow: ww with FYM & 83 & Madrid: ww with straw \\
\hline 30 & Rau: s with straw \& GM \& BL & 84 & Sproda: sb with FYM \\
\hline 31 & Oldenburg: wb with straw \& GM \& BL & 85 & Bad Lauchstadt: s with GM \\
\hline 32 & Methau: sb with straw & 86 & Rau: ww with straw \& GM \& BL \\
\hline 33 & Oldenburg: s with slurry & 87 & Novi Sad: ww with straw \& BL \& slurry \\
\hline 34 & Muencheberg: s with FYM & 88 & Madrid: sb with straw \\
\hline 35 & Tartu: sw with FYM & 89 & Novi Sad: ww with straw \& BL \\
\hline 36 & Novi Sad: $m$ with straw \& BL \& slurry & 90 & Prah Ruzyne: ww with straw \& GM \& BL \\
\hline 37 & Vienna: ww with FYM & 91 & Bologna $1: \mathrm{m}$ with straw \\
\hline 38 & Novi Sad: $m$ with straw \& BL & 92 & Muencheberg: $p$ with FYM \\
\hline 39 & Muencheberg: ww with straw & 93 & Speyer: ww with straw \& GM \& BL \\
\hline 40 & Iasi: m with FYM & 94 & Sproda: ww with straw \\
\hline 41 & Lukavec: $\mathrm{p}$ with straw \& GM & 95 & Madrid: sb with FYM \\
\hline 42 & Bologna 1: ww with FYM & 96 & Ivanovice: wb with FYM \\
\hline 43 & Oldenburg: ww with straw \& GM \& BL & 97 & Lukavec: wb with FYM \\
\hline 44 & Novi Sad: m with FYM & 98 & Muencheberg: $\mathrm{p}$ with straw \\
\hline 45 & Puch: m with straw & 99 & Sproda: sb with straw \\
\hline 46 & Iasi: $m$ with straw \& BL & 100 & Prah Ruzyne: wb with FYM \\
\hline 47 & Oldenburg: wb with slurry & 101 & Tartu: sw with straw \& BL \\
\hline 48 & Limburgerhof: ww with straw \& GM & 102 & Rau: wb with straw \& GM \& BL \\
\hline 49 & Oldenburg: ww with slurry & 103 & Rau: wb with FYM \\
\hline 50 & Bologna 1: ww with straw & 104 & Ivanovice: wb with straw \& BL \\
\hline 51 & Bad Lauchstadt: $p$ with GM & 105 & Tartu: sb with FYM \\
\hline 52 & Novi Sad: s with straw \& BL & 106 & Madrid: ww with FYM \\
\hline 53 & Muencheberg: wr with straw & 107 & Prah Ruzyne: wb with straw \& GM \& BL \\
\hline 54 & Speyer: wb with FYM & & \\
\hline
\end{tabular}




\section{Sensitivity analysis}

\section{A. Type of organic input}

Including estimations of attainable yield Excluding estimations of attainable yield outside experimental set-up

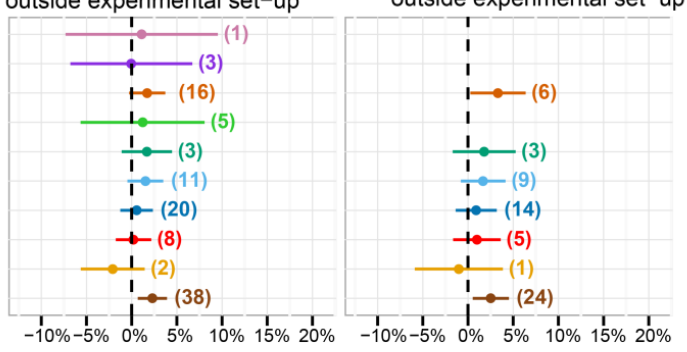

$\rightarrow$ straw \& slurry

- straw \& green manure \& slurry

$\rightarrow$ straw \& green manure \& beet leaves

- straw \& green manure

$\rightarrow$ straw \& beet leaves \& slurry

$\rightarrow$ straw \& beet leaves

$\rightarrow$ straw

$\rightarrow$ slurry

$\rightarrow$ green manure

$\rightarrow$ farm yard manure

\section{B. Crop type}

Including estimations of attainable yield Excluding estimations of attainable yield outside experimental set-up outside experimental set-up
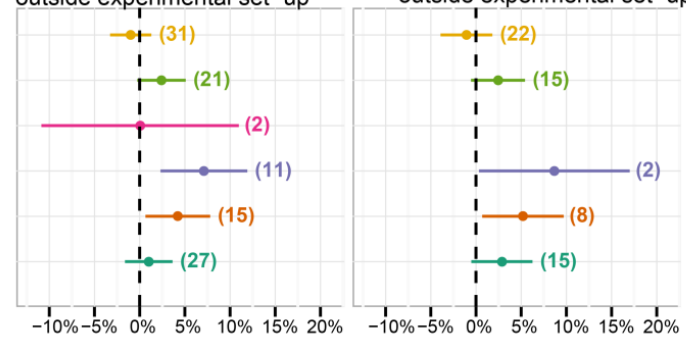

$\rightarrow$ wheat

$\rightarrow$ sugar beet

$\rightarrow$ rye

$\rightarrow$ potatoes

$\rightarrow$ maize

$\rightarrow$ barley

\section{Spring or winter sown cereal}

Including estimations of attainable yield Excluding estimations of attainable yield

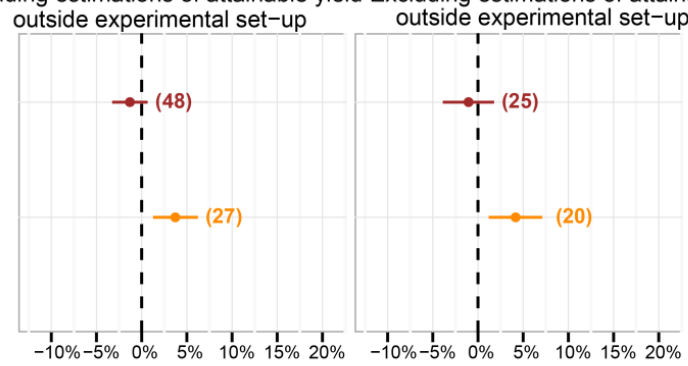

Additional yield effect of organic inputs

Supplementary Fig. 2. 6: Results of sensitivity analysis for including or excluding estimations of maximum yield outside the experimental set-up. Circles are mean effect size, lines show the 95\% confidence interval. The number in brackets is the number of data sets in each group. GM= green manure or cover crop. 


\section{Model selection}

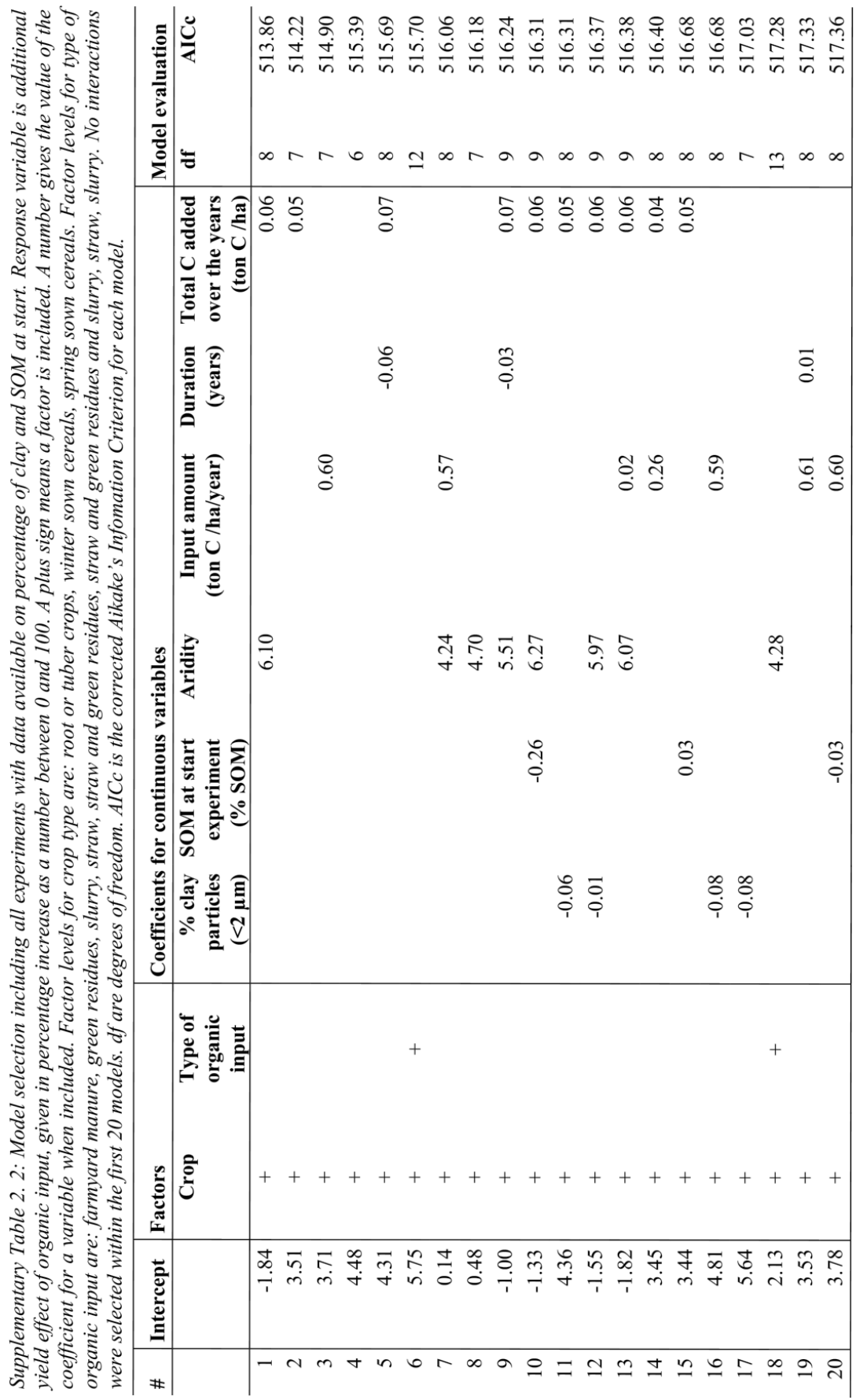




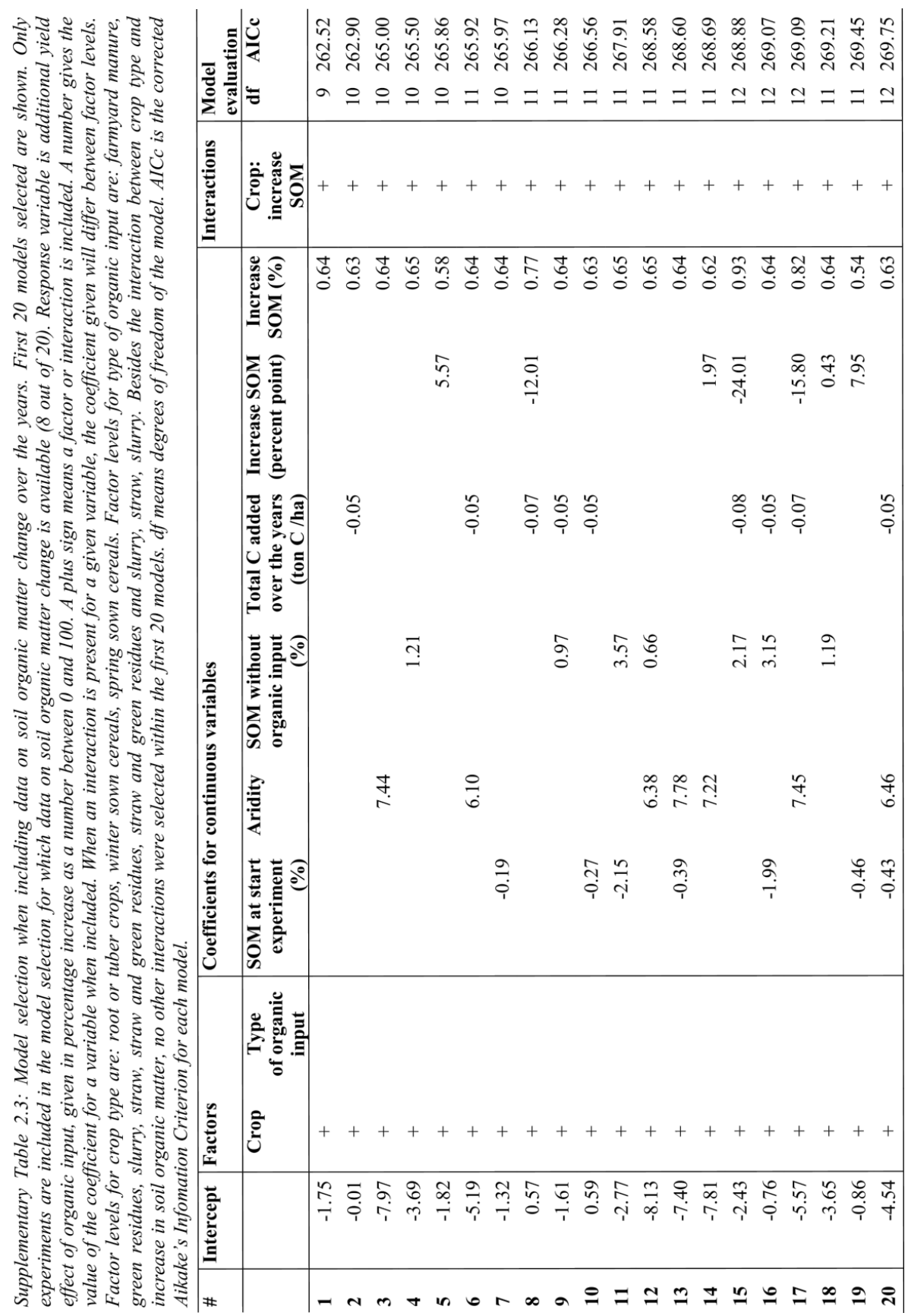




\section{Savings of mineral fertilisers when using organic inputs (at equal yields)}

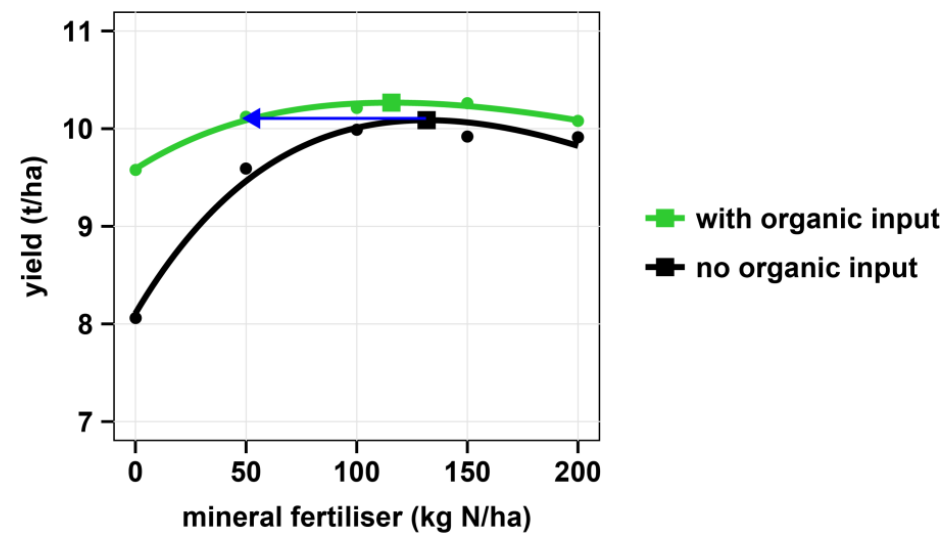

Supplementary Fig. 2.7: Illustration of difference in mineral fertiliser $N$ application rate needed to reach equal crop yield with and without organic inputs. Squares indicate the maximum of each curve. The blue arrow shows the difference in mineral fertiliser $N$ needed to achieve a similar level of high yield ( $N$ savings). Data is from maize grown in Novi Sad between 1996 and 2003, with and without farmyard manure.

Supplementary Table 2.4: Comparing mineral fertiliser $N$ needed to achieve equal yields with and without organic inputs (as illustrated in supplementary Fig. 6). Mineral fertiliser $N$ requirements are compared at the highest yield which is achieved both with and without organic inputs. Analysis and results only for data sets with $N$ contents of organic inputs measured/reported (38 data sets across 8 experiments).

\begin{tabular}{|c|c|c|c|c|c|}
\hline Organic input & $\begin{array}{r}\# \\
\text { data } \\
\text { sets }\end{array}$ & $\begin{array}{l}\text { Mean fertiliser } \\
\text { N savings with } \\
\text { organic inputs } \\
\text { (kg N/ha/year) }\end{array}$ & $\begin{array}{r}\text { Mean mineral } \\
\text { fertiliser N } \\
\text { added to straw } \\
\text { or green } \\
\text { manures } \\
(\mathrm{kg} \mathrm{N} / \mathrm{ha} / \text { year) }\end{array}$ & $\begin{array}{r}\text { Mean total N } \\
\text { in organic } \\
\text { inputs } \\
(\mathrm{kg} \mathrm{N} / \mathrm{ha} / \text { year })\end{array}$ & $\begin{array}{r}\Delta \text { mineral } \\
\text { fertiliser } \mathbf{N}+ \\
\text { added N + } \\
\text { total } \mathbf{N} \text { organic } \\
\text { inputs } \\
\text { (kg N/ha/year) }\end{array}$ \\
\hline FYM & 17 & -76.92 & 0.00 & 120.22 & 43.30 \\
\hline Slurry & 1 & -109.25 & 0.00 & 189.68 & 80.42 \\
\hline Straw & 15 & -7.42 & 0.00 & 22.18 & 14.76 \\
\hline $\begin{array}{l}\text { Straw \& beet } \\
\text { leaves }\end{array}$ & 2 & -81.16 & 16.67 & 79.42 & 14.93 \\
\hline $\begin{array}{l}\text { Straw \& GM } \\
\& \text { beet leaves }\end{array}$ & 3 & -64.44 & 16.67 & 49.30 & 1.53 \\
\hline
\end{tabular}


Chapter 3 


\section{Chapter 3.}

\section{Nitrogen fertiliser replacement values for organic inputs appear to increase with $\mathrm{N}$ application rates}

Renske Hijbeek ${ }^{1}$, Hein F.M. ten Berge ${ }^{2}$, Andy P. Whitmore ${ }^{3}$, Dietmar Barkusky ${ }^{4}$, Jaap J. Schröder ${ }^{2}$, and Martin K. van Ittersum ${ }^{1}$

${ }^{1}$ Plant Production Systems, Wageningen University and Research, Wageningen, the Netherlands.

${ }^{2}$ Plant Research International, Wageningen University and Research, Wageningen, the Netherlands.

${ }^{3}$ Sustainable Soils and Grassland Systems, Rothamsted Research, Harpenden, UK

${ }^{4}$ Leibniz Centre for Agricultural Landscape Research (ZALF), Eberswalder Straße 84, 15374 Muencheberg, Germany

Nutrient Cycling in Agroecosystems (DOI 10.1007/s10705-017-9875-5) 


\begin{abstract}
Nitrogen (N) supply from organic inputs (such as farmyard manure (FYM), slurries or crop residues) to crops is commonly expressed in the input's Nitrogen Fertiliser Replacement Value ( $N F R V$ ). Values for $N F R V$ can be determined by comparison of crop yield or $\mathrm{N}$ uptake in amended plots against mineral fertiliser-only plots. Most commonly, $N F R V$ is defined as the amount of mineral fertiliser $\mathrm{N}$ saved when using organic input-N (kg/kg), while attaining the same crop yield. Factors known to affect NFRV are crop type cultivated, soil type, manuring history and method or time of application.
\end{abstract}

We investigated whether long-term $N F R V$ depends on $\mathrm{N}$ application rates. Using data from eight long term experiments in Europe, values of $N F R V$ at low total $\mathrm{N}$ supply were compared with values of $N F R V$ at high total $\mathrm{N}$ supply. Our findings show that FYM has a significant higher $N F R V$ value at high total $\mathrm{N}$ supply than at low total $\mathrm{N}$ supply (1.12 vs $0.53, p=0.04)$. For the other input types investigated, $N F R V$ was also higher at high total $\mathrm{N}$ supply than at low total $\mathrm{N}$ supply, but sample sizes were too small or variations too large to find significant differences.

Farmers in Europe usually operate at high rates of total $\mathrm{N}$ applied. If fertiliser supplements are based on $N F R V$ of the manure estimated at low total $\mathrm{N}$ supply, $\mathrm{N}$ fertiliser requirements might be overestimated. This might lead to overuse of $\mathrm{N}$, lower $\mathrm{N}$ use efficiency and larger losses of $\mathrm{N}$ to the environment.

Keywords: Nitrogen Fertiliser Replacement Value, Mineral Fertiliser Equivalent, organic inputs, mineral fertiliser, Nitrogen, soil fertility, crop yield

$\begin{array}{ll}\text { Abbreviations } \\ \text { DM } & \text { dry matter weight } \\ \text { FM } & \text { fresh matter weight } \\ \text { FYM } & \text { farmyard manure } \\ \text { K } & \text { potassium } \\ \text { LS } & \text { least squares } \\ \text { N } & \text { nitrogen }\end{array}$




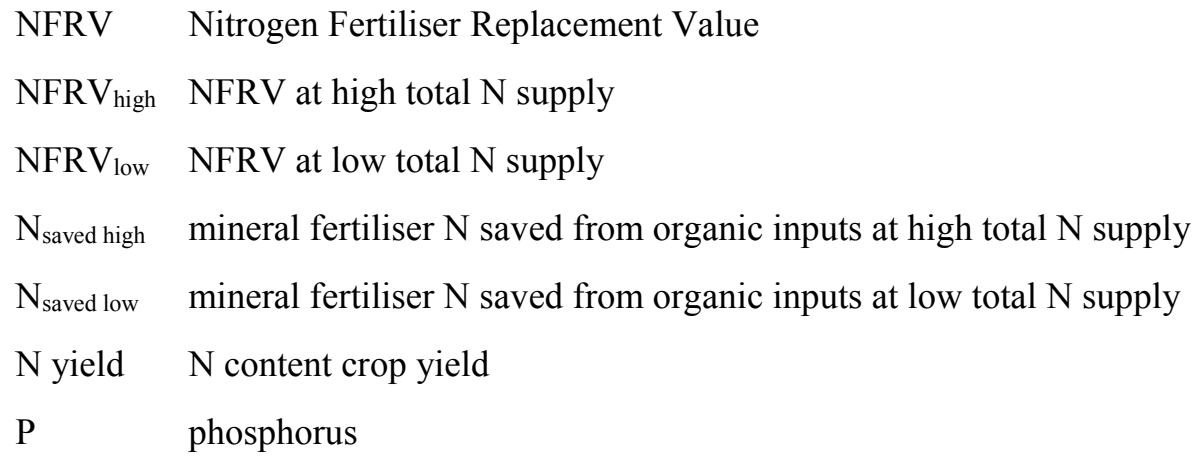

\subsection{Introduction}

Efficient use of nitrogen $(\mathrm{N})$ requires careful matching of $\mathrm{N}$ supply to crop demand. Often application of mineral fertilisers is combined with application of organic inputs such as farmyard manure (FYM), slurries, and crop residues (also called organic manures, organic fertilisers or organic inputs). $\mathrm{N}$ in organic inputs generally has a lower availability to crops than $\mathrm{N}$ in mineral fertilisers, mainly depending on the $\mathrm{C}: \mathrm{N}$ ratio of the input (Flavel \& Murphy 2006). Therefore, $\mathrm{N}$ in organic inputs must be carefully matched with mineral fertiliser $\mathrm{N}$ application to avoid leaching while making sure sufficient $\mathrm{N}$ is available for crop growth. This requires the characterization of the organic inputs by their Nitrogen Fertiliser Replacement Value (NFRV), also called the Mineral Fertiliser Equivalent (Jensen 2013).

$N F R V$ can be based on the amount of mineral fertiliser $\mathrm{N}$ which is substituted by an amount of organic input- $\mathrm{N}(\mathrm{kg} / \mathrm{kg})$ while attaining the same crop yield (Herron \& Erhart 1965; Schilling 1987; Schröder 2005b). Crop yields can be expressed as fresh matter weights (FM), dry matter weights (DM) or N contents ( $\mathrm{N}$ yields, Jensen 2013). These are all valid procedures, with the difference that values of $N F R V$ based on $\mathrm{N}$ yields are often slightly lower than those based on DM or FM weights (Jensen 2013). N in organic inputs is always accompanied by other nutrients, such as phosphorus $(\mathrm{P})$, potassium $(\mathrm{K})$ or sulphur (S) which also affect crop yields. It is therefore important to exclude these effects when estimating values of $N F R V$ based on yields (either DM, FM or $\mathrm{N}$ yields, Schröder 2005b)

Lory et al. (1995) have suggested to calculate $N F R V$ using economic $\mathrm{N}$ rates (mineral fertiliser $\mathrm{N}$ application rates at which marginal crop yields offset marginal fertiliser costs) with and without organic inputs. Yields at economic $\mathrm{N}$ rates with and without 
organic inputs might however differ, which hampers comparison at equal yield levels. In addition, economic $\mathrm{N}$ rates are dependent on prices of fertilisers and harvested products, which makes estimations less robust through time and space.

Another manner to determine $N F R V$ of organic inputs is by using isotope dilution techniques. Using ${ }^{15} \mathrm{~N}$ labelled materials, the fate of $\mathrm{N}$ from either organic inputs or mineral fertilisers is measured among plant and soil fractions and compared (Diekmann et al. 1993; Janzen et al. 1990). Additional methods to calculate $N F R V$ (such as the analysis of near infrared reflectance spectra of organic inputs) have been proposed but need further development (Delin et al. 2012).

Values for $N F R V$ differ when estimated in the first year of application of organic inputs (short-term $N F R V$ ) or after repeated applications and several years (long-term NFRV, Gutser et al. 2005; Schröder 2005a), with higher values found for long-term $N F R V$. For FYM, NFRV ranges between 0.10 and 0.70 (Birkmose 2009; Jensen 2013; Pikula et al. 2016; Webb et al. 2013). For slurry, NFRV ranges between 0.20 and 0.90 (Birkmose 2009; Delin et al. 2012; Jensen 2013; Kundler et al. 1989; Langmeier et al. 2002; Webb et al. 2013). For straw, $N F R V$ has been estimated to be around zero (Dhillon and Dev (1984) as cited by Katyal 1993). For green manures, $N F R V$ has been estimated ca. 0.4 (Janzen et al. 1990), but this will probably depend on the species of green manure cultivated.

Factors known to affect $N F R V$ (at a given dose of the input) include the form of $\mathrm{N}$ in the input, crop type cultivated, soil type, method of application, time of application and the manuring history which may govern $\mathrm{N}$ retention and losses (Birkmose 2009; Jensen 2013; Katyal 1993; Kundler et al. 1989; Webb et al. 2013). Here we evaluate the effect of an additional factor on $N F R V$ which is currently not taken into account: the total $\mathrm{N}$ supply. We address the following research question: Does $N F R V$ of organic inputs depend on total $\mathrm{N}$ supply?

\subsection{Materials and methods}

To answer the research question, values for long-term $N F R V$ were calculated based on yield response curves (either DM or FM weights of marketable products) at low and high total $\mathrm{N}$ supply. This required data from field trials where different $\mathrm{N}$ rates were applied with and without organic inputs. In such a set-up, mineral fertiliser $\mathrm{N}$ saved with an addition of organic input at low mineral fertiliser rates $\left(N_{\text {saved low }}\right)$ can be compared with mineral fertiliser $\mathrm{N}$ saved by adding the same amount of organic input at high 
mineral fertiliser rates ( $\left.N_{\text {saved high }}\right)$. In these cases, sufficient $\mathrm{P}$ and $\mathrm{K}$ has to be applied to ensure these macro-nutrients are not a yield limiting factor and affect the calculation of $N F R V$ of organic inputs. Organic inputs however do not only supply $\mathrm{N}, \mathrm{P}$ and $\mathrm{K}$ but also other nutrients, such as sulphur (S). Over the past decades, $\mathrm{S}$ was often not yield limiting due to the ample supply from the atmosphere (Eriksen 2009). More recently this has changed but not always adjusted for in field experiments.

In Chapter 2, a database was compiled with data from 20 long term experiments. All these 20 experiments fulfilled the following six criteria: (1) at least four increasing levels of mineral fertiliser $\mathrm{N}$ rates without organic inputs; (2) at least four increasing mineral fertiliser $\mathrm{N}$ rates with organic inputs; (3) P and $\mathrm{K}$ applied in ample amounts on all fields; (4) at least five years of yield data; (5) if crops are cultivated in rotation, yield data available for at least two rotation cycles; (6) yield data reported for individual crop types (no aggregated data of whole-rotation yield output were used).

Assessing $N F R V$ called for an additional requirement: (7) $\mathrm{N}$ contents of organic inputs must be known. Using these seven criteria, 38 data sets (with multiple crops and organic input types) were assembled from eight experiments in five countries across Europe (Table 3.1).

The experiments ranged in duration between 15 to 44 years. These data, therefore, can be used to consider long-term $N F R V$, including the greater part of the residual effect of manure (Hernández et al. 2013; Jensen 2013; Schröder 2005a). The setup of these experiments implies that mineral fertiliser $\mathrm{N}$ rates are always confounded with total $\mathrm{N}$ supply. We therefore use the term 'total $\mathrm{N}$ supply'.

For each data set, two yield response curves to mineral fertiliser-N were fitted, one without $\left(\mathrm{Y}^{0}\right)$ and one with organic inputs $\left(\mathrm{Y}^{\mathrm{A}}\right)$, following George (1984), see Fig. 3.1. $Y=a+b * 0.99^{N}+c * N+\varepsilon$

In Equation 3.1, $Y$ is crop yield ( $\mathrm{t} / \mathrm{ha}$ ) expressed in either fresh or dry matter weight of the marketable product, $N$ is the mineral fertiliser $\mathrm{N}$ rate $(\mathrm{kg} \mathrm{N} / \mathrm{ha}), a, b$ and $c$ are parameters to be fitted and $\boldsymbol{\varepsilon}$ is the error term. 


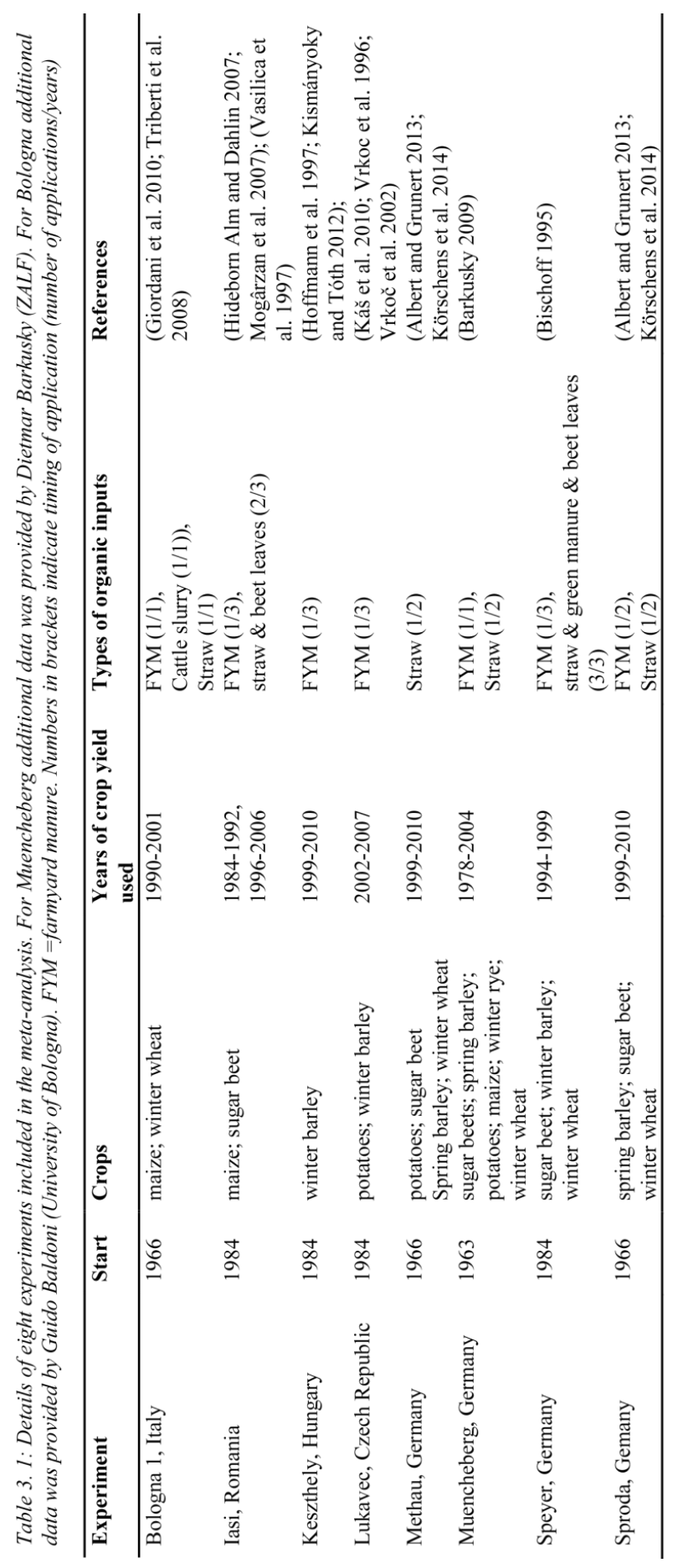


For each pair of curves, the amount of mineral fertiliser saved with an organic input was calculated at low and high total $\mathrm{N}$ supply ( $N_{\text {saved low }}$ and $\left.N_{\text {saved high }}\right) . N_{\text {saved low }}$ was defined as the amount of mineral fertiliser $\mathrm{N}$ required without organic inputs to match the yield obtained with the input alone (Equation 3.2; $\mathrm{N}=0$ ):

$Y^{0}\left(N_{\text {saved low }}\right)=Y^{A}(N=0)$

To calculate $N_{\text {saved high, }}$ the highest yield level which was reached by both response curves within the experimental set-up was determined for each pair of response curves and called $Y_{\max }^{0, A}$. This could be the maximum of one of the two response curves (as in Fig. 3.1a) or the highest yield reached within the experimental set-up (as in Fig. 3.1b).
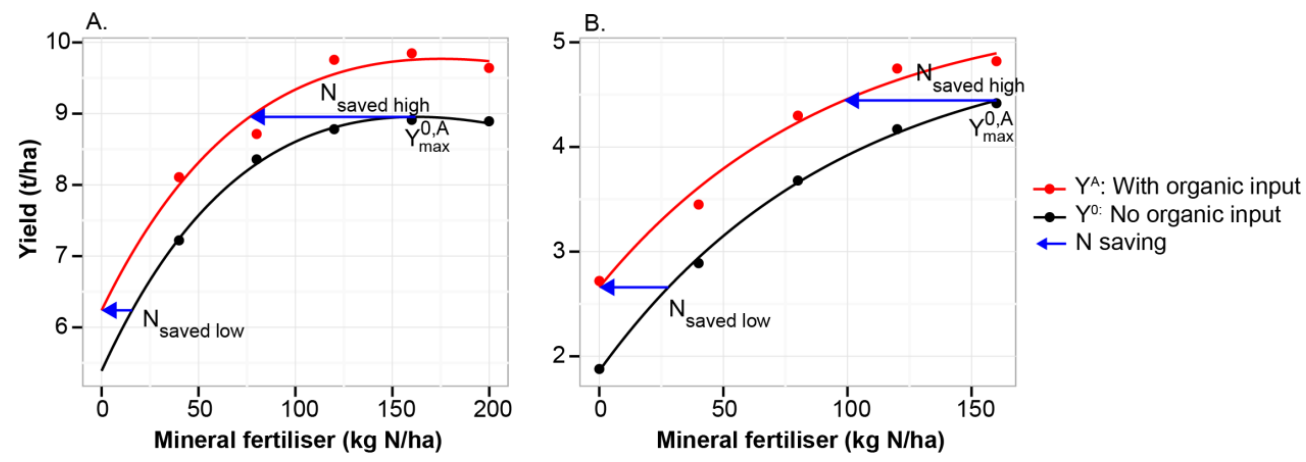

Fig 3. 1: Illustration of calculating savings of $N$ with organic inputs at low total $N$ supply ( $N_{\text {saved low }}$ ) and at high total $N$ supply $\left(N_{\text {saved high }}\right) . Y^{0}$ is the yield response curve without organic inputs. $Y^{A}$ is the yield response curve with organic inputs. At the left yields are shown from maize grown in Muencheberg between 1995-2003, with and without straw. At the right yields are shown from winter barley grown in Keszthely between 1999-2010, with and without farmyard manure.

Accordingly, $N_{\max }^{0}$ was defined as the mineral fertiliser $\mathrm{N}$ rate needed to reach $Y_{\max }^{0, A}$ without organic inputs. Following, $N_{\text {saved high }}$ is the reduction in mineral $\mathrm{N}$ fertiliser when reaching $Y_{\max }^{0, A}$ with organic inputs (Equation 3.3):

$Y^{A}\left(N_{\text {max }}^{0}-N_{\text {saved high }}\right)=Y_{\text {max }}^{0, A}$

Thus, $N_{\text {saved low }}$ represents the reduction of mineral fertiliser when using organic inputs at low total $\mathrm{N}$ supply. $N_{\text {saved high }}$ represents the reduction of mineral fertiliser when using organic inputs at high total $\mathrm{N}$ supply matching the highest yield possible. For each dataset, a pair of response curves with $N_{\text {saved low }}$ and $N_{\text {saved high indicated is presented in }}$ the supplementary information (Supplementary Fig. 3.1 to 3.4, pages 54 to 56). 
To find $N F R V_{\text {low }}$ and $N F R V_{\text {high, }}$, both $N_{\text {saved low }}$ and $N_{\text {saved high }}$ were divided by the total N content of the organic inputs (Equations 3.4 and 3.5).

$$
\begin{aligned}
& N F R V_{\text {low }}=\frac{N_{\text {saved low }}}{\text { Total } N \text { organic input }} \\
& N F R V_{\text {high }}=\frac{N_{\text {saved high }}}{\text { Total } N \text { organic input }}
\end{aligned}
$$

Following, for each pair of response curves, the difference between $N F R V_{\text {low }}$ and $N F R V_{\text {high }}$ was calculated. Statistical models based on the function lme (linear mixedeffects model) of package nlme (Pinheiro et al. 2015) were used to find the least squares (LS) means for $N F R V_{\text {low }}$ and $N F R V_{\text {high }}$ per type of organic input. These models can account for random effects. In this analysis, the eight experiment locations were included as random effects. All data were processed in R version 3.2.5.

\subsection{Results}

For FYM, mean $N F R V_{\text {low }}$ was $0.53( \pm 0.26-95 \%$ Confidence Interval $[\mathrm{CI}])$ and mean $N F R V_{\text {high }}$ was $1.12\left( \pm 0.71-95 \% \mathrm{CI} ; \mathrm{N}=17\right.$, Table 3.2). $N F R V_{\text {high }}$ was 2.13 times larger than $N F R V_{\text {low }}(p=0.04$, Table 3.2). For slurry, only one dataset was available. For this set, the ratio between $N F R V_{\text {high }}$ and $N F R V_{\text {low }}$ was $1.65(\mathrm{~N}=1$, Table 3.2).

For straw, one third of the $N F R V$ values were negative at low total $\mathrm{N}$ supply, while almost half (47\%) of the $N F R V$ values for straw were negative at high total $\mathrm{N}$ supply. Mean $N F R V_{\text {low }}$ for straw was $0.12( \pm 0.36-95 \% \mathrm{CI})$ and mean $N F R V_{\text {high }}$ was $0.35( \pm$ $1.67-95 \% \mathrm{CI}) . N F R V_{\text {high }}$ for straw was 3.07 times larger than mean $N F R V_{\text {low }}$, but not significantly so due to the large variation in the effects of straw on mineral fertiliser requirements $(p=0.79)$.

In five data sets, a combination of straw and green residues (green manures and/or beet leaves) was used as an organic input. At low total $\mathrm{N}$ supply, this combination had a negative $N F R V$ in two cases and no negative $N F R V$ at high total $\mathrm{N}$ supply. Mean $N F R V_{\text {low }}$ was $0.14( \pm 0.39-95 \% \mathrm{CI})$ and mean $N F R V_{\text {high }}$ was $0.91( \pm 1.21-95 \% \mathrm{CI})$. For the combination of straw and green residues, $N F R V_{\text {high }}$ was 6.6 times larger than $N F R V_{\text {low, }}$ but not significantly so, due to the small sample size (Table 3.2). 


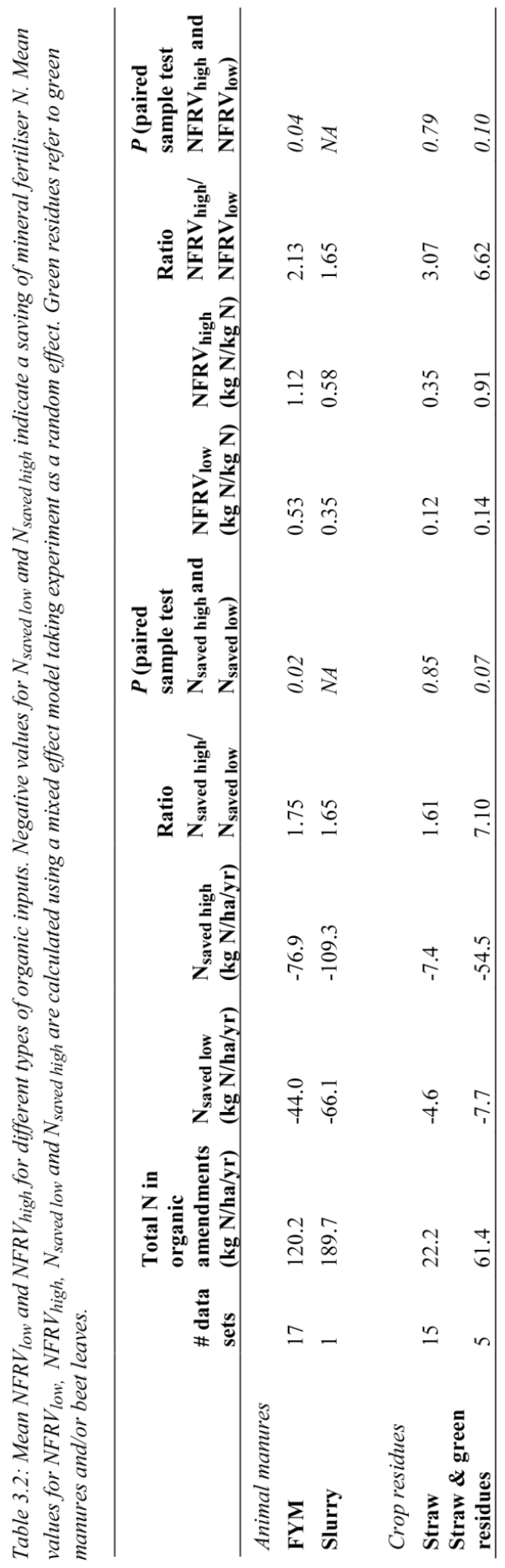




\subsection{Discussion}

For all types of organic inputs, mean $N F R V$ was higher at high total $\mathrm{N}$ supply than at low total $\mathrm{N}$ supply. Only for FYM the difference was significant $(p=0.04)$. For the other types of organic input either the sample sizes were too small or the variation too large.

Currently, values for $N F R V$ are often estimated by applying organic inputs without mineral fertilisers. In Europe, farmers often apply a mixture of organic inputs and mineral fertilisers, thus having a higher total $\mathrm{N}$ supply (Potter et al. 2010). We compared values for $N F R V$ at high total $\mathrm{N}$ supply (either the highest yield within the experimental set-up or the maximum of a response curve) with values of $N F R V$ for organic inputs at low total $\mathrm{N}$ supply (at the start of the response curves). In practice, farmers will (1) operate within environmental restrictions on $\mathrm{N}$ applications and (2) try to achieve an economic optimum. Therefore, most often farmers will target yields somewhat below the maximum of the $\mathrm{N}$ response curves, which will generally be closer to the values we calculated for $N F R V_{\text {high }}$ than for $N F R V_{\text {low. }}$.

Crop residues are often not used by farmers to replace mineral fertilisers as they have a high C: $\mathrm{N}$ ratio and might require $\mathrm{N}$ for decomposition (Knapp et al. 1983). In these cases, crop residues have a negative $N F R V$. Straw had a negative NFRV in one third $\left(N F R V_{\text {low }}\right)$ to half $\left(N F R V_{\text {high }}\right)$ of the cases in our study. A combination of green manures and straw had a negative NFRV in two fifth $\left(N F R V_{\text {ow }}\right)$ to none ( $\left.N F R V_{\text {high }}\right)$ of the cases.

Our findings are based on 38 datasets from eight long term experiments. Besides straw and FYM, however, there were only a limited number of observations per organic input type (Table 3.2). Further work is needed to assess to what extent $N F R V$ differs between low and high total $\mathrm{N}$ supply for the other input types, for different soil and climate conditions and in combination with different crop types. Such an exercise would require a much larger dataset, preferably with $\mathrm{N}$ contents of organic inputs available.

A number of mechanisms might change the shape of the yield response curve and therefore cause a difference between the values of $N F R V_{\text {low }}$ and $N F R V_{\text {high }}$, on which we will now elaborate. A first mechanism could be that organic inputs provide other benefits than $\mathrm{N}$ to the crops (other nutrients or soil improvements), which has not been adjusted for in the mineral fertiliser only plots. In this case, the calculated values of $N F R V$ cannot be solely attributed to $\mathrm{N}$ but include additional yield effects (Janssen 2002; Wadman et al. 1987). Elimination of the limitation(s) that caused such additional yield effect (e.g. by supplying a mineral $\mathrm{S}$ fertilizer) would result in a steeper mineral fertilizer 
response (i.e. a better conversion of applied mineral fertiliser $\mathrm{N}$ into DM or FM yield). Consequently, $N F R V_{\text {high }}$ would decrease and approach $N F R V_{\text {low }}$. A second alternative explanation is that addition of mineral fertiliser might increase available $\mathrm{N}$ from the input (or vice versa). Third, addition of mineral fertiliser could increase uptake efficiency of $\mathrm{N}$ from organic input (or vice versa). Finally, a combination of above mechanisms might take place at the same time.

In our study, savings of mineral fertiliser when using organic inputs were compared at low and high total $\mathrm{N}$ supply. At low $\mathrm{N}$ supply, using only organic inputs was compared with using only mineral fertiliser. At high total $\mathrm{N}$ supply, using a combination of organic inputs and mineral fertiliser was compared with using only mineral fertiliser. The larger value of NFRV at high total N supply could suggest that the NFRV of organic inputs is higher when combined with mineral fertiliser than without. This suggestion could be further investigated by calculating NFRV (at equal yield) of organic inputs when applied in different amounts. If validated, this would open a new perspective on the advantage of distributing available organic inputs among many farmers in a given region: the region would require less fertiliser to produce the same yield output, than when organic inputs were concentrated in few farms.

In this study, we have used yield response curves expressed in either dry or fresh matter to calculate values for $N F R V_{\text {low }}$ and $N F R V_{\text {high. }}$. Other methods exist to calculate $N F R V$, such as based on $\mathrm{N}$ content (Jensen 2013) or using isotope dilution techniques (Diekmann et al. 1993; Janzen et al. 1990). An exploration of different methods into $\mathrm{NFRV}_{\text {low }}$ and $\mathrm{NFRV}_{\text {high }}$ might give further insights into possible mechanisms.

\subsection{Conclusions}

Currently, values for $N F R V$ are often based on experiments where crop yields in plots with only organic inputs (no mineral fertilisers) are compared with crop yields in plots with only mineral fertiliser, at relatively low total $\mathrm{N}$ supply. In many European countries, however, farmers operate at high total $\mathrm{N}$ supply. $N F R V$ coefficients play a key role in fertiliser recommendation systems and tools (e.g. MANNER-NPK, Nicholson et al. 2013) and various national Action Programmes in response to the EU Nitrates Directive (EEC 1991). For example, current Action Programmes in the UK, Denmark and the Netherlands use $N F R V$ values of $0.10,0.45$ and $0.30-0.60 \mathrm{~kg} / \mathrm{kg}$, respectively for total $\mathrm{N}$ in FYM, and values of $0.45,0.75$ and $0.60-0.80 \mathrm{~kg} / \mathrm{kg}$ for pig 
slurry (Dalgaard et al. 2014; RVO 2014; UK 2015) ${ }^{1}$. These values are often a political compromise, but based on short or long-term estimations of NFRV. These statutory values define, in combination with $\mathrm{N}$ application standards, the maximum amounts of $\mathrm{N}$ fertiliser that farmers in those countries may apply, depending on crop and soil type.

This meta-analysis of eight long term experiments on different types of organic inputs shows that $N F R V$ of FYM was roughly up to two times larger at high than at low total $\mathrm{N}$ supply rate. Currently, $N F R V$ is usually assessed at the 'lower end' of the $\mathrm{N}$ response curve. Considering that farmers in Europe normally operate at relatively high mineral fertilisation rates, the use of $N F R V$ determined at the 'lower' end of the $\mathrm{N}$ response curve may underestimate $N F R V$ of organic inputs. When using these lower values to estimate the $\mathrm{N}$ fertilizer replacement value of organic inputs, complementary mineral $\mathrm{N}$ fertiliser requirements are estimated to be larger than actually needed for achieving certain yields. This might lead to overuse, lower $\mathrm{N}$ use efficiency and more losses to the environment.

If our findings can be further generalized, the observed contrast in NFRV between the respective $\mathrm{N}$ ranges may have practical implications for fertiliser recommendations, depending on the mechanisms underlying the contrast. Similarly, the contrast might justify adjustment of statutory values for fertiliser equivalency coefficients as used to regulate $\mathrm{N}$ use in the Action Programmes - under the Nitrates Directive - of various EU member states.

\subsection{Acknowledgments}

We thank all who set up, maintained and shared data from long-term experiments in Europe through their publications. We thank Guido Baldoni (University of Bologna) for providing additional data, and Margaret Glendining (Rothamsted Research) for providing an overview on long term experiments in Europe and sharing her network. We are grateful to Gerrit Gort (Wageningen University and Research) for his support on statistics.

\footnotetext{
${ }^{1}$ Values for the Netherlands refer to arable crops on sandy soils
} 


\section{Supplement Chapter 3}

Supplementary Fig.3.1 Mineral fertiliser N savings from FYM at low and high total $\mathrm{N}$ supply

Supplementary Fig. 3.2 Mineral fertiliser N savings from slurry at low and high total $\mathrm{N}$ supply

Supplementary Fig. 3.3 Mineral fertiliser N savings from a combination of straw and green residues at low and high total $\mathrm{N}$ supply

Supplementary Fig. 3.4 Mineral fertiliser N savings from straw at low 56 and high total $\mathrm{N}$ supply 


\section{N savings from FYM at low and high total $N$ supply}

A. Bologna winter wheat

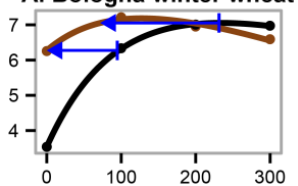

D. Kezthely winter barley

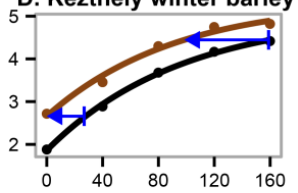

G. Muencheberg sugar beet (DM)

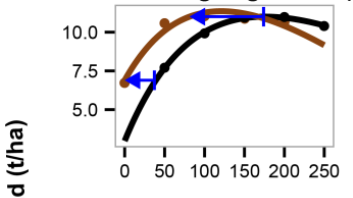

J. Muencheberg winter wheat (DM)

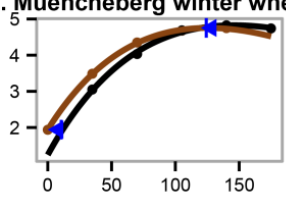

M. Speyer winter barley (DM)

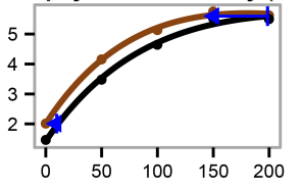

P. Sproda spring barley ( $86 \%$ DM)

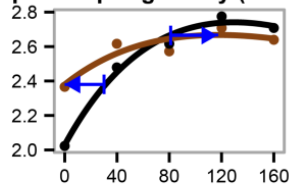

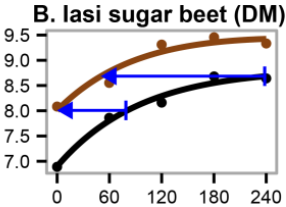

E. Lukavec potatoes
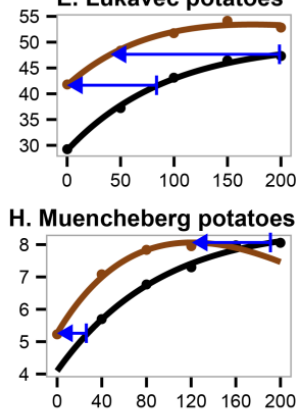

K. Muencheberg maize (DM)

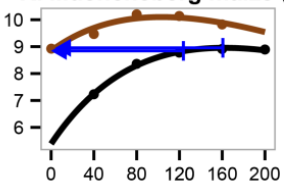

N. Speyer winter wheat (DM)

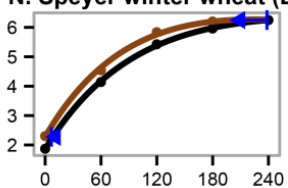

C. lasi maize (DM)

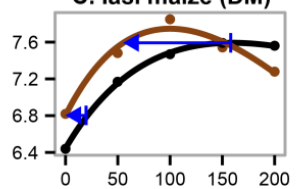

F. Lukavec winter barley

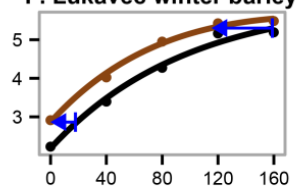

e (DM)

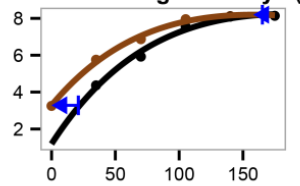

L. Muencheberg spring barley (DM)

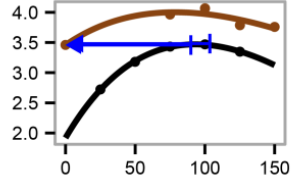

0 . Sproda sugar beet

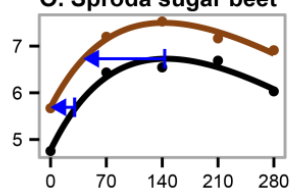

Q. Sproda winter wheat (86\% DM)

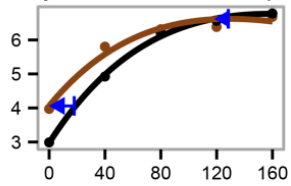

$\rightarrow$ FYM

$\rightarrow-$ no organic amendment

$\longleftarrow$ mineral fertiliser $N$ saving

Mineral fertiliser (kg N/ha)

Supplementary Fig. 3. 1: Yield response curves to mineral fertiliser, with and without FYM. Blue arrows pointing to the left indicate a saving of mineral fertiliser $N$ when applying $F Y M$. Blue arrows pointing to the right indicate additional mineral fertiliser $N$ is needed when applying FYM. Years of yield data: A) 1990-2000; B) 1986-2006; C) 1984-1992; D) 1999-2010; E) 2002-2007; F) 2002-2007; G) 1985-1993; H) 1983-1999; I) 1996-2004; J) 19842002: K) 1995-2003; L) 1978-1982; M) 1994-1999; N) 1994-1999; O) 1999-2010; P) 1999-2010; Q) 1999-2010 


\section{N savings from slurry at low and high total $\mathbf{N}$ supply}

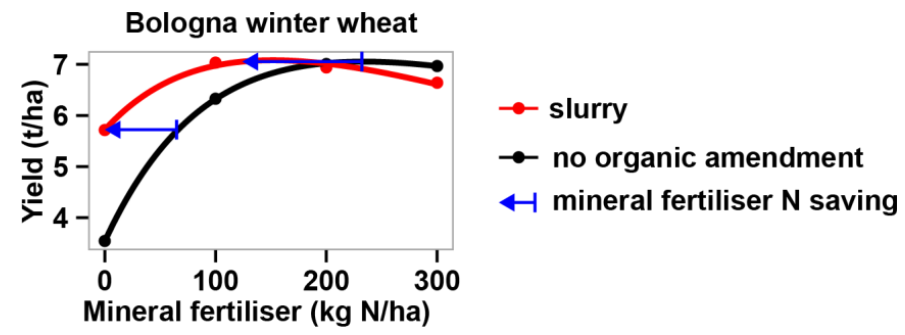

Supplementary Fig. 3. 2: Yield response curves of winter wheat to mineral fertiliser, with and without slurry applied in Bologna (1999-2010). Blue arrows pointing to the left indicate saving of mineral fertiliser $N$ when applying slurry at low and high total $N$ supply.

\section{$\mathrm{N}$ savings from a combination of straw and green residues at low and high total $\mathbf{N}$ supply}
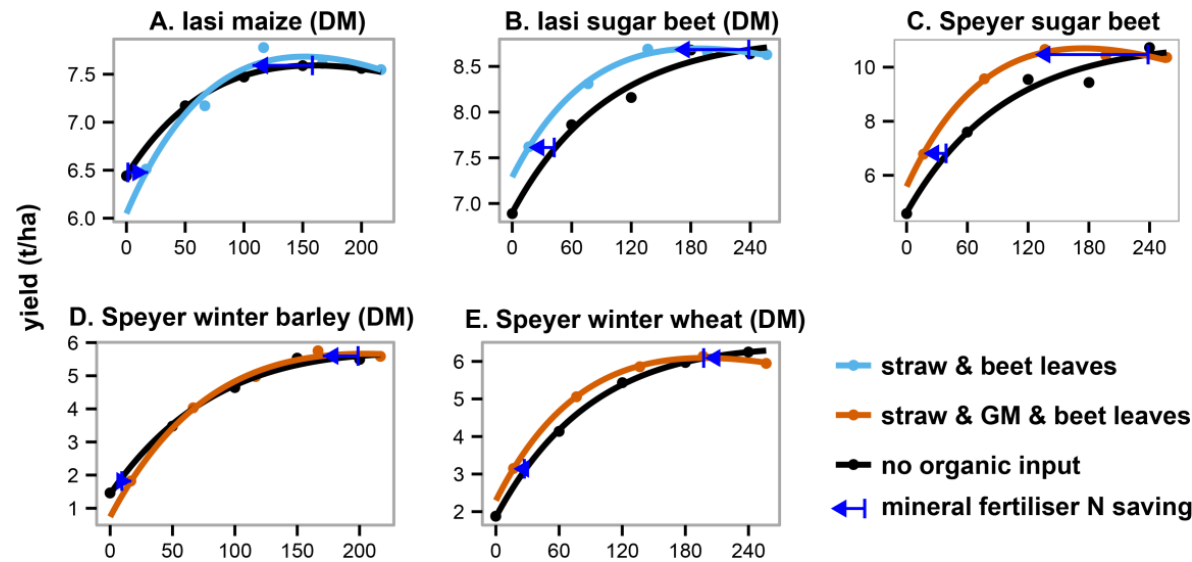

\section{E. Speyer winter wheat (DM)}

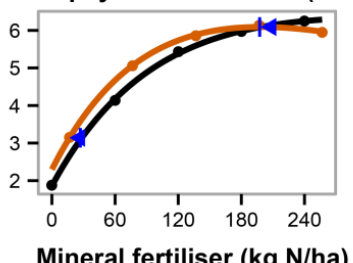

- straw \& beet leaves

- straw \& GM \& beet leaves

$\sim$ no organic input

$\leftrightarrow$ mineral fertiliser $\mathrm{N}$ saving

Mineral fertiliser (kg N/ha)

Supplementary Fig. 3. 3: Yield response curves to mineral fertiliser, with and without a combination of straw and green residues. $X$-axes indicate mineral fertiliser $N$, including additional mineral fertiliser $N$ added for the cultivation of green manures or decomposition of straw (at each site on average $16.7 \mathrm{~kg} \mathrm{~N} / \mathrm{ha}$ /year). Blue arrows pointing to the left indicate a saving of mineral fertiliser $N$ for a combination of straw and green residues. Blue arrows pointing to the right indicate additional mineral fertiliser $N$ is needed for a combination of straw and green residues. Years of yield data: A) 1984-1992; B) 1986-2006; C) 1994-1999; D) 1994-1999; E) 1994-1999. 


\section{$\mathrm{N}$ savings from straw at low and high total $\mathrm{N}$ supply}

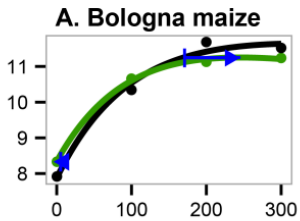

D. Methau spring barley ( $86 \%$ DM)
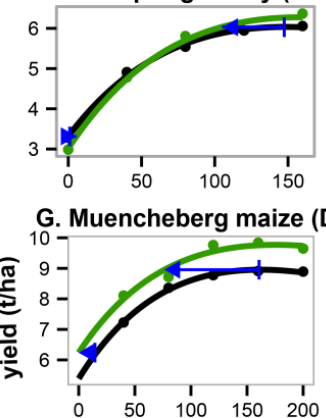

J. Muencheberg sugar beet (DM)

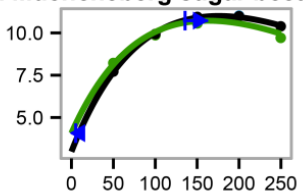

M. Sproda spring barley (86\% DM)

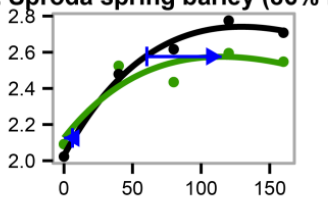

$\sim$ no organic amendment
B. Bologna winter wheat

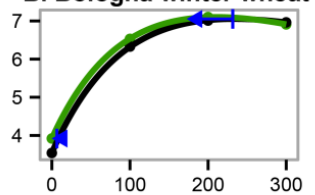

E. Methau sugar beet

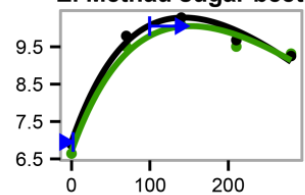

H. Muencheberg potatoes (DM)

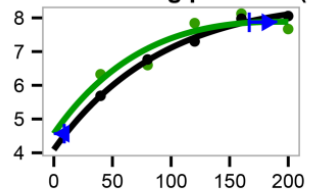

Muencheberg winter rye (DM)

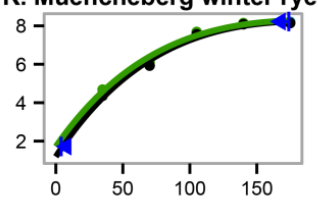

N. Sproda sugar beet

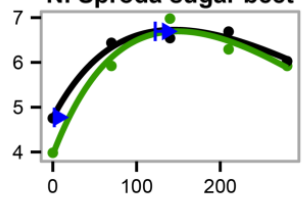

Mineral fertiliser (kg N/ha)
C. Methau potatoes (FM)

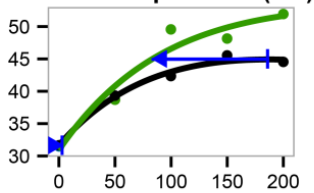

F. Methau winter wheat ( $86 \%$ DM)

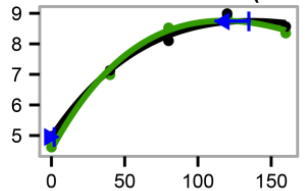

I. Muencheberg spring barley (DM)

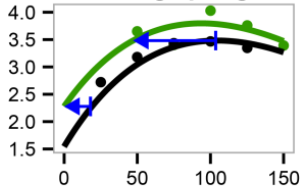

L. Muencheberg winter wheat (DM)

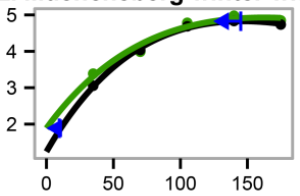

O. Sproda winter wheat ( $86 \%$ DM)

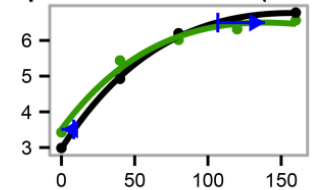

$\sim$ straw $\longleftarrow$ mineral fertiliser $\mathrm{N}$ saving

Supplementary Fig. 3. 4: Yield response curves to mineral fertiliser, with and without straw application. Blue arrows pointing to the left indicate a saving of mineral fertiliser $N$ when applying straw. Blue arrows pointing to the right indicate additional mineral fertiliser $N$ is needed when applying straw. Years of yield data: A) 19912001; B) 1990-2000; C) 1999-2010; D) 1999-2010; E) 1999-2010; F) 1999-2010; G) 1995-2003; H) 1983-1999; I) $1978-1982$; J) 1985-1993; K) 1996-2004; L) 1984-2002; M) 1999-2010; N) 1999-2010; O) 1999-2010 


\section{Chapter 4.}

\section{Drivers and barriers for arable farmers to use organic inputs in six agro-ecological zones across Europe}

Renske Hijbeek ${ }^{1}$, Anette A. Pronk ${ }^{2}$, Martin K. van Ittersum ${ }^{1}$, Jan Verhagen ${ }^{2}$, Greet Ruysschaert $^{3}$, Jo Bijttebier ${ }^{3}$, Laura Zavattaro ${ }^{4}$, Luca Bechini ${ }^{5}$, Norman Schlatter ${ }^{6}$, Hein F.M. ten Berge ${ }^{2}$

${ }^{1}$ Plant Production Systems, Wageningen Plant Research, Wageningen University and Research, the Netherlands

${ }^{2}$ Agrosystems Research, Wageningen University and Research, the Netherlands

${ }^{3}$ Flanders research institute for agriculture, fisheries and food, Belgium

${ }^{4}$ Department of Agricultural Forest and Food Sciences, Università degli Studi di Torino, Italy

${ }^{5}$ Department of Agricultural and Environmental Sciences, Università degli Studi di Milano, Italy

${ }^{6}$ Department for Soil Health and Plant Nutrition, Austrian Agency for Health and Food Safety, Austria.

To be submitted 


\section{Abstract}

Soil organic matter (SOM) can be built up by using organic inputs (such as straw, compost, farmyard manure or the cultivation of green manures or cover crops). SOM is known to have benefits for long-term soil fertility and can provide certain ecosystem services. This could be an incentive to stimulate farmers to use more organic inputs. Farmers' behaviour is known to be motivated by a large number of factors. Using the theory of planned behaviour, we aim to disentangle these factors. We address the following research question: What are currently the main drivers and barriers for arable farmers in Europe to use organic inputs?

This study focuses on six agro-ecological zones in four European countries (Austria, Belgium, Italy and the Netherlands) and four practices (straw incorporation, cultivation of green manure or cover crops, application of compost and application of farmyard manure). In a first step, relevant factors were identified for each practice using five to ten semi-structured interviews with farmers per agro-ecological zone. In a second step, these factors were quantified as either drivers or barriers in a large scale farm survey among 1180 farmers.

In the semi-structured interviews, 91 relevant factors were identified influencing farmers' decisions to use an organic input. In the larger farm survey, $60 \%$ of the factors included were evaluated as drivers, while $40 \%$ were evaluated as barriers for the use of organic inputs. Major drivers to use organic inputs were related to perceived effects on soil quality (such as improved soil structure or reduced erosion) and the positive influence from social referents (such as fellow farmers or agricultural advisors). Major barriers to use organic inputs were financial (increased costs or foregone income) and perceived effects on crop protection (such as increased pressure from weeds, pests and diseases, or increased pesticide use).

Our study shows that farmers perceive a trade-off between improved soil quality on the one hand and increased pressures from weeds, pests and diseases and financial consequences on the other hand when using organic inputs. Motivating farmers to use organic inputs therefore requires specific guidance on how to adapt cultivation practices in order to reduce the pressure of weeds, pests and diseases for specific soil types, weather conditions, and crops cultivated. In addition, more research is needed on the long-term financial effects of using organic inputs.

Key-words: drivers; barriers; straw; farmyard manure; green manures; cover crops; compost; soil organic matter; Europe; agro-ecological zones 


\section{Abbreviations}
AEZ agro-ecological zone
CT conservation tillage
FYM farmyard manure
SOM soil organic matter

\subsection{Introduction}

Using organic inputs (such as straw, green manures, compost or animal manure) contributes to the soil organic matter (SOM) content of a soil (Panagos et al. 2015). SOM is generally considered an important indicator for soil fertility (Christensen \& Johnston 1997; Reeves 1997) as it is known to stabilize soil structure, increase nutrient availability and improve water holding capacity (Johnston et al. 2009; Watts \& Dexter 1997). In addition, SOM content can have environmental benefits such as supporting soil biodiversity or sequestering carbon (Chang et al. 2007; Freibauer et al. 2004).

Recently, a decline in SOM content has been identified as a threat to soil quality at European scale (Stolte et al. 2015; Toth et al. 2008). Precise magnitudes of decline are unknown as monitoring of SOM is currently sparse (ten Berge et al. 2017) or give contrasting results. For Great Britain, monitoring studies suggest no changes in SOM content over the last decades (Chapman et al. 2013; Reynolds et al. 2013). For Austria and the Netherlands, positive changes in SOM content have been reported (Dersch 2015; Reijneveld et al. 2009). For Germany, Italy, Belgium, Finland and Denmark, a negative change in SOM content of arable soils over the last decades has been reported (Capriel 2013; Fantappiè et al. 2011; Goidts \& van Wesemael 2007; Heikkinen et al. 2013; Taghizadeh-Toosi et al. 2014).

Currently, maintenance of SOM content is included in the cross-compliance standards of Good Agricultural and Environmental Conditions (GAEC, EC 2013). Most member states have specified only a ban on burning of stubble, but a small number of countries has added additional measures including the use of organic inputs (such as solid manures or soil organic manures; Frelih-Larsen et al. 2016). Frelih-Larsen et al. (2016) recommend a strengthening of GAEC 6 by adding a requirement to incorporate crop residues, either directly or following mulching, after composting or after use as animal bedding. Before enforcing such a measure, it is important to understand the current drivers and barriers for farmers in Europe to use organic inputs. 
Van den Putte et al. (2010) argue that farmers often have few incentives to use soil conservation measures because productive capacities of farms are not affected by soil degradation on the short term. Glenk et al. (2017) made an economic farm level analysis of SOM management in two areas in Scotland and Spain and found varied effects on farm gross margin, depending on input type and region. They did however note that farmers' behaviour may be motivated by factors which are not directly economic such as perceived workability of the soil, or soil health for future generations. Simple costbenefit models might therefore not capture the complexity of farmers' behaviour and attitudes (Lynne et al. 1988). Burton (2004) argues that understanding farmers' willingness to adopt certain management practices improves when the theory of planned behaviour (Ajzen 1991) is used as a conceptual framework.

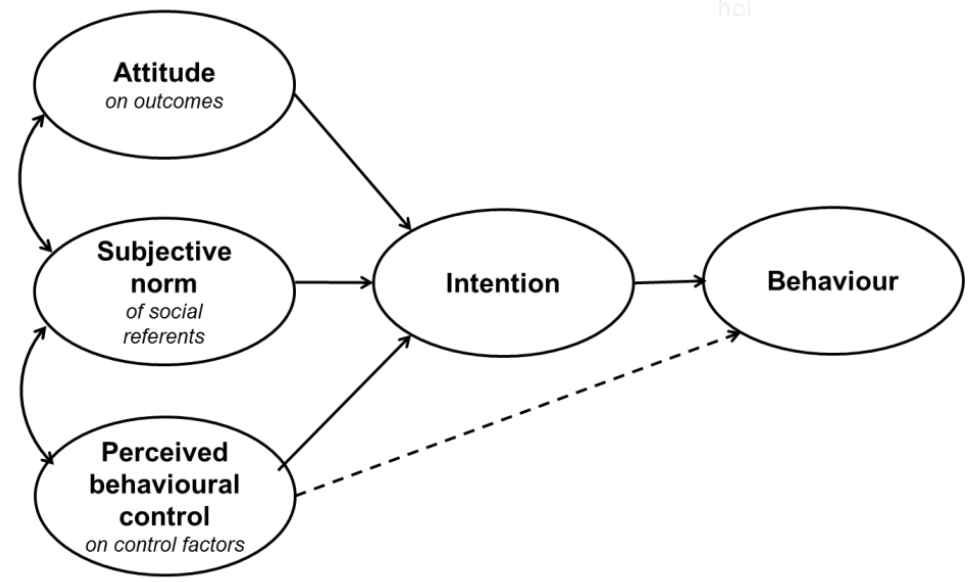

Fig 4. 1: Illustration of the framework of the Theory of planned behaviour (Ajzen 1991).

According to the theory of planned behaviour (Fig. 4.1), people base their behaviour on three main constructs: 1) their attitude, 2) their subjective (social) norm and 3) the degree of perceived behavioural control. In this framework, an attitude refers to the degree to which a person expects a certain outcome, together with the desirability of that outcome. An outcome is an expected result or impact of the practice, for example increased weed pressure or improved soil fertility. Subjective norm refers to the influence from social referents to perform a behaviour. Social referents in this case are for example fellow farmers or an agricultural advisor. Perceived behavioural control refers to perceived support or hindrance from control factors. A control factor is a specific, often local, condition that governs the impact of the practice, or facilitates or hampers its adoption. These three constructs together lead to an intention, which might lead to a certain behaviour (Ajzen 1991). 
The theory of planned behaviour has been successfully applied previously in an agricultural context. For example, Werner et al. (2017) found that in Germany, attitudes and perceived behavioural control were linked to intentions of farmers to cultivate cover crops.

In this study, the theory of planned behaviour is used to identify drivers and barriers for the use of different organic inputs. We presume that specific drivers and barriers will be context-specific, depending among others on soil types and climates. Therefore, we assess drivers and barriers in six regions with specific combinations of slope, soil texture and climate, hereafter called agro-ecological zones (AEZ). We ask the following research question: What are currently the main drivers and barriers for arable farmers to use organic inputs?

\subsection{Materials and methods}

\subsubsection{Study approach}

The study approach consisted of two steps: 1) a qualitative step to identify relevant outcomes, referents and control factors for each practice; 2) a quantitative step to quantify each relevant outcome, referent or control factor (Fig. 4.2). For the first step, semi-structured interviews were held with a small number of farmers, whilst for the second step, a much larger farm survey was conducted. In this manner, a bottom-up approach is used relying on farmers' knowledge of their local farming conditions in each AEZ.

\begin{tabular}{|c|c|}
\hline Step 1: Qualitative & Step 2: Quantitative \\
\hline Objective: To find relevant & Objective: To quantify each \\
\hline $\begin{array}{c}\text { control factors } \\
\text { Method: semi-structured } \\
\text { interviews }\end{array}$ & $\begin{array}{c}\text { control factor as a driver or } \\
\text { barrier } \\
\text { (on a scale from }-10 \text { to }+10 \text { ) } \\
\text { Method: larger farm survey }\end{array}$ \\
\hline
\end{tabular}

Fig 4. 2: Overview of the study approach.

\subsubsection{Study area}

This study formed part of the European project CATCH-C in which AEZs in Europe were identified based on three environmental factors: climate, slope and soil texture. Each AEZ has more or less homogeneous conditions for each factor (Hijbeek et al. 2013). Six AEZs were studied in four countries (Austria, Belgium, Italy and the 
Netherlands). Selection of AEZs in each country was mainly based on the area of the AEZ and the economic importance of agriculture in the AEZ. Six AEZs were selected (Fig. 4.3 and Table 4.1): Austria (AT1), Belgium (BE1), Italy (IT1, IT2) and the Netherlands (NL1, NL2). Within each AEZ, data collection was focused on arable farmers.

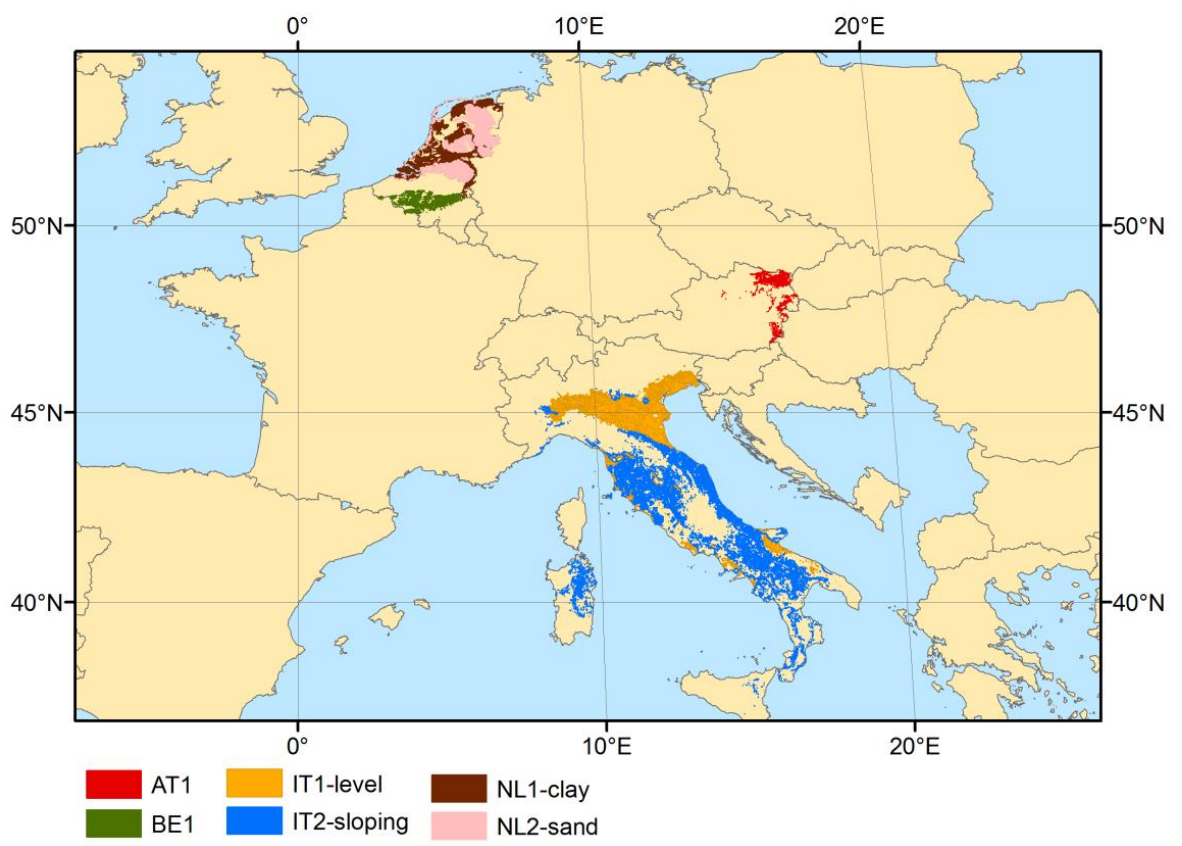

Fig 4. 3: Map of study area indicating the six AEZs in four European countries (Austria, Belgium, Italy and the Netherlands).

In Austria, AT1 has a relatively dry climate (mean aridity index of 0.51 ), level or gentle slopes and a medium soil texture (meaning $>15 \%$ sand and $18-35 \%$ clay or $15-65 \%$ sand and $<18 \%$ clay). In Belgium, BE1 has a relatively wet climate (mean aridity index 0.73 ), a medium fine soil texture (meaning $<15 \%$ sand, $<35 \%$ clay) and level to gently sloping lands.

In Italy, IT1 and IT2 both have a very dry climate. IT1 is mainly present in the Po plain and has more level land. IT2 is mostly located in the hills of centre and southern Italy and has steeper slopes. To differentiate this difference, in figures and tables IT1 is labelled IT1-level and IT2 is labelled IT2-sloping. To keep the text flowing, this adjective is not added in the text. 
In the Netherlands, NL1 and NL2 both have a wet climate and level land. NL1 however has medium or medium fine soil textures and NL2 has only coarse soil textures (meaning $>65 \%$ sand and $<18 \%$ clay). To differentiate this difference in soil texture between the two AEZs in the Netherlands, NL1 is labelled NL1-clay and NL2 is labelled NL2-sand in figures and tables.

Table 4. 1 Characteristics of each AEZ. Climate zones follow Metzger et al. (2005). Aridity index of each climate zone is calculated by dividing annual precipitation by potential evapotranspiration, using spatial climatic data for the period 1975-2009 (Janssen et al. 2009). A lower aridity index indicates a drier climate. Soil texture classes follow classes used in the European soil database (EC\& ESBN 2004).

\begin{tabular}{|c|c|c|c|c|}
\hline & Climate zone & $\begin{array}{l}\text { Average aridity } \\
\text { index of the climate } \\
\text { zone }\end{array}$ & Slope & Soil texture \\
\hline AT1 & Pannonian & 0.51 (dry) & level $\left(0^{\circ}\right)$ or gentle $\left(2-3^{\circ}\right)$ & medium \\
\hline BE1 & Atlantic Central & 0.73 (wet) & nearly level $\left(1^{\circ}\right)$ & medium fine \\
\hline IT1-level & Mediterranean North & 0.38 (very dry) & level $\left(0^{\circ}\right)$ or gentle $\left(2-3^{\circ}\right)$ & $\begin{array}{l}\text { coarse to medium fine } \\
\text { medium or medium }\end{array}$ \\
\hline IT2-sloping & Mediterranean North & 0.38 (very dry) & gentle to moderate $\left(2-7^{\circ}\right)$ & fine \\
\hline & Atlantic North anc & & & medium or medium \\
\hline NL1-clay & Central & 0.76 (wet) & level $\left(0^{\circ}\right)$ & fine \\
\hline NL2-sand & Atlantic Central & 0.76 (wet) & level $\left(0^{\circ}\right)$ & coarse \\
\hline
\end{tabular}

Farmers were questioned on four types of organic inputs: incorporation of small grain cereal straw or grain maize straw; cultivation of green manures or cover crops; application of compost; and application of farmyard manure (FYM). Not all practices were included in each AEZ (Table 4.2). Incorporation of straw was included in five AEZs. Cultivation of green manures or cover crops was included in six AEZs. Application of compost was included in two AEZs. Application of FYM was included in only one AEZ.

Table 4. 2: Overview of AEZs and types of organic inputs included in the farm survey.

\begin{tabular}{l|c|c|c|c}
\hline & $\begin{array}{c}\text { Incorporation of } \\
\text { straw }\end{array}$ & $\begin{array}{c}\text { Cultivation of green } \\
\text { manures or cover crops }\end{array}$ & Compost & FYM \\
\hline AT1 & & $\mathrm{X}$ & & \\
BE1 & $\mathrm{X}$ & $\mathrm{X}$ & $\mathrm{X}$ & $\mathrm{X}$ \\
IT1-level & $\mathrm{X}$ & $\mathrm{X}$ & & \\
IT2-sloping & $\mathrm{X}$ & $\mathrm{X}$ & & \\
NL1-clay & $\mathrm{X}$ & $\mathrm{X}$ & & \\
NL2-sand & $\mathrm{X}$ & $\mathrm{X}$ & $\mathrm{X}$ & \\
\hline
\end{tabular}

\subsubsection{Step 1: semi-structured interviews}

In the first step, five to ten farmers were interviewed in each AEZ to identify outcomes, referents and control factors for each practice. The objective of these semi-structured interviews was to use farmers' knowledge to identify relevant factors for each practice, 
based on the theory of planned behaviour. Farmers were asked five questions to identify outcomes of each practice, four questions to identify social referents for each practice and three questions to identify control factors for each practice (specific questions asked are listed in Supplementary Table 4.1, page 84).

The semi-structured interviews in the six AEZs resulted in 285 identified outcomes, referents and control factors. Each of these was related to a type of organic input and an AEZ. As could be expected, a substantial number of these items were similar, or almost similar, across different types of organic inputs and AEZs. Therefore, mentioned outcomes, referents and control factors were clustered in 101 classes (40 outcome classes, 12 referent classes and 49 control factor classes). Following, they were given shorthand labels (such as soil structure, or contract workers), which had overlap between outcomes, referents and control factors (e.g. the label contract worker could refer to a referent or a control factor). This resulted in 91 labels. The 91 labels were classified into nine main categories (Table 4.3). The nine main categories were: soil type \& climate, soil quality, crop protection, land use, technical, financial, environmental impact, legal and social (Fig. 4.4).

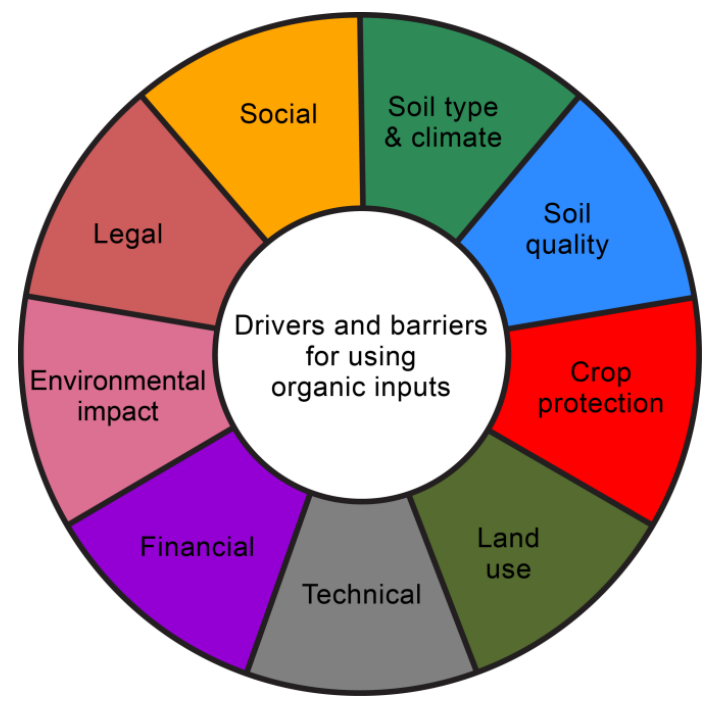

Fig 4. 4: Overview of the nine main categories used for clustering outcomes, referents and control factors as identified in the semi-structured interviews. 


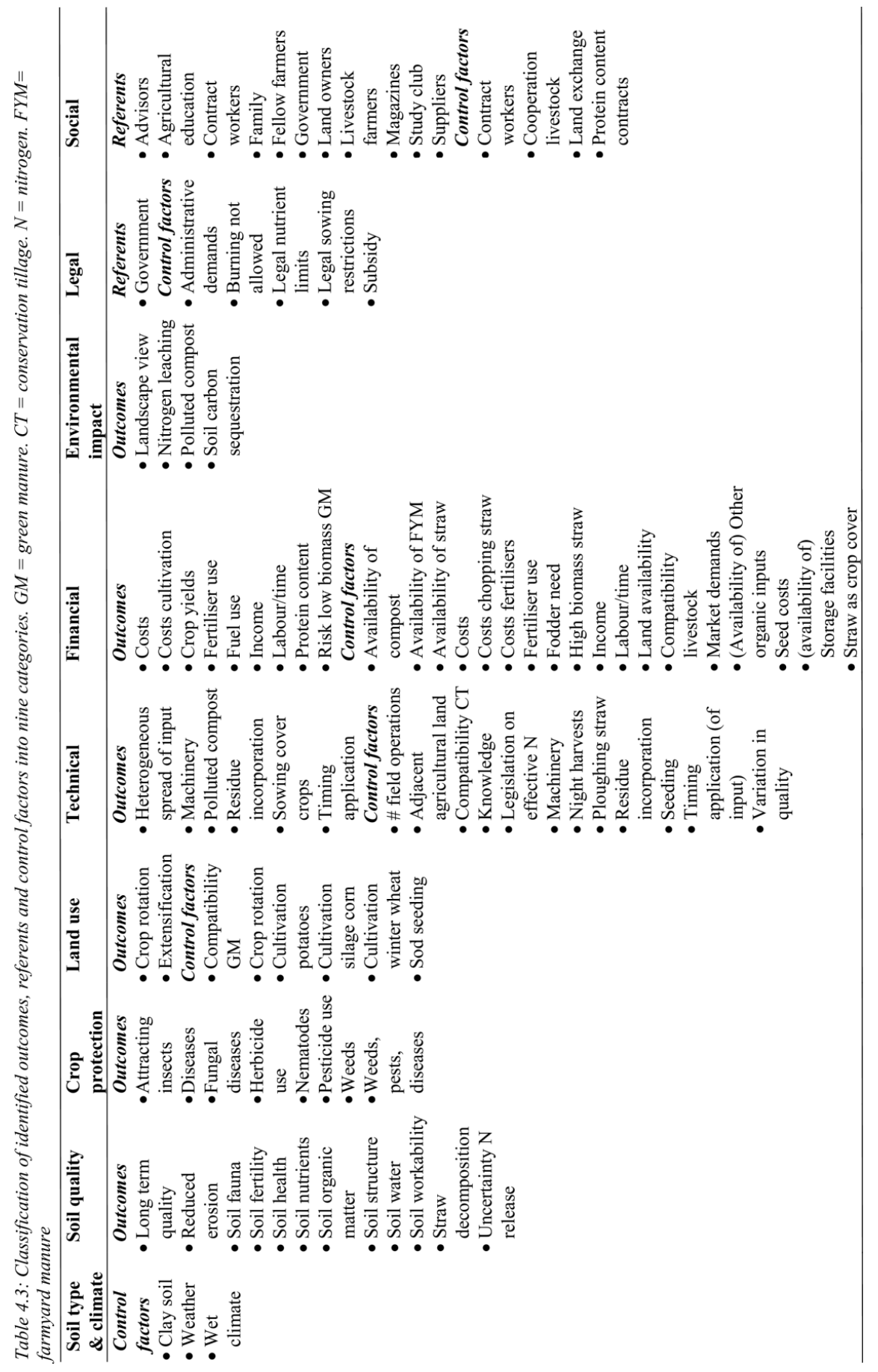




\subsubsection{Step 2: farm survey}

The outcomes, referents and control factors for the use of organic inputs identified in the semi-structured interviews were quantified in a large farm survey. For each outcome, referent and control factor, two questions were asked, based on the theory of planned behaviour. In this manner, the attitude, subjective norm and perceived behavioural control on the use of organic inputs could be calculated.

The sampling for the questionnaires depended on the availability of a valid sampling frame of arable farmers within each country (i.e. contact details of farmers). The most ideal sampling frame to obtain a completely random sample is a nation-wide database of farmers' addresses. Such a database was available for Flanders (Belgium) and the Netherlands. In these countries farmers were invited by letter to participate in the farm survey. In Austria and Italy researchers depended on farmers' associations, farmers' extension services or other contacts to distribute the questionnaires. Questionnaires were filled online (Austria and the Netherlands) or as a paper questionnaire (Belgium and Italy). Response rates varied between 12 to $59 \%$ (Table 4.4 ).

To reduce the length of the questionnaires and increase the response rate, in Belgium and the Netherlands questionnaires were split into two or three parts allocated to different groups of farmers. As such, each group of farmers received a questionnaire with a common introduction section combined with in-depth questions only on a specific type of organic input. Questions on the incorporation of straw were then for example only sent to a subset of farmers. To reduce errors in farmers' answers, respondents were not obliged to fill out every question. In the case of partly completed questionnaires, only the filled parts were used in the analysis. For these two reasons, numbers of farmers can differ between analyses. Questionnaires were returned during the summer and autumn of 2013. Filled questionnaires were checked on irregularities (typing mistakes or extreme numbers) and if any, removed from analysis.

Table 4. 4: Numbers of farmers included in the semi-structured interviews (step 1) and the larger farm survey (step 2) $N A=$ not applicable.

\begin{tabular}{l|r|rrr} 
& $\begin{array}{r}\text { Step 1 } \\
\text { Semi-structured } \\
\text { interviews }\end{array}$ & $\begin{array}{r}\text { Step 2 } \\
\text { Questionnaires } \\
\text { sent }\end{array}$ & $\begin{array}{r}\text { Response } \\
\text { Response rate }\end{array}$ \\
\hline AT1 & 8 & open online survey & 34 & $N A$ \\
BE1 & 7 & 1600 & 430 & $27 \%$ \\
IT1-level & 8 & 211 & 124 & $59 \%$ \\
IT2-sloping & 9 & 165 & 98 & $59 \%$ \\
NL1-clay & 10 & 2700 & 336 & $12 \%$ \\
NL2-sand & 5 & 2000 & 241 & $12 \%$ \\
\hline
\end{tabular}


In the farm survey, farmers were also asked if they used each type of organic input. Hence, farmers were asked whether they cultivate green manures or cover crops, incorporate straw, use FYM or compost, on at least one of their fields.

\section{Quantification of attitudes}

For each identified outcome (i), two types of questions were asked in the farm survey: 1) To which degree a farmer expects a certain outcome (i.e., result, effect) from the given practice ('belief strength') and 2) how the outcome is valued on a scale from 'bad' to 'good' ('outcome valuation'). For example: a possible outcome from the application of compost is improved soil structure. In the farm survey, farmers were first asked to which degree they expect compost to improve soil structure $(1=$ little, $5=$ much) and second how they evaluate an improvement in soil structure $(1=$ bad, $5=$ good). Outcome valuations were lowered by three points to give a negative to positive scaling $(-2$ to +2$)$. In the data analysis, beliefs strengths and outcome valuations were multiplied to obtain an attitude score for each outcome (Equation 4.1, values for attitude ranging from -10 to +10 ).

attitude $_{i}=$ belief $_{\text {strength }} *\left(\right.$ outcome valuation $\left._{i}-3\right)$

\section{Quantification of subjective norm}

For each social referent (k) identified in the semi-structured interviews, two types of questions were asked in the farm survey: 1) how motivated they are to comply with the referents' view ('motivation to comply') and 2) to which degree the referent is positive or negative towards a practice ('normative belief'). For example: A social referent for the incorporation of straw are fellow farmers. In the farm survey, farmers were first asked if they thought fellow farmers are positive on the incorporation of straw $(1=$ negative, $5=$ positive). Second, farmers were asked how motivated they are to comply with the opinion of fellow farmers $(1=$ little, $5=$ much $)$. Normative beliefs were lowered by three points to give a negative to positive scaling $(-2$ to +2$)$. In the data analysis, motivations to comply and normative beliefs were multiplied to obtain a subjective norm score for each referent (Equation 4.2, values for subjective norm ranging from -10 to $+10)$.

subjective norm $_{k}=$ motivation to comply $y_{k} *\left(\right.$ normative belie $\left.f_{k}-3\right)$

Quantification of perceived behavioural control

For each identified control factor (m), also two types of questions were asked in the farm survey: 1) to which degree that control factor is valid for the farm ('control strength') and 2) to which degree the control factor makes the practice attractive or difficult 
('control power'). For example: a control factor for using compost is the availability of compost in the farmers' region. In the farm survey, farmers were first asked if there is compost availability in the region $(1=$ not agree, $5=$ agree $)$ and second how much they thought availability of compost will affect utilization $(1=$ negative, $5=$ positive $)$. Control powers were lowered by three points to give a negative to positive scaling ( -2 to +2$)$. In the data analysis, control strengths and control powers were multiplied to obtain a value for perceived behavioural control for each control factor (Equation 4.3, values for perceived behavioural control ranging from -10 to +10 ).

perceived behavioural control $_{m}=$ control $_{\text {strength }} *\left(\right.$ control power $\left._{m}-3\right)$

\section{Classification as drivers or barriers}

For each attitude, subjective norm and perceived behavioural control, the mean value across all respondents in an AEZ was calculated, together with the $95 \%$ confidence interval. The $95 \%$ confidence interval was calculated as $1.96 * \frac{s d}{\sqrt{N}}$ in which sd is the standard deviation and $\mathrm{N}$ is the number of farmers who answered the question. Significantly positive values (when zero was not included in the $95 \%$ confidence interval) were considered drivers. Significantly negative values were considered barriers.

Each driver or barrier belonged to one of the 91 sub categories (Table 4.3) and nine main categories (Fig. 4.4). If two identified factors for a type of organic input and AEZ fell into the same subcategory (e.g. soil fertility) and they were both positive (or both negative), the average was taken. When two identified factors for a practice and AEZ fell into the same sub category but the signs differed (the one being negative and the other positive) they were kept separate in the analysis (meaning the sub category represents both a driver and a barrier for a given practice). The latter was done because apparently sometimes an outcome or control factor (e.g. soil fertility) can be both a driver and a barrier, and we wanted to keep this information visible in the results.

\subsection{Results}

\subsubsection{Characteristics of farmers in the survey}

When conducting the farm survey, we aimed to target arable farmers with specific climates, slopes and soil textures (Table 4.1), based on European scale datasets. Targeting farmers with similar conditions for slope and soil texture however proved to be difficult as these characteristics differ at smaller geographical scales. Overall, soil 
textures and slopes of the respondents in each AEZ showed correspondence with the targeted AEZs but there was also considerable variation within each AEZ (Table 4.5).

Table 4. 5: Characteristics (slope, soil texture) of the AEZ and their farms in the survey, averaged per AEZ. $N$ indicates number of farmers on which the analysis is based, if a range is specified, this means that the number of farmers varied by practice.

\begin{tabular}{|c|c|c|c|c|c|c|}
\hline & $\begin{array}{r}\text { AT1 } \\
(\mathrm{N}=34) \\
\end{array}$ & $\begin{array}{r}\text { BE1 } \\
(\mathrm{N}=371-395) \\
\end{array}$ & $\begin{array}{r}\text { IT1-level } \\
(\mathrm{N}=102-114) \\
\end{array}$ & $\begin{array}{r}\text { IT2-sloping } \\
(\mathrm{N}=82-85) \\
\end{array}$ & $\begin{array}{r}\text { NL1-clay } \\
(\mathrm{N}=331-333) \\
\end{array}$ & $\begin{array}{r}\text { NL2-sand } \\
(\mathrm{N}=217-219) \\
\end{array}$ \\
\hline \multicolumn{7}{|c|}{$\begin{array}{l}\text { Slope (mean percentage } \\
\text { farm area) }\end{array}$} \\
\hline Level $\left(0^{\circ}\right)$ & $18 \%$ & $39 \%$ & $80 \%$ & $8 \%$ & $100 \%$ & $100 \%$ \\
\hline Nearly level $\left(1^{\circ}\right)$ & $22 \%$ & $31 \%$ & $10 \%$ & $8 \%$ & $0 \%$ & $0 \%$ \\
\hline Gently sloping $\left(2-3^{\circ}\right)$ & $32 \%$ & $22 \%$ & $5 \%$ & $31 \%$ & $0 \%$ & $0 \%$ \\
\hline Sloping $\left(4-7^{\circ}\right)$ & $16 \%$ & $7 \%$ & $4 \%$ & $39 \%$ & $0 \%$ & $0 \%$ \\
\hline Steep $\left(>8^{\circ}\right)$ & $12 \%$ & $2 \%$ & $1 \%$ & $14 \%$ & $0 \%$ & $0 \%$ \\
\hline \multicolumn{7}{|c|}{$\begin{array}{l}\text { Soil texture (mean } \\
\text { percentage farm area) }\end{array}$} \\
\hline Sand & $26 \%$ & $8 \%$ & $12 \%$ & $1 \%$ & $1 \%$ & $93 \%$ \\
\hline Loam & $40 \%$ & $91 \%$ & $72 \%$ & $62 \%$ & $7 \%$ & $1 \%$ \\
\hline Clay & $32 \%$ & $1 \%$ & $16 \%$ & $38 \%$ & $91 \%$ & $1 \%$ \\
\hline Peat & $0 \%$ & $0 \%$ & $0 \%$ & $0 \%$ & $0 \%$ & $4 \%$ \\
\hline
\end{tabular}

In Austria, respondents to the farm survey had a very diverse range of slopes and soil textures. In Belgium, farmers had mainly loamy soils (91\%) and mostly level to gently sloping lands. In Italy, IT1 farmers had mainly level land and in IT2 farmers had mainly gentle to steep sloping land. In the Netherlands, farmers in NL1 had mainly clay soils and farmers in NL2 had mainly sandy soils.

\subsubsection{Current use of organic inputs}

In all AEZs, farmers used organic inputs to some degree (Table 4.6). When cultivating cereals, the majority of farmers incorporated straw sometimes to always, although some differences between AEZs were observed. In BE1, fewer farmers incorporated straw $(26 \%)$, probably at least partly due to the high use of FYM (in which case straw is exported to livestock farms and then again imported as FYM). When cultivating grain maize, the majority of farmers also incorporated straw sometimes to always, only in NL1 this was not the case.

A large difference in the cultivation of green manures or cover crops is observed between the six AEZs (Table 4.6). While in AT1, BE1, NL1 and NL2 most farmers cultivated green manures or cover crops on at least one of their fields $(>80 \%)$, only a small minority cultivated green manures or cover crops in IT1 and IT2 (10\%). 
Table 4. 6: Use of organic inputs in each AEZ. Bold numbers indicate combinations of AEZ and input type for which questions on outcomes, referents and control factors are included in the farm survey. For straw incorporation, percentages are calculated as share of the farmers who cultivate the specified crop.

\begin{tabular}{|c|c|c|c|c|c|c|}
\hline & AT1 & BE1 & IT1-level & IT2-sloping & NL1-clay & NL2-sand \\
\hline \multicolumn{7}{|c|}{$\begin{array}{l}\text { Straw incorporation } \\
(\% \text { farmers incorporating straw } \\
\text { sometimes to always) })^{1}\end{array}$} \\
\hline small grain cereal straw & $71 \%$ & $26 \%$ & - & - & $68 \%$ & $60 \%$ \\
\hline maize straw & $88 \%$ & $94 \%$ & - & - & $38 \%$ & $65 \%$ \\
\hline cereals, maize or sunflower & - & - & $93 \%$ & $69 \%$ & - & - \\
\hline \multicolumn{7}{|c|}{$\begin{array}{l}\text { Cultivation of green manure or } \\
\text { cover crops on at least one field } \\
(\% \text { farms) }\end{array}$} \\
\hline Green manure or cover crop & $93 \%$ & $87 \%$ & $10 \%$ & $10 \%$ & $84 \%$ & $83 \%$ \\
\hline \multicolumn{7}{|c|}{$\begin{array}{l}\text { Application FYM or compost } \\
\text { (\% farmers applying compost or } \\
\text { FYM on at least some part of } \\
\text { the land) }\end{array}$} \\
\hline Compost & $17 \%$ & $8 \%$ & $42 \%$ & $55 \%$ & $35 \%$ & $29 \%$ \\
\hline FYM & $46 \%$ & $71 \%$ & $57 \%$ & $67 \%$ & $39 \%$ & $16 \%$ \\
\hline
\end{tabular}

A higher percentage of farmers in IT1 and IT2 (42 and 55\%) used compost compared to farmers in AT1 and BE1 (17\% and 8\%), with NL1 and NL2 in between (35\% and 29\%). The use of FYM varies widely, with the highest percentage of farmers using FYM in BE1 and IT2 (71\% and 67\%) and the lowest in NL2 (16\%). In the Netherlands, farmers on sandy soils are often located near pig farms, which create a large availability of slurry, possibly explaining the low use of FYM.

\subsubsection{Drivers and barriers for the incorporation of straw}

Incorporation of straw was included in the farm survey of five AEZs (BE1, IT1, IT2, NL1 and NL2). The total number of outcomes, referents and control factors identified for the incorporation of straw was 93 (summed over the five AEZ's, or on average 15.5 per AEZ). Out of these, 48 were evaluated significantly positive as drivers and 33 were evaluated significantly negative as barriers by the farmers (Fig. 4.5). Of the drivers, around $40 \%$ were related to soil quality $(\mathrm{N}=19)$.

\footnotetext{
${ }^{1}$ Only farmers are included when a specific crop (maize, cereal) was present in the a crop rotation of farm. In Italy, sunflower was also included in the question on straw incorporation.
} 
A. Incorporation of straw in BE1
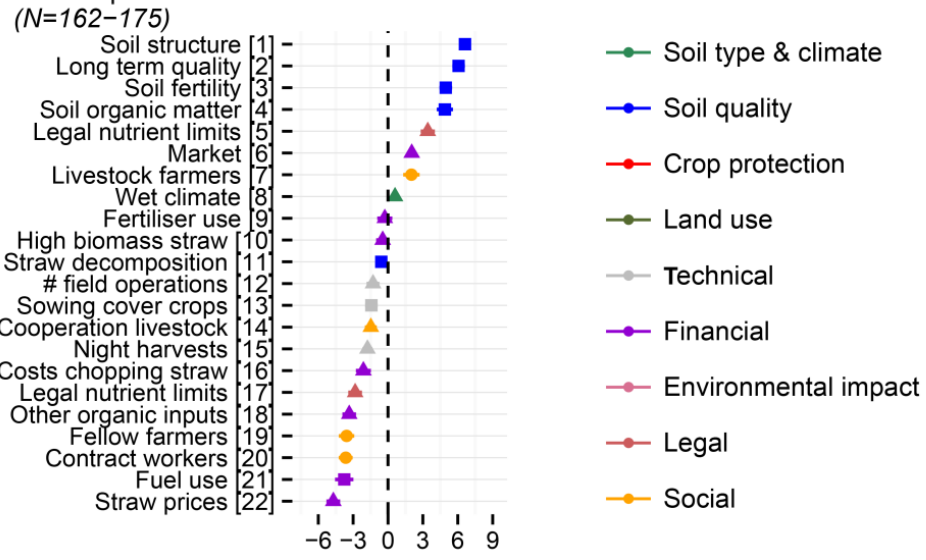

B. Incorporation of straw in IT1-level ( $N=103-115)$
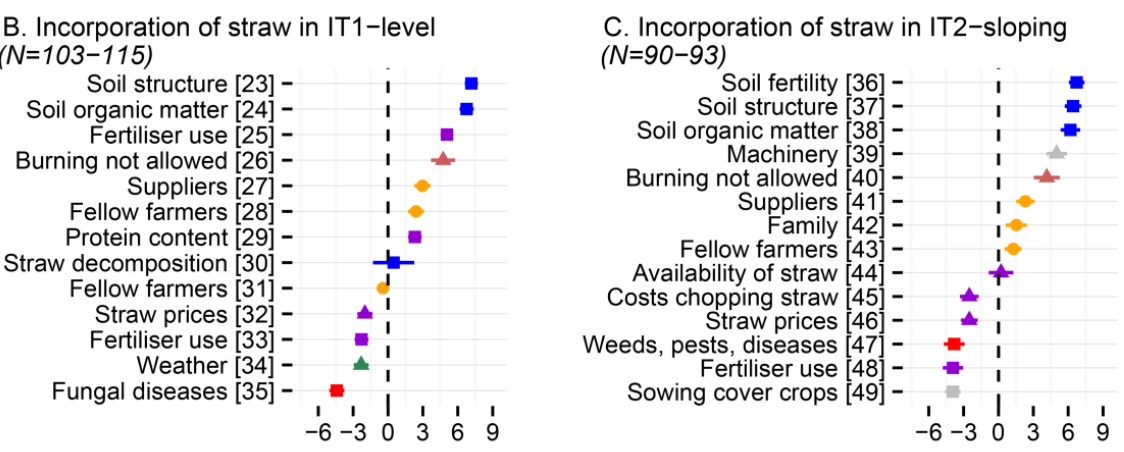

D. Incorporation of straw in NL1-clay ( $N=99)$

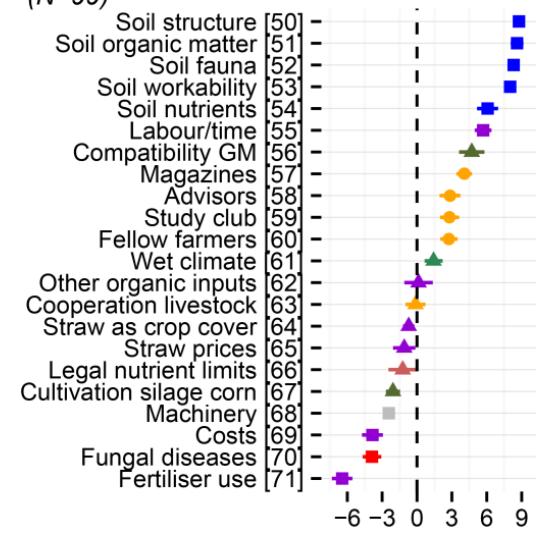

E. Incorporation of straw in NL2-sand $(N=61)$

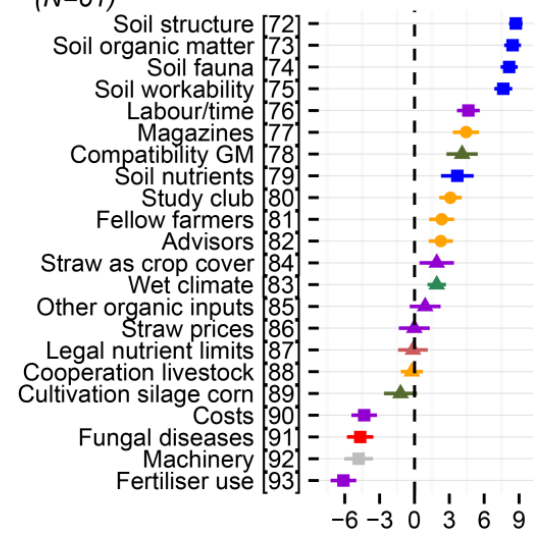

Fig 4. 5: Drivers and barriers for incorporation of straw per AEZ. $\mathbf{\square}=$ mean attitude score on outcome; $\bullet=$ mean subjective norm of referent $\boldsymbol{\Delta}=$ mean perceived behavioural control on control factor. Lines indicate $95 \%$ confidence interval. $N=$ numbers of farmers included in analysis. Numbers in [] link to farmers' descriptions in Supplementary Table 4.2. GM= green manure. Colours indicate main categories. 
Of the barriers, Almost half was financial $(\mathrm{N}=15)$, yet there were also some financial drivers $(\mathrm{N}=6)$. All outcomes and control factors related to crop protection were evaluated as barriers (4 out of 4 ).

In all AEZs, effects on soil structure and SOM content were identified as outcomes and evaluated as drivers for straw incorporation (Fig. 4.5). In almost all AEZs - besides BE1 - weeds, pests and diseases in general or specifically fungal diseases were evaluated as a barrier for straw incorporation. In addition, costs of straw incorporation and loss of income from selling straw were also evaluated as barriers for straw incorporation in all AEZs. In most AEZs, subjective norms of referents were positive on straw incorporation. Only in BE1, a negative subjective norm exists from fellow farmers and contract workers.

In BE1, legal nutrient limits were seen as a driver as well as a barrier. Like the Netherlands, the region of Flanders in Belgium (where the study was conducted), is a Nitrate Vulnerable Zone, which gives stricter limitations on nutrient inputs for farmers. Straw is however not counted within the legal nutrient limits, therefore it is seen by some farmers as an easy manner to increase SOM content. At the same time, other farmers prefer to add $\mathrm{N}$ to straw for decomposition, in which case the legal nutrient limits are a barrier. The relatively high application of FYM in BE1 (Table 4.6) also makes incorporation of straw less attractive.

In Italy (both IT1 and IT2), legal prohibition of burning straw was considered a driver for straw incorporation. In IT1 specifically, effects of straw incorporation on product quality (protein content) was a driver, while in IT2 availability of adequate machinery for chopping and incorporating residue was a driver.

In the Netherlands (NL1 and NL2), reduced labour or time requirements for straw incorporation (compared to removing it from the land) and positive effects on workability of the soil were considered important drivers. Fertiliser use was evaluated by farmers as a strong barrier, because farmers believe additional fertiliser is needed for straw decomposition.

\subsubsection{Drivers and barriers for the cultivation of green manures or cover crops}

Cultivation of green manures or cover crops was evaluated in the farm survey of all six AEZs (Fig. 4.6). 


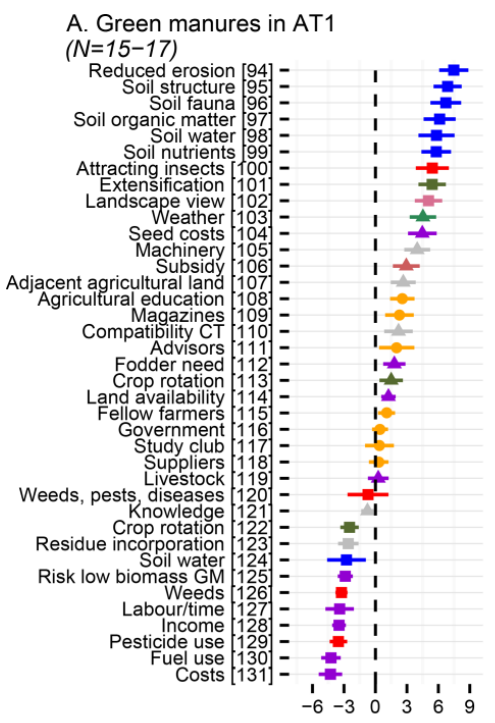

C. Green manures in IT1-level ( $N=106-123)$

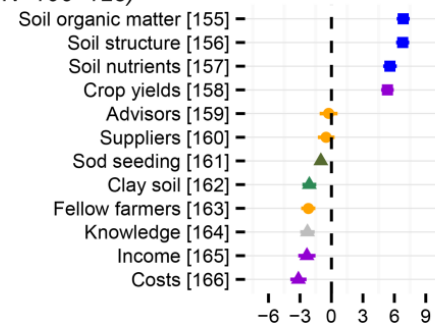

E. Green manures in NL1-clay

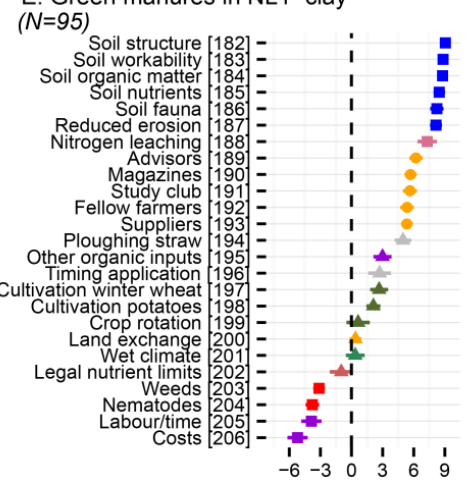

B. Green manures in BE1 $(N=175-190)$

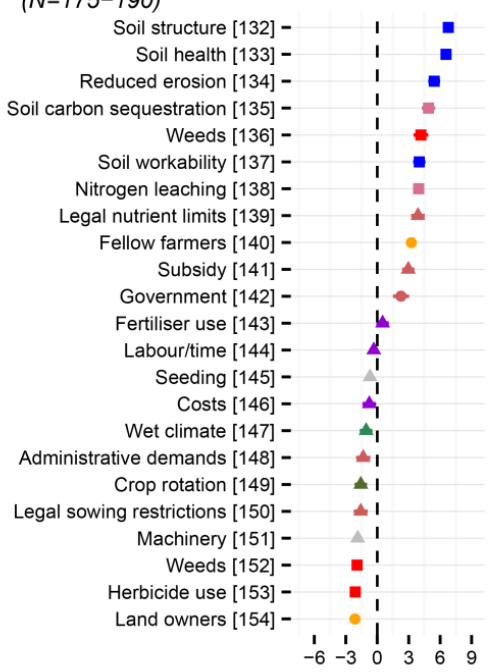

D. Green manures in IT2-sloping ( $N=88-95)$

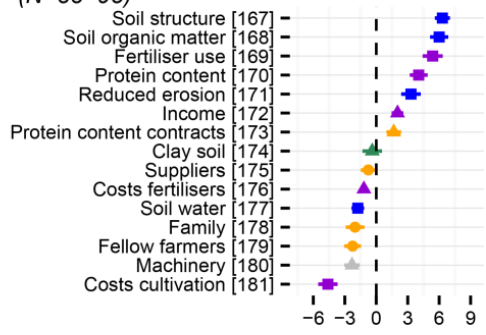

F. Green manures in NL2-sand $(N=146)$

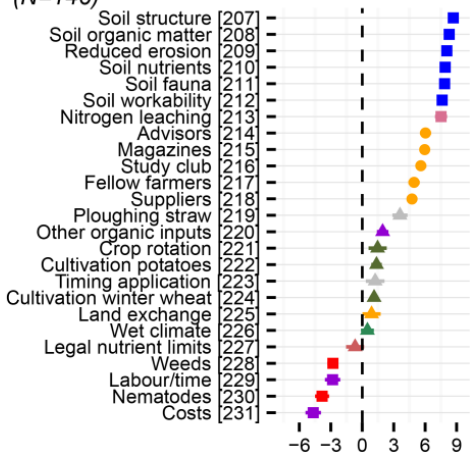

Fig 4. 6: Drivers and barriers for cultivation of green manures or cover crops per AEZ. $\mathbf{\square}=$ mean attitude score on outcome; $\bullet=$ mean subjective norm of referent $\mathbf{\Delta}=$ mean perceived behavioural control on control factor. Lines indicate 95\% confidence intervals. $N=$ numbers of farmers included in analysis. Numbers in [] link to farmers' descriptions in Supplementary Table 4.3. GM= green manure. $C T=$ conservation tillage. For legend of colours see Fig. 4.5 or 4.7 
The total number of outcomes, referents and control factors identified for the cultivation of green manure or cover crops was 138 (summed over the six AEZ's, or on average 23 per AEZ). The majority $(\mathrm{N}=80)$ was evaluated significantly positive as drivers, a minority $(\mathrm{N}=42)$ was evaluated significantly negative as barriers. A small minority $(\mathrm{N}=16)$ was not significantly different from zero (Fig. 4.6). Of the drivers, $35 \%$ was related to soil quality $(\mathrm{N}=28)$. One third of the barriers was financial $(\mathrm{N}=14)$, yet there were also some financial drivers $(\mathrm{N}=9)$. All outcomes and control factors related to environmental impact were evaluated as drivers (5 out of 5 ).

Like for straw incorporation, effects on soil structure and SOM content were identified and evaluated as drivers in each AEZ for the cultivation of green manures or cover crops (Fig. 4.6). The effect of green manures or cover crops on soil erosion was also identified and evaluated as a driver in almost each AEZ, except in IT1 (not included in survey because it was not identified as an outcome or control factor in the semi-structured interviews). In the Netherlands (NL1 and NL2) subjective norms of all referents were positive, unlike for example Italy (IT1 and IT2) where especially fellow farmers and family were perceived to have a negative view on the cultivation of green manures or cover crops.

In four AEZs (AT1, BE1, NL1 and NL2) weeds, pests and diseases (as a general term) or more specifically increases in weeds, nematodes, herbicide use or pesticide use (as specific terms) were evaluated negatively as barriers for the cultivation of green manures or cover crops. In BE1 however, positive effects of green manures or cover crops on weeds were also a driver. In IT1 and IT2 issues with crop protection were not mentioned in the semi-structured interviews with the farmers and therefore not included in the farm survey. In all AEZs, costs and effects on income were important barriers for the cultivation of green manures or cover crops.

In AT1, effects of cultivating green manures or cover crops on the water holding capacity of the soil was evaluated as well a driver as a barrier (Fig. 4.6a). Previous studies have shown - on average - no significant effect on water holding capacity from the cultivation of green manures or cover crops in this area (Bodner 2013; Bodner et al. 2011). Austrian farmers can receive a subsidy for the cultivation of green manures or cover crops, which is evaluated as a driver. To receive a subsidy, farmers have to follow specific trainings.

In Flanders (BE1), farmers can also receive a subsidy for cultivating green manures or cover crops at the time the survey was conducted. To be eligible for subsidy, farmers in Flanders have to sow the green manure before a certain date (before the $1^{\text {st }}$ of September 
or the $15^{\text {th }}$ of October, depending on their location). As the time period between harvest of some crops and legal sowing date is perceived as too short, this preconditions was considered a barrier.

In Italy (IT1 and IT2), costs were a major barrier for the cultivation of green manures or cover crops. Additional costs include production factors such as seeds, but also mechanical operations such as tillage or sowing. Interestingly, farmers perceived a positive effect of green manure or cover crops on fertiliser use in IT2, with savings of fertiliser in the following cash crop. In IT1, having clay soils was seen as a barrier for the cultivation of green manure or cover crops. On clay soils, seedbed preparation for green manures might be more complicated due to excessive soil water content.

In the Netherlands (NL1 and NL2), improved workability of the soil was evaluated as an important driver. This relates to perceived reductions in fuel costs and perceived reductions in the loss of soil during harvest. In the Netherlands (NL1 and NL2), requirements in labour and time to cultivate green manures or cover crops was considered a barrier. This relates specifically to the small time frame available at the end of summer after harvesting the main crop for the sowing of the green manure.

\subsubsection{Drivers and barriers for the application of compost or FYM}

Application of compost was included in the farm survey of two AEZs (BE1 and NL2sand), while the use of FYM was included only in BE1. As both types of input are often imported on arable farms, the results of these two input types are presented together. The total number of outcomes, referents and control factors identified for the application of compost or FYM was 54 (summed over three AEZs, or on average 18 per AEZ). Out of these, 23 were evaluated significantly positive as drivers and 25 were evaluated significantly negative as barriers (Fig. 4.7). Of the drivers, more than half were related to soil quality $(\mathrm{N}=13)$. Forty percent of the barriers was financial $(\mathrm{N}=10)$ and almost a quarter of the barriers was technical $(\mathrm{N}=6)$. A number of outcomes and control factors related to crop protection, environmental impact and legal aspects were identified (respectively 2, 2 and 1). These were all evaluated as barriers.

For compost, the effect on SOM content was evaluated positively by farmers as a driver in both AEZs (Fig. 4.7). In BE1, effects of compost on various aspects related to soil quality were also evaluated as drivers (e.g. soil life, soil health, soil fertility and soil structure). In the Netherlands compost may be applied throughout the year - in contrast to animal manures - making it a more attractive option compared to other organic inputs. Therefore, the legally allowed timing of application was also evaluated as a driver for 
compost in NL2. Availability of alternative organic inputs such as animal manure, pollution of compost and required labour and time for spreading were considered barriers for using compost in both BE1 and NL2. In addition a range of other issues were evaluated as barriers in BE1, such as availability, required knowledge, nitrogen leaching, increases in weeds, pests and diseases, legal nutrient restrictions, availability of appropriate machinery and compatibility with residue incorporation.
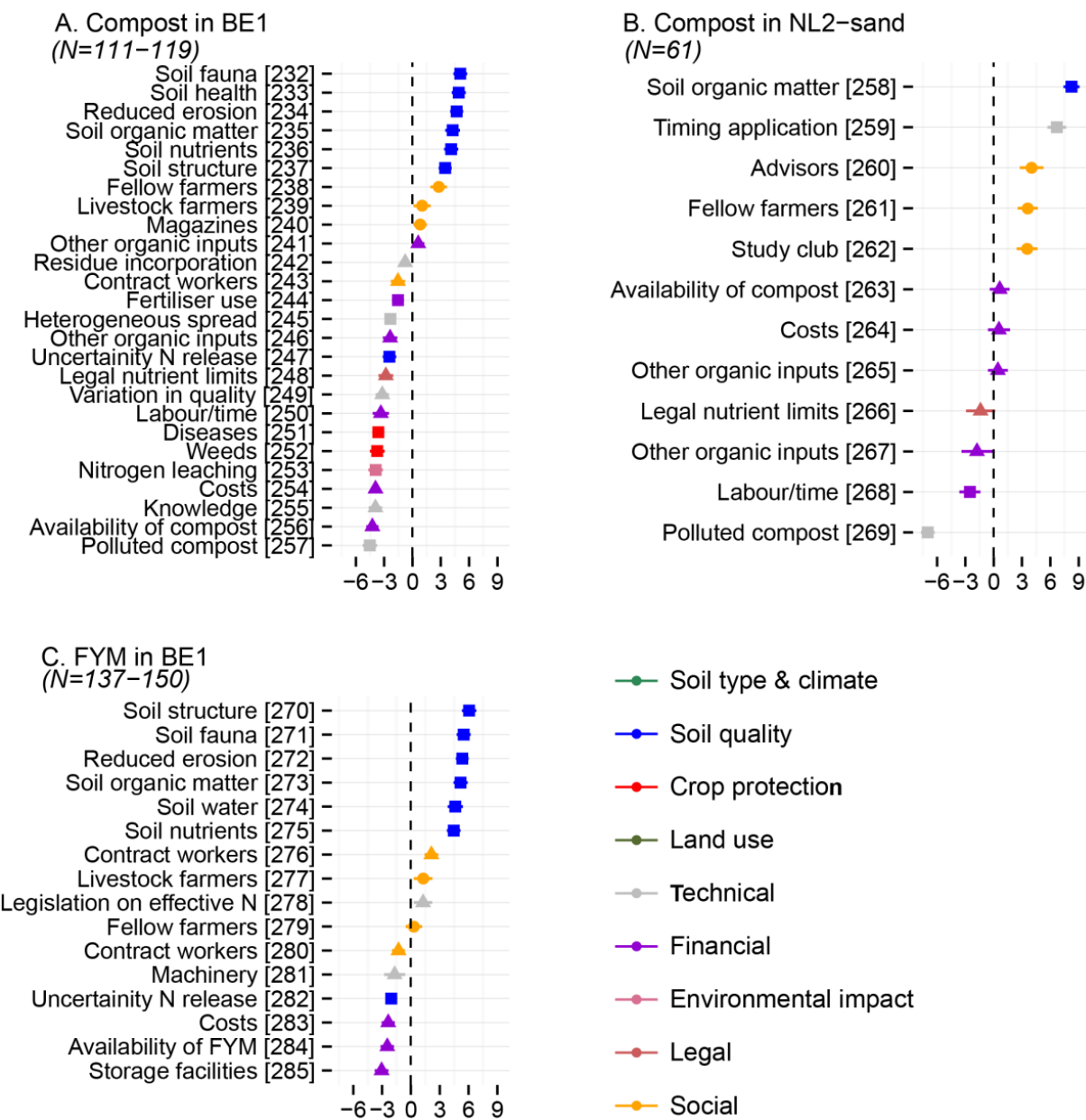

Fig 4. 7: Drivers and barriers for application of compost or FYM per AEZ. = = mean attitude score on outcome; $\bullet=$ mean subjective norm of referent $\boldsymbol{\Delta}=$ mean perceived behavioural control on control factor. Lines indicate 95\% confidence intervals. $N=$ numbers of farmers included in analysis. Numbers in [] link to farmers' descriptions in Supplementary Tables 4.4 to 4.5. FYM = farmyard manure. $N=$ nitrogen. Colours indicate main categories. 
For the application of FYM, a similar range of positive effects were found on soil quality as from compost (e.g. soil life, soil health, soil fertility and soil structure). An important barrier for FYM in Flanders was the need for appropriate storage facilities during winter. Many farmers state that they do not have such a storage place and that this makes the use of FYM unattractive.

\subsubsection{Drivers and barriers aggregated per category}

Of all the 285 identified outcomes, referents and control factors in the semi-structured interviews, 151 were evaluated significantly positive as a driver and 100 were evaluated significantly negative as a barrier (Fig. 4.8).
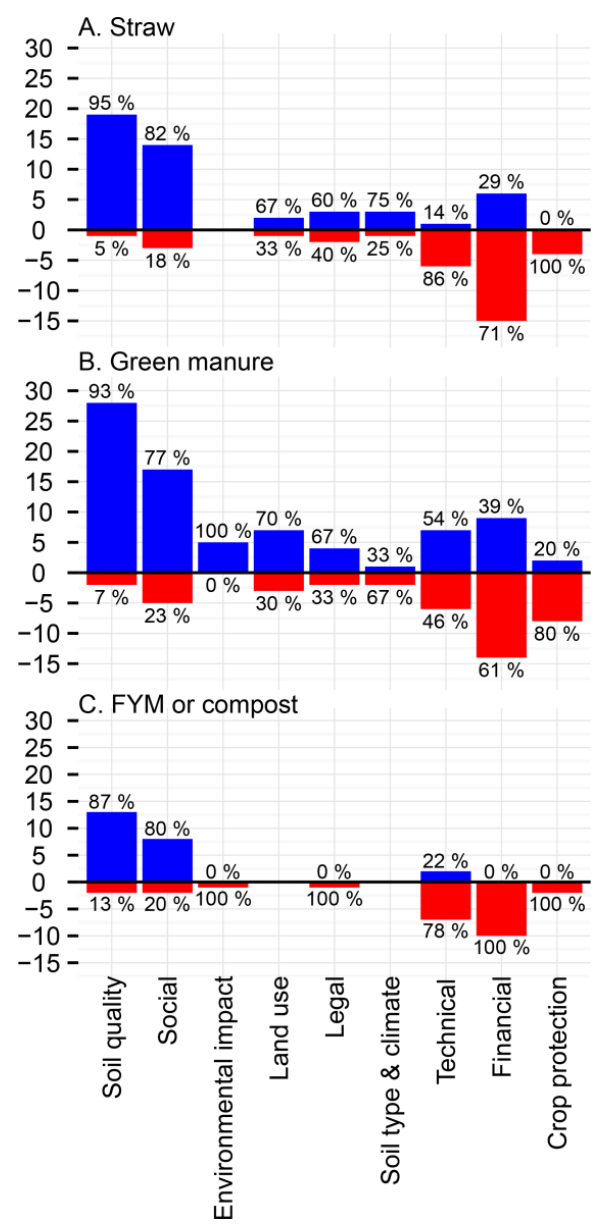

Fig 4. 8: Counts and percentages of drivers and barriers per practice and category. Red colours indicate barriers and blue colour indicates drivers. 
Aggregating drivers across AEZs, soil quality stands out as the most important driver for using organic inputs. For all types of organic input, soil quality consistently has the highest count and percentages of cases in which it is evaluated as a driver (except environmental impact of green manures or cover crops, Fig. 4.8b).

For each type of organic input, financial consequences are most often mentioned as a barrier, but crop protection has the highest percentage of cases in which it is evaluated as a barrier compared to the total sum of barriers and driver in that category. Both financial consequences and crop protection are therefore important barriers for the types of organic input considered in this study.

\subsection{Discussion}

\subsubsection{Drivers and barriers identified}

In this study, a large number of outcomes, referents and control factors (285) were identified being relevant to farmers for using organic inputs. To support data analysis, a clustering was made consisting of 91 labels falling into nine main categories (Table 4.3). Using a bottom-up approach, the categories were based on insights provided by farmers.

For all types of organic inputs, important drivers were perceived effects on soil quality and a positive influence from social referents. In contradiction to the assumption that farmers have too few incentives to use soil conservation measures because productive capacities are not affected by soil degradation on the short term (Van den Putte et al. 2010), farmers in our survey show a great interest in maintaining long term soil fertility and SOM contents. Effects on SOM content and soil fertility are consistently amongst the top drivers for each type of organic input (Fig.4.5, 4.6 and 4.7). We confirmed the notion that farmers' behaviour is motivated by a wide array of factors which are not all directly economic (Glenk et al. 2017) as financial aspects were only a selected part of the total listed drivers and barriers. If mentioned, financial consequences of using organic inputs were more often evaluated negative than positive.

In our farm survey, farmers consistently evaluated the effects of organic inputs on crop protection negatively. From field experiments, cereal straw is known to spread an important fungal disease causing grain contamination (Fusarium head blight, FHB) to subsequent cereals in crop rotations (Maiorano et al. 2008), although some measure to relieve this pressure are also known. For example, the spread of FHB can be reduced when crop residues are incorporated into the soil (Blandino et al. 2012). Organic inputs have been observed to reduce soil-borne diseases, but only if they are rich in nitrogen 
(Bailey and Lazarovits 2003). In a recent literature review on the role of compost on soil-borne plant diseases, Mehta et al. (2014) found a large variation in effects, but mainly positive effects on disease suppression when composts were enriched with specific soil microbes. In a more general observation, Bailey and Lazarovits (2003) note that it takes time to develop disease suppressive soils when using organic inputs and that benefits manifest only after a number of successive years. If farmers see negative effects on crop protection in the first year of using a specific type of organic input, they might however not be willing -without convincing evidence - to wait and see if this changes in the future.

\subsubsection{Relating drivers and barriers to the use of organic inputs}

When considering the use of organic inputs in each AEZ (Table 4.6), the most striking was the difference in cultivation of green manures or cover crops. In both IT1 and IT2, only $10 \%$ of farmers cultivated green manures or cover crops, whilst in the other AEZs this percentage was above $83 \%$. Looking at the drivers and barriers for the cultivation of green manures or cover crops (Fig. 4.6), the number of identified outcomes, referents and control factors is smaller in IT1 and IT2 (12 and 15 respectively) compared to the other AEZs (ranging from 23 in BE1 to 38 in AT1). This situation, however, cannot satisfactorily explain the low adoption in Italy, because a similar situation (small number of outcomes, referents and control factors) was also found for straw incorporation, for which the adoption was higher. Relatively more outcomes, referents and control factors were evaluated as barriers compared to drivers in IT1 and IT2 (50\% and 47\%) than in the other AEZs (ranging from 16\% in NL1 and NL2 to $43 \%$ in BE1).

As in the other AEZs, costs and foregone income were also mentioned in IT1 and IT2 as barriers for the cultivation of green manures or cover crops. In IT1 and IT2 however, fellow farmers and family were also perceived to have a negative view on the cultivation of green manures or cover crops whilst suppliers and advisors were somewhat neutral. In Italy, suppliers have a more positive view regarding straw incorporation (Fig. 4.5b,c). Thus, it appears that the community around farmers does not help in promoting the adoption of green manures or cover crops. From the personal experience of the Italian co-authors it is known that, because green manure is still a relatively new practice for Italian farmers, communication and learning from peers are very important factors to increase the adoption. From the experience of farmers who are already successful with green manures or cover crops in Italy, other farmers could learn what are the best species or mixes, seed rate, seeding date, seeding technique, and termination technique in a 
given soil and climate. Currently the adoption of green manures or cover crops is however low so that farmers have little exposure to these practices.

\subsubsection{Straw incorporation and $N$ requirements}

For the incorporation of straw, legal nutrient limits are mentioned to be relevant in BE1, NL1 and NL2. Flanders (Belgium) and the Netherlands are designated Nitrate Vulnerable Zones (EEC 1991). In these cases, farmers are restricted by legal nutrient limits when using mineral fertilisers and/or organic inputs. In BE1, legal nutrient limits are as well a driver and barrier for the incorporation of straw. This can be explained by the variability in $\mathrm{N}$ demands of straw decomposition. In certain cases, incorporation of straw can supply $\mathrm{N}$ to crops, whilst in other circumstances, it can induce temporary $\mathrm{N}$ immobilization and needs $\mathrm{N}$ for decomposition (Chapter 3 of this thesis; Silgram \& Chambers 2002). A similar phenomenon is seen in IT1, where fertiliser use is evaluated as a driver and a barrier for the incorporation of straw by farmers.

\subsubsection{Limitations of the study}

\section{Agro-ecological zones}

For this study, farmers were clustered in AEZs to assess drivers and barriers for the use of organic inputs of large groups of farmers in certain areas. The aim was to assess these drivers and barriers for farmers with similar environmental conditions (soil textures, slopes, climates) After data collection, it became obvious that slope and soil texture varied greatly within each AEZ. For the purpose of this study, it was however not possible to divide farmers on their separate farm characteristics, because numbers per group would become too small to make meaningful comparisons. In further chapters of this thesis which are based on the farm survey (Chapters 5 and 6), environmental conditions for each individual farm will be calculated and used as such in the data analysis.

\section{Underlying beliefs}

In this study, we assessed means of the combined scores for attitude, subjective norm and perceived behavioural control. These concepts are based on underlying farmers' beliefs (e.g. attitudes are formed by belief strengths and outcome valuations, Equation 4.1). In future work, these two separate components might be explored in more detail, as done for example by Bechini et al. (2015) for straw incorporation in Italy and by Viaene et al. (2016) for compost in Flanders. 


\section{Assessing the different types of organic inputs separately}

Drivers and barriers were analysed separately for the use of each type of organic input. Farmers indicated that the use of one type of organic input depends on the use of another type of organic input (for example, if a farmer already uses slurry, that might be a reason not to use FYM). Both the Netherlands and Belgium have a large supply of animal manure due to the presence of a relatively large livestock sectors (Oenema and Berentsen 2004; Viaene et al. 2016). Sometimes, animal slurry is even offered for free to arable farmers. In these cases, this cheap offer of slurry is a barrier for the use of for example compost (BE1 and NL2, Fig. 4.7). In a case study in the Netherlands (Chapter 5 of this thesis), an aggregated measure of all organic inputs used by a farmer will be used, expressed in total $\mathrm{C}$ or effective $\mathrm{C}$. In addition, drivers and barriers for increasing SOM content (as a general concept) will be analysed, including underlying beliefs.

\subsection{Conclusion}

Major drivers for the use of organic inputs across six AEZs in this study were perceived effects on soil quality (e.g. soil structure, soil fertility, soil health) and in most cases a positive influence from social referents. Major barriers for the use of organic inputs were perceived negative effects on (or the need for) crop protection (e.g. effects on the incidence of weeds, pests and diseases or effects on herbicide or pesticide requirements) and financial consequences (higher costs; income forgone).

Our findings shows that farmers perceive a trade-off between improved soil quality on the one hand and increased pressures from weeds, pests and diseases and financial consequences on the other hand when using organic inputs. If agricultural and environmental policies aim to include the use of organic inputs as a measure to maintain or increase SOM contents (as proposed by Frelih-Larsen et al. 2016), then farmers need specific guidance on how reduce the pressure of weeds, pests and diseases. Ideally, this advice would be differentiated for specific soil types, weather conditions, and crops cultivated.

On the moment, financial consequences of using organic inputs cannot be assumed to be neutral on the short term, at least not from a farmers' perspective. Therefore, more research is needed on the long-term financial effects of using organic inputs. If the use of organic inputs has societal benefits beyond the farm-gate (e.g. biodiversity conservation or soil carbon sequestration), these financial consequences could be accounted for. 


\subsection{Acknowledgements}

Our gratitude goes to all European farmers who spared some of their time to fill in the questionnaire. Setting up a large scale farm survey would not have been possible without numerous colleagues across different institutes. In Austria, main contacts were the provincial and regional officials of the chamber of agriculture in Lower Austria. In Belgium, data was collected with the help of Erwin Wauters (ILVO). In Italy, we received support from universities of Ancona, Bari, Milano, Napoli Udine, Pisa, Teramo, Tuscia, Ancona and Perugia; provincial and regional officials; farmers unions (Coldiretti, Confagricoltura, Confederazione Italiana Agricoltori); CadirLab (Quargnento, AL); Consorzio Agrario di Siena; advisors of the Italian Farm Accountancy Data Network; Chiara Costamagna; students of the University of Torino and University of Milano. In the Netherlands, Rob Smidt helped with extracting farmers' addresses from the database and Bert Rijk supported the survey logistics. We thank all colleagues for their efforts and support. 


\section{Supplement chapter 4}

$\begin{array}{lll}\text { Supplementary Table 4.1 Questions asked in semi-structured interviews } & 84\end{array}$

Supplementary Table 4.2 Farmers' descriptions of outcomes, referents 85

and control factors for the incorporation of straw

Supplementary Table 4.3 Farmers' descriptions of outcomes, referents and control factors for the cultivation of green manures or cover crops

Supplementary Table 4.4 Farmers' descriptions of outcomes, referents and control factors for the application of compost

Supplementary Table 4.5 Farmers' descriptions of outcomes, referents and control factors for the application of FYM 


\section{Questions asked in semi-structured interviews}

Supplementary Table 4. 1 Questions asked in the semi-structured interviews. For each type of organic input in each AEZ, all questions were asked with each farmer, which resulted in a list of outcomes, referents and control factors. Between brackets [] the specific type of organic input was mentioned by the interviewer.

\section{A. General questions on the BMP}

Do you use [this practice]?

\section{B. Questions to elicit behavioural outcomes (with the example of low pressure tires):}

What do you believe are the advantages of [this practice]?

What do you believe are the disadvantages of [this practice]?

Is there anything else you associate with [this practice]?

Would [this practice] lead to any good or bad things?

Can you think of other consequences of [this practice]?

\section{Questions to elicit normative referents:}

Are there any individuals or groups who would approve of [this practice]?

Are there any individuals or groups who would disapprove of [this practice]?

Are there any other individuals or groups who come to mind when you think about [this practice]?

Are there people or groups of people who try to influence your decision to use [this practice]?

\section{Questions to elicit control factors:}

What factors or circumstances would enable (make it easy) you to use [this practice]?

What factors or circumstances would make it difficult or impossible for you to use [this practice]?

Are there any other issues that come to mind when you think about the difficulty of using [this practice]? 


\section{Incorporation of straw}

Supplementary Table 4. 2: Labels (as used in the figures) and related farmers 'descriptions of outcomes, referents and control factors for the incorporation of straw

\begin{tabular}{|c|c|c|c|c|}
\hline AEZ & [\#] & Label & Category TPB & Farmers' description \\
\hline BE1 & [1] & Soil structure & outcome & Improved soil structure \\
\hline BE1 & [2] & Long term quality & Outcome & Good investment for my soil \\
\hline BE1 & [3] & Soil fertility & outcome & Increased soil fertility \\
\hline BE1 & [4] & Soil organic matter & outcome & More soil humus \\
\hline BE1 & [5] & Legal nutrient limits & control factor & $\begin{array}{l}\text { Straw is not calculated as source of } \mathrm{N} \\
\text { and } \mathrm{P} \text { in legislation }\end{array}$ \\
\hline BE1 & [6] & Market & control factor & Not easy to find a buyer for straw \\
\hline BE1 & [7] & Livestock farmers & referent & Animal farmers \\
\hline BE1 & [8] & Wet climate & control factor & $\begin{array}{l}\text { Straw is often too wet and of bad } \\
\text { quality }\end{array}$ \\
\hline BE1 & [9] & Fertiliser use & control factor & $\begin{array}{l}\text { Additional nitrogen is needed to } \\
\text { digest straw }\end{array}$ \\
\hline BE1 & [10] & High biomass straw & control factor & $\begin{array}{l}\text { Dry matter yield of straw is high on } \\
\text { my field }\end{array}$ \\
\hline BE1 & [11] & Straw decomposition & outcome & Straw is hard to digest \\
\hline BE1 & [12] & \# field operations & control factor & $\begin{array}{l}\text { Two operations are needed instead of } \\
\text { one }\end{array}$ \\
\hline BE1 & [13] & Sowing cover crops & outcome & Sowing cover crops is difficult \\
\hline BE1 & [14] & Cooperation livestock & control factor & $\begin{array}{l}\text { Agreement with animal farmer (straw } \\
\text { against manure) }\end{array}$ \\
\hline BE1 & [15] & Night harvests & control factor & I prefer to harvest cereals at night \\
\hline BE1 & [16] & Costs chopping straw & control factor & Increased cost for chopping straw \\
\hline BE1 & [17] & Legal nutrient limits & control factor & $\begin{array}{l}\text { Not allowed to give enough nitrogen } \\
\text { to digest straw }\end{array}$ \\
\hline BE1 & [18] & Other organic inputs & control factor & I often use manure \\
\hline BE1 & [19] & Fellow farmers & referent & Other arable farmers \\
\hline BE1 & [20] & Contract workers & referent & Contract worker \\
\hline BE1 & [21] & Fuel use & outcome & Additional fuel is needed \\
\hline BE1 & [22] & Straw prices & control factor & Good prices for straw \\
\hline IT1-level & [23] & Soil structure & outcome & Improved soil structure \\
\hline IT1-level & [24] & Soil organic matter & outcome & Higher soil organic matter \\
\hline IT1-level & {$[25]$} & Fertiliser use & outcome & Reduced use of mineral fertilisers \\
\hline IT1-level & [26] & Burning not allowed & control factor & Crop residues burn is forbidden \\
\hline IT1-level & [27] & Suppliers & referent & $\begin{array}{l}\text { Advisors of companies selling } \\
\text { production factors }\end{array}$ \\
\hline IT1-level & [28] & Fellow farmers & referent & Other farmers \\
\hline IT1-level & [29] & Protein content & outcome & $\begin{array}{l}\text { Increased protein content in wheat } \\
\text { grain }\end{array}$ \\
\hline IT1-level & [30] & Straw decomposition & outcome & $\begin{array}{l}\text { Slow decomposition of crop residues } \\
\text { in soil }\end{array}$ \\
\hline IT1-level & [31] & Fellow farmers & referent & Farm that collect crop residues \\
\hline IT1-level & [32] & Straw prices & control factor & Residues selling at a high price \\
\hline IT1-level & [33] & Fertiliser use & outcome & Increased nitrogen fertiliser use \\
\hline
\end{tabular}




\begin{tabular}{|c|c|c|c|c|}
\hline IT1-level & [34] & Weather & control factor & $\begin{array}{l}\text { Adverse environmental conditions } \\
\text { that hinder residues degradation }\end{array}$ \\
\hline IT1-level & [35] & Fungal diseases & outcome & Increased risk of fungal diseases \\
\hline IT2-sloping & [36] & Soil fertility & outcome & Increased soil fertility \\
\hline IT2-sloping & [37] & Soil structure & outcome & Improved soil structure \\
\hline IT2-sloping & [38] & Soil organic matter & outcome & Higher soil organic matter \\
\hline IT2-sloping & [39] & Machinery & control factor & I have adequate machineries \\
\hline IT2-sloping & [40] & Burning not allowed & control factor & $\begin{array}{l}\text { Legislation forbids crop residues } \\
\text { burning }\end{array}$ \\
\hline IT2-sloping & [41] & Suppliers & referent & Advisors of producer association \\
\hline IT2-sloping & [42] & Family & referent & Family members \\
\hline IT2-sloping & [43] & Fellow farmers & referent & Other farmers \\
\hline IT2-sloping & [44] & Availability of straw & control factor & Crop residues given for free \\
\hline IT2-sloping & [45] & Costs chopping straw & control factor & $\begin{array}{l}\text { Residues chopping and distribution is } \\
\text { expensive }\end{array}$ \\
\hline IT2-sloping & [46] & Straw prices & control factor & $\begin{array}{l}\text { Crop residue sale is possible, high } \\
\text { price residues \& else loss of income }\end{array}$ \\
\hline IT2-sloping & [47] & Weeds, pests, diseases & outcome & More weeds, pests and diseases \\
\hline IT2-sloping & [48] & Fertiliser use & outcome & Increased nitrogen fertiliser use \\
\hline IT2-sloping & [49] & Sowing cover crops & outcome & $\begin{array}{l}\text { Following crop sowing hindered by } \\
\text { residues }\end{array}$ \\
\hline NL1-clay & [50] & Soil structure & outcome & Improves soil structure \\
\hline NL1-clay & [51] & Soil organic matter & outcome & Provides organic matter to the soil \\
\hline NL1-clay & [52] & Soil fauna & outcome & Improves soil fauna \\
\hline NL1-clay & [53] & Soil workability & outcome & Improves soil cultivation \\
\hline NL1-clay & [54] & Soil nutrients & outcome & $\begin{array}{l}\text { When straw is not removed nutrients } \\
\text { stay in the field }\end{array}$ \\
\hline NL1-clay & {$[55]$} & Labour/time & outcome & $\begin{array}{l}\text { Easier to incorporate straw than to } \\
\text { remove it }\end{array}$ \\
\hline NL1-clay & [56] & Compatibility GM & control factor & I sow a green manure after my wheat \\
\hline NL1-clay & [57] & Magazines & referent & Magazines are positive \\
\hline NL1-clay & [58] & Advisors & referent & $\begin{array}{l}\text { Extension agents recommend the } \\
\text { incorporation of straw }\end{array}$ \\
\hline NL1-clay & [59] & Study club & referent & Study club is positive \\
\hline NL1-clay & [60] & Fellow farmers & referent & Other arable farmers are positive \\
\hline NL1-clay & [61] & Wet climate & control factor & $\begin{array}{l}\text { The weather is often too wet to } \\
\text { remove the straw }\end{array}$ \\
\hline NL1-clay & {$[62]$} & Other organic inputs & control factor & $\begin{array}{l}\text { There are enough other ways to apply } \\
\text { organic matter }\end{array}$ \\
\hline NL1-clay & [63] & Cooperation livestock & control factor & $\begin{array}{l}\text { I have a corporation with a husbandry } \\
\text { farm for the straw }\end{array}$ \\
\hline NL1-clay & [64] & Straw as crop cover & control factor & $\begin{array}{l}\text { I use the straw to cover beats and } \\
\text { potatoes }\end{array}$ \\
\hline NL1-clay & {$[65]$} & Straw prices & control factor & $\begin{array}{l}\text { Price is often too good to incorporate } \\
\text { it }\end{array}$ \\
\hline NL1-clay & [66] & Legal nutrient limits & control factor & $\begin{array}{l}\text { The Manure and Fertiliser Act makes } \\
\text { it impossible to apply the necessary N } \\
\text { to the straw to decompose }\end{array}$ \\
\hline
\end{tabular}




\begin{tabular}{|c|c|c|c|c|}
\hline NL1-clay & [67] & Cultivation silage corn & control factor & $\begin{array}{l}\text { I have silage corn: to incorporate } \\
\text { straw of corn I need to change to corn } \\
\text { cop mix }\end{array}$ \\
\hline NL1-clay & [68] & Machinery & outcome & $\begin{array}{l}\text { Incorporation does not need heavy } \\
\text { machinery }\end{array}$ \\
\hline NL1-clay & [69] & Costs & outcome & Costs extra money \\
\hline NL1-clay & [70] & Fungal diseases & outcome & Increases fungal diseases \\
\hline NL1-clay & [71] & Fertiliser use & outcome & Decomposition of straw needs extra $\mathrm{N}$ \\
\hline NL2-sand & [72] & Soil structure & outcome & Improves soil structure \\
\hline NL2-sand & [73] & Soil organic matter & outcome & Provides organic matter to the soil \\
\hline NL2-sand & [74] & Soil fauna & outcome & Improves soil fauna \\
\hline NL2-sand & [75] & Soil workability & outcome & Improves soil cultivation \\
\hline NL2-sand & [76] & Labour/time & outcome & $\begin{array}{l}\text { Easier to incorporate straw than to } \\
\text { remove it }\end{array}$ \\
\hline NL2-sand & [77] & Magazines & referent & Magazines are positive \\
\hline NL2-sand & [78] & Compatibility GM & control factor & I sow a green manure after my wheat \\
\hline NL2-sand & [79] & Soil nutrients & outcome & $\begin{array}{l}\text { When straw is not removed nutrients } \\
\text { stay in the field }\end{array}$ \\
\hline NL2-sand & [80] & Study club & referent & Study club is positive \\
\hline NL2-sand & [81] & Fellow farmers & referent & Other arable farmers are positive \\
\hline NL2-sand & [82] & Advisors & referent & $\begin{array}{l}\text { Extension agents recommend the } \\
\text { incorporation of straw }\end{array}$ \\
\hline NL2-sand & [83] & Wet climate & control factor & $\begin{array}{l}\text { The weather is often too wet to } \\
\text { remove the straw }\end{array}$ \\
\hline NL2-sand & [84] & Straw as crop cover & control factor & $\begin{array}{l}\text { I use the straw to cover beats and } \\
\text { potatoes }\end{array}$ \\
\hline NL2-sand & [85] & Other organic inputs & control factor & $\begin{array}{l}\text { There are enough other ways to apply } \\
\text { organic matter }\end{array}$ \\
\hline NL2-sand & [86] & Straw prices & control factor & $\begin{array}{l}\text { Price is often too good to incorporate } \\
\text { it }\end{array}$ \\
\hline NL2-sand & [87] & Legal nutrient limits & control factor & $\begin{array}{l}\text { The Manure and Fertiliser Act makes } \\
\text { it impossible to apply the necessary N } \\
\text { to the straw to decompose }\end{array}$ \\
\hline NL2-sand & [88] & Cooperation livestock & control factor & $\begin{array}{l}\text { I have a corporation with a husbandry } \\
\text { farm for the straw }\end{array}$ \\
\hline NL2-sand & [89] & Cultivation silage corn & control factor & $\begin{array}{l}\text { I have silage corn: to incorporate } \\
\text { straw of corn I need to change to corn } \\
\text { cop mix }\end{array}$ \\
\hline NL2-sand & [90] & Costs & outcome & Costs extra money \\
\hline NL2-sand & [91] & Fungal diseases & outcome & Increases fungal diseases \\
\hline NL2-sand & [92] & Machinery & outcome & $\begin{array}{l}\text { Incorporation does not need heavy } \\
\text { machinery }\end{array}$ \\
\hline NL2-sand & [93] & Fertiliser use & outcome & Decomposition of straw needs extra $\mathrm{N}$ \\
\hline
\end{tabular}




\section{Cultivation of green manures or cover crops}

Supplementary Table 4. 3: Labels (as used in the figures) and related farmers 'descriptions of outcomes, referents and control factors for the cultivation of green manures or cover crops

\begin{tabular}{|c|c|c|c|c|}
\hline AEZ & [\#] & Label & Category TPB & Farmers' description \\
\hline AT1 & {$[94]$} & Reduced erosion & outcome & Reduced erosion \\
\hline AT1 & [95] & Soil structure & outcome & Soil is rooted and loosened \\
\hline AT1 & [96] & Soil fauna & outcome & Enhanced soil life \\
\hline AT1 & [97] & Soil organic matter & outcome & Increased humus content \\
\hline AT1 & [98] & Soil water & outcome & $\begin{array}{l}\text { Improved water storage over the } \\
\text { winter }\end{array}$ \\
\hline AT1 & [99] & Soil nutrients & outcome & $\begin{array}{l}\text { Fixation of nitrogen \& enrichment } \\
\text { soil other nutrients }\end{array}$ \\
\hline AT1 & {$[100]$} & Attracting insects & outcome & $\begin{array}{l}\text { Attractive \& food for (beneficial) } \\
\text { insects }\end{array}$ \\
\hline AT1 & {$[101]$} & Extensification & outcome & Relaxing of the crop rotation \\
\hline AT1 & [102] & Landscape view & outcome & More beautiful landscapes \\
\hline AT1 & {$[103]$} & Weather & control factor & Sufficient precipitation \\
\hline AT1 & [104] & Seed costs & control factor & Cheap seeds \\
\hline AT1 & {$[105]$} & Machinery & control factor & $\begin{array}{l}\text { Available technical equipment \& use } \\
\text { of cultivator }\end{array}$ \\
\hline AT1 & {$[106]$} & Subsidy & control factor & Support by ÖPUL \\
\hline AT1 & {$[107]$} & $\begin{array}{l}\text { Adjacent agricultural } \\
\text { land }\end{array}$ & control factor & Contiguous agricultural area \\
\hline AT1 & {$[108]$} & Agricultural education & referent & Agricultural school \\
\hline AT1 & [109] & Magazines & referent & Literature \\
\hline AT1 & {$[110]$} & Compatibility CT & control factor & $\begin{array}{l}\text { Combination with mulch or non- } \\
\text { inversion tillage }\end{array}$ \\
\hline AT1 & [111] & Advisors & referent & $\begin{array}{l}\text { Advisor of the Chamber of } \\
\text { Agriculture \& "Bioforschung Austria" }\end{array}$ \\
\hline AT1 & [112] & Fodder need & control factor & Fodder for the animals \\
\hline AT1 & [113] & Crop rotation & control factor & Gaps in the crop rotation are needed \\
\hline AT1 & [114] & Land availability & control factor & Higher availability of agricultural area \\
\hline AT1 & {$[115]$} & Fellow farmers & referent & Other farmers \\
\hline AT1 & [116] & Government & referent & Politicians \\
\hline AT1 & {$[117]$} & Study club & referent & $\begin{array}{l}\text { Society "Distelverein" (Association } \\
\text { for Agriculture and Nature } \\
\text { Conservation) }\end{array}$ \\
\hline AT1 & [118] & Suppliers & referent & Advisors of seed companies \\
\hline AT1 & [119] & Livestock & control factor & Reduced livestock \\
\hline AT1 & {$[120]$} & Weeds, pests, diseases & outcome & $\begin{array}{l}\text { "Green bridges" cause a higher } \\
\text { disease pressure }\end{array}$ \\
\hline AT1 & {$[121]$} & Knowledge & control factor & No sufficient know-how \\
\hline AT1 & [122] & Crop rotation & outcome & $\begin{array}{l}\text { Not possible to use the field for cash } \\
\text { crops }\end{array}$ \\
\hline AT1 & {$[123]$} & Residue incorporation & outcome & $\begin{array}{l}\text { Difficult incorporation of crop } \\
\text { residues }\end{array}$ \\
\hline AT1 & [124] & Soil water & outcome & $\begin{array}{l}\text { Loss of water that is no longer } \\
\text { available for the main crop }\end{array}$ \\
\hline
\end{tabular}




\begin{tabular}{|c|c|c|c|c|}
\hline AT1 & [125] & Risk low biomass GM & outcome & High risk of failure \\
\hline AT1 & [126] & Weeds & outcome & Higher weed pressure \\
\hline AT1 & [127] & Labour/time & outcome & Time consuming \\
\hline AT1 & [128] & Income & outcome & Reduction of the income \\
\hline AT1 & [129] & Pesticide use & outcome & Higher application of plant protection \\
\hline AT1 & [130] & Fuel use & outcome & Higher use of fuel \\
\hline AT1 & [131] & Costs & outcome & Higher costs \\
\hline BE1 & [132] & Soil structure & outcome & Improved soil structure \\
\hline BE1 & [133] & Soil health & outcome & Increased soil health \\
\hline BE1 & [134] & Reduced erosion & outcome & Lower erosion risk \\
\hline BE1 & [135] & $\begin{array}{l}\text { Soil carbon } \\
\text { sequestration }\end{array}$ & outcome & More carbon in soil \\
\hline BE1 & [136] & Weeds & outcome & Prevents development of weeds \\
\hline BE1 & [137] & Soil workability & outcome & Can be tilled earlier to till in spring \\
\hline BE1 & [138] & Nitrogen leaching & outcome & Prevents nitrogen leaching \\
\hline BE1 & [139] & Legal nutrient limits & control factor & $\begin{array}{l}\text { I fertilize as much as is allowed on } \\
\text { my parcels }\end{array}$ \\
\hline BE1 & [140] & Fellow farmers & referent & Other arable farmers \\
\hline BE1 & [141] & Subsidy & control factor & $\begin{array}{l}\text { Subsidy compensates cost of cover } \\
\text { crops }\end{array}$ \\
\hline BE1 & [142] & Government & referent & $\begin{array}{l}\text { Flemish government stimulates cover } \\
\text { crops by providing subsidy }\end{array}$ \\
\hline BE1 & [143] & Fertiliser use & control factor & $\begin{array}{l}\text { Additional fertilization is needed for } \\
\text { white mustard }\end{array}$ \\
\hline BE1 & [144] & Labour/time & control factor & $\begin{array}{l}\text { Additional labour for sowing and } \\
\text { incorporation }\end{array}$ \\
\hline BE1 & [145] & Seeding & control factor & I grow seed for cover crop myself \\
\hline BE1 & [146] & Costs & control factor & Increase of total cost \\
\hline BE1 & [147] & Wet climate & control factor & $\begin{array}{l}\text { Weather conditions are often bad in } \\
\text { autumn }\end{array}$ \\
\hline BE1 & [148] & $\begin{array}{l}\text { Administrative } \\
\text { demands }\end{array}$ & control factor & $\begin{array}{l}\text { Too much administration to get } \\
\text { subsidy }\end{array}$ \\
\hline BE1 & [149] & Crop rotation & control factor & Crops are harvested late in autumn \\
\hline BE1 & {$[150]$} & $\begin{array}{l}\text { Legal sowing } \\
\text { restrictions }\end{array}$ & control factor & sowing before Sept 1 to get subsidy \\
\hline BE1 & [151] & Machinery & control factor & $\begin{array}{l}\text { No appropriate machinery for sowing } \\
\& \text { incorporation }\end{array}$ \\
\hline BE1 & {$[152]$} & Weeds & outcome & Might result in more weeds \\
\hline BE1 & [153] & Herbicide use & outcome & Increased use of herbicides \\
\hline BE1 & [154] & Land owners & referent & Owner of land \\
\hline IT1-level & {$[155]$} & Soil organic matter & outcome & Higher soil organic matter \\
\hline IT1-level & {$[156]$} & Soil structure & outcome & Improved soil structure \\
\hline IT1-level & [157] & Soil nutrients & outcome & Higher soil nitrogen content \\
\hline IT1-level & {$[158]$} & Crop yields & outcome & Higher crop yield \\
\hline IT1-level & [159] & Advisors & referent & Advisors of professional organisation \\
\hline IT1-level & {$[160]$} & Suppliers & referent & $\begin{array}{l}\text { Advisors of companies selling } \\
\text { production factors \& producer } \\
\text { associations }\end{array}$ \\
\hline
\end{tabular}




\begin{tabular}{|c|c|c|c|c|}
\hline IT1-level & [161] & Sod seeding & control factor & I do sod seeding \\
\hline IT1-level & {$[162]$} & Clay soil & control factor & Clay soils \\
\hline IT1-level & {$[163]$} & Fellow farmers & referent & Other farmers \\
\hline IT1-level & [164] & Knowledge & control factor & I know green manure benefits \\
\hline IT1-level & {$[165]$} & Income & control factor & No incentives for green manure \\
\hline IT1-level & {$[166]$} & Costs & control factor & Additional costs for green manure \\
\hline IT2-sloping & {$[167]$} & Soil structure & outcome & Improved soil structure \\
\hline IT2-sloping & {$[168]$} & Soil organic matter & outcome & Higher soil organic matter \\
\hline IT2-sloping & [169] & Fertiliser use & outcome & Reduced use of mineral fertilisers \\
\hline IT2-sloping & {$[170]$} & Protein content & outcome & $\begin{array}{l}\text { Increased protein content in following } \\
\text { crop }\end{array}$ \\
\hline IT2-sloping & {$[171]$} & Reduced erosion & outcome & Reduced erosion \\
\hline IT2-sloping & {$[172]$} & Income & control factor & I have incentives for green manure \\
\hline IT2-sloping & {$[173]$} & $\begin{array}{l}\text { Protein content } \\
\text { contracts }\end{array}$ & control factor & $\begin{array}{l}\text { Cultivation contracts that remunerate } \\
\text { high protein content }\end{array}$ \\
\hline IT2-sloping & [174] & Clay soil & control factor & Clay soils \\
\hline IT2-sloping & {$[175]$} & Suppliers & referent & $\begin{array}{l}\text { Advisors of companies selling } \\
\text { production factors \& producer } \\
\text { associations }\end{array}$ \\
\hline IT2-sloping & {$[176]$} & Costs fertilisers & control factor & Low prices of mineral fertilisers \\
\hline IT2-sloping & {$[177]$} & Soil water & outcome & $\begin{array}{l}\text { Green manure depletes the soil water } \\
\text { content }\end{array}$ \\
\hline IT2-sloping & [178] & Family & referent & Family members \\
\hline IT2-sloping & [179] & Fellow farmers & referent & Other farmers \\
\hline IT2-sloping & {$[180]$} & Machinery & control factor & Lack of adequate machineries \\
\hline IT2-sloping & {$[181]$} & Costs cultivation & outcome & Higher cultivation costs \\
\hline NL1-clay & {$[182]$} & Soil structure & outcome & Better soil structure \\
\hline NL1-clay & [183] & Soil workability & outcome & Improve soil handling \\
\hline NL1-clay & {$[184]$} & Soil organic matter & outcome & More organic matter \\
\hline NL1-clay & {$[185]$} & Soil nutrients & outcome & $\begin{array}{l}\text { Support long term soil fertility \& } \mathrm{N} \\
\text { mineralisation }\end{array}$ \\
\hline NL1-clay & {$[186]$} & Soil fauna & outcome & Increase soil fauna \\
\hline NL1-clay & [187] & Reduced erosion & outcome & Less wind and soil erosion \\
\hline NL1-clay & {$[188]$} & Nitrogen leaching & outcome & Less nitrogen leaching \\
\hline NL1-clay & [189] & Advisors & referent & $\begin{array}{l}\text { Extension agents recommend green } \\
\text { manures }\end{array}$ \\
\hline NL1-clay & {$[190]$} & Magazines & referent & Magazines are positive \\
\hline NL1-clay & [191] & Study club & referent & Study club is positive \\
\hline NL1-clay & [192] & Fellow farmers & referent & Other arable farmers are positive \\
\hline NL1-clay & [193] & Suppliers & referent & $\begin{array}{l}\text { Green manure seed salesmen are } \\
\text { positive }\end{array}$ \\
\hline NL1-clay & [194] & Ploughing straw & control factor & I like to plough down my straw \\
\hline NL1-clay & [195] & Other organic inputs & control factor & $\begin{array}{l}\text { Enough other ways to apply organic } \\
\text { matter }\end{array}$ \\
\hline NL1-clay & [196] & Timing application & control factor & $\begin{array}{l}\text { It is not always possible to apply } \\
\text { liquid manure in time }\end{array}$ \\
\hline
\end{tabular}




\begin{tabular}{|c|c|c|c|c|}
\hline NL1-clay & [197] & $\begin{array}{l}\text { Cultivation winter } \\
\text { wheat }\end{array}$ & control factor & I mainly grow winter wheat \\
\hline NL1-clay & [198] & Cultivation potatoes & control factor & I grow a lot of early potatoes \\
\hline NL1-clay & [199] & Crop rotation & control factor & $\begin{array}{l}\text { sometimes growing season is too } \\
\text { short for good crop }\end{array}$ \\
\hline NL1-clay & [200] & Land exchange & control factor & $\begin{array}{l}\text { I exchange land with husbandry } \\
\text { farmers }\end{array}$ \\
\hline NL1-clay & [201] & Wet climate & control factor & $\begin{array}{l}\text { In the fall there are not enough dry } \\
\text { days to sow green manures }\end{array}$ \\
\hline NL1-clay & {$[202]$} & Legal nutrient limits & control factor & $\begin{array}{l}\text { Nitrogen quotum too low to grow } \\
\text { green manures }\end{array}$ \\
\hline NL1-clay & [203] & Weeds & outcome & More weeds in following crop \\
\hline NL1-clay & [204] & Nematodes & outcome & More nematodes \\
\hline NL1-clay & [205] & Labour/time & outcome & Requires extra time \\
\hline NL1-clay & [206] & Costs & outcome & Increases costs \\
\hline NL2-sand & [207] & Soil structure & outcome & Better soil structure \\
\hline NL2-sand & [208] & Soil organic matter & outcome & More organic matter \\
\hline NL2-sand & [209] & Reduced erosion & outcome & Less wind and soil erosion \\
\hline NL2-sand & [210] & Soil nutrients & outcome & $\begin{array}{l}\text { Support long term soil fertility \& } \mathrm{N} \\
\text { mineralisation }\end{array}$ \\
\hline NL2-sand & [211] & Soil fauna & outcome & Increase soil fauna \\
\hline NL2-sand & [212] & Soil workability & outcome & Improve soil handling \\
\hline NL2-sand & [213] & Nitrogen leaching & outcome & Less nitrogen leaching \\
\hline NL2-sand & [214] & Advisors & referent & $\begin{array}{l}\text { Extension agents recommend green } \\
\text { manures }\end{array}$ \\
\hline NL2-sand & [215] & Magazines & referent & Magazines are positive \\
\hline NL2-sand & [216] & Study club & referent & Study club is positive \\
\hline NL2-sand & [217] & Fellow farmers & referent & Other arable farmers are positive \\
\hline NL2-sand & [218] & Suppliers & referent & $\begin{array}{l}\text { Green manure seed salesmen are } \\
\text { positive }\end{array}$ \\
\hline NL2-sand & [219] & Ploughing straw & control factor & I like to plough down my straw \\
\hline NL2-sand & [220] & Other organic inputs & control factor & $\begin{array}{l}\text { Enough other ways to apply organic } \\
\text { matter }\end{array}$ \\
\hline NL2-sand & [221] & Crop rotation & control factor & $\begin{array}{l}\text { sometimes growing season is too } \\
\text { short for good crop }\end{array}$ \\
\hline NL2-sand & {$[222]$} & Cultivation potatoes & control factor & I grow a lot of early potatoes \\
\hline NL2-sand & [223] & Timing application & control factor & $\begin{array}{l}\text { It is not always possible to apply } \\
\text { liquid manure in time }\end{array}$ \\
\hline NL2-sand & [224] & $\begin{array}{l}\text { Cultivation winter } \\
\text { wheat }\end{array}$ & control factor & I mainly grow winter wheat \\
\hline NL2-sand & {$[225]$} & Land exchange & control factor & $\begin{array}{l}\text { I exchange land with husbandry } \\
\text { farmers }\end{array}$ \\
\hline NL2-sand & {$[226]$} & Wet climate & control factor & $\begin{array}{l}\text { Not enough dry days to sow green } \\
\text { manures }\end{array}$ \\
\hline NL2-sand & [227] & Legal nutrient limits & control factor & $\begin{array}{l}\text { Nitrogen quota too low to grow green } \\
\text { manures }\end{array}$ \\
\hline NL2-sand & {$[228]$} & Weeds & outcome & More weeds in following crop \\
\hline NL2-sand & [229] & Labour/time & outcome & Requires extra time \\
\hline NL2-sand & [230] & Nematodes & outcome & More nematodes \\
\hline
\end{tabular}




NL2-sand [231] Costs outcome Increases costs

\section{Application of compost}

Supplementary Table 4. 4: Labels (as used in the figures) and related farmers 'descriptions of outcomes, referents and control factors for the use of compost

\begin{tabular}{|c|c|c|c|c|}
\hline AEZ & {$[\#]$} & Label & Category TPB & Farmers' description \\
\hline BE1 & [232] & Soil fauna & outcome & Improved soil life \\
\hline BE1 & [233] & Soil health & outcome & Improved soil health \\
\hline BE1 & {$[234]$} & Reduced erosion & outcome & Lower erosion risk \\
\hline BE1 & {$[235]$} & Soil organic matter & outcome & Increased humus content of soil \\
\hline BE1 & {$[236]$} & Soil nutrients & outcome & $\begin{array}{l}\text { Improved long term } \mathrm{N} \text { release by } \\
\text { the soil }\end{array}$ \\
\hline BE1 & {$[237]$} & Soil structure & outcome & Obtain less heavy soils \\
\hline BE1 & [238] & Fellow farmers & referent & $\begin{array}{l}\text { Other arable farmers make little use } \\
\text { of compost }\end{array}$ \\
\hline BE1 & [239] & Livestock farmers & referent & $\begin{array}{l}\text { I can do animal farmers in area a } \\
\text { favour by using their } \\
\text { slurry/farmyard manure }\end{array}$ \\
\hline BE1 & [240] & Magazines & referent & agricultural magazines \\
\hline BE1 & [241] & Other organic inputs & control factor & $\begin{array}{l}\text { I prefer organic fertilizer of animal } \\
\text { origin \& solid/liquid }\end{array}$ \\
\hline BE1 & [242] & Residue incorporation & control factor & I incorporate straw \\
\hline BE1 & [243] & Contract workers & control factor & $\begin{array}{l}\text { Dependent on contractor to spread } \\
\text { compost }\end{array}$ \\
\hline BE1 & [244] & Fertiliser use & outcome & $\begin{array}{l}\text { Supply of nitrogen needed to digest } \\
\text { compost }\end{array}$ \\
\hline BE1 & [245] & Heterogeneous spread & outcome & no homogenous spread \\
\hline BE1 & [246] & Other organic inputs & control factor & $\begin{array}{l}\text { More than enough slurry \& manure } \\
\text { available }\end{array}$ \\
\hline BE1 & [247] & Uncertainty $\mathrm{N}$ release & outcome & $\begin{array}{l}\text { Unsure on timing of } \mathrm{N} \text { release for } \\
\text { crop }\end{array}$ \\
\hline BE1 & [248] & Legal nutrient limits & control factor & $\begin{array}{l}\text { Legislation for fertilization is too } \\
\text { strict }\end{array}$ \\
\hline BE1 & [249] & Variation in quality & control factor & Much variation in quality \\
\hline BE1 & [250] & Labour/time & control factor & $\begin{array}{l}\text { Slurry is spread for me. compost } \\
\text { not }\end{array}$ \\
\hline BE1 & [251] & Diseases & outcome & Higher risk on diseases \\
\hline BE1 & [252] & Weeds & outcome & More weeds \\
\hline BE1 & [253] & Nitrogen leaching & outcome & $\begin{array}{l}\text { Higher risk on too high } \mathrm{N} \text { residue in } \\
\text { autumn }\end{array}$ \\
\hline BE1 & [254] & Costs & control factor & $\begin{array}{l}\text { Expensive or difficult } \\
\text { transport/compared to } \\
\text { alternatives/variable/ }\end{array}$ \\
\hline BE1 & [255] & Knowledge & control factor & $\begin{array}{l}\text { Not enough knowledge on } \\
\text { composition/ no experience }\end{array}$ \\
\hline BE1 & [256] & Availability of compost & control factor & $\begin{array}{l}\text { Not sure on availability when } \\
\text { needed \& low offer }\end{array}$ \\
\hline BE1 & {$[257]$} & Polluted compost & outcome & Contains waste products \\
\hline NL2-sand & [258] & Soil organic matter & outcome & Compost provides organic matter \\
\hline
\end{tabular}




\begin{tabular}{|c|c|c|c|c|}
\hline NL2-sand & [259] & Timing application & outcome & Can be applied in the fall/winter \\
\hline NL2-sand & [260] & Advisors & referent & Extension agents are positive \\
\hline NL2-sand & [261] & Fellow farmers & referent & Other arable farmers are positive \\
\hline NL2-sand & [262] & Study club & referent & Study club is positive \\
\hline NL2-sand & [263] & Availability of compost & control factor & It is not available in my region \\
\hline NL2-sand & [264] & Costs & control factor & Compost application increases costs \\
\hline NL2-sand & [265] & Other organic inputs & control factor & $\begin{array}{l}\text { Plenty of other possibilities to apply } \\
\text { organic matter }\end{array}$ \\
\hline NL2-sand & [266] & Legal nutrient limits & control factor & $\begin{array}{l}\text { The levy free Phosphate level is too } \\
\text { low }\end{array}$ \\
\hline NL2-sand & [267] & Other organic inputs & control factor & Slurry is largely available \\
\hline NL2-sand & [268] & Labour/time & outcome & Cost more labour to apply \\
\hline NL2-sand & [269] & Polluted compost & outcome & It can contain unwanted waste \\
\hline
\end{tabular}

\section{Application of FYM}

Supplementary Table 4. 5: Labels (as used in the figures) and related farmers 'descriptions of outcomes, referents and control factors for the use of FYM

\begin{tabular}{|c|c|c|c|c|}
\hline AEZ & [\#] & Label & Category TPB & Farmers' description \\
\hline BE1 & {$[270]$} & Soil structure & outcome & $\begin{array}{l}\text { Better soil structure compared to } \\
\text { slurry }\end{array}$ \\
\hline BE1 & {$[271]$} & Soil fauna & outcome & More soil life \\
\hline BE1 & {$[272]$} & Reduced erosion & outcome & Lower erosion risk \\
\hline BE1 & [273] & Soil organic matter & outcome & $\begin{array}{l}\text { More organic matter compared to } \\
\text { slurry }\end{array}$ \\
\hline BE1 & {$[274]$} & Soil water & outcome & $\begin{array}{l}\text { Improved water holding capacity of } \\
\text { the soil }\end{array}$ \\
\hline BE1 & {$[275]$} & Soil nutrients & outcome & $\begin{array}{l}\text { Higher N supplying capacity of the } \\
\text { soil \& soil fertility }\end{array}$ \\
\hline BE1 & [276] & Contract workers & control factor & Depending on the contractor \\
\hline BE1 & {$[277]$} & Livestock farmers & referent & Animal farmers offer more slurry \\
\hline BE1 & [278] & $\begin{array}{l}\text { Legislation on effective } \\
\mathrm{N}\end{array}$ & control factor & $\begin{array}{l}\text { Working with system of effective } \\
\text { nitrogen }\end{array}$ \\
\hline BE1 & [279] & Fellow farmers & referent & Other arable farmers apply it a lot \\
\hline BE1 & {$[280]$} & Contract workers & control factor & $\begin{array}{l}\text { Contractor not available when } \\
\text { farmyard manure has to be spread }\end{array}$ \\
\hline BE1 & [281] & Machinery & control factor & $\begin{array}{l}\text { Appropriate machinery not available } \\
\& \text { homogeneous spread }\end{array}$ \\
\hline BE1 & [282] & Uncertain $\mathrm{N}$ release & outcome & $\begin{array}{l}\text { Less sure on timing and quantity of } \mathrm{N} \\
\text { release by the soil compared to } \\
\text { mineral fertilizer and slurry }\end{array}$ \\
\hline BE1 & [283] & Costs & control factor & $\begin{array}{l}\text { Slurry is less expensive for me/ } \\
\text { transport costs FYM }\end{array}$ \\
\hline BE1 & [284] & Availability of FYM & control factor & $\begin{array}{l}\text { Limited supply of farmyard manure } \\
\text { in my area/ supply varies/region }\end{array}$ \\
\hline BE1 & {$[285]$} & Storage facilities & control factor & $\begin{array}{l}\text { Farmyard manure has to be stored on } \\
\text { the farm/ appropriate storage } \\
\text { capacity }\end{array}$ \\
\hline
\end{tabular}




\section{Chapter 5}

How are farmers' beliefs on soil organic matter related to their use of organic inputs? A case study in the Netherlands

Renske Hijbeek ${ }^{1}$, Annette A. Pronk ${ }^{2}$, Martin K. van Ittersum ${ }^{1}$, Hein F.M. ten Berge ${ }^{2}$, Jo Bijttebier $^{3}$ and Jan Verhagen ${ }^{2}$

${ }^{1}$ Plant Production Systems, Wageningen University and Research, Wageningen, the Netherlands.

${ }^{2}$ Agrosystems Research, Wageningen University and Research, the Netherlands

${ }^{3}$ Flanders Research Institute for Agriculture, Fisheries and Food, Belgium

Accepted for publication in Soil Use and Management under the title: "What drives farmers to increase soil organic matter? A case study in the Netherlands" 


\begin{abstract}
Soil organic matter (SOM) is an important resource base for arable farming. For policies on SOM to be effective, insight is needed on why and under which conditions farmers are willing to increase SOM content.

This study uses the theory of planned behaviour to analyse what prevents or encourages Dutch farmers to increase the percentage of SOM content of their fields. In an online survey, 435 arable farmers were asked questions to understand their attitude (perceived benefits), subjective norm (social pressure) and perceived behavioural control (anticipated impediments and obstacles) related to management of SOM. Farmers' answers were related to their intention to increase SOM content, use of organic inputs and perceived increase of SOM content.

Our results show that Dutch farmers are well aware of the possible benefits of SOM content for crop productivity. Most Dutch farmers also have a positive subjective norm on SOM (rating 5.84 on a scale from -10 to +10 , based on e.g. scientific research or agricultural advisors). Consequently, most farmers in our survey have a high or very high intention to increase SOM content $(90.1 \%)$. A higher intention to increase SOM content was correlated with the use of organic inputs as expressed in total and effective $\mathrm{C}(P=0.003$ and $P=0.002$ respectively), but this did not lead to a perceived increase in SOM content. The Dutch Manure and Fertiliser Act and the need to cultivate profitable crops (such as potatoes or sugar beets) were indicated as important impeding factors for increasing SOM content.
\end{abstract}

Keywords: soil organic matter; soil management; organic inputs; theory of planned behaviour; farmers' intentions; farmers' behaviour; soil conservation

\title{
Abbreviations
}

C carbon

FYM farmyard manure

SO standard output

SOM soil organic matter 


\subsection{Introduction}

Soil organic matter (SOM) content co-determines many soil properties including soil structure, nutrient availability and soil health (Johnston et al. 2009). Increasing SOM content can therefore be seen as a strategic means to safeguard long term farm productivity. As such, SOM management is an important farm objective for many Dutch arable farmers (Mandryk et al. 2014).

Farmers can use different practices to increase SOM content of their fields. They can use more organic inputs (such as animal manures or compost) instead of mineral fertilisers, include more cereals in their crop rotation or cultivate green manures (Magdoff \& Weil 2004). These practices might conflict with other farm objectives such as profit maximization, labour use efficiency or minimization of gross margin variation. Farmers need to balance these objectives, which can prevent implementation of practices to increase SOM content of their topsoil. This can become especially more challenging when short-term profits outweigh long-term objectives (Ingram et al. 2014; Mandryk 2016).

In the Netherlands, organic inputs are widely available for arable farmers due to the large livestock sector and related production of animal manures. Since the 1980s however, restrictions on the use of organic manure have been implemented (Schröder \& Neeteson 2008), which has caused some concern for farmers' abilities to maintain or increase SOM contents. Using approximately two million soil samples, Reijneveld et al. (2009) showed that between 1984 and 2004, average SOM content remained stable in agricultural soils in the Netherlands. Some increases in SOM content were found in regions with lower initial SOM contents and decreases in SOM content in regions with higher initial SOM content.

Maintenance of SOM is a policy target, as documented in European policy documents (EC 2011a, b) and international food security and climate objectives (UNFCCC 2015). Through maintenance of SOM, soil is being protected as a resource base for food production, soil life is conserved (Chang et al. 2007) and carbon sequestered (Smith 2016). For policies on SOM to be effective, insight is needed on why and under which conditions farmers are willing to increase SOM content.

Behavioural research approaches aim to identify what prevents or encourages individuals from displaying a certain type of behaviour. In this case, we would like to understand what prevents or encourages Dutch arable farmers to increase SOM content. 
Several models have been developed to try to understand and predict human behaviour. The most widely used of these models is the theory of planned behaviour (Ajzen 1991), which will be used in this study.

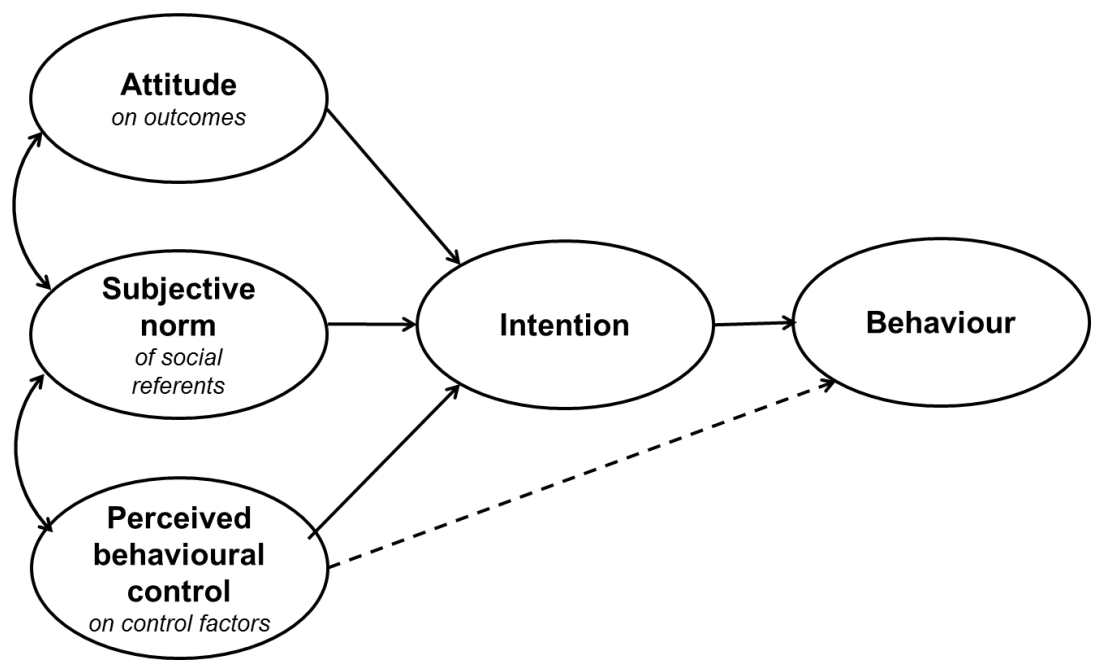

Fig 5. 1: Illustration of the framework of the Theory of planned behaviour (Ajzen, 1991). When experiences are clear and risks are low, perceived behaviour control is directly linked to actual behaviour.

According to the theory of planned behaviour, people base their behaviour on three main constructs: 1) their attitude, 2) their subjective (social) norm and 3) the degree of perceived behavioural control. In this framework, an attitude refers to the degree to which a person expects a certain impact or outcome. The subjective norm refers to the social pressure to perform a behaviour. Perceived behaviour control refers to the perceived ease of performing a behaviour, and reflects both past experiences and anticipated impediments and obstacles. These three constructs together lead to an intention, which might lead to a certain behaviour (Ajzen 1991, Fig. 5.1, other relations between component might also be possible).

According to the theory of planned behaviour, attitudes, subjective norm and perceived behavioural control are formed by underlying beliefs. These can be beliefs on the outcomes of a certain behaviour, beliefs on the views of social referents or beliefs on the strength of control factors restricting a certain behaviour.

When recently asked for their concerns on the future of soil fertility, Dutch farmers place SOM content at the top of the list (Reijneveld 2013). It is however yet unknown how 
the different elements of the theory of planned behaviour play a role in farmers' intention to increase SOM content or use of organic inputs. In this study the theory of planned behaviour is used to analyse why and under which conditions Dutch arable farmers are willing to increase the percentage of SOM content of their fields. We address the following research questions for arable farmers in the Netherlands:

1. Which beliefs form farmers' attitudes, subjective norms and perceived behavioural controls regarding SOM and its management?

2. How do these beliefs (Q. 1) influence the intention of farmers to increase SOM content?

3. How does actual behaviour (use of organic inputs) correspond to farmers' intention to increase SOM content?

\subsection{Materials and Methods}

A farm survey was conducted among 435 arable farmers in the Netherlands (Section 5.2.1). Using this survey, we first studied the underlying beliefs of attitude, subjective norm and perceived behavioural control of Dutch farmers regarding SOM and its management (Section 5.2.2). Second, we related these beliefs to farmers' intention to increase SOM content (Section 5.2.3). Farmers' intention to increase SOM content was then related to actual (as stated by respondent) use of organic inputs (Section 5.2.4). Finally, perceived change in SOM was related to perceived behavioural control, intentions to increase SOM content and the use of organic inputs (Section 5.2.5).

\subsubsection{Online farm survey}

An online survey was held among arable farmers in the Netherlands. We focused only on arable farmers because (compared to livestock farmers) arable farmers cultivate less grass and feedstocks and are therefore assumed to be more dependent on high soil fertility and related SOM content. Three groups of farmers were targeted: farmers on sandy soils, farmers on loam soils and farmers on clay soils (Supplementary Fig. 5.1, page 121). Addresses were obtained from the national agricultural census 2012 (CBS 2012). While selecting addresses the following two criteria were used to exclude pensioners and hobby farmers: 1) year of birth after 1947 and 2) spending more than 20 hours labour per week to farming. In total, 4770 letters were sent to farmers with a personal link and password to the online questionnaire. 
Before data analysis, two criteria were used to select only arable farmers from the respondents (following Andersen et al. 2007): 1) more than 2/3 of the monetary value of agricultural outputs from arable crops; and 2) less than $50 \%$ of farm land was grassland (either temporary or permanent). In addition, farmers with less than 10 ha of land or having peat soils (either reporting peat soils and/ or more than $12 \% \mathrm{SOM}$ on average across all fields) were also excluded from data analysis.

Each farmer was asked to provide information on age, gender, farm size (ha), crop rotation, soil texture and average SOM content. To reduce errors, farmers could leave certain questions unanswered (for example due to confidentiality of crop rotation or manure application). In those cases, only filled sections were used in the data analysis. Economic farm sizes (expressed in the monetary value of agricultural output at farmgate price) were calculated using farm activities (e.g. crops cultivated, ha) and Standard Output (SO) coefficients for the Netherlands (Eurostat 2013). Economic intensity of each farm was calculated by dividing economic farm size by farm ha (and thus expressed in $€ / h a)$. In addition, farmers were asked to indicate which type of organic inputs they used and how much.

\subsubsection{Finding underlying beliefs of attitude, subjective norm and perceived behavioural control regarding SOM and its management}

\section{Farmers' attitude}

A literature review revealed nine outcomes that SOM may have for soil properties, processes and functions in arable farming: improved soil structure, rooting, workability, water holding capacity, soil life, nutrient release, nutrient binding capacity, soil fungi and productivity (Allison 1973; Gregorich et al. 1994; Johnston et al. 2009; Murphy 2014).

For each outcome $(\mathrm{N}=9$, Table 5.1$)$, farmers were asked to rate its probability of occurrence on a Likert scale from not very likely (1) to very likely (5). For instance, farmers were asked to rate the likelihood that SOM improves workability of their soil. This is called the belief strength. Farmers were also asked to evaluate each outcome. In the same example, farmers were asked to evaluate workability from negative (1) to positive (5). This is called the outcome valuation. Outcome valuations were lowered by three points to give a negative to positive scaling $(-2$ to +2$)$.

For each farmer, an attitude on each outcome (i) was found by multiplying belief strength with outcome valuation (Equation 5.1). Consequently, attitude values ranged 
between -10 and +10 . Mean attitude values for each outcome were found by taking the average across all farmers.

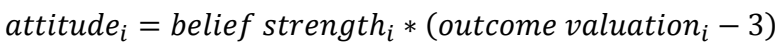

Table 5. 1: Expected outcomes of increasing SOM content, farmers' referents and control factors included in the farm survey. For each factor, two types of scales were used, scale 1 and scale 2. Scores on these respective scales were multiplied to find farmers' attitudes, subjective norm and perceived behavioural control on increasing SOM content, following Equations 5.1 to5. 3.

\begin{tabular}{|c|c|c|}
\hline & Scale 1 & Scale 2 \\
\hline A. Outcomes & Belief strength & Outcome valuation \\
\hline Improved soil structure & not likely (1) - likely (5) & bad $(-2)$ to good $(+2)$ \\
\hline Easy rooting & not likely (1) - likely (5) & bad $(-2)$ to $\operatorname{good}(+2)$ \\
\hline Increased productivity & not likely (1) - likely (5) & bad $(-2)$ to $\operatorname{good}(+2)$ \\
\hline Improved workability & not likely (1) - likely (5) & bad $(-2)$ to good $(+2)$ \\
\hline Increased water holding capacity & not likely (1) - likely (5) & bad $(-2)$ to $\operatorname{good}(+2)$ \\
\hline More soil life & not likely (1) - likely (5) & bad $(-2)$ to $\operatorname{good}(+2)$ \\
\hline Continuous nutrient release & not likely (1) - likely (5) & bad $(-2)$ to $\operatorname{good}(+2)$ \\
\hline $\begin{array}{l}\text { Increased binding capacity of } \\
\text { nutrients }\end{array}$ & not likely (1) - likely (5) & bad $(-2)$ to $\operatorname{good}(+2)$ \\
\hline Increase in fungi & not likely (1) - likely (5) & bad $(-2)$ to good $(+2)$ \\
\hline B. Referents & Normative belief & Motivation to comply \\
\hline Advisors & negative $(-2)$ to positive $(+2)$ & none (1) to very much (5) \\
\hline Research & negative $(-2)$ to positive $(+2)$ & none (1) to very much (5) \\
\hline Magazines & negative $(-2)$ to positive $(+2)$ & none (1) to very much (5) \\
\hline Study clubs & negative $(-2)$ to positive $(+2)$ & none (1) to very much (5) \\
\hline Fellow farmers & negative $(-2)$ to positive $(+2)$ & none (1) to very much (5) \\
\hline C. Control factors & Control strength & Control power \\
\hline $\begin{array}{l}\text { Effects of SOM are long term instead } \\
\text { of short term }\end{array}$ & none (1) to very much (5) & negative $(-2)$ to positive $(+2)$ \\
\hline Costs of organic inputs & none (1) to very much (5) & negative $(-2)$ to positive $(+2)$ \\
\hline Availability of organic inputs & none (1) to very much (5) & negative $(-2)$ to positive $(+2)$ \\
\hline Crop rotation with specialized crops ${ }^{1}$ & none (1) to very much (5) & negative $(-2)$ to positive $(+2)$ \\
\hline Dutch Manure and Fertiliser Act & none (1) to very much (5) & negative $(-2)$ to positive $(+2)$ \\
\hline
\end{tabular}

Usually, overall attitude of farmers is calculated as the sum of the attitude values for the separate outcomes. In this study however, we aimed for consistency in scales between categories by keeping all scales between -10 to +10 . Therefore, the mean attitude value of all outcomes was taken as a proxy for overall attitude (which had no further consequences in data analysis except for improving readability of tables).

\footnotetext{
${ }^{1}$ In the Dutch questionnaire the term 'hakvruchten' was used. This category of crops includes potatoes, sugar beets, carrots, onions and other vegetables
} 
Farmers were not only asked to rate specific outcomes of SOM (such as improved water holding capacity or nutrient binding capacity), but also to rate the overall effect of SOM on crop productivity as a more general term (thus bypassing any presumed mechanisms of contribution to crop yields). To assess how the perceived specific outcomes of SOM are related to perceived effect of SOM on productivity as a general term, a correlation analysis was done using a Spearman correlation (Kendall 1948).

\section{Farmers' subjective norm}

As part of the CATCH-C project, a series of open interviews revealed five social referents to be most important for arable farmers in the Netherlands, being: advisors, research, magazines, study clubs and fellow farmers (Pronk et al. 2014). These five referents were included in our questionnaire. For each referent $(\mathrm{N}=5$, Table 5.1), farmers were asked if they thought the referent had a negative or positive view on increasing SOM. For example, farmers were asked if they thought agricultural advisors are positive on increasing SOM ( 1 to 5). This is called the normative belief of farmers' referents on SOM. For each social referent, farmers were also asked how motivated they are to comply with the referents' view. For example, farmers were asked how motivated they are to comply with the opinion of fellow farmers (1 to 5). This is called the farmers' motivation to comply.

For each farmer, subjective norm for each social referent $(\mathrm{k})$ was found by multiplying normative belief with the motivation to comply (Equation 5.2). Normative beliefs were lowered by three points to give a negative to positive scaling $(-2$ to +2$)$. This resulted in a subjective norm value for each referent for each farmer between -10 and +10 . Mean values of subjective norm for each referent were found by taking the average value of the farmers in the survey. Means of all subjective norm scores ( $\mathrm{N}=5$, see Table 5.1) were taken as a proxy for overall subjective norm.

subjective norm $_{k}=$ motivation to comply $y_{k}\left(\right.$ normative belief $\left.f_{k}-3\right)$

Farmers' perceived behavioural control

Perceived behavioural control of farmers on increasing SOM content was assessed using five control factors: the long-term effect of SOM, costs of organic inputs, availability of organic inputs, cultivation of specialized crops and the Dutch Manure and Fertiliser Act. For each control factor $(\mathrm{N}=5$, Table 5.1), farmers were asked how strongly they thought the factor was applicable to them. For example, farmers were asked if availability of organic inputs was limited in their region on a scale from 1 to 5 . This is 
called the control strength. For each control factor, farmers were also asked to what extent they thought the control factor hampers increasing SOM content. For example, farmers were asked if they thought limited availability prevents increasing SOM on a scale from 1 to 5 . This is called the control power.

For each farmer, perceived behavioural control of each control factor (m) was found by multiplying control strength with control power (Equation 5.3). Values for control power were lowered by three points to obtain a negative to positive scaling $(-2$ to +2$)$. This resulted in a value for perceived behavioural control for each control factor for each farmer between -10 and +10 . Mean values were found by taking the average score of all farmers in the survey. Means of all values for perceived behavioural control $(\mathrm{N}=5$, see Table 5.1) were taken as a proxy for overall perceived behavioural control.

perceived behavioural control $_{m}=$ control strength $_{m} *\left(\right.$ control power $\left._{m}-3\right)$

\section{Dependency of farmers' beliefs on farm characteristics}

Statistical tests were done to assess if beliefs of attitude, subjective norm and perceived behavioural control were dependent on certain farm characteristics such as soil texture, age, farm size or farm intensity. Farms and farmers were classified according to their age, soil texture, farm size and farm intensity. For soil texture, the dominant soil texture present on a farm (largest share of farm land being either sand, loam or clay) was chosen as an indicator. When constructing classes based on continuous variables (such as age or farm intensity), farmers were divided into three equally sized groups $(\mathrm{N}=145)$ where possible.

For each class, means of beliefs were calculated and a test of significant difference was done using a Kruskal-Wallis rank sum test (McDonald 2009). If a significant difference was found, pairwise comparisons were done using the Conover-Iman test (Holm, 1979) to find which group means actually differed (e.g. whether attitudes of farmers on the effect of SOM on water holding capacity on clay soils differed from those farmers on loam soils or farmers on sandy soils or both).

\subsubsection{Testing correlations between underlying beliefs and farmers' intention to increase SOM}

Farmers were asked to indicate their intention to increase SOM content on a Likert scale from low (1) to high (5). Correlations were tested between intention to increase SOM content and stated beliefs on outcomes, referents and control factors. In addition, 
correlation tests were done between farmers' intention to increase SOM content and calculated values of attitude, subjective norm and perceived behavioural control using Spearman's rank correlation test (Kendall 1948).

\subsubsection{Testing correlations between farmers' intention to increase SOM content and (stated) use of organic inputs}

Farmers were asked to report their use of organic inputs, such as compost, slurry, farmyard manure (FYM) and the incorporation of straw. Fresh weight quantities as reported by farmers were converted to total carbon (C) and effective $\mathrm{C}$ content (see for conversion coefficients Supplementary Table 5.1, page 122). To calculate effective C, humification coefficients were used indicating the remaining fraction of residues which is still present in the soil after one year (Wolf \& Janssen 1991). This conversion allowed for the calculation of an annual input of organic inputs expressed in total $\mathrm{C}$ and effective C per ha, which we refer to as 'actual organic input'. Following, farmers' intentions to increase SOM were correlated with their annual organic input.

\subsubsection{Testing correlations between perceived change in SOM, perceived behavioural control, intentions to increase SOM and use of organic inputs}

Farmers were asked to state whether SOM content of their fields showed an increasing or decreasing trend, on a scale from 1 to 5 . This perceived trend was correlated with actual organic input (as defined above), farmers' intentions to increase SOM and the use of organic inputs. All correlations were tested using Spearman's rank correlation test.

\subsection{Results}

\subsubsection{Farm and Farmers' characteristics and actual use of organic inputs}

Of the 4770 farmers who were sent an invitation, 542 farmers filled out the section of the survey that dealt with SOM. Of these farmers, 501 were confirmed to be arable farmers (more than $2 / 3$ of the Standard Output (SO) comes from arable crops and less than $50 \%$ of farm land is grassland). Of these 501 farmers, 10 were excluded from analysis because their farm size was smaller than 10 ha. Another 52 farmers were excluded because they either reported to farm peat soils or have an average SOM content above $12 \%$. Four farmers were removed because their stated application of organic 
inputs seemed unreasonably high (more than two times the legally permitted $\mathrm{N}$ application), which we interpreted as typographical error. As a result, 435 farmers were included in the analysis.

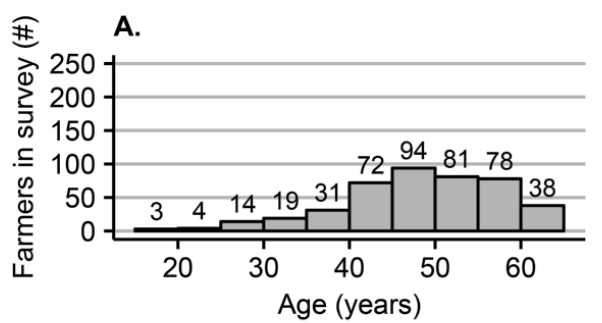

B.
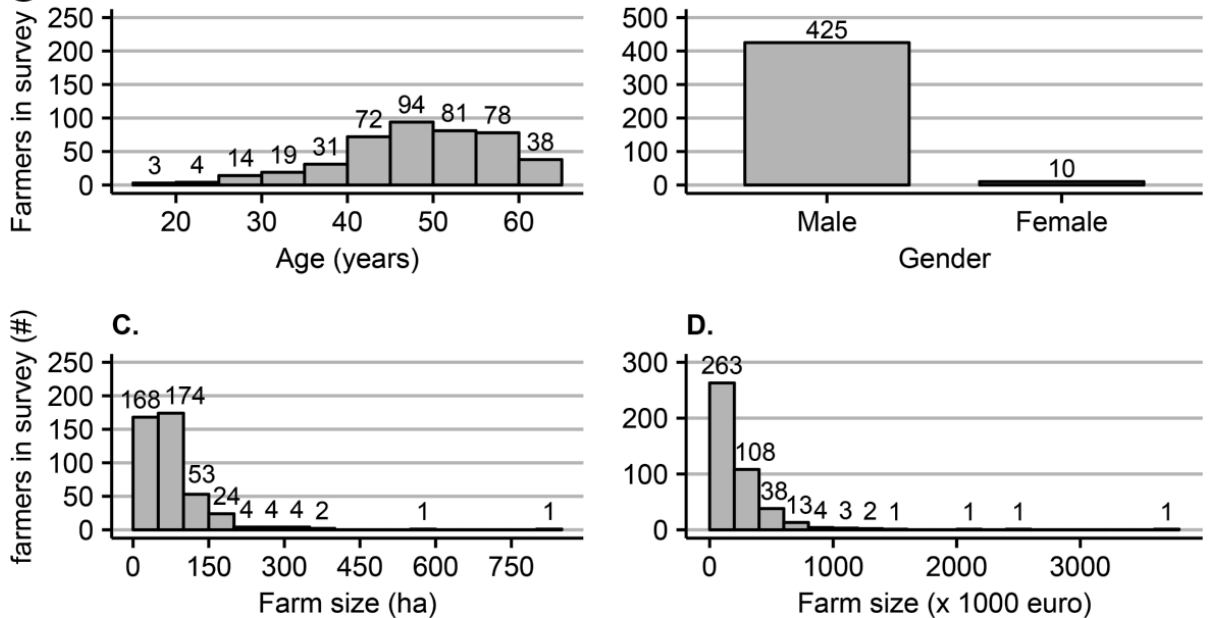

D.
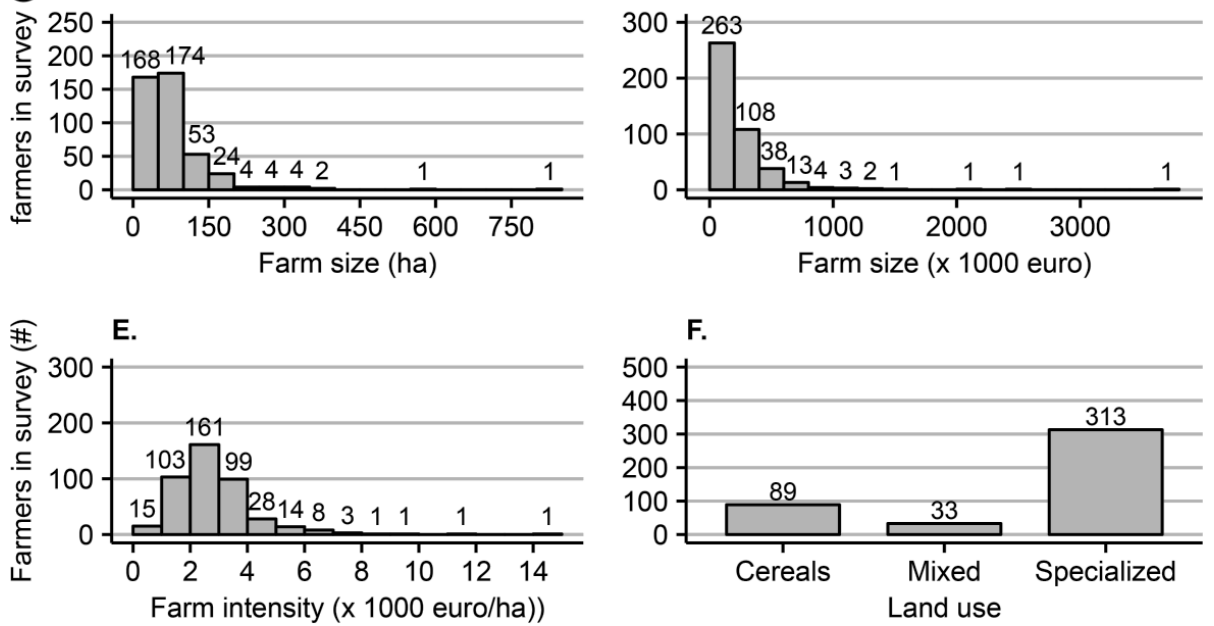

F.
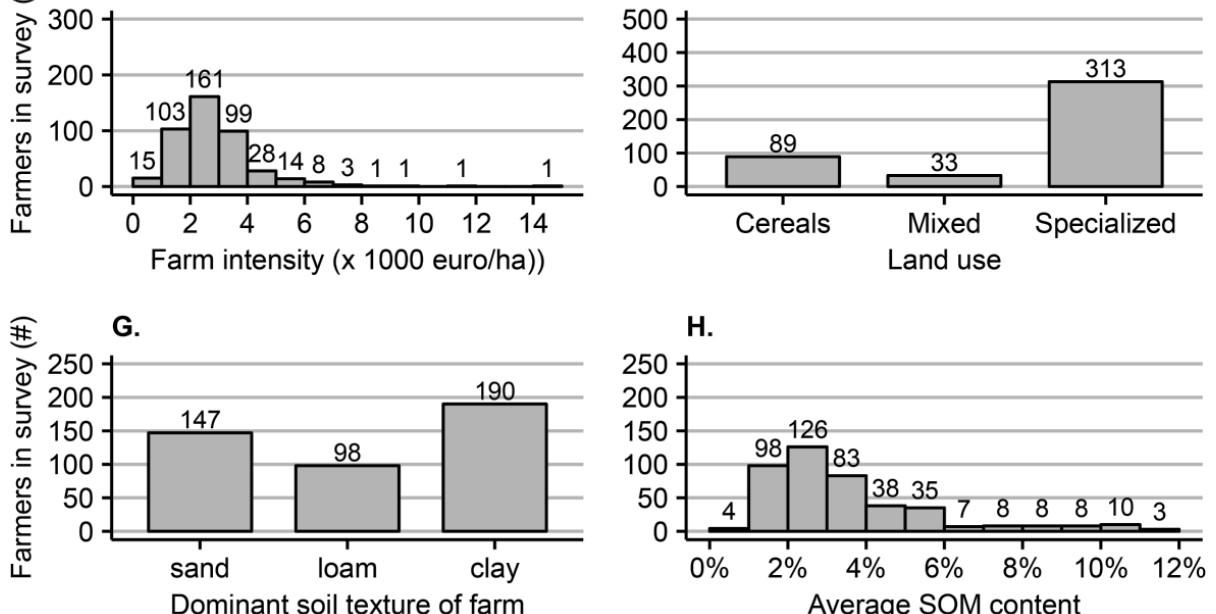

H.

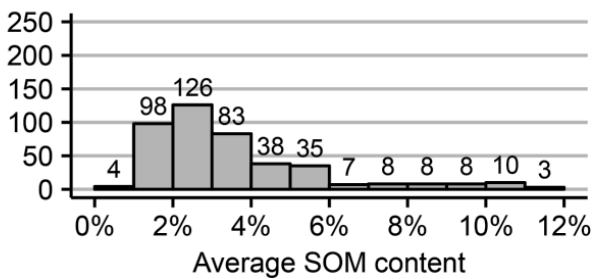

Fig 5. 2: Characteristics of farmers in the farm survey $(N=435)$. Land use categories: Cereals indicates more than 50\% of farm land is cultivated with cereals such as wheat, barley, rye, oat, triticale and/or grass. Specialized land use indicates more than 50\% of farm land is cultivated with specialized crops such as potatoes, sugar beets, carrots, onions. Mixed land use means none of both categories is present on more than $50 \%$ of farm land. 
Mean age of farmers included in the analysis was 48.8 years old, with median age exactly 50 years (Fig. 5.2a). Farmers in our survey were some years younger compared to the entire population of Dutch farmers, for which mean age was 55 years in 2012 (Voskuilen et al. 2013). The difference in age can at least partly be attributed to our criteria used for address selection (only farmers born after 1947 were included).

Farm size can be expressed in ha or monetary values, for example by using the monetary value of agricultural output at farm-gate price (SO). Mean farm size of the farmers included in the analysis was 79.4 ha (Fig. 5.2c), which was larger than the mean farm size of Dutch arable farmers in the same year (57.2 ha according to CBS (2017), excluding farms $\mathrm{SO}<€ 25,000$ ). Mean economic farm size was $€ 238,924$ (Fig. 5.2d), which was also larger than mean economic farm size of Dutch arable farmers in 2013 ( $€ 187,700$ according to CBS (2017), excluding farms $\mathrm{SO}<€ 25,000$ ).

Mean reported SOM contents of farms was 3.61\% SOM (Fig.5.2e), which is very similar to mean SOM content of Dutch arable farms on mineral soils in the last decades (around $20 \mathrm{~g} \mathrm{C} / \mathrm{kg}$ soil in the upper $25 \mathrm{~cm}$, or approximately $3.5 \% \mathrm{SOM}$, as reported by Reijneveld (2013). Most farmers cultivated specialized crops (such as potatoes, sugar beets or onions) on more than half of their land (Fig.5.2h).

Most farmers $(\mathrm{N}=409)$ also provided information on their use of organic inputs (Fig. 5.3). The majority of the farmers (around $87 \%$ ) cultivated green manures on some parts of their land, but exact percentages of farm land cultivated with green manures differed widely (Fig. 5.3a). Slurry was the most often used animal manure, with $81 \%$ of the farmers using some amount of slurry (Fig. 5.3b). Most farmers did not use FYM (N = 271), while 21 farmers used less than 1 tonne FYM per ha (together 292 farmers, Fig. 5.3c). Most farmers did not use compost $(\mathrm{N}=258)$, and 35 farmers used less than 2 tonnes compost per ha (together 293, Fig. 5.3d).

When grain maize or other cereals were cultivated, more than half of the farmers incorporated the straw, from at least sometimes up to always (Fig. 5.3e). When converting organic inputs into total $\mathrm{C}$ content, mean application was 1.35 tonne $\mathrm{C} /$ ha/year $( \pm 0.06-95 \%$ Confidence Interval [CI], Fig. 5.3f). When converting organic inputs into effective $\mathrm{C}$ content, mean application was 0.57 tonne effective $\mathrm{C} / \mathrm{ha} / \mathrm{year}( \pm$ 0.04, 95\% CI, Fig. 5.3g). 
A.

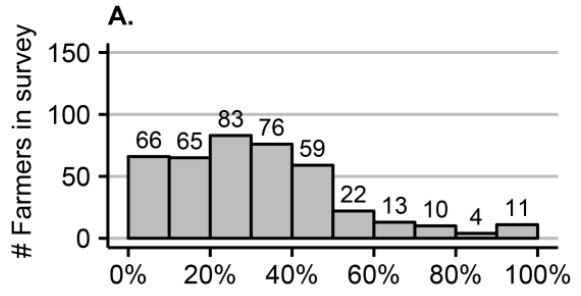

Percentage farm land with green manures

C.
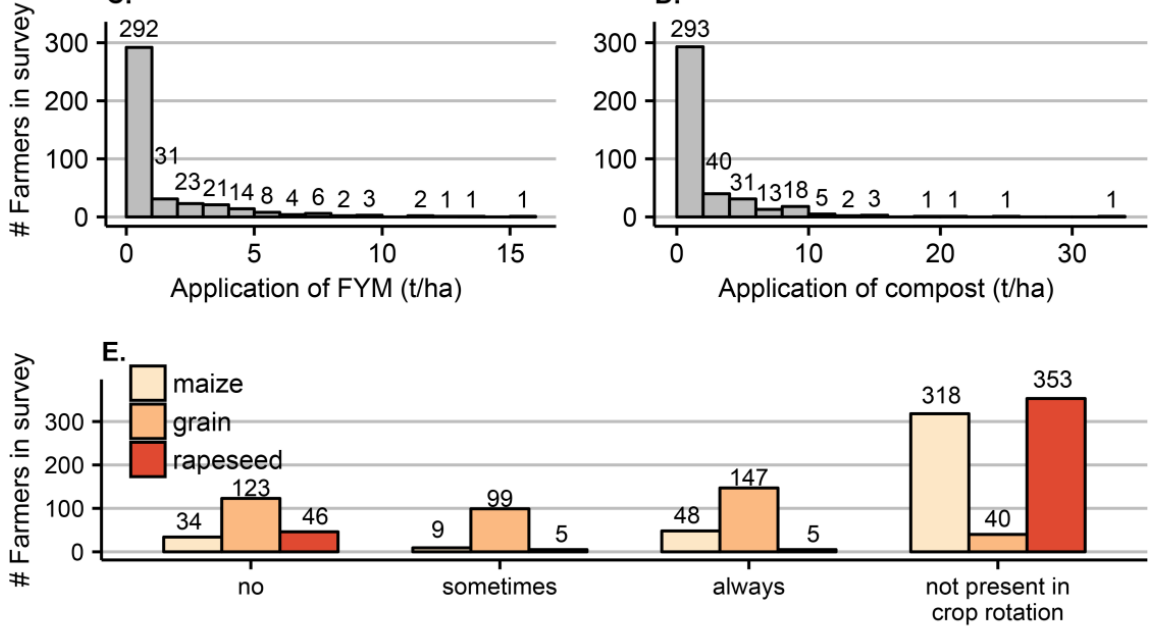

Incorporation of straw (when crop present in rotation)

F.

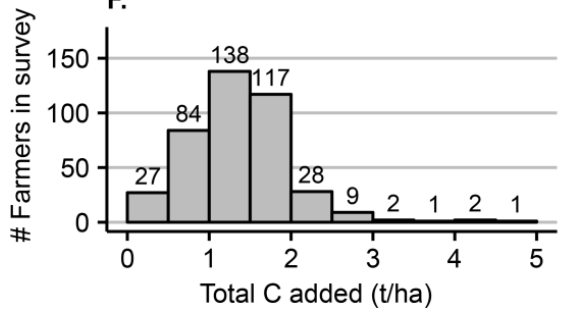

B.

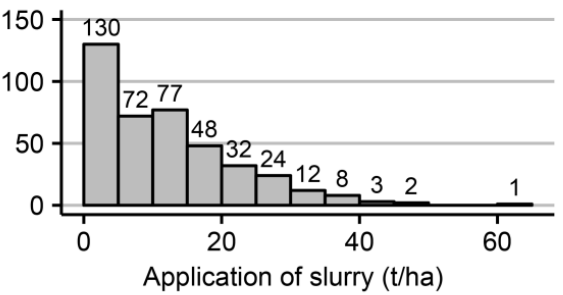

D.

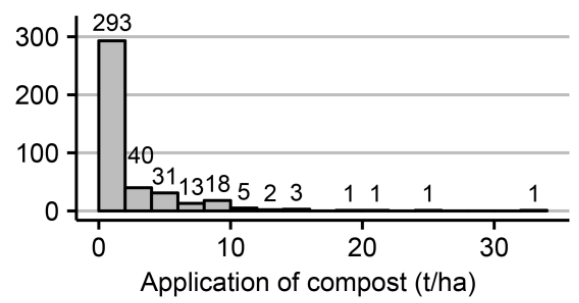

Fig 5. 3: Use of organic inputs by farmers in the farm survey $(N=435)$. 


\subsubsection{Beliefs of Dutch farmers on SOM}

\section{Farmers' attitude}

Dutch farmers had a strong positive valuation on eight outcomes of SOM and a negative valuation of one outcome (the last being soil fungi, Fig 5.4b).

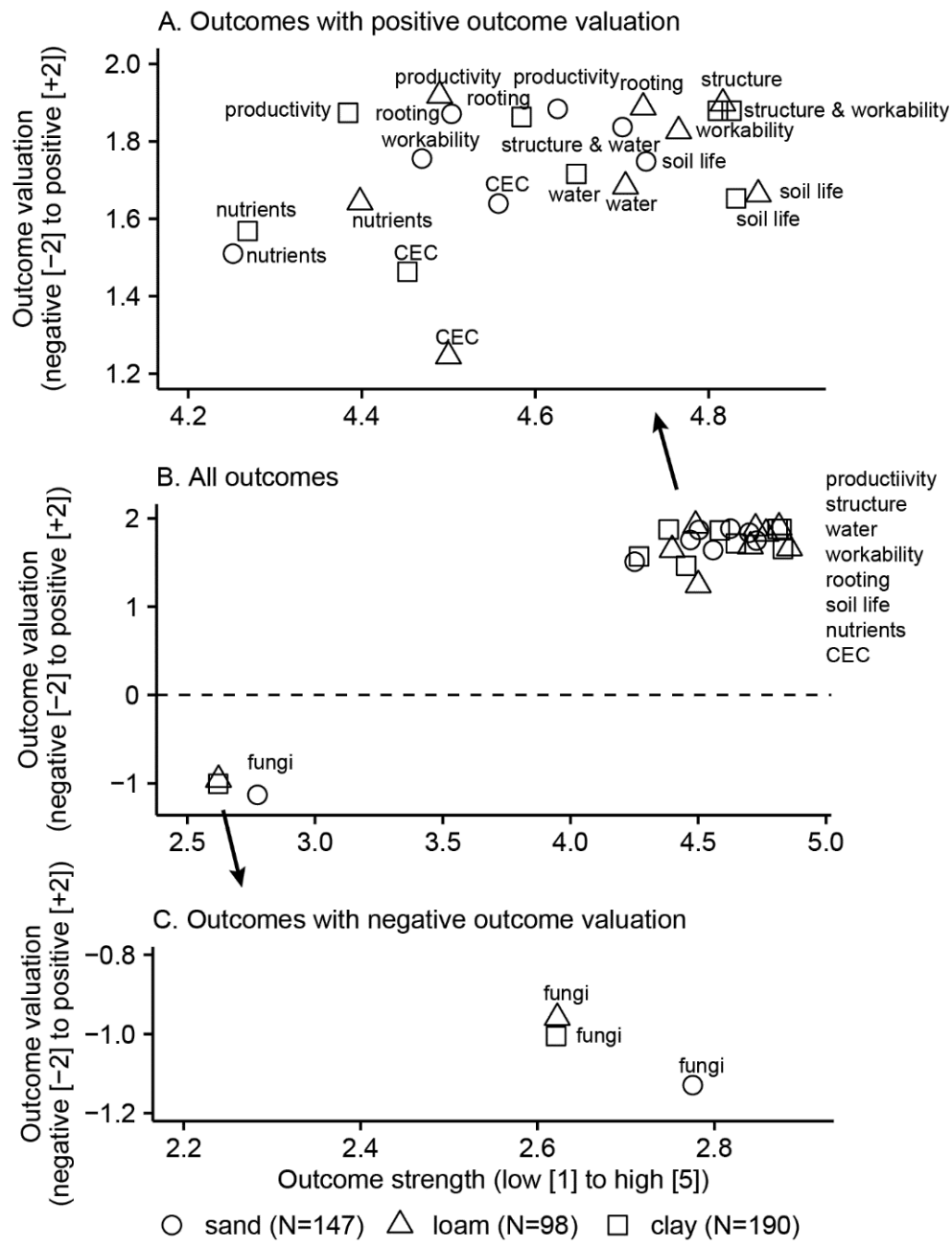

Fig 5. 4: Mean values of outcome strengths related to mean outcome valuations. CEC $=$ nutrient binding capacity; nutrients $=$ nutrient release.

Among the positive outcomes, nutrient release and nutrient binding capacity were considered the least strong outcomes of SOM content and were also evaluated least positive by Dutch arable farmers (Fig. 5.4a). At the other end of the spectrum, soil 
structure was considered one of the strongest outcomes of SOM and was also evaluated most positively by Dutch arable farmers. For farmers on sandy soils, water holding capacity takes exactly the same position as soil structure for both outcome strength and valuation. For farmers on clay soil, workability takes almost the exact same position as soil structure for outcomes strength and valuation.

Farmers evaluated the general term 'soil life' positive, but when asked specifically for soil fungi, this was the only outcome of SOM which was evaluated negatively (Fig. $5.4 \mathrm{c}$ ). The perceived strength of SOM causing soil fungi was however much weaker than the strength of the other perceived outcomes (2.6-2.8 and.4.3-4.9 respectively).

Combining outcome strengths and valuations into attitude scores, farmers with different soil textures had a significantly different attitude on a number of outcomes from SOM. These outcomes were: workability, productivity, water holding capacity, nutrient binding capacity and soil fungi (Table 5.2).

Table 5. 2: Attitudes on SOM (calculated using Equation 5.1). Farmers are grouped by the dominant soil texture of their farm. Letters indicate a significant difference within one column between outcome scores. * indicates a significant difference between at least two outcome scores within one row (using the post hoc Conover-Iman test).

\begin{tabular}{|c|c|c|c|c|c|c|}
\hline & Sand $(N=147$ & & $\operatorname{Loam}(N=98)$ & & Clay $(N=190)$ & \\
\hline & $\begin{array}{c}\text { Attitude } \\
(-10 \text { to }+10)\end{array}$ & Rank & $\begin{array}{c}\text { Attitude } \\
(-10 \text { to }+10)\end{array}$ & Rank & $\begin{array}{c}\text { Attitude } \\
(-10 \text { to }+10)\end{array}$ & Rank \\
\hline Improved soil structure & $8.76^{\mathrm{ab}}$ & 3 & $9.17^{\mathrm{a}}$ & 1 & $9.12^{\mathrm{a}}$ & 1 \\
\hline Easy rooting & $8.54^{\mathrm{bc}}$ & 4 & $8.92^{\mathrm{ab}}$ & 2 & $8.61^{\mathrm{b}}$ & 3 \\
\hline Improved workability & $7.99^{\mathrm{cd} *}$ & 6 & $8.70^{\mathrm{ab} *}$ & 3 & $9.08^{\mathrm{a} *}$ & 2 \\
\hline Increased productivity & $8.83^{\mathrm{a} *}$ & 1 & $8.62^{\mathrm{c} *}$ & 4 & $8.30^{\mathrm{c} *}$ & 4 \\
\hline Increased water holding capacity & $8.78^{\mathrm{ab} *}$ & 2 & $7.99^{\mathrm{c} *}$ & 6 & $8.04^{\text {bc } *}$ & 6 \\
\hline More soil life & $8.44^{\mathrm{abc}}$ & 5 & $8.10^{\mathrm{bc}}$ & 5 & $8.07^{\mathrm{bc}}$ & 5 \\
\hline Continuous nutrient release & $6.64^{\mathrm{e}}$ & 8 & $7.36^{\mathrm{d}}$ & 7 & $6.87^{\mathrm{d}}$ & 7 \\
\hline $\begin{array}{l}\text { Increased binding capacity of } \\
\text { nutrients }\end{array}$ & $7.70^{\mathrm{d} *}$ & 7 & $5.87^{\mathrm{e} *}$ & 8 & $6.68^{\mathrm{d} *}$ & 8 \\
\hline Increase in soil fungi & $-3.19^{\mathrm{f} *}$ & 9 & $-2.50^{\mathrm{f*}}$ & 9 & $-2.44^{\mathrm{e} *}$ & 9 \\
\hline MEAN & 6.94 & & 6.91 & & 6.93 & \\
\hline
\end{tabular}

Despite these differences in attitude for specific benefits of SOM, mean attitudes on the overall benefit of SOM did not vary significantly between soil textures (mean attitude scores vary non-significantly between 6.90 and 6.96). This shows that farmers across different soil textures appreciated the effects of SOM content equally, but for different reasons. On sandy soils, farmers valued the effect of SOM content on productivity, water holding capacity and soil structure the most. On loam and clay soils, farmers valued the effect of SOM content on soil structure, ease of rooting and workability the most. 
How are the perceived effects of SOM on specific soil characteristics related to perceived effects of SOM on crop productivity? On sandy and clay soils correlations were overall highest (Fig. 5.5). On sandy soils, perceived effects of SOM on crop productivity was strongest correlated with perceived effects of SOM on continuous nutrient release and water holding capacity (Spearman's rho $>0.5$ ). On clay soils, perceived effects of SOM on crop productivity was strongest correlated with perceived effects of SOM on ease of rooting and soil life.(Spearman's rho $>0.5$ ). On loam soils, perceived effects of SOM crop productivity was strongest correlated with perceived effect of SOM on ease of rooting (Spearman's rho $>0.5$ ).

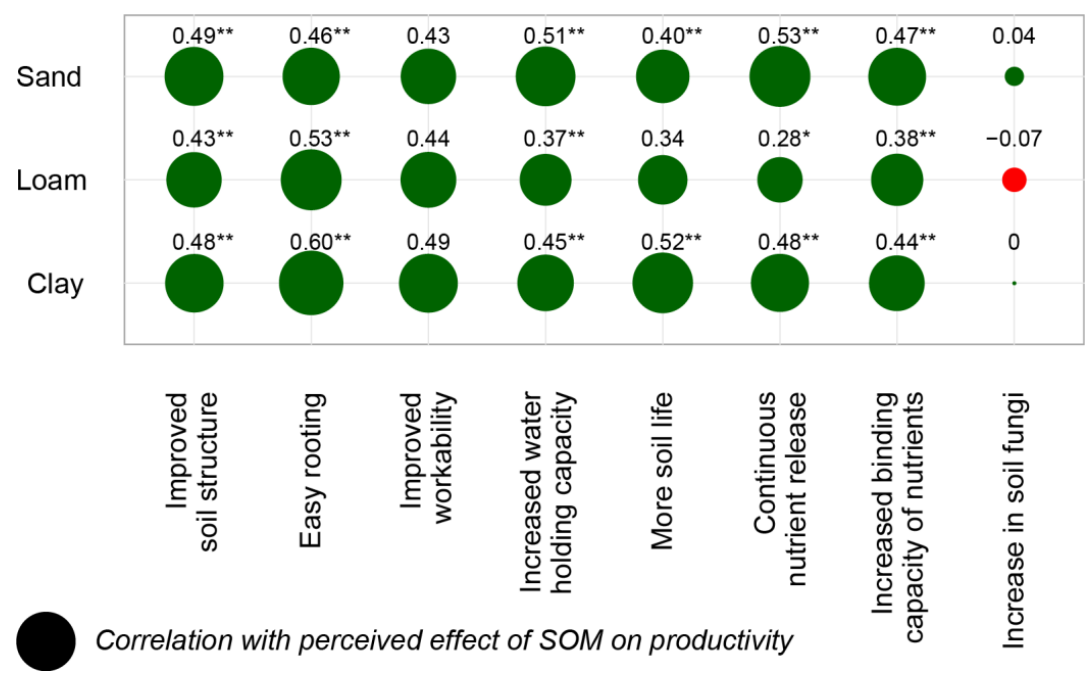

Fig 5. 5: Correlations between perceived effect of SOM on specific soil characteristics and perceived effects of $S O M$ on productivity, using Spearman's rank correlation test. Numbers indicate Spearman's rho. Stars show confidence level of correlation coefficients (* means $P<0.05$. ** means $P<0.01$ ).

\section{Farmers' subjective norm}

Considering the subjective norm of Dutch arable farmers, there were significant differences dependent on the age group. The results indicate that younger farmers are less motivated to comply with views from the given referents (such as fellow farmers, research or advisors, Fig. 5.6). Overall, advisors were thought to be most positive about increasing SOM content, whilst fellow farmers were thought to be least positive on increasing SOM content. 


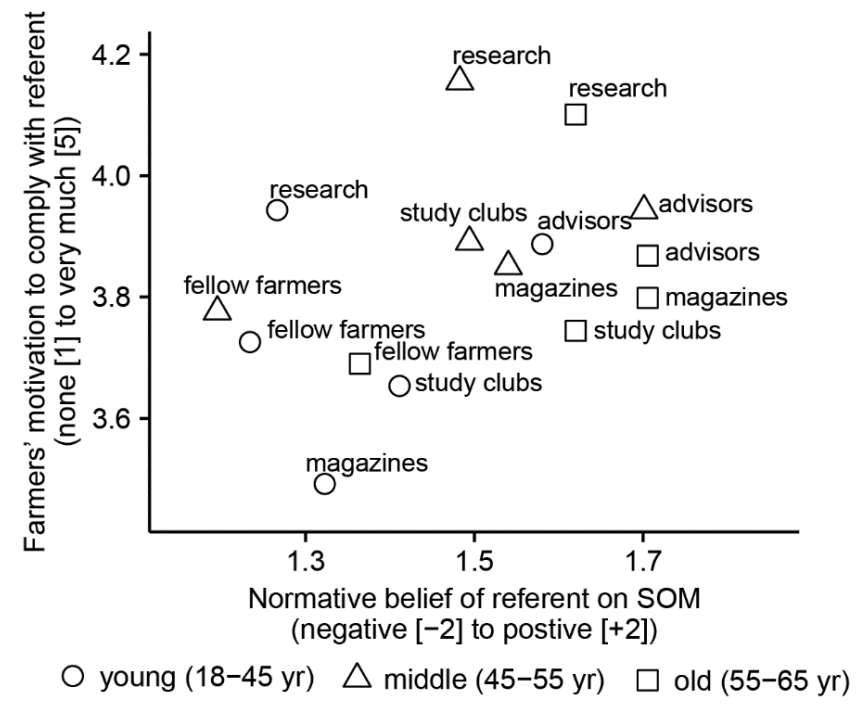

Fig 5. 6: Mean values of normative belief related to mean motivation to comply with referents. Shapes indicate age groups of farmers.

On average, subjective norm of farmers to increase SOM content was positive (5.84 on a scale from -10 to +10$)$. Age group had a significant effect on the subjective norm. Older farmers (55-65 year) had a significantly more positive overall subjective norm on increasing SOM content than medium age (45-55 year) or younger (18-45 year) farmers (6.29 vs 5.96 and 5.28 respectively, Table 5.3).

Table 5. 3: Subjective norm on SOM (calculated using Equation 5.2). Farmers are classified according to their age. Letters indicate a significant difference within one column between referent scores. * indicate a significant difference between at least two referent scores within one row (using the post hoc Conover-Iman test).

\begin{tabular}{|c|c|c|c|c|c|c|}
\hline & \multicolumn{2}{|c|}{$\begin{array}{l}\text { Young 18-45 yr } \\
\quad(N=124)\end{array}$} & \multicolumn{2}{|c|}{$\begin{array}{l}\text { Middle 45-55 yr } \\
(\mathrm{N}=176)\end{array}$} & \multicolumn{2}{|c|}{$\begin{array}{l}\text { Old 55-65 yr } \\
(\mathrm{N}=131)\end{array}$} \\
\hline & $\begin{array}{l}\text { Subjective norm } \\
(-10 \text { to }+10)\end{array}$ & Rank & $\begin{array}{l}\text { Subjective norm } \\
(-10 \text { to }+10)\end{array}$ & Rank & $\begin{array}{l}\text { Subjective norm } \\
(-10 \text { to }+10)\end{array}$ & Rank \\
\hline Advisors & $6.25^{\mathrm{a}}$ & 1 & $6.80^{\mathrm{a}}$ & 1 & $6.75^{\mathrm{ab}}$ & 2 \\
\hline Research & $5.06^{\mathrm{b} *}$ & 3 & $6.27^{\mathrm{ab} *}$ & 2 & $6.83^{a *}$ & 1 \\
\hline Study club & $5.41^{\mathrm{b} *}$ & 2 & $5.94^{\mathrm{b} *}$ & 4 & $6.23^{\mathrm{b} *}$ & 4 \\
\hline Magazines & $4.85^{\mathrm{b} *}$ & 4 & $6.03^{b *}$ & 3 & $6.55^{\mathrm{ab} *}$ & 3 \\
\hline Fellow farmers & $4.81^{\mathrm{b}}$ & 5 & $4.74^{\mathrm{c}}$ & 5 & $5.07^{\mathrm{c}}$ & 5 \\
\hline MEAN & $5.28 *$ & & $5.96^{*}$ & & $6.29 *$ & \\
\hline
\end{tabular}




\section{Farmers' perceived behavioural control}

Considering the perceived behavioural control of Dutch arable farmers, the long-term effect of SOM was evaluated as the factor with the highest control strength and valuated most positively (Fig. 5.7). Availability and costs of organic inputs were considered more or less neutral in control power, while Dutch law on manure and fertiliser use (The Dutch Manure and Fertiliser Act) and crop rotations were considered to have a negative influence on SOM management.

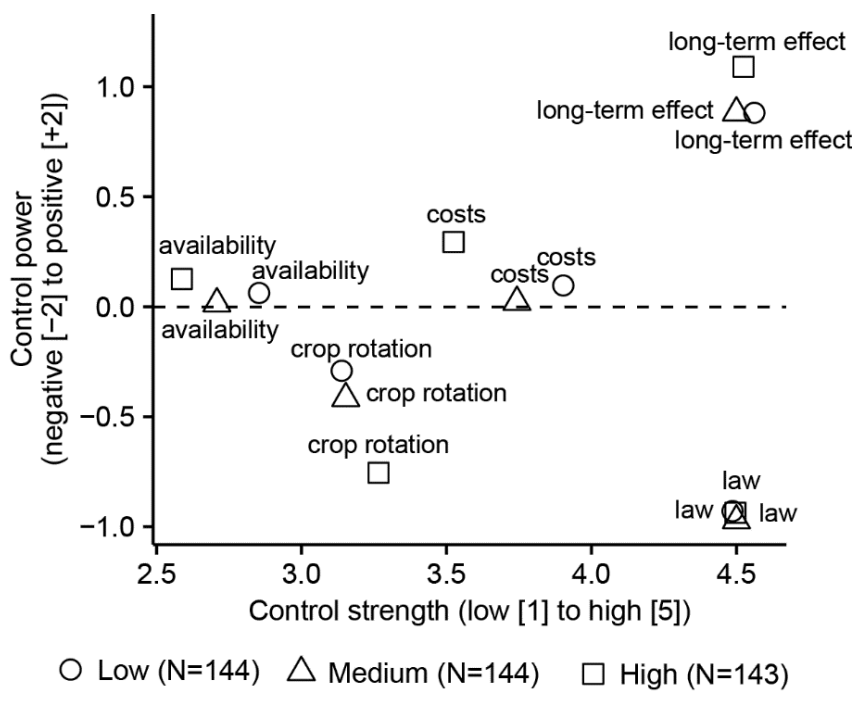

Fig 5. 7: Mean values of control strength related to control power. Crop rotation = crop rotation with specialized crops. Law = Dutch Manure and Fertiliser Act. Shapes indicate farm intensity.

There were some significant differences in perceived behavioural control, depending on farm intensity $(€ /$ ha). Farmers with high intensive farms were most positive on the longterm effect of SOM content. Farmers with medium intensive farms were most negative on the costs of organic inputs. Farmers with low intensive farms were least negative on the effects of specialized crops on the management of SOM. Overall perceived behavioural control was not significantly different across farm intensities (Table 5.4).

For low, medium and high intensive farms, control factors had exactly the same ranking in order of relevance. For all farm intensities, the Dutch Manure and Fertiliser Act was considered the most hampering factor, followed by crop rotations with specialized crops. 
Table 5. 4: Perceived behavioural control on SOM content by farmers (calculated using Equation 5.3). Farmers were divided into equally sized groups according to their farm intensity. Low intensive farms: $<2273.4 € /$ ha. Medium intensive farms: 2273.4 - $3062.4 \mathrm{E} / \mathrm{ha}$. High intensive farms: $>3062.44 \mathrm{E} / \mathrm{ha}$. A different uppercase letter indicates a significant difference within one column between control factors. * indicates a significant difference between at least two values for perceived behavioural control within one row (using the post hoc Conover-Iman test).

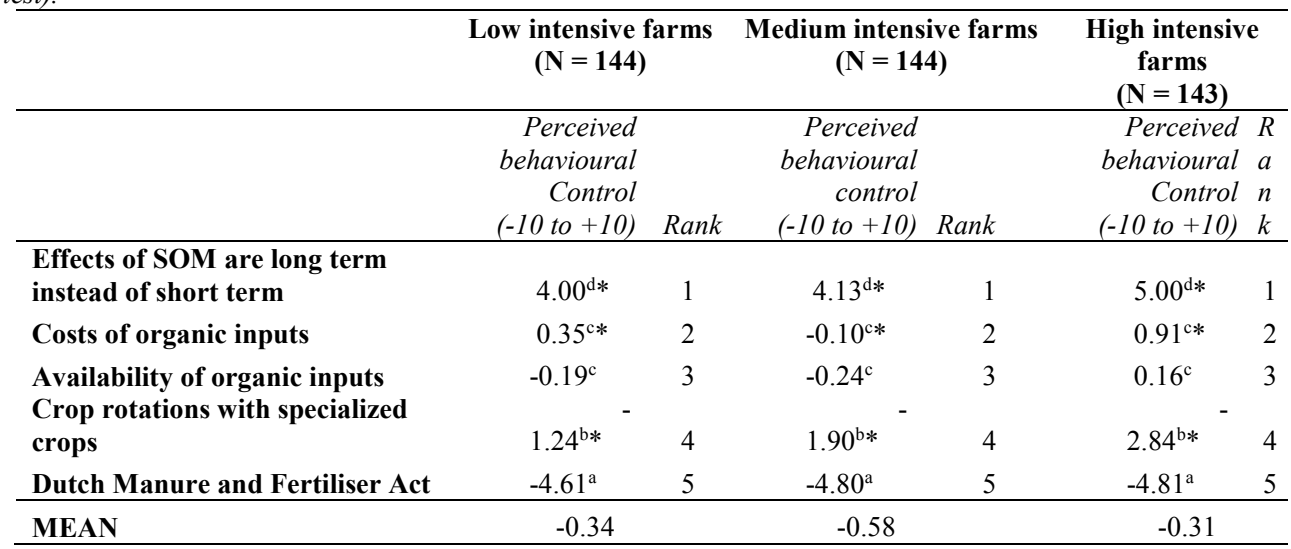

\subsubsection{Correlations between farmers' beliefs and farmers' intention to increase SOM}

Most Dutch farmers who participated in the survey stated an intention to increase SOM content $(90.1 \%)$. On a scale from 1 to $5,71.9 \%$ gave a 5 and $18.2 \%$ a 4 . Only $2.5 \%$ of the farmers did not want to increase SOM content of their fields (indicating either 1 or 2 on a scale of 5) and $7.4 \%$ of the farmers was neutral (indicating a 3 ).

In the previous sections, underlying beliefs of Dutch arable farmers on SOM were assessed. How are these underlying beliefs related to farmers' intention to increase SOM content? Almost all beliefs on outcomes and social referents were significantly but weakly related to farmers' intentions to increase SOM content. Beliefs on control factors were much less related to farmers' intentions to increase SOM content (Table 5.5)

For outcomes, (Table 5.5a), belief strengths and outcome valuations were more or less equally related to farmers' intention to increase SOM content (significant spearman Rho's between 0.15 and 0.30). The strongest relation was found between perceived increase in crop productivity and intention to increase SOM content.

There was a stronger correlation between normative beliefs of referents and farmers' intentions to increase SOM content than between the motivations to comply with those referents and farmers' intentions to increase SOM content (Table 5.5b, 0.22-0.33 vs 
0.11-0.16). Subjective norms based on advisors and study clubs were slightly stronger related with intentions to increase SOM content than the subjective norms of research, magazines and fellow farmers.

Table 5. 5: Correlations between farmers' intentions to increase SOM content and beliefs on expected outcomes, referents and control factors on increasing SOM content. Tests of significance were done using Spearman's rank correlation test. Numbers indicate Spearman's rho.

\begin{tabular}{|c|c|c|c|c|c|c|}
\hline & $\begin{array}{r}\text { Correlation } \\
\text { with } \\
\text { intention to } \\
\text { increase } \\
\text { SOM } \\
\end{array}$ & $P$ value & $\begin{array}{r}\text { Correlation } \\
\text { with } \\
\text { intention to } \\
\text { increase } \\
\text { SOM } \\
\end{array}$ & $P$ value & $\begin{array}{r}\text { Correlation } \\
\text { with } \\
\text { intention to } \\
\text { increase } \\
\text { SOM } \\
\end{array}$ & $P$ value \\
\hline A. Outcomes & \multicolumn{2}{|c|}{ Belief strength } & \multicolumn{2}{|c|}{ Outcome valuation } & & Attitude \\
\hline Improved soil structure & 0.21 & 0.000 & 0.29 & 0.000 & 0.28 & 0.000 \\
\hline Easy rooting & 0.16 & 0.001 & 0.26 & 0.000 & 0.24 & 0.000 \\
\hline Increased productivity & 0.30 & 0.000 & 0.26 & 0.000 & 0.32 & 0.000 \\
\hline Improved workability & 0.22 & 0.000 & 0.15 & 0.002 & 0.18 & 0.000 \\
\hline $\begin{array}{l}\text { Increased water holding } \\
\text { capacity }\end{array}$ & 0.18 & 0.000 & 0.29 & 0.000 & 0.27 & 0.000 \\
\hline More soil life & 0.18 & 0.000 & 0.26 & 0.000 & 0.24 & 0.000 \\
\hline Continuous nutrient release & 0.17 & 0.000 & 0.16 & 0.001 & 0.18 & 0.000 \\
\hline $\begin{array}{l}\text { Increased binding capacity of } \\
\text { nutrients }\end{array}$ & 0.21 & 0.000 & 0.27 & 0.000 & 0.26 & 0.000 \\
\hline Increase in soil fungi & -0.07 & 0.127 & 0.07 & 0.143 & 0.12 & 0.013 \\
\hline B. Referents & \multicolumn{2}{|c|}{ Normative belief } & \multicolumn{2}{|c|}{ Motivation to comply } & \multicolumn{2}{|c|}{ Subjective norm } \\
\hline Advisors & 0.33 & 0.000 & 0.13 & 0.006 & 0.29 & 0.000 \\
\hline Research & 0.25 & 0.000 & 0.08 & 0.084 & 0.21 & 0.000 \\
\hline Magazines & 0.25 & 0.000 & 0.16 & 0.001 & 0.24 & 0.000 \\
\hline Study clubs & 0.33 & 0.000 & 0.09 & 0.053 & 0.29 & 0.000 \\
\hline Fellow farmers & 0.22 & 0.000 & 0.11 & 0.027 & 0.21 & 0.000 \\
\hline C. Control factors & \multicolumn{2}{|c|}{ Control strength } & \multicolumn{2}{|c|}{ Control power } & \multicolumn{2}{|c|}{$\begin{array}{r}\text { Perceived behavioural } \\
\text { control }\end{array}$} \\
\hline $\begin{array}{l}\text { Effects of SOM are long term } \\
\text { instead of short term }\end{array}$ & 0.05 & 0.291 & 0.12 & 0.010 & 0.11 & 0.018 \\
\hline Costs of organic inputs & 0.10 & 0.043 & 0.15 & 0.002 & 0.13 & 0.007 \\
\hline Availability of organic inputs & 0.07 & 0.177 & -0.03 & 0.591 & -0.05 & 0.267 \\
\hline $\begin{array}{l}\text { Crop rotation with specialized } \\
\text { crops }\end{array}$ & 0.15 & 0.002 & -0.11 & 0.021 & -0.13 & 0.008 \\
\hline Dutch Manure and Fertiliser Act & 0.19 & 0.000 & -0.08 & 0.091 & -0.06 & 0.212 \\
\hline
\end{tabular}


Control factors were not or only weakly related with farmers' intention to increase SOM content (Table 5.5c, significant numbers ranging between -0.11 to 0.19 ). Significant relations between perceived behavioural control and intentions to increase SOM content were only found for costs of organic inputs, long-term effects of SOM and crop rotations with specialized crops. This indicates that despite low availability of organic inputs or the restrictions of the Dutch Manure and Fertiliser Act, farmers still have the intention to increase SOM content. If they succeed in doing so is a different question.

\subsubsection{Correlations between farmers' intention to increase SOM and actual use of organic inputs}

Comparing farmers' intention to increase SOM content with their use of organic inputs, a positive correlation was found with the use of slurry and compost $(p=0.044$ and $p=0.035$ respectively, Table $5.6 \mathrm{c}$ ).

Table 5. 6: Actual use of organic inputs by farmers with different intentions to increase SOM content. For incorporation of straw, only farmers for which the mentioned cereal is included in their crop rotation are shown. $P$ values below 0.05 indicate a significant positive trend between a intention to increase SOM and the use of an organic input (straw - spearman rank correlation test, all others - Jonckheere-Terpstra trend test).

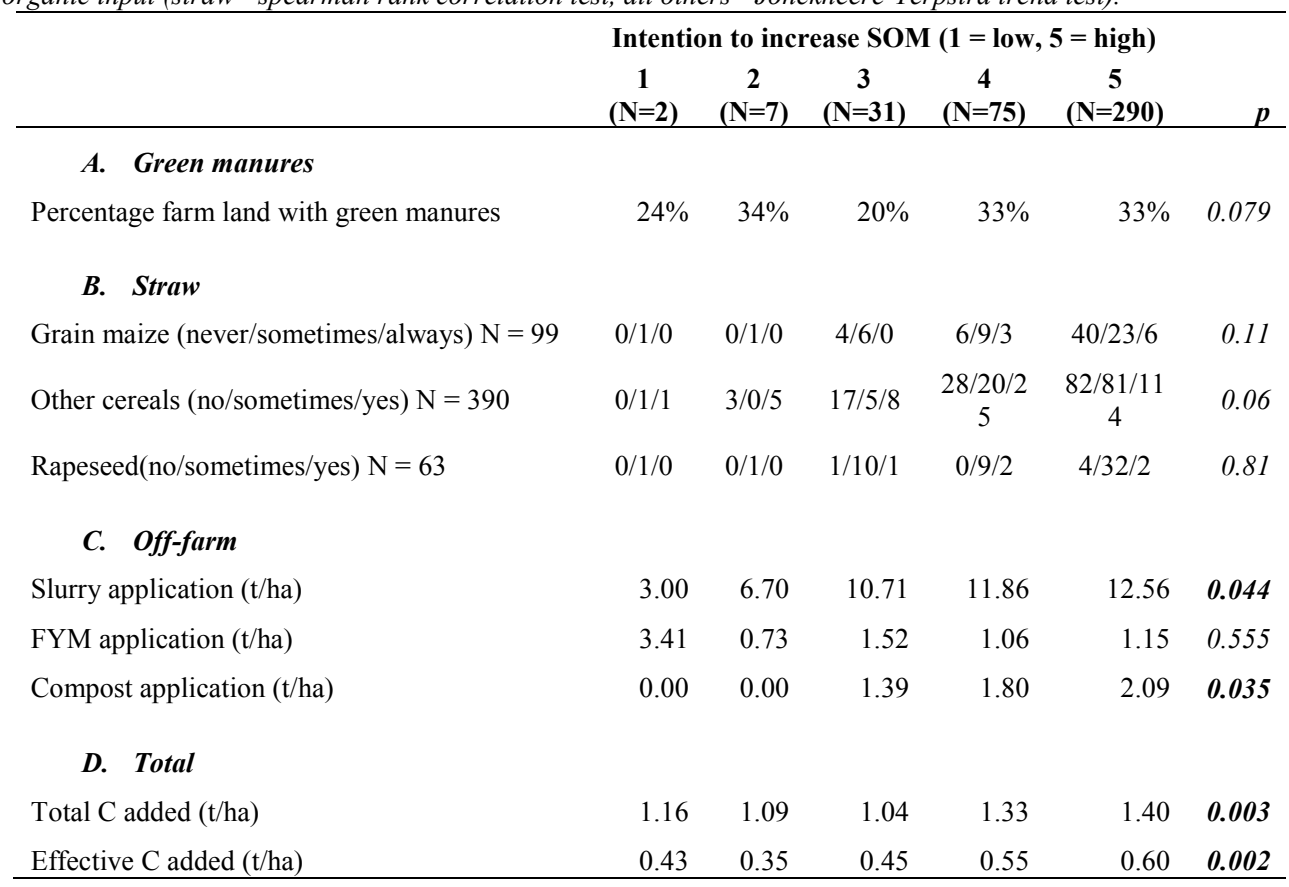


When converting all organic inputs into total $\mathrm{C}$ added or total effective $\mathrm{C}$ added (Table $5.6 \mathrm{~d}$ ), in both cases application amounts increased with higher intentions to increase SOM content ( $p=0.003$ and $p=0.002$ respectively).

\subsubsection{Correlations between perceived change in SOM, perceived behavioural control, intentions to increase SOM and use of organic inputs}

Farmers also indicated if SOM contents on their farm increased or decreased. Asked if SOM content was decreasing on their farms, on a scale from 1 to 5 , only $1 \%$ indicated a 5 (meaning large decrease of SOM content). Following, 11\% of the farmers indicated to perceive some decrease. Around one third (33.6\%) of the farmers gave a neutral indication, while the majority ( $55 \%$ of the farmers) indicated a 1 or a 2 , meaning that the SOM content of their farms was stable or increasing.

Perceived change in SOM content was significantly related to the perceived behavioural control of farmers (Table 5.7, significant numbers ranging between -0.22 and 0.25 ). Among the different control factors, perceiving the Dutch Manure and Fertiliser Act as a strong obstacle was strongest related with perceived trends in SOM content.

Table 5. 7: Correlations between farmers' beliefs on control factors and perceived increase in SOM content. Tests of significance are done using Spearman's rank correlation test. Numbers indicate Spearman's rho.

\begin{tabular}{|c|c|c|c|c|c|c|}
\hline & $\begin{array}{r}\text { Correlation } \\
\text { with } \\
\text { perceived } \\
\text { increase in } \\
\text { SOM } \\
\end{array}$ & $P$ value & $\begin{array}{r}\text { Correlation } \\
\text { with } \\
\text { perceived } \\
\text { increase in } \\
\text { SOM } \\
\end{array}$ & $P$ value & $\begin{array}{r}\text { Correlatio } \\
\text { n with } \\
\text { perceived } \\
\text { increase in } \\
\text { SOM } \\
\end{array}$ & $P$ value \\
\hline Control factors & \multicolumn{2}{|c|}{ Control strength } & \multicolumn{2}{|c|}{ Control power } & \multicolumn{2}{|c|}{$\begin{array}{r}\text { Perceived behavioural } \\
\text { control }\end{array}$} \\
\hline $\begin{array}{l}\text { Effects of SOM are long term } \\
\text { instead of short term }\end{array}$ & 0.04 & 0.392 & 0.21 & 0.000 & 0.17 & 0.000 \\
\hline Costs of organic inputs & -0.11 & 0.021 & 0.11 & 0.024 & 0.11 & 0.024 \\
\hline Availability of organic inputs & -0.22 & 0.000 & 0.09 & 0.059 & 0.05 & 0.310 \\
\hline $\begin{array}{l}\text { Crop rotation with specialized } \\
\text { crops }\end{array}$ & -0.16 & 0.001 & 0.12 & 0.013 & 0.13 & 0.008 \\
\hline $\begin{array}{l}\text { Dutch Manure and Fertiliser } \\
\text { Act }\end{array}$ & -0.19 & 0.000 & 0.25 & 0.000 & 0.24 & 0.000 \\
\hline
\end{tabular}

No correlation was found between the use of organic inputs and perceived increase in SOM (Fig. 5.8). This might be due to the time it takes before organic inputs have an effect on SOM content and thus before any change will be perceived by the farmers (for 
example through soil analyses) - this can take decades. At the same time, the lack of correlation also illustrates how difficult it can be for farmers to increase SOM content.

There was a weak but significant negative correlation between perceived increase in SOM and the intention to increase SOM content (Spearman's Rho -0.16). The more SOM content was perceived to decrease, the higher was farmers' intention to increase SOM content. Thus, a perceived decrease in SOM content can lead to a higher intention to increase SOM content, which again can lead to an increase in the use of organic inputs (Fig. 5.8). In addition, a significant correlation was found between perceived behavioural control and perceived increase (or decrease) of SOM content, highlighting the apparent importance of control factors on the long term.

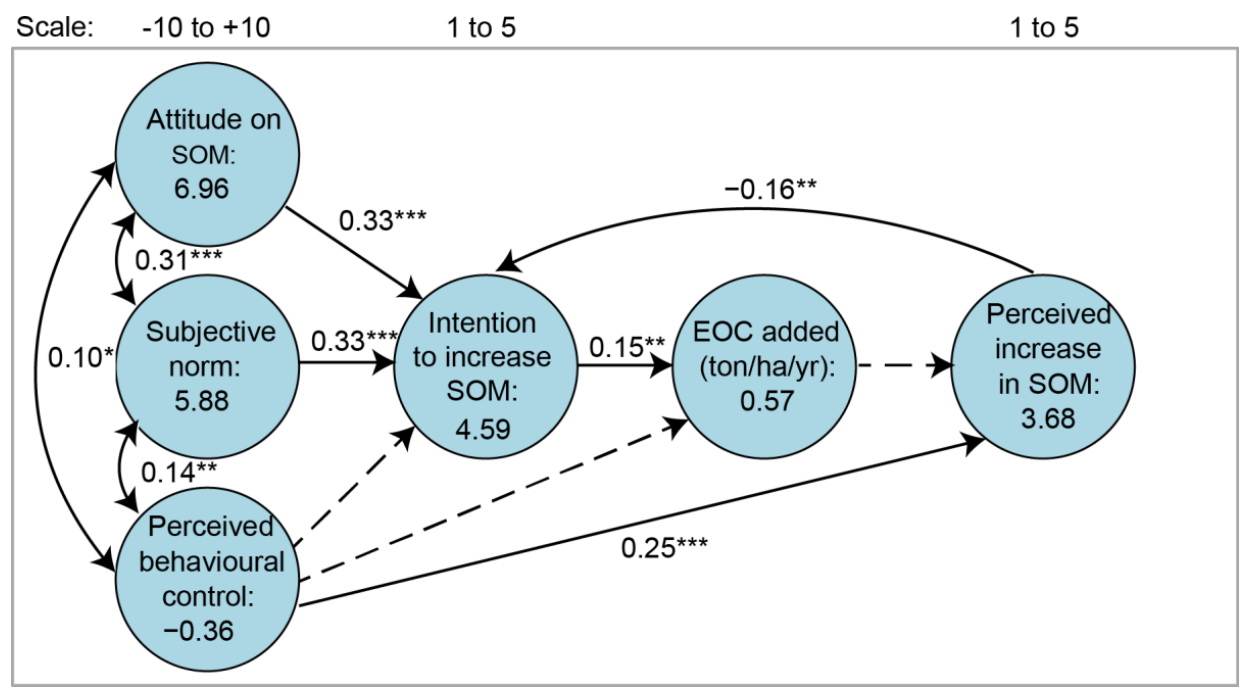

Fig 5. 8: Correlations between farmers' attitude, subjective norm, perceived behavioural control, intention to increase SOM and perceived increase of SOM using Spearman's rank correlation test. Numbers in circles indicate mean values. Numbers besides arrows give correlation coefficients (Spearman's rho). Numbers at top of figure indicate potential ranges. Dotted lines indicate relations with no significant correlation. Stars show confidence level of correlation coefficients (* means $P<0.05$. ** means $P<0.01$

\subsection{Discussion}

The 435 Dutch arable farmers included in the analysis of this study were somewhat younger and had larger farms (both in total land area cultivated and economic size) than average Dutch arable farmers. The differences were however small. In addition, SOM contents of farmers' soils corresponded very well with the average for the Netherlands 
(3.6 vs 3.5\% SOM). The outcomes of this study could therefore be considered representative for the larger population of Dutch arable farmers.

In the Netherlands, farmers usually have sufficient access to mineral fertilisers (Eurostat 2012; Potter et al. 2010). It is therefore not surprising that Dutch farmers value nutrient release and nutrient binding capacity of SOM the least (Table 5.2 and Fig. 5.4): they do not primarily rely on these functions of SOM for crop production. Farmers value the effect of SOM content on soil structure more, especially where it improves workability on clay soils and water holding capacity on sandy soils. In this respect, farmers' views align well with findings from field experiments (Barzegar et al. 2002; Hamza \& Anderson 2005; Rawls et al. 2003; Soane 1990; Watts \& Dexter 1997).

Farmers with a higher intention to increase SOM content used significantly more compost and slurry $(P=0.035$ and 0.044 respectively $)$ and applied significantly more total $\mathrm{C}$ and effective $\mathrm{C}$ to their soils $(P=0.003$ and 0.002 respectively). We however found that the use of organic inputs was not directly related to a perceived increase in SOM content. Increasing SOM content by using organic inputs often takes many years or even decades (Körschens et al. 2013), which could be one explanation for this lack of correlation.

Comparing farm intensities, farmers with high intensive farms (with the highest economic output per ha), value the long-term effect of SOM more than medium or low intensive farms and see the costs of organic inputs as less of a constraint (Table 5.4). At the same time, farmers with more intensive farms cultivate more specialized crops (including root and tuber crops), which makes it more difficult for them to increase SOM content. This can be an additional challenge considering root and tuber crops depend more on a good soil structure for successful crop growth than cereals (Verheijen 2005b). Over the past decades, the ratio of gross margins between specialized crops and cereals has gone up (KWIN 2015), thereby making crop rotations with higher shares of cereals economically challenging.

Comparing age groups, younger farmers were less motivated to comply with social referents than older farmers, especially when it comes to messages received from research, farmers' magazines and study clubs (Fig. 5.6). In general, advisors were perceived to be most positive about increasing SOM content, especially compared with fellow farmers, who were perceived to be the least positive. 
This study looked specifically at farmers' beliefs in increasing SOM content in the Netherlands. In the Netherlands there is a large supply of animal manure due to the presence of a relatively large livestock sector (Oenema \& Berentsen 2004), making this a relatively cheap source of nutrients. In addition, costs of fertilizers are low relative to land prices in the Netherlands. Therefore, in other countries nutrient supply of SOM and costs of organic inputs might play a larger role.

\subsection{Conclusion}

Using the theory of planned behaviour, this study has gained insight into the underlying beliefs of farmers to increase SOM content. We found that Dutch arable farmers are well aware of the benefits of SOM. Most Dutch farmers also have a positive subjective norm on SOM (rating 5.84 on a scale from -10 to +10 ). Advisors seem most positive on increasing SOM content, whilst Dutch arable farmers are most motivated to comply with findings from research.

Farmers' attitude, subjective norm and perceived decrease in SOM content were significantly related to their intention to increase SOM content (Fig. 5.8). In our farm survey, this intention was very strong: $90.1 \%$ of the farmers stated a high or very high intention to increase SOM content of their fields.

In contrast, perceived behavioural control had no significant correlation with farmers' intention to increase SOM content. Perceived behavioural control did have a significant positive correlation with perceived increase in SOM content. From a farmers point of view, this indicates that increase of SOM content is to a large degree beyond their direct influence. Important impeding factors on SOM management were found to be the Dutch Manure and Fertiliser Act and need for crop rotations with specialized crops.

Currently, Dutch and European laws on manure and fertiliser use mainly focus on reducing nutrient leaching to surface waters, not necessarily enhancing organic matter applications. There is however potential to re-use organic wastes with low nutrient contents to arable land (van der Kolk \& Zwart 2013). Meyer-Kohlstock et al. (2015) recently found that only one third of biowaste is used as compost in Europe. International policies to increase SOM content could therefore start by investigating how the availability of organic inputs can be increased by facilitating the use of organic wastes. Meyer-Kohlstock et al. (2015) recommend setting recycling targets and implementation of collection systems. In addition, incentives are needed for farmers to 
cultivate crops in a more balanced crop rotation, i.e. a higher share of cereals or other crops which are beneficial for SOM content.

\subsection{Acknowledgements}

We thank all Dutch farmers who participated in the online farm survey. Gratitude goes to Rob Smidt for extracting farmers' addresses from the database and to Bert Rijk for supporting survey logistics. We thank Greet Ruysschaert, Marian Vlaswinkel, Joske Houtkamp, Mark Kronen, Jan Reimer and Zwier van der Vegte for testing our questionnaire and giving useful suggestions for improvement. Finally, thanks to all our colleagues in the $\mathrm{CATCH}-\mathrm{C}$ project for the pleasant collaboration. 


\section{Supplement Chapter 5}

Supplementary Fig. 5.1 Soil texture map of the Netherlands

Supplementary Table 5.1 Conversion coefficients for $\mathrm{C}$ and effective $\mathrm{C}$ contents of organic inputs

\section{Soil texture map of the Netherlands}

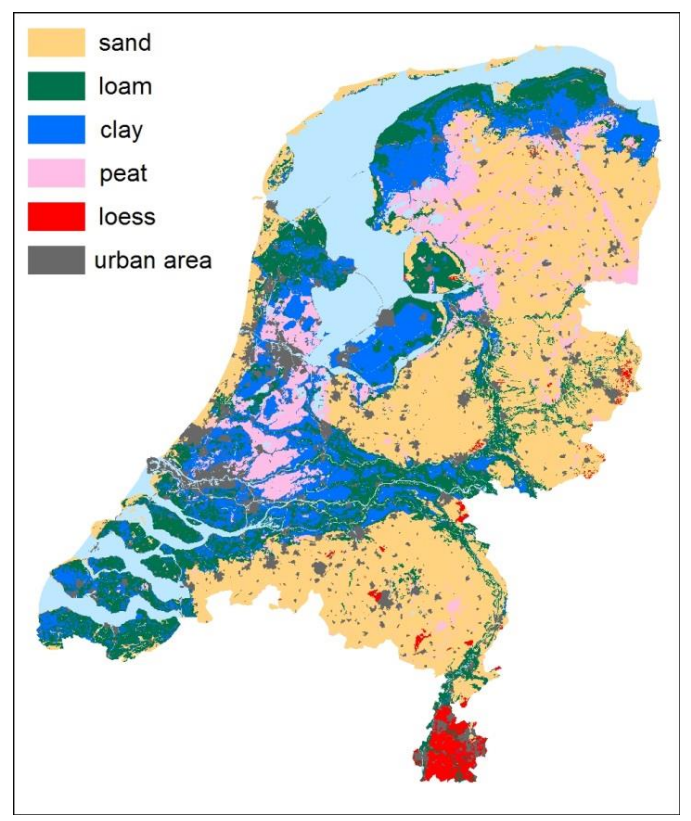

Supplementary Fig. 5. 1: Soil texture map of the Netherlands. Sampling area for this study includes farmers on sand, loam and clay soils. Figure is adapted from the Dutch soil map (WUR-Alterra, 2006). 


\section{Conversion coefficients for $C$ and effective $C$ contents of organic inputs}

Supplementary Table 5. 1: Conversion coefficients for calculating total and effective $C$ content of organic inputs. If estimates of biomass or $C$ content are based on multiple literature sources, averages are taken. Where information was absent, carbon content of dry organic plant material is assumed to be 0.425 tonne $C$ per tonne dry organic matter (Janssen, 2002). FM = Fresh matter.

\begin{tabular}{|c|c|c|c|c|}
\hline \multirow[b]{2}{*}{ On-farm } & \multicolumn{2}{|c|}{ Conversion coefficients } & \multirow[t]{2}{*}{ Comments } & \multirow[t]{2}{*}{ References } \\
\hline & $\begin{array}{r}\text { Total C } \\
\text { (tonnes } \\
\mathrm{C} / \mathrm{ha} \text { ) }\end{array}$ & $\begin{array}{r}\text { Effective C } \\
\text { (tonnes effective } \\
\mathrm{C} / \mathrm{ha} \text { ) }\end{array}$ & & \\
\hline Green manures & 1.28 & 0.34 & $\begin{array}{l}\text { For each ha } \\
\text { cultivated with } \\
\text { green manures }\end{array}$ & $\begin{array}{l}\text { (De Jonge } 1981 \text { as cited by } \\
\text { Dekker et al. 2004; Florentín } \\
\text { 2011; Timmer et al. 2004) }\end{array}$ \\
\hline Straw from maize & 1.60 & 0.57 & $\begin{array}{l}\text { For each ha } \\
\text { cultivated with } \\
\text { maize, when } \\
\text { incorporated }\end{array}$ & $\begin{array}{l}\text { On biomass estimates: } \\
\text { (LNE 2009) } \\
\text { On straw to grain ratios:(De } \\
\text { Jonge } 1981 \text { as cited by Dekker et } \\
\text { al. 2004; Fleischer et al. 1989; Lal } \\
\text { 1995) }\end{array}$ \\
\hline $\begin{array}{l}\text { Straw from other } \\
\text { cereals (such as } \\
\text { wheat, barley, rye, } \\
\text { oat, triticale) }\end{array}$ & 1.63 & 0.54 & $\begin{array}{l}\text { For each ha } \\
\text { cultivated with } \\
\text { cereals, when } \\
\text { incorporated }\end{array}$ & $\begin{array}{l}\text { On biomass estimates: } \\
\text { (KWIN 2015; LNE 2009) } \\
\text { On straw to grain ratios: } \\
\text { (Bauder 2000; De Jonge 1981 as } \\
\text { cited by Dekker et al. 2004; Lal } \\
\text { 1995) }\end{array}$ \\
\hline $\begin{array}{l}\text { Straw from } \\
\text { rapeseed }\end{array}$ & 1.15 & 0.40 & $\begin{array}{l}\text { For each ha } \\
\text { cultivated with } \\
\text { rapeseed, } \\
\text { when } \\
\text { incorporated }\end{array}$ & $\begin{array}{l}\text { On biomass estimates: } \\
\text { (KWIN 2015) } \\
\text { On straw to grain ratios: } \\
\text { (De Jonge } 1981 \text { as cited by } \\
\text { Dekker et al. } 2004 \text {; Lal 1995) }\end{array}$ \\
\hline Off-farm & $\begin{array}{r}\text { (tonne } \\
\mathrm{C} / \text { tonne } \mathrm{FM} \\
\text { organic } \\
\text { input) }\end{array}$ & $\begin{array}{r}\text { (tonne effective } \\
\mathrm{C} / \text { tonne FM } \\
\text { organic input) }\end{array}$ & & \\
\hline Slurry & 0.03 & 0.011 & & $\begin{array}{l}\text { (CBAV 2017; de Vries 2014; } \\
\text { LNE 2009; Pronk \& Korevaar } \\
\text { 2008) }\end{array}$ \\
\hline FYM & 0.08 & 0.044 & & $\begin{array}{l}\text { (De Jonge } 1981 \text { as cited by CBAV } \\
\text { 2017; De Vries et al. 2012; } \\
\text { Dekker et al. 2004; LNE 2009; } \\
\text { Pronk \& Korevaar 2008) }\end{array}$ \\
\hline Compost & 0.10 & 0.093 & & $\begin{array}{l}\text { (De Jong } 1981 \text { as cited by CBAV } \\
\text { 2017; Dekker et al. 2004; LNE } \\
\text { 2009; Pronk \& Korevaar 2008) }\end{array}$ \\
\hline
\end{tabular}




\section{Chapter 6}

\section{Do farmers perceive a deficiency of soil organic matter? A European and farm level analysis}

Renske Hijbeek ${ }^{1}$, Anouk Cormont ${ }^{2}$, Gerard Hazeu ${ }^{3}$, Luca Bechini ${ }^{4}$, Laura Zavattaro ${ }^{5}$, Bert Janssen ${ }^{1}$, Magdalena Werner ${ }^{6}$, Norman Schlatter ${ }^{7}$, Gema Guzmán ${ }^{8}$, Jo Bijttebier ${ }^{9}$, Annette A. Pronk ${ }^{10}$, Michiel van Eupen ${ }^{2}$, Martin K. van Ittersum ${ }^{1}$

${ }^{1}$ Plant Production Systems, Wageningen Plant Research, Wageningen University and Research, the Netherlands

${ }^{2}$ Earth informatics, Wageningen Environmental Research, Wageningen University and Research, the Netherlands

${ }^{3}$ Spatial Knowledge Systems, Wageningen Environmental Research, Wageningen University and Research, the Netherlands

${ }^{4}$ Department of Agricultural and Environmental Sciences, Università degli Studi di Milano, Italy

${ }^{5}$ Department of Agricultural Forest and Food Sciences, Università degli Studi di Torino, Italy

${ }^{6}$ Centre of Biodiversity and Sustainable Land Use, University of Göttingen, Germany

${ }^{7}$ Department for Soil Health and Plant Nutrition, Austrian Agency for Health and Food Safety, Austria.

${ }^{8}$ Department of Agronomy, University of Cordoba, Spain

${ }^{9}$ Flanders research institute for agriculture, fisheries and food, Belgium

${ }^{10}$ Agrosystems Research, Wageningen University and Research, the Netherlands

Ecological Indicators (2017) 83: 390-403 


\begin{abstract}
Agricultural soils with too little soil organic matter (SOM) content are characterized by fertility problems. A number of authors have tried to specify threshold values for SOM content to indicate what is 'too little', ranging from 1 to $5 \%$, below which yields may be affected. How much SOM content is sufficient, however, depends on a number of environmental factors. In addition, up to date farmers' perceptions were not included when developing thresholds. Therefore, this study focuses on the following three objectives: (1) to put forward a risk indicator for SOM deficiency based on environmental factors and agricultural land use; (2) to test the risk indicator using farmers' perceptions and (3) to establish threshold values for SOM content based on farmers' perceptions.
\end{abstract}

For objective 1, literature was reviewed on effects of environmental factors and land use on SOM deficiency. Findings were combined into nine options for a risk indicator on SOM deficiency, mapped at European scale. For objective 2, a farm survey was done among 1452 arable farmers in five European countries (Belgium, Germany, Austria, Spain and Italy). Associations between perceived deficiency of SOM by farmers and environmental factors, land use and the risk indicator were investigated. For objective 3 , farmers' perceptions on SOM deficiency were related to the average SOM content of their fields.

Mapping the risk indicator at European scale gives a high to very high risk of SOM deficiency for 7 to $37 \%$ of European agricultural land, mainly located in Southern and Eastern Europe. Of the farmers in our survey, $18 \%$ perceived a high to very high SOM deficiency. A weak correlation was found between the risk indicator and farmers' perceptions of SOM deficiency (0.15-0.18, Spearman's rank correlation). Stronger relations were found between separate environmental factors and perceived SOM deficiency. Apparently, having a more extreme environmental condition for one factor gives a higher chance of perceiving a deficiency of SOM than a combination of moderate environmental conditions. Based on farmers' perceptions threshold intervals for SOM content were established (sand: $1.2-4.7 \%$, loam: $0.6-2.6 \%$ and clay: 1.0 $2.4 \%)$.

If policies on SOM management want to include benefits for crop production, targeting areas with a relatively high risk of SOM deficiency, more extreme environmental conditions or with very low SOM contents (below the given threshold intervals) seems most promising. 
Keywords: soil organic matter; soil organic carbon; productive capacity; risk indicator; farmers' perceptions; SOM deficiency; threshold value; critical level; land use; arable farming; Europe; crops; agriculture

\section{Abbreviations}

IQR inter-quartile range

L lower extreme: lowest point observed within Q1 - $(1.5 * \mathrm{IQR})$ and Q3 + $(1.5 * \mathrm{IQR})$

$\mathrm{L}_{\mathrm{L}} \quad$ lower extreme for the range of SOM contents of farmers with a low perceived deficiency of SOM

LVL lower extreme for the range of SOM contents of farmers with a very low perceived deficiency of SOM

Q1 first quartile

Q3 third quartile

SOM soil organic matter

$\mathrm{U} \quad$ upper extreme: highest point observed within Q1 - $(1.5 * \mathrm{IQR})$ and Q3 + $(1.5 * \mathrm{IQR})$

$\mathrm{U}_{\mathrm{H}} \quad$ upper extreme of the range of SOM contents of farmers with a high perceived deficiency of SOM

$\mathrm{U}_{\mathrm{VH}} \quad$ upper extremes of the range of SOM content of farmers with a very high perceived deficiency of SOM

\subsection{Introduction}

Percentages of soil organic matter (SOM) in soils vary widely, from below $1 \%$ for some sandy soils, to almost $100 \%$ for certain peat soils (Loveland \& Webb 2003). When pastures or forests are converted to arable land, SOM content decreases often to less than $10 \%$ SOM, depending on soil texture, climate, land use and management (Verheijen 2005b). This decrease in SOM also reduces the global carbon stock (Smith 2004), which could be an incentive to maintain or increase SOM content in arable soils above certain levels, especially if this improves productive capacity. 
SOM improves a number of soil properties relevant for productive capacity such as soil structure, water holding capacity and buffering of nutrients (Hudson 1994; Johnston et al. 2009; Oades 1984). Farming on soils with a loose soil structure, low water holding capacity or low availability of nutrients can generate less profit, which would be an incentive for farmers to maintain SOM content above certain threshold values (Gardner $\&$ Barrows 1985; Kimetu et al. 2008; Scrimgeour \& Shepherd 1998). At the same time, demands for organic inputs (such as straw) are increasing with new markets for bioenergy and renewable materials emerging (Nicholson et al. 2014).

With a decrease in SOM content, most soil properties change along a continuum (Karlen et al. 2001), making it difficult to define a critical or desirable $\mathrm{C}$ content for farmers (Sparling et al. 2003). Even so, for the percentage of SOM to be a useful indicator for productive capacity, target values need to be specified. Sparling et al. (2003) argue in favour of a minimum or threshold soil $\mathrm{C}$ value: "below which there would be loss of desirable soil characteristics, productive capacity and ecological functions that were not readily restored within an acceptable timeframe". This study follows this definition, focussing mainly on the relevance for productive capacity. With sufficient supply of external inputs or when target yields are low, threshold values will mostly depend on the contribution of SOM to stability of soil structure and related ease of cultivation (Janssen \& De Willigen 2006).

Setting threshold values can be an important guide for farmers to improve their management and for policy makers when providing farm subsidies. A number of authors have tried to specify minimum or threshold values for SOM for crop production (also called critical levels), using a range of approaches such as information from soil surveys, literature reviews, soil organic carbon modelling, expert opinions or a combination of these. Table 6.1 shows a summary of these threshold values. Often, values mentioned by authors are very tentative. When based on experiments, threshold values are often related to observed losses in aggregate stability or direct losses in yield.

When threshold values depend on soil texture, typically higher values are given for soils with more clay or fine silt particles. How much SOM is needed however will probably not only depend on soil texture, but also on other environmental factors (such as slope or climate) and land use (types of crops cultivated). 


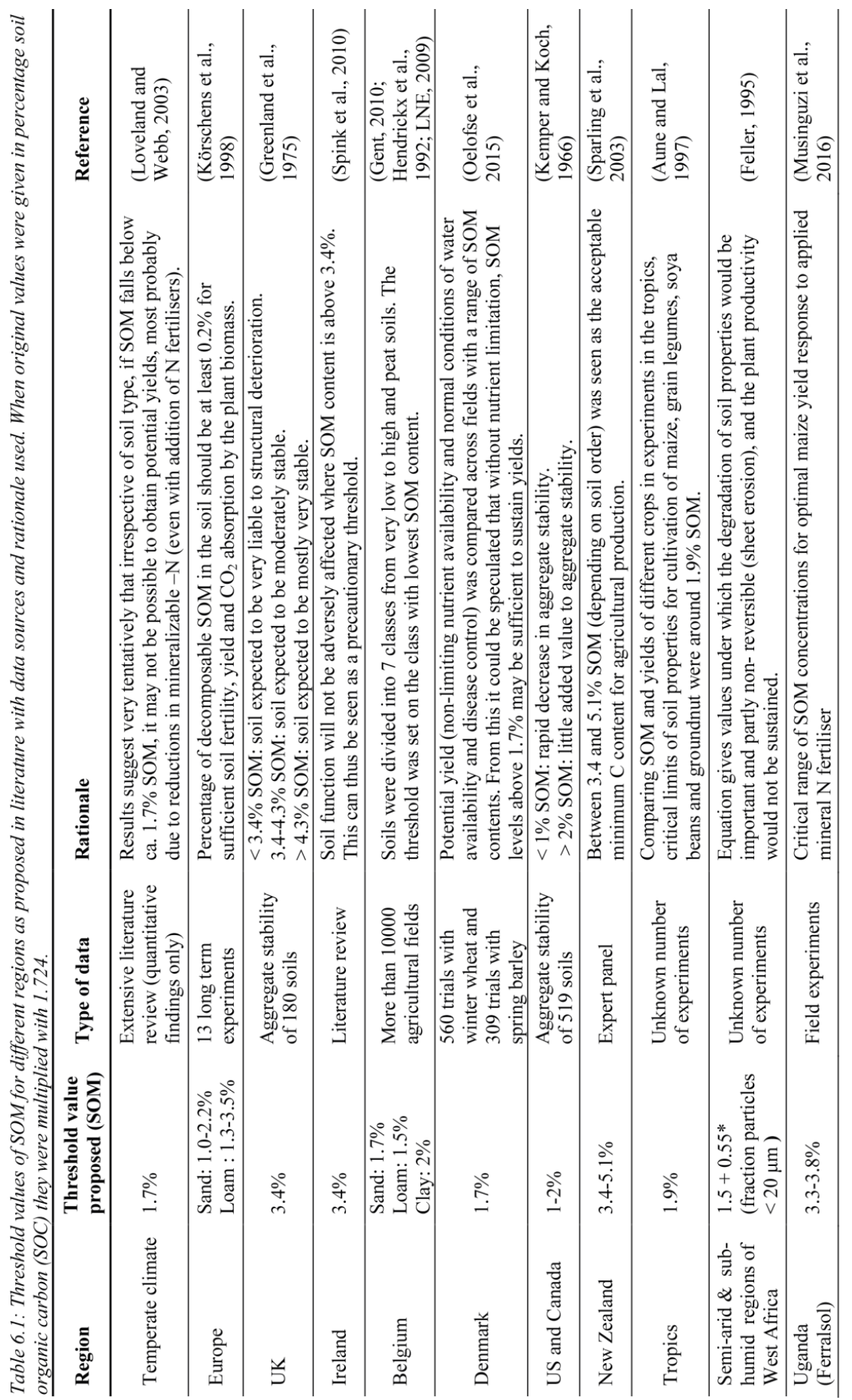


Furthermore, none of the studies asked farmers for their views whilst farmers are the group of stakeholders with the longest and most practical exposure to SOM of their fields.

For targeted and effective policies on SOM management, more insight is needed under which circumstances increases in SOM content benefit the productive capacity of soils. It is hereby imperative to base this insight not only on results from experimental fields, but also on farmers' knowledge and perceptions. Currently, it is unclear which areas have a high risk of SOM deficiency for productive capacity and farmers' knowledge has not been included when proposing thresholds for SOM content in agricultural soils.

Therefore, this study focuses on the following three research objectives:

1. To put forward a risk indicator for SOM deficiency based on environmental factors and land use.

2. To test the risk indicator using farmers' perceptions.

3. To establish threshold values for SOM content based on farmers' perceptions.

Objectives 1 and 3 give insight where policies on SOM management can increase productive capacities of soils, whilst objective 2 brings together farmers' knowledge and existing scientific evidence.

\subsection{Methodology}

For objective 1, literature was reviewed on the influence of different environmental factors and land use on the relationship between SOM content and productive capacity. Effects of environmental factors and land use were combined into an aggregated risk indicator on SOM deficiency, mapped at European scale (Section 6.2.1).

For objectives 2 and 3, a farm survey was conducted to estimate farmers' perceptions on SOM deficiency of their fields. Following, farmers' perceptions were related to environmental factors, land use, the combined risk indicator and the average SOM content of farmers' fields (Section 6.2.2).

\subsubsection{Developing a risk indicator on SOM deficiency}

In this study, a higher risk of SOM deficiency indicates that with similar soil management, a farmer has an increased chance of perceiving a reduction in productive capacity due to low SOM contents compared to a farmer with a lower risk of SOM 
deficiency. A reduction in productive capacity might be observed directly (e.g. lower yields) or indirectly (reduced workability of the soil). From this definition it follows that specific problems perceived by the farmer due to SOM deficiency (e.g. concerning soil structure) can be solved by increasing SOM content. The risk of SOM deficiency for the productive capacity of agricultural soils depends on environmental conditions and land use. In this paper, we aim to define a risk indicator on SOM deficiency with a scale from 1 to 5 .

To develop a risk indicator on SOM deficiency (objective 1), a number of consecutive steps were followed. First scientific literature was reviewed to find effects of environmental factors and land use on the risk of SOM deficiency. Following, findings were used to define a risk indicator on SOM deficiency. Finally, the risk indicator on SOM deficiency was mapped at European scale. Each step is explained below.

Literature review on effects of environmental factors and land use on SOM and risk of SOM deficiency

Relevant environmental factors for SOM deficiency were identified based on three criteria: 1) The factor is not changed by human management (therefore shaping the context in which farmers have to operate); 2) Datasets have to be available at European scale; 3) Literature has to be available on how the environmental factor influences the relation between SOM content and productive capacity. Following these criteria, the following three environmental factors were selected: land slope, soil texture, and climate.

Soil texture was chosen to describe soil types instead of soil taxonomy classes for a number of reasons: 1) Soil classifications schemes such as the World Reference Base for Soil Resources (ISSS Working Group, WRB 1998) have many taxonomy classes (WRB has 32 main groups) which makes statistical analyses difficult. 2) We wanted to compare the risk indicator with farmers' perceptions in which case we relied on farmers' descriptions of soils. Farmers are more aware of their soil texture than of the scientific names given to their soil profiles. 3) Soil textures have more easily understandable relations with aggregate stability, water holding capacity and productive capacity than do soil classifications.

Scientific literature was searched using online search engines (Google scholar, ISI Web of knowledge) to find how these different factors plus land use (types of crops cultivated) influence the effect of SOM content on productive capacity. Based on the 
literature, two types of effects on the relation between SOM and productive capacity were identified for each environmental factor and land use: 1) a direct effect on actual SOM content (e.g. wetter climates slow down decomposition rates) and 2) an indirect effect on how likely it will be that SOM affects productive capacity (e.g. wetter climates give a higher chance on soil compaction which SOM might alleviate). The second effect illustrates that in some conditions, SOM will have a larger contribution to productive capacity than others. The difference between the two types of effects is schematically shown in Fig 6.1.

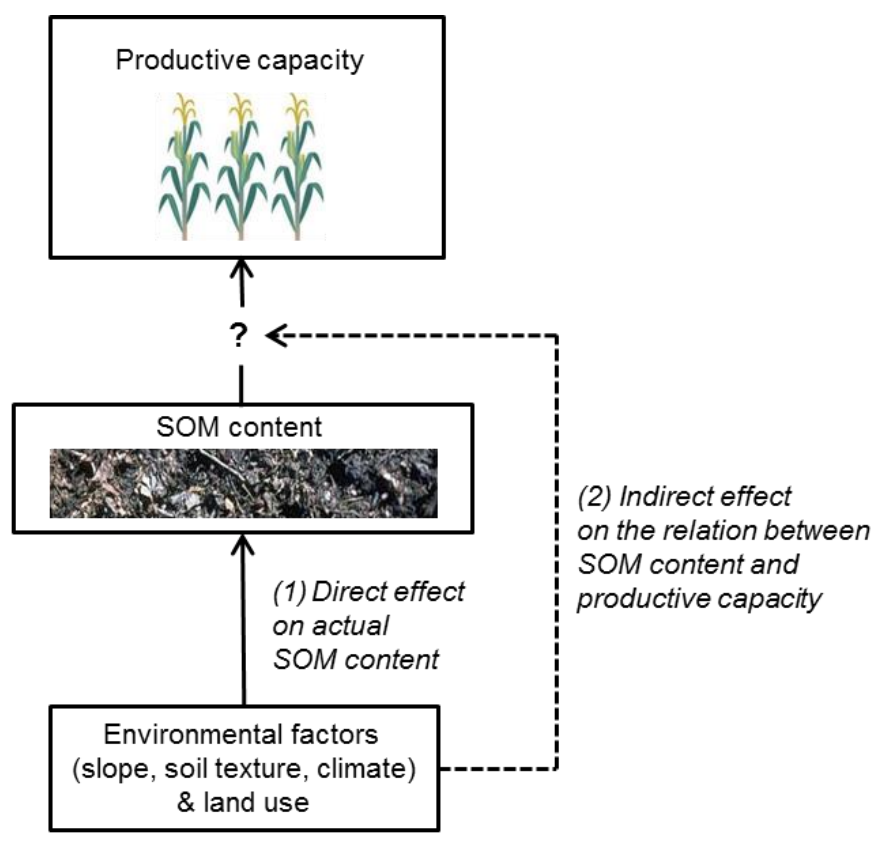

Fig 6. 1: Schematic overview of two types of effects of environmental factors and land use on the relation between SOM and productive capacity: (1) a direct effect on actual SOM content and (2) an indirect effect on the possible contribution of SOM content to productive capacity. Corn figure adapted from Thomas (2010).

In the following four paragraphs, the specific effects of each environmental factor and land use are described. A summary of the literature findings is given per effect type in Table 6.2. Often, findings were described in trends rather than precise magnitudes. Therefore, qualitative diagrams were drawn for each factor, showing an increase, decrease or parabolic curve along an environmental spectrum (Fig 6.2). 


\section{Slope effect}

Soils on steeper slopes often have less SOM while they would benefit more from the soil structural effects of SOM content and steeper slopes are more prone to erosion (Fox $\&$ Bryan 2000; Gregorich et al. 1998). Erosion causes a loss of soil and thus SOM, while SOM itself can reduce runoff by increasing porosity and enhancing aggregate stability, both diminishing surface sealing and promoting infiltration rates (Benito \& Diaz-Fierros 1992; Malinda 1995; Rhoton et al. 2002). Therefore, soils on steeper slopes are expected to have a higher risk of SOM deficiency to maintain productive capacity (Fig 6.2a)

\section{Soil texture effect}

SOM content improves structures of both very heavy and very light soils. Light sandy soils normally have a loose soil structure, which can be improved by adding organic inputs (Chaney \& Swift 1986; Johnston et al. 2009; Tisdall \& Oades 1982). SOM binds more easily to clay particles and therefore, on average, clay soils have a higher SOM content (Körschens et al. 1998; Reeves 1997; Verheijen et al. 2005). When clay soils are very heavy, however, they are - despite the higher SOM contents - more prone to soil compaction. Soil compaction causes mechanical impedance for root growth and inadequate aeration (Janssen \& van der Weert 1977; Wiersum 1957). Increasing SOM contents can reduce compaction of soils (Soane 1990). Therefore, soils at both ends of the soil texture spectrum are expected to have a higher risk of SOM deficiency than in the middle (Fig 6.2b).

\section{Climate effect}

Soil productivity benefits from SOM in both very dry and very wet climates. For crops cultivated in hot and dry areas, SOM increases water holding capacity (Díaz-Zorita et al. 1999). In wet climates, SOM prevents soil compaction and water logging (Soane 1990). At the same time, soils in cold and wet climates are expected to have more SOM content due to slower decomposition (Gonçalves \& Carlyle 1994; Verheijen 2005b). Yet apparently, effects of reduced decomposition are often not sufficient to prevent compaction. Therefore, a parabolic relationship is proposed between aridity and risk of SOM deficiency (Fig 6.2c).

\section{Land use effect (types of crops cultivated)}

The type of crops a farmer cultivates (i.e. land use) has an effect on the SOM balance, whilst also determining the dependence on soil structure for crop growth. 


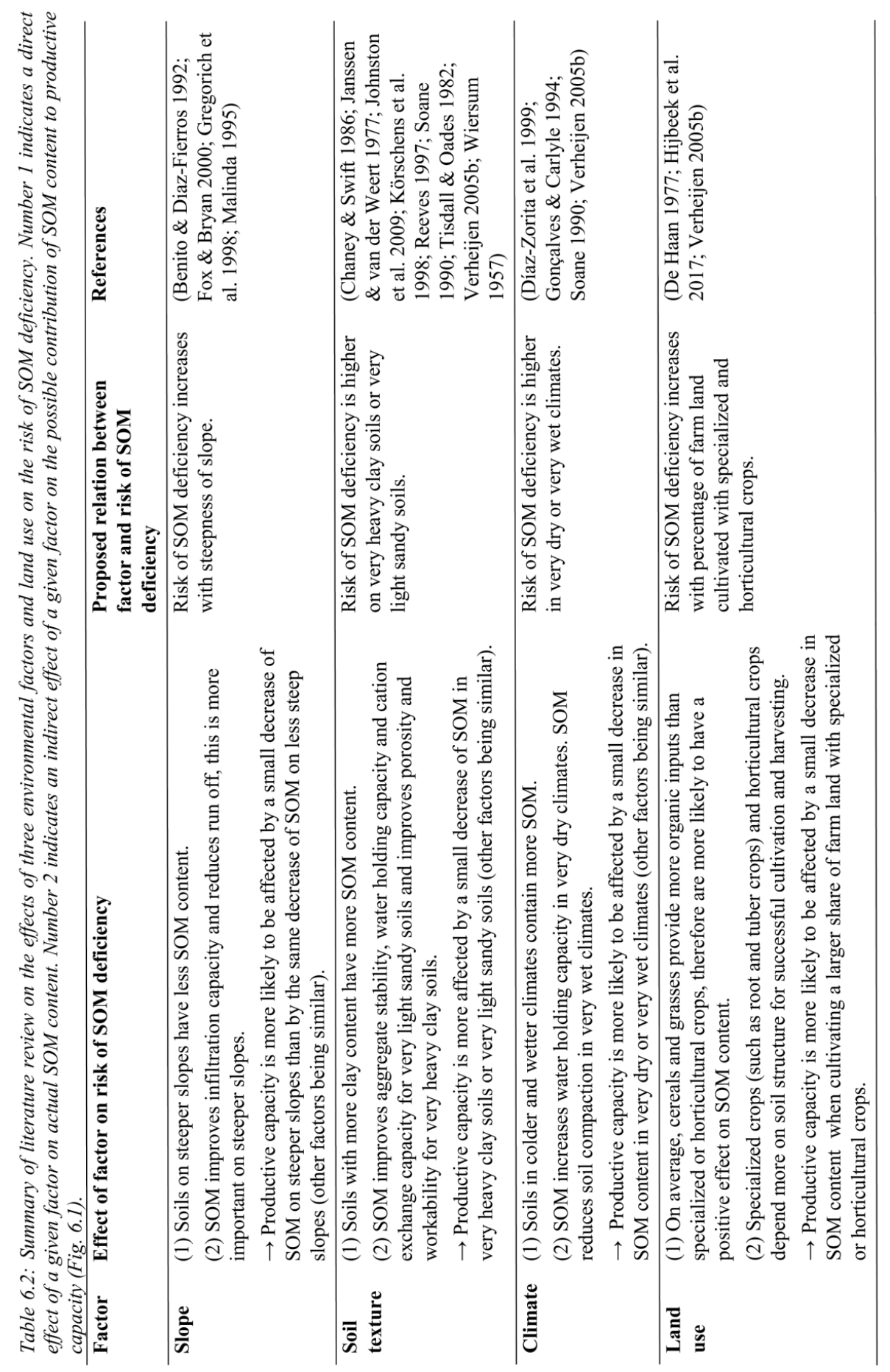


In general, cereals and grass provide more crop residues (root, stubble, leaves) which can be returned to the field as organic inputs than specialized or horticultural crops (such as root or tuber crops, legumes or flowers (Zwart et al. 2013)).In addition, most specialized and horticultural crops have a less developed root system and therefore depend more on a better soil structure for their successful cultivation and harvesting (De Haan 1977; Hijbeek et al. 2017; Verheijen 2005b). Specialized and horticultural crops thus contribute less to the amount of SOM content whilst benefiting more from it. Therefore, soils with more specialized and/or horticultural crops than cereals are expected to have a higher risk of SOM deficiency (Fig 6.2d).
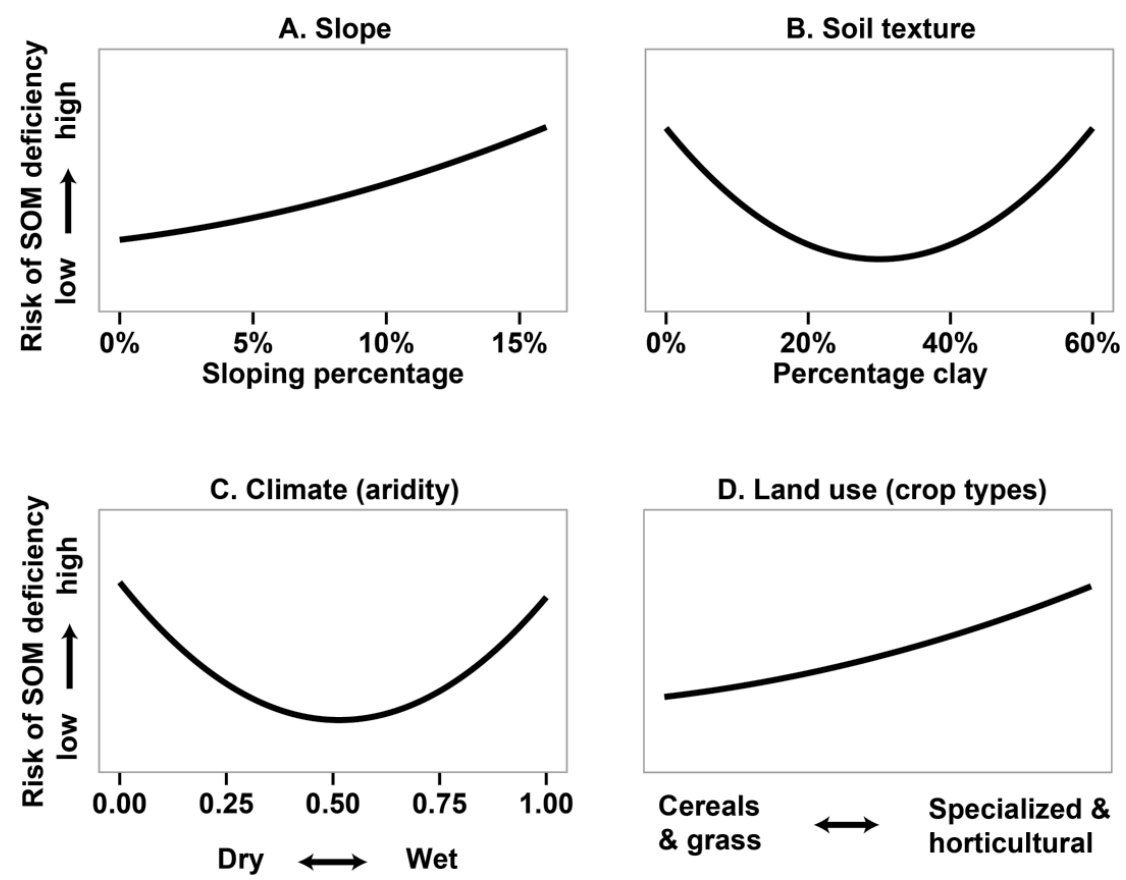

Fig 6. 2: Proposed relationships between environmental factors and land use and risk of SOM deficiency, based on literature. X-axes show ranges of different environmental factors and land use. Y-axes show risk of SOM deficiency

\section{Combining effects of environmental factors and land use into a risk indicator}

Environmental effects and land use do not affect SOM deficiency in solitude, but interact with each other. For example, a farmer will probably have a higher risk of SOM deficiency on a sandy soil when the farm is on a steep slope than on level land. This risk will again be different, depending on land use or climate. 
Effects of all four factors (Fig. 6.2) interact with each other. Therefore, effects of different environmental factors and land use were combined into a risk indicator on SOM deficiency. This risk indicator gives a risk score of SOM deficiency for each combination of slope, soil texture, climate and land use on a scale of 1 to 5 .

To calculate the risk indicator, effects of environmental factors and land use were added one by one using expert views. First, effects of soil texture and land slope were combined into a soil risk score. Each combination of soil texture and slope was given a score between 1 and 5, where 1 indicates a very low soil risk of SOM deficiency (e.g. a loamy soil with no slope) and 5 a very high soil risk of SOM deficiency (e.g. a sandy soil on a steep slope). Assigning the numbers 1 to 5 included some arbitrary choices. To reduce the effect of this arbitrariness, three types of combination options were proposed, resulting in a low, medium and high estimate for soil risk (Supplementary Tables 6.16.3 , page 155$)$.

Second, soil risk scores were combined with aridity into an environmental risk score. Each combination of a soil risk and a degree of aridity was given a score between 1 and 5. Again, 1 indicates a very low environmental risk of SOM deficiency (e.g. a low soil risk with an intermediate climate) and 5 a very high environmental risk of SOM deficiency (e.g. high soil risk with a very dry climate). Again, three types of combination options were proposed, resulting in a low, medium and high estimate for environmental risk (Supplementary Tables 6.4-6.6, page 156).

Finally, environmental risk scores were combined with type of land use into a total risk score on SOM deficiency. Each combination of environmental risk and land use was given a score between 1 and 5, where 1 indicates a very low risk of SOM deficiency (e.g. low environmental risk with cereals or grass) and 5 a very high risk of SOM deficiency (e.g. high environmental risk with specialized crops). One combination option was proposed, in which cereals and grass reduce the risk and specialized and horticultural crops increase the risk of SOM deficiency (Supplementary Table 6.7, page 157).

A flow diagram of the procedure to combine the different factors into a risk indicator is shown in Fig. 6.3. The procedure resulted in nine different versions of the risk indicator ( 3 options for soil risk $\mathrm{x} 3$ options for environmental risk $\mathrm{x} 1$ option for the effect of land use). 


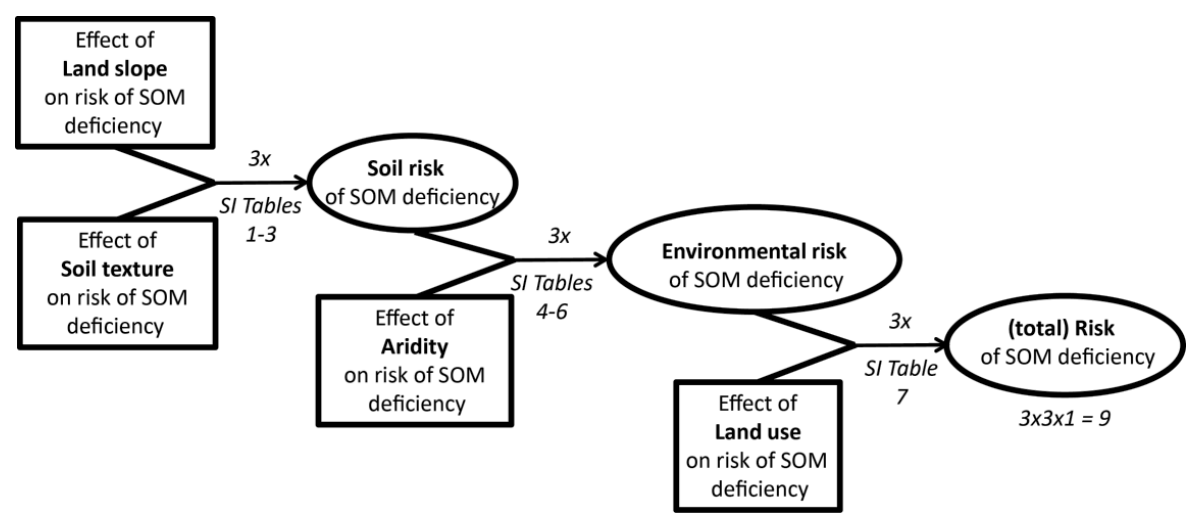

Fig 6. 3: Flow diagram of the procedure followed to combine effects of different factors into a risk indicator on SOM deficiency. SI = Supplementary Information.

\section{Creating a spatial overview of the risk of SOM deficiency in Europe}

To create a spatial overview on risk of SOM deficiency in Europe, a dataset was needed for each environmental factor and land use. For slope, the GTOPO30 (a global elevation dataset; USGS 1996) was used. For soil texture, the European Soil Database (EC \& ESBN 2004) was selected. For climate, the degree of aridity was calculated by dividing annual precipitation with potential evapotranspiration, using spatialized climatic data for the period 1975-2009 (Janssen et al. 2009). For land use, the land use dimension of the European farm typology as developed by Andersen et al. (2007) was used.

Datasets were combined spatially using QUICKScan (Verweij et al. 2016). For each data pixel $\left(\mathrm{km}^{2}\right)$, QUICKScan used the rules from Supplementary Tables 6.1-6.7 and calculated a combined risk score on SOM deficiency. This resulted in nine maps showing estimated risk of SOM deficiency with European coverage.

\subsubsection{Perceived deficiency of SOM by farmers}

To test the risk indicator (objective 2) and to establish threshold values for SOM content (objective 3), a farm survey was held in five European countries. Respondents came from a wide range of soil types, climate zones and land uses across Europe. By doing so, we capitalized on many years of practical farming experience across different soils and SOM contents. 
All farmers were asked if they perceived a deficiency of SOM on a Likert scale from 1 to 5 (very low to very high SOM deficiency). This number is a holistic measurement of SOM deficiency perceived by farmers. Farmers' perceptions might be based on many aspects (experience, observations, information, instinct, tacit knowledge), which they translate into one number. Underlying mechanisms and disadvantages of insufficient SOM (such as little water holding capacity, poor soil structure, little nutrient supply) all play a role, but in this study are aggregated together into one term (SOM deficiency).

As seen in Fig 6.1, environmental factors and land use affect the relation between SOM and productivity in two ways: (1) a direct effect on actual SOM content (e.g. wetter climates slow down decomposition rates) and (2) an indirect effect on how likely it will be that SOM affects productive capacity (e.g. wetter climates give a higher chance on soil compaction which SOM might alleviate). To account for both mechanisms, first, average SOM contents of farms were related to environmental factors and land use. Then, perceived deficiency of SOM was related to environmental factors and land use separately and to the risk indicator. In this manner, we compared scientific findings on the influence of environmental factors and land use on SOM deficiency with farmers' practical experience. Next, perceived deficiency of SOM was related to the average SOM content of each farm to find threshold values. Finally, farmers with a very high or very low perceived deficiency of SOM were clustered around gradients of environmental factors and land use. Each of these steps is explained in more detail below. All data was processed in R (version 3.2.5).

\section{Farm survey}

A large-scale farm survey was held in five European countries (Belgium, Germany, Austria, Spain and Italy). This survey was sent out as part of a European research project CATCH-C. The sampling for the questionnaires depended on the availability of a valid sampling frame within each country (i.e. contact details of farmers). The most ideal sampling frame to obtain a completely random sample is a nation-wide database of farmers' addresses. Such a database was available for Flanders in Belgium and some states in Germany. In the other countries, researchers had to depend on farmers' associations, farmers' extension services or other contacts to distribute the questionnaire. Questionnaires were distributed online (Austria), as paper questionnaire (Belgium and Italy), or both (Germany and Spain). In Spain questionnaires were only distributed in Andalusia. 
Questionnaires were returned during the summer and autumn of 2013. Filled questionnaires were checked on irregularities (typing mistakes or extreme numbers) and if any, removed from analysis. Because of the specific nature of peat soils (Lucas, 1982), farmers reporting peat soils or reporting an average SOM content above $12 \%$ were excluded from analysis. To reduce errors in farmers' answers, farmers were not obliged to fill out every question. If a farmer was uncertain of the SOM content of their soils, they could tick the option: "I do not know". Questions on slope or land use information could also be left unanswered. In those cases, only the filled parts of the questionnaire were used in the analysis.

\section{Relating SOM contents to environmental factors and land use}

Environmental factors and land use are known to affect SOM content (Fox \& Bryan 2000; Gonçalves \& Carlyle 1994; Gregorich et al. 1998; Körschens et al. 1998; Verheijen et al. 2005). SOM contents of farmers' fields in our survey were related to the factors identified above (slope, soil texture, climate and land use) to assess if patterns are similar as found in the literature.

Farmers were asked to declare the average SOM content of their fields and to report different soil textures present on their farm, slopes of their land and types of crops cultivated. Farms were then classified according to their dominant soil textural class (largest percentage of farm land in a certain soil texture class), dominant slope (largest percentage farm land with a certain slope) and land use type ( $>50 \%$ farm land with cereals and/or grass; $>50 \%$ with specialized and/or horticultural crops; a mix of these two categories and forage crops). Supplementary Table 6.8 (page 157) gives an overview of the crops cultivated by the farmers in our survey and how they were classified. Farm locations were used to calculate an aridity index.

For each environmental factor, similar classes were used as in the risk indicator (Supplementary Tables 6.1-6.7). Following, ranges of SOM contents were calculated for each class. Because SOM contents among farms did not have a normal distribution (distribution was slightly skewed to the right), group medians were compared using the non-parametric Kruskal-Wallis test (Conover 1971; Pohlert 2014). If applicable, a posthoc Nemenyi test was used to see which group medians differed (Sachs 1997).

\section{Relating perceived deficiency of SOM to environmental factors and land use}

Perceived deficiency of SOM by farmers was compared with patterns found in the literature. Frequency distributions of SOM deficiency (expressed on a 1 to 5 Likert 
scale) were made, classifying farmers by their soil texture, slope, climate or land use. For each environmental factor and land use, similar classes were used as in the risk indicator (Supplementary Tables 6.1-6.7). Following, a non-parametric test using ordinal data, the Jonckheere-Terpstra test (Jonckheere 1954; Seshan 2012) was done to assess if trends in perceived SOM deficiency by farmers followed similar patterns as found in the literature (Fig 6.2).

\section{Relating perceived deficiency of SOM to the risk indicator}

Using the indicator developed in Section 2.1.2, a risk of SOM deficiency was calculated for each farmer. To assess if a high risk indication also corresponds with a high perceived deficiency of SOM by farmers, a Spearman's rank correlation test (Kendall 1948) was performed.

\section{Establishing threshold intervals of SOM based on farmers' perceptions}

Can threshold values for SOM be determined, based on farmers' perceptions? To find the answer to this question, SOM contents of farms were related to perceived deficiency of SOM. First, farmers were classified according to their perceived deficiency of SOM: very low, low, neutral, high, or very high perceived deficiency of SOM. A low or very low perceived deficiency of SOM means farmers have a positive perception on the SOM content of their fields, while a high or very high perceived deficiency of SOM means farmers have a negative perception on the SOM content of their fields. Ranges of SOM contents were calculated for each level of SOM deficiency (from very low to very high).

Because SOM contents did not have a normal distribution, inter-quartile ranges were used to calculate lower and upper extremes (Frigge et al. 1989; McGill et al. 1978). With this non-parametric method, the distance between the first quartile (Q1) and the third quartile $(\mathrm{Q} 3)$ is the inter-quartile range (IQR). Values lower than Q1 $-\left(1.5^{*} \mathrm{IQR}\right)$ and higher than $\mathrm{Q} 3+\left(1.5^{*} \mathrm{IQR}\right)$ were considered outliers. Causes for numbers to be an outlier can be either extreme soil conditions or mistakes in the recordings. The upper extreme is the highest SOM value not being an outlier. The lower extreme is the lowest SOM value not being an outlier.

Based on the lower extremes of farmers with a low perceived deficiency of SOM and the upper extremes of farmers with a high perceived deficiency of SOM, threshold intervals for SOM were calculated for each soil textural class. Below each interval, farmers perceive a neutral, high or very high deficiency of SOM. Above each interval, farmers perceive a neutral, low or very low deficiency of SOM. 


\section{Clustering farmers along gradients of environmental factors and land use}

Below a certain SOM content, farmers could be found with any perceived degree of SOM deficiency (from very low to very high SOM deficiency). At these low SOM contents, different farmers might have the same SOM content, one perceiving a very low deficiency of SOM and the other a very high deficiency of SOM. Using only farmers with a low SOM content and with either a very high or very low perceived deficiency of SOM, a principal component analysis was done to find possible causes. Instead of using classes for each environmental factor or land use type, for the principal component analysis continuous variables were used. For soil texture, the percentage of farm land with sandy soils was used as a variable. For slope, the percentage of land with moderate or steep slopes was used. For land use, the percentage of farm land cultivated with specialized or horticultural crops was used. As climate could not be converted into a continuous variable at farm level, it was left out of the principal component analysis.

\subsection{Results}

\subsubsection{A spatial overview of the risk of SOM deficiency in Europe}

Fig 6.4 shows the spatial distribution of estimated risk of SOM deficiency in Europe, using nine different manners of combining environmental factors and land use. This figure is based on four datasets (Section 6.1.1) that are combined following the scheme of Fig 6.3.

Depending on the manner in which environmental factors and land use are combined (Supplementary Tables 6.1 to 6.7), 7 to 37\% of agricultural land in Europe has a high or very high risk of SOM deficiency (Fig. 6.4). It is self-evident that combining high estimates for soil risks and high estimates for environmental risks gives the largest share of a high total risk of SOM deficiency.

Higher estimates for soil or environmental risk might give a larger share of agricultural land with a higher risk of SOM deficiency, the distribution between areas is very similar (Fig 6.4). On all maps, soils with a high or very high risk of SOM deficiency are mainly located in southern and eastern European countries (in areas with drier climates, steeper slopes, coarse soils and/or more cultivation of specialized or horticultural crops). Soils with a lower risk of SOM deficiency are mainly located northern and western European countries. 


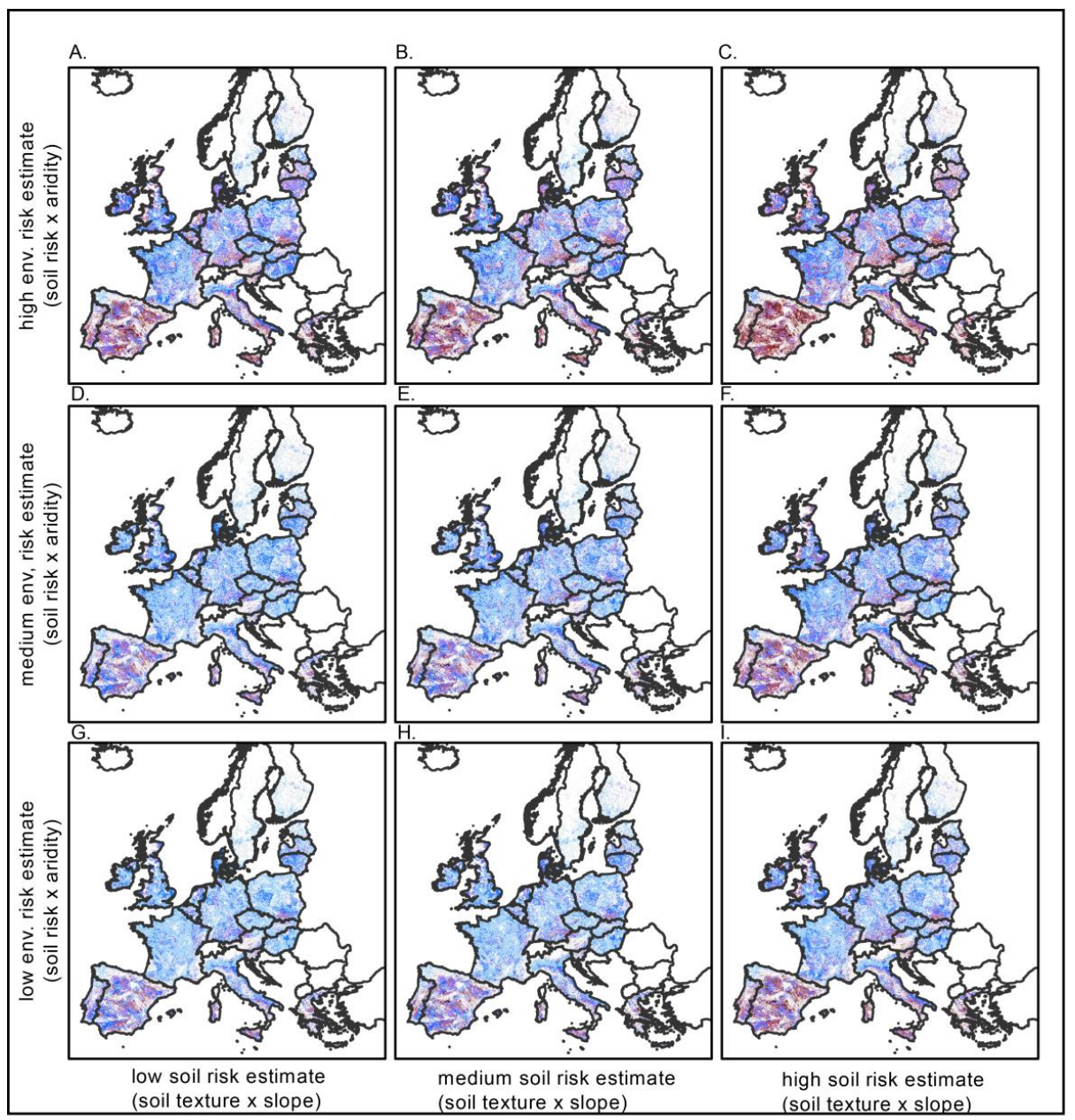

\begin{tabular}{ll}
\multicolumn{1}{c}{$\begin{array}{c}\text { Soil risk estimate } \\
\text { (soil texture } x \text { slope) }\end{array}$} & $\begin{array}{l}\text { Env. risk } \\
\text { (soil risk }\end{array}$ \\
A. Low & Low \\
B. Medium & Low \\
C. High & Low \\
D. Low & Medium \\
E. Medium & Medium \\
F. High & Medium \\
G. Low & High \\
H. Medium & High \\
I. High & High
\end{tabular}

$$
\text { (total) Risk of SOM deficiency: very low low average high } \square \text { very high }
$$

Fig 6. 4 Percentage of European agricultural land area with a low to very high risk of SOM deficiency within each of the nine risk indicator options. Maps are obtained following the procedure of Fig. 6.3. 


\subsubsection{Perceived deficiency of SOM by farmers}

\section{Respondents to farm survey}

In total 1642 arable farmers (all cultivating more than 50\% of their farm land with arable crops) responded to the farm survey. Seventeen respondents were removed from analysis because of irregularities in answers. An additional 83 farmers reported to have peat soils and/or had an average SOM content above $12 \%$ and were also excluded from analysis. A summary of farm characteristics per country is provided in Supplementary Table 6.9 (page 158).

Not all farmers provided information on slope, soil texture and land use (Table 6.3). In total 1447 farmers provided information on slope, 1481 on soil texture and 1466 on land use. For all farmers included in the analysis (1542) an aridity index was calculated. Using the information on environmental factors and land use, a risk indication on SOM deficiency was calculated for 1371 farmers. In addition, 683 farmers reported an average SOM content, while 1469 farmers gave an indication of perceived deficiency of SOM. Relatively more farmers from Austria and Germany reported SOM contents than did farmers from Belgium, Italy and Spain (respectively, 68\%, 62\%, 42\%, 34\% and 22\%), probably because in Austria and Germany soil analyses are more common.

Table 6.3: Numbers of farmers providing specific information in the farm survey. In total 1542 farmers were included in the analysis. To reduce errors, farmers could leave questions unanswered, therefore numbers differ per category.

\begin{tabular}{|c|c|c|c|c|}
\hline & $\begin{array}{r}\text { Total } \\
\text { (n) }\end{array}$ & $\begin{array}{r}\text { Farmers } \\
\text { providing } \\
\text { average SOM } \\
\text { content }(n)\end{array}$ & $\begin{array}{r}\text { Farmers } \\
\text { providing } \\
\text { perceived } \\
\text { deficiency of } \\
\text { SOM (n) }\end{array}$ & $\begin{array}{r}\text { Farmers } \\
\text { providing } \\
\text { average SOM } \\
\text { content and } \\
\text { perceived } \\
\text { deficiency of } \\
\text { SOM (n) } \\
\end{array}$ \\
\hline Farmers with information on slope & 1447 & 665 & 1402 & 657 \\
\hline Farmers with information on soil texture & 1481 & 680 & 1433 & 672 \\
\hline Farmers with an aridity index calculated & 1542 & 683 & 1469 & 675 \\
\hline $\begin{array}{l}\text { Farmers with information on land use } \\
\text { Farmers for which risk indicator can be } \\
\text { calculated }\end{array}$ & 1466 & 668 & 1411 & 660 \\
\hline
\end{tabular}

SOM contents related to environmental factors and land use

SOM contents reported by farmers in the survey were very variable, ranging from 0.5 to $11.6 \%$ SOM (mean $2.6 \%$, median $2.2 \%$, standard deviation $1.3 \%$ ). This indicates that our survey covered a wide range of conditions. In Section 2.1.1, the effects of environmental factors and land use on the risk of SOM deficiency were discussed, 
including effects on actual SOM content. How do SOM contents reported by our farmers vary with environmental factors and land use? In Fig 6.5, SOM contents of farmers' fields are related to their slope, soil texture, aridity and land use.

\section{A. Slope}

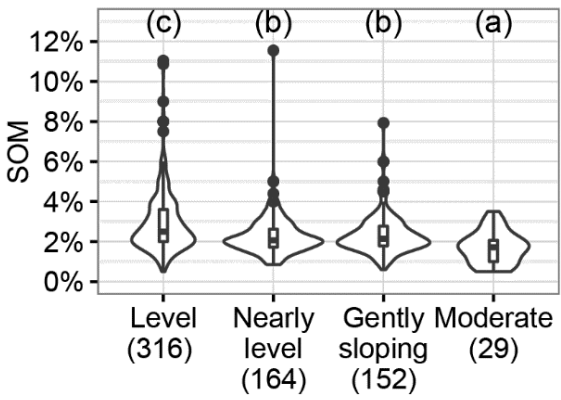

C. Climate

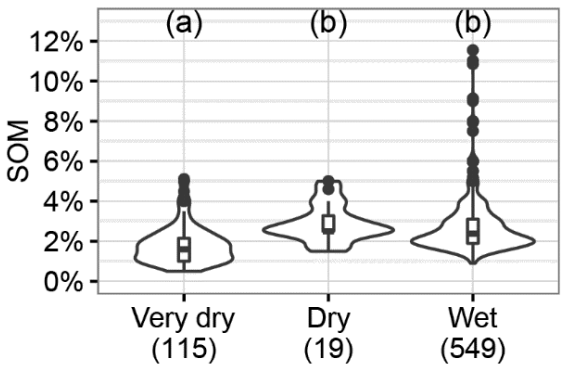

B. Soil texture

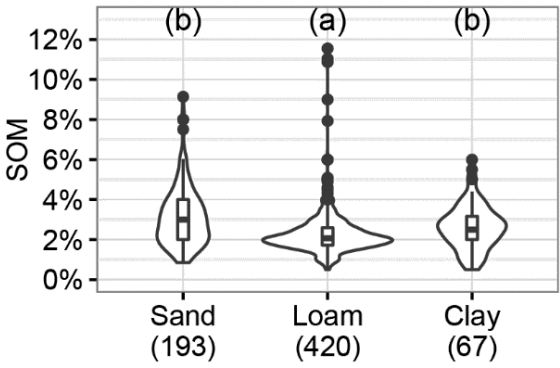

D. Dominant Land use

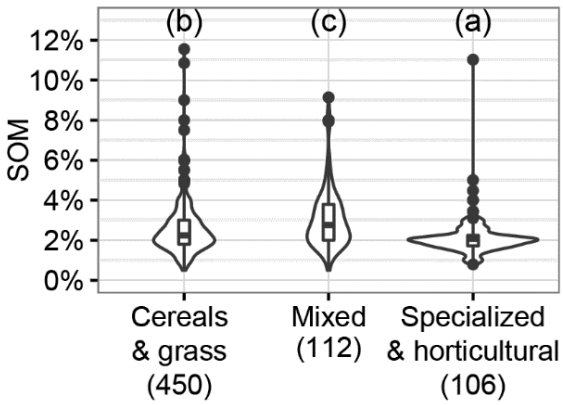

Fig 6. 5 Range of SOM content per environmental factor and land use type as reported by the farmers. $X$-axes are classes of different environmental factors and land use. Y-axes are the SOM contents reported by farmers. Violin shapes show the density distribution of farmers reporting a certain SOM content. Inside the violins, boxplots give medians, quartiles, lower extremes and upper extremes. If the letters above the violins differ, there is a significant difference between the medians (using a Nemenyi test).

On farmers' fields, the effect of slope (Fig. 6.5a) was as expected: soils with steeper slopes have lower SOM content. The effect of soil texture however is less clear: in our dataset (Fig. 6.5b) farmers with loamy soils have the lowest SOM content, while this was expected for farms with sandy soils. This might be due to some unbalance in the sampling design as slightly more farms with loamy soils are located in drier climates with steeper slopes. Soils on steeper slopes and in drier climates are expected to have lower SOM content due to faster decomposition and/or increased erosion risk (Gregorich et al., 1998), so this might be interfering with the effect of soil texture. 
As expected, farms in very dry climates and farms with more specialized and/or horticultural crops have less SOM content (Fig. 6.5c,d). However, SOM contents on farms in wet climates do not differ significantly from SOM contents on farms with dry climates. The lack of a significant difference might be due to the low number of farms in dry climates (19). Interestingly, farms with mixed cropping systems reported the highest average SOM content, higher than those with mainly cereals and/or grass.

\section{Perceived deficiency of SOM related to environmental factors and land use}

Comparing patterns based on the literature (6.2a) and perceived deficiency of SOM by farmers (6.6a), some similarities can be observed. From findings in the literature, risk of SOM deficiency is expected to increase with increasing slopes (Fig 6.2a). A similar pattern is observed in our farm data on mean perceived SOM deficiency per class ( $p=$ 0.004, Jonckheere-Terpstra trend test, Fig 6.6a).
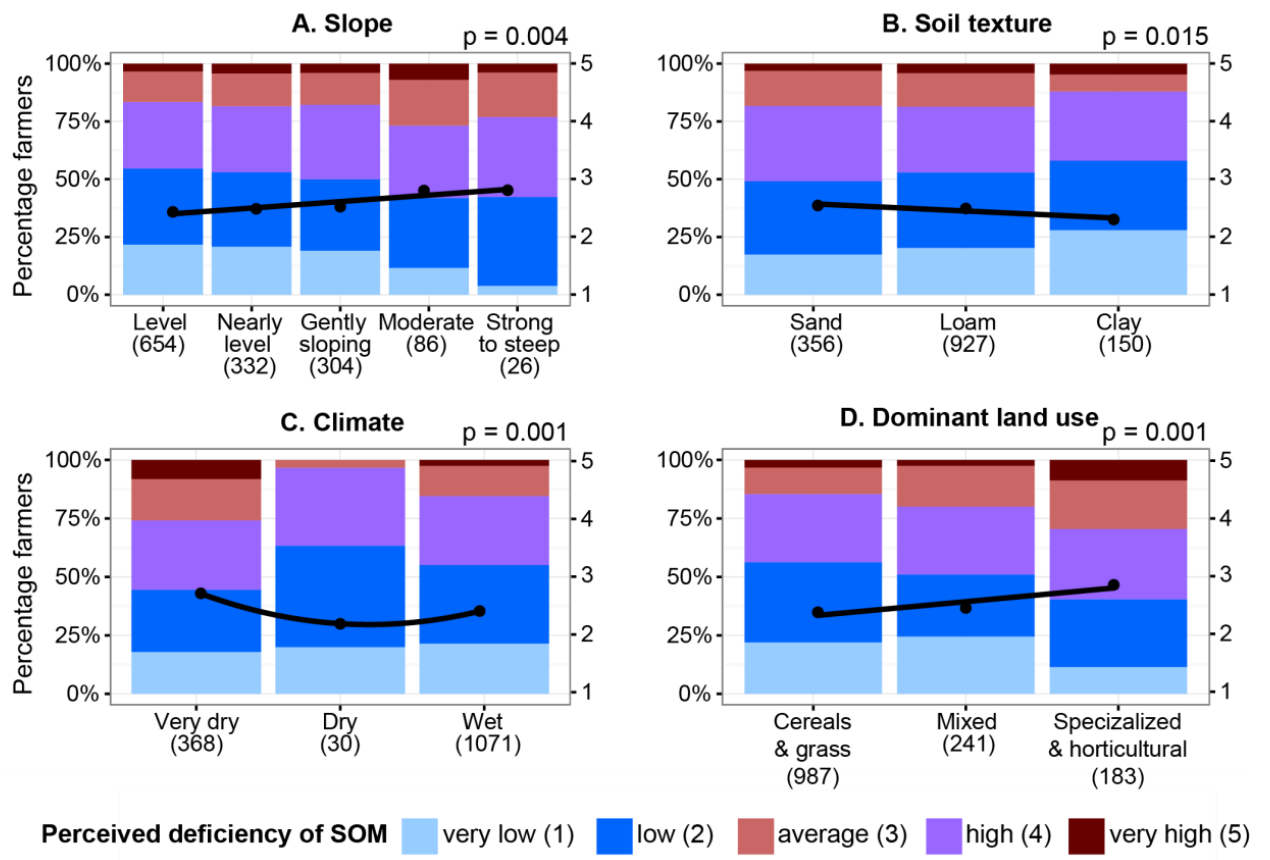

Perceived deficiency of SOM

very low (1)

Fig 6. 6 Frequency distributions of perceived deficiency of SOM related to environmental factors and land use. $X$-axes are classes of each environmental factor and land use. Colours indicate percentage of farmers perceiving a certain deficiency of SOM (left y-axis). Circles indicate mean perceived deficiency per class (right y-axis). Pvalues give significance of trends using the Jonckheere-Terpstra trend test. Lines between means are fitted using the function lm (least squares). 
From the literature, a parabolic curve was expected in which risk of SOM deficiency first decreases with increasing clay content, and then starts to increase for very heavy clay soils (Fig. 6.2b). Based on our farm survey, perceived deficiency of SOM by farmers does decrease with increasing clay content $(p=0.015$, Fig. $6.6 b)$, but our farm data does not show a parabolic curve. The latter could be explained because our farm survey did not include many farms with very heavy clay soils (fine or very fine soils with more than $35 \%$ clay particles).

From findings in the literature, soil in very dry and very wet climates are expected to have a higher risk of SOM deficiency than soils in intermediate climates (Fig. 6.2c). In our farm data, a significant tendency for a parabolic curve can be observed $(p=0.001$, Fig. 6.6c).

Finally, based on findings from literature, farms cultivating more specialized or horticultural crops are expected to have a higher risk of SOM deficiency (Fig 6.2d). A significant trend $(p=0.001$, Fig. $6.6 \mathrm{~d})$ was found with a higher perceived deficiency of SOM by farmers cultivating more specialized or horticultural crops than those with mixed crops and those with more cereals and/or grass.

\section{Perceived deficiency of SOM related to the risk indicator}

Farmers' perceptions confirm the proposed relationships between environmental factors and land use and risk of SOM deficiency on which the risk indicator is based (as discussed in the previous section). How does the risk indicator itself correlate with perceived deficiency of SOM by farmers? Do farmers with a higher risk indication for SOM deficiency also perceive a higher deficiency of SOM on their fields? Among the farmers of our survey up to a quarter had a high to very high risk of SOM deficiency (3$25 \%$, depending on the risk indicator option). Among the same farmers, $18 \%$ experienced a high to very high SOM deficiency, which is within the same range. Using Spearman's rank correlation test however, there was only a weak positive correlation between the risk indicator and farmers' perceptions (both Likert scale 1-5). Depending on which of the nine risk indicator options, the Spearman's rank correlation coefficient differed between 0.15 and 0.18 , albeit with high significance $(\mathrm{p}<0.0001)$. The low correlations indicate that none of the nine risk indicator options gives a very accurate prediction of SOM deficiency as perceived by farmers. 


\section{Threshold values of SOM based on farmers' perceptions}

Ranges of SOM content for each degree of perceived SOM deficiency (very low, low, neutral, high or very high) were dependent on the dominant soil texture of the farms (Fig. 6.7).

\section{A. Sandy soils}

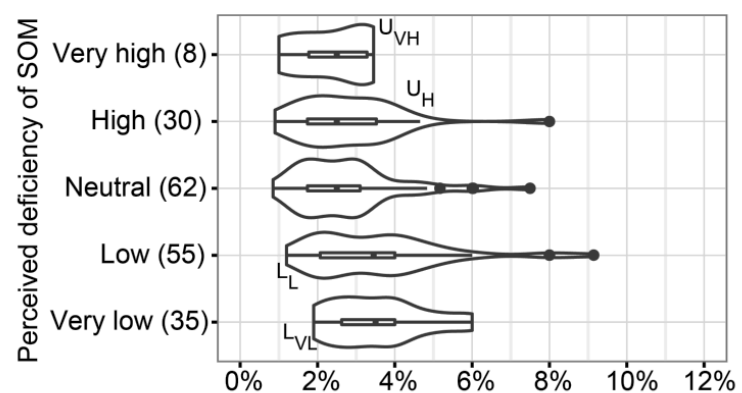

B. Loamy soils

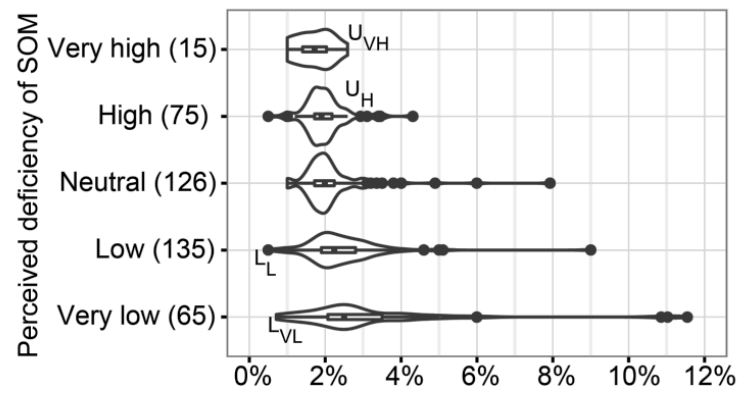

C. Clay soils

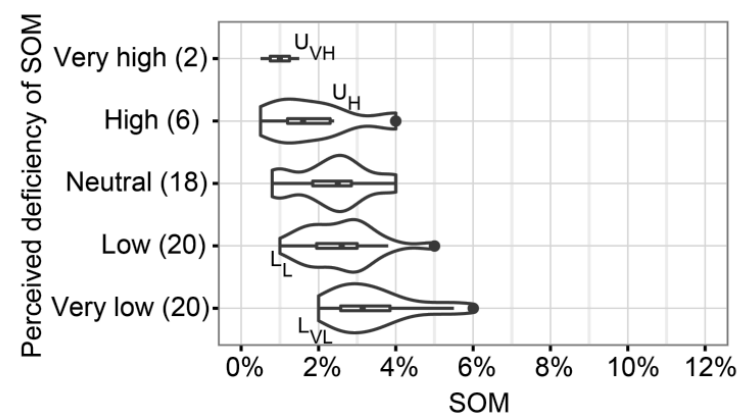

Fig 6. 7: SOM contents reported by farmers, classified by perceived deficiency of SOM (672 farmers) in (a) sandy, (b) loamy and (c) clay soils. X-axes are SOM contents reported by farmers. Y-axes are perceived SOM deficiency. Violin shapes show the density distribution of farmers reporting a certain SOM content. Inside the violin shapes, boxplots show medians, first and third quartiles and lower and upper extremes. L indicates lower extreme of farmers with a low $\left(L_{L}\right)$ or very low $\left(L_{V L}\right)$ perceived SOM deficiency. U indicates upper extreme of farmers with a high $\left(U_{H}\right)$ or very high $\left(U_{V H}\right)$ perceived SOM deficiency. Points are considered outliers. 
Within each violin shape of Fig. 6.7, boxplots show the lower (L) and upper (U) extremes of SOM content for each group. Points below the lower extremes and points above the upper extreme are considered outliers.

Lower extremes of SOM for farmers with a low or very low perceived deficiency of $\mathrm{SOM}\left(\mathrm{L}_{\mathrm{L}}\right.$ or $\left.\mathrm{L}_{\mathrm{VL}}\right)$, tend to be higher than lower extremes of SOM for farmers with a high or very high perceived deficiency of SOM. This is the case for both sandy and clay soils (Fig. 6.7a,c). This indicates a certain SOM content is needed before farmers start perceiving a (very) low SOM deficiency. For farmers on sandy soils, $\mathrm{L}_{\mathrm{L}}$ and $\mathrm{L}_{\mathrm{V} L}$ were $1.2 \%, 1.9 \%$ SOM respectively. For farmers on loamy soils, $\mathrm{L}_{\mathrm{L}}$ and $\mathrm{LVL}_{\mathrm{L}}$ are $0.6 \%$ and $0.7 \%$ SOM respectively. For farmers on clay soils, $\mathrm{L}_{\mathrm{L}}$ and $\mathrm{L}_{\mathrm{L}}$ were $1.0 \%$ and $2.0 \% \mathrm{SOM}$ respectively.

Upper extremes of SOM content for farmers with a high or very high perceived deficiency of SOM $\left(\mathrm{U}_{\mathrm{H}}\right.$ or $\left.\mathrm{U}_{\mathrm{VH}}\right)$, are lower than upper extremes of SOM content for farmers with a low or very low perceived deficiency of SOM. This is the case for all three soil textures (Fig. 6.7). This indicates that farmers only perceive a high or very high SOM deficiency up to a certain percentage of SOM content. Above this SOM content $\left(\mathrm{U}_{\mathrm{H}}\right)$, no farmer perceives a high or very high SOM deficiency. For farmers on sandy soils, $U_{H}$ and $U_{v H}$ were $4.7 \%$ and $3.4 \%$ SOM respectively. For farmers on loamy soils, $\mathrm{U}_{\mathrm{H}}$ and $\mathrm{U}_{\mathrm{VH}}$ were both $2.6 \% \mathrm{SOM}$. For farmers on clay soils, $\mathrm{U}_{\mathrm{H}}$ and $\mathrm{U}_{\mathrm{VH}}$ were $2.4 \%$ and $1.5 \%$ SOM respectively.

For each soil texture, $\mathrm{L}_{\mathrm{L}}$ and $\mathrm{U}_{\mathrm{H}}$ values are combined into a threshold interval (yellow areas Fig 6.8, sand: $1.2-4.7 \%$, loam: $0.6-2.6 \%$ and clay: $1.0-2.4 \%$ ). Below each interval, farmers perceive a neutral, high or very high deficiency of SOM (red areas, Fig. 6.8).
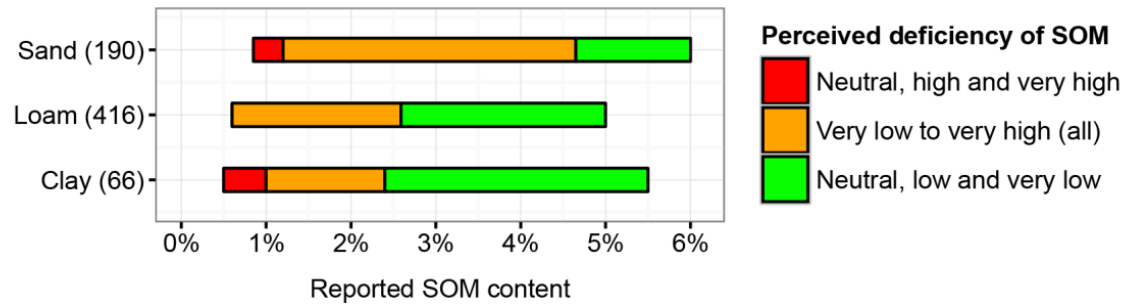

Fig 6. 8: Threshold intervals (in yellow) of SOM based on farmers' perceptions, dependent on dominant soil texture of a farm. Yellow areas indicate the threshold interval. Below each interval, farmers perceive a neutral, high or very high deficiency of SOM (red areas). Above each interval, farmers perceive a neutral, low or very low deficiency of SOM (green areas). Numbers of farmers are indicated between brackets. 
Above each interval, farmers perceive a neutral, low or very low deficiency of SOM (green areas, Fig. 6.8). Within each threshold interval, farmers can perceive any degree of SOM deficiency (from very low to very high), indicating that other factors (such as crop types cultivated, tillage management or irrigation) are more important.

\section{Clusters of farmers along gradients of environmental factors and land use}

The maximum SOM content of farmers with a very high perceived deficiency of SOM is 3.4\% SOM ( $U_{v h}$ for sandy soils, see Fig. $\left.6.7 \mathrm{a}\right)$. No farmers with more than $3.4 \% \mathrm{SOM}$ perceived a very high SOM deficiency, in any texture class. Below this value, SOM content might be similar among farmers, but farmers can have a very different perception of SOM deficiency, ranging from very low to very high (Fig. 6.7).

Soil texture seems to explain some but not all of the differences in perceived deficiency of SOM. To gain more insight on the difference in perceived SOM deficiency of farmers with a low SOM content, only farmers with less than 3.4\% SOM were selected for a principal component analysis.

The principal component analysis (Fig. 6.9) shows that farmers with a very low perceived deficiency of SOM on their farm (blue dots) can be found pretty much anywhere along the axes of soils, slopes and crops. Farmers with very high perceived deficiency of SOM (red dots) however, are mainly found at the extreme ends of the axes.

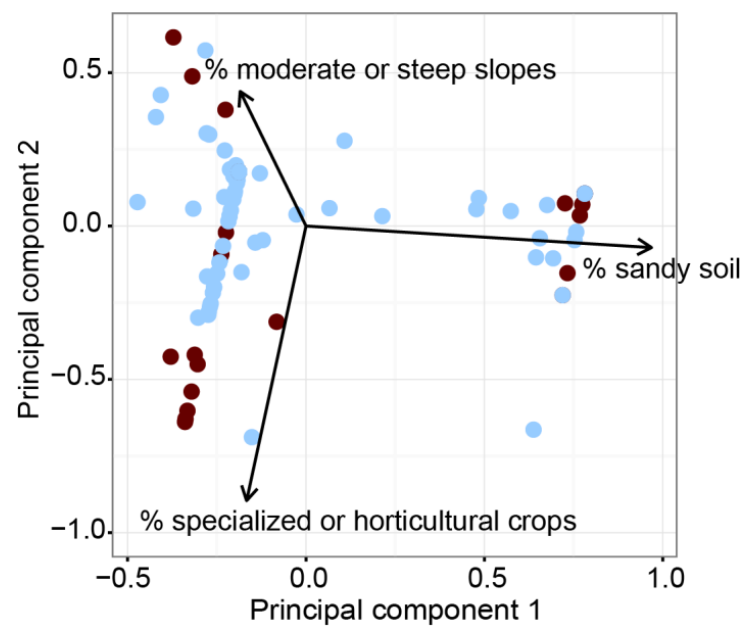

Perceived deficiency of SOM: very low $\bullet$ very high

Fig 6. 9: Clusters of farmers (with $<3.4 \%$ SOM) perceiving a very high or a very low SOM deficiency. Axes (principal component 1 and 2) are combinations of percentage of farm land with sandy soil, moderate or steep slopes and shares of specialized and/or horticultural crops. 
At the extreme end of an axis, farmers score very strongly on only one environmental factor (slope, texture, land use). They either have a high percentage of steep slopes, a high percentage of sandy soil or a high percentage of specialized and/or horticultural crops. This would indicate that not so much the combination of environmental factors and land use determines a very high perceived deficiency of SOM, but rather an extreme value for one of these factors.

\subsection{Discussion}

\subsubsection{Putting forward a risk indicator on SOM deficiency}

Up to date, a number of European risk maps have been developed on different soil degradation themes, such as soil erosion (Kirkby et al. 2004), soil compaction (Houšková \& Montanarella 2008) and landslides (Günther et al. 2014). Until now no European risk map on SOM deficiency has been made, although three European maps show actual soil organic carbon, minimum soil organic carbon and maximum soil organic carbon (Stolbovoy \& Montanarella 2008). Our maps represent a first attempt to highlight areas where farmers have a higher risk of SOM deficiency to maintain productive capacity. Fig. 6.4 shows a high to very high risk of SOM deficiency for 7 to $37 \%$ of European agricultural land (depending on the option to combine factors), mainly located in Southern and Eastern Europe. The maps also show that most of the European agricultural land falls within the class "very low", "low" or "middle" risk of SOM deficiency. The farm survey gave similar results with $18 \%$ of the interviewees perceiving a high to very high SOM deficiency. Ca. $53 \%$ of the interviewees perceived a "very low" or "low" SOM deficiency and of the remaining farmers $29 \%$ giving an indication in the middle. This could be regarded an encouraging result, showing that for most of the European farmers we have contacted, covering a wide range of cropping, climatic and soil types, a too low SOM content is not an issue.

\subsubsection{Testing the risk indicator using farmers' perceptions}

Relating the risk indicator on SOM deficiency to perceived SOM deficiency by farmers, there is a significant positive correlation $(p<0.001)$. The correlation is however very weak (Spearman's rank correlation coefficient of 0.15 to 0.18 ) and with large samples significance of a correlation can be misleading (Lantz 2013). Nonetheless, the correlation indicates that farmers in areas with a higher risk indication are more likely to experience a deficiency of SOM, but not unambiguously so. Stronger relations seem 
to exist between the individual factors and perceived SOM deficiency (Fig. 6.6). These relations resemble the findings from the literature (Fig 6.2) on which the risk indicator is based.

Why does combining the factors into one indicator not increase predictive capacity? A preliminary answer can be found in the results of the Principal Component Analysis (Fig 6.9). Apparently, having a more extreme environmental condition for only one factor (for example, a very sandy soil or land with a very steep slope) gives a higher chance of perceiving a deficiency of SOM, rather than a certain combination of moderate factors (in this case, a slightly sandy soil combined with a gentle slope). One explanation could be that it might be easier for farmers to adapt their management in a situation with a combination of moderate environmental factors than to adapt to one extreme environmental condition.

We now consider which is the best measure: the risk indicator or farmers' perceptions? The answer is probably that both have their value. While the risk indicator is more objective as it uses a standardized approach, it is also more reductionist, disregarding specific management practices (tillage type, use of organic inputs or irrigation), land use history, farmers' expertise and the actual SOM content that influence farmers' perceptions. Perceptions of farmers are more holistic, but also subjective, depending on personal preferences and factors other than those included in the risk indicator, which probably explains the large variation. In addition, defining the risk indicator included a number of arbitrary choices, not unseen in soil quality targeting, as working within a continuum sometimes requires human value judgement when grouping variables (Sparling et al. 2003).

\subsubsection{Using farmers' perceptions to define threshold values for SOM content}

Based on farmers' perceptions, threshold intervals for SOM were determined for soil texture (sand: $1.2-4.7 \%$, loam: $0.6-2.6 \%$ and clay: 1.0-2.4\%). When SOM content falls below a threshold interval, a farmer will perceive benefit from more SOM, irrespective of other factors. When SOM content is above a threshold interval, farmers will not perceive benefit from more SOM. Within each threshold interval, farmers can perceive any level of SOM deficiency (from very low to very high), indicating that other factors (such as management) are more relevant. 
Setting threshold intervals instead of specific threshold values is a better representation of both the fluidity of the data, the variation in contextual factors, and the large variation in farmers' perceptions at equal SOM contents, revealed by our farm survey. These intervals should therefore be taken as indications of where low soil productive capacity might occur because of low SOM contents. Compared to previously suggested threshold values for SOM content (Table 6.1, values ranging between 1 and 5.1\% SOM), our intervals fall in the middle of the range for sandy soils and are at the lower end for loam and clay soils.

\subsubsection{Limitations of the study and suggestions for further research}

Correctly combining environmental factors and land use seems to be challenging, especially for more extreme conditions. As a consequence, this indicator could be improved when more precise knowledge becomes available on how SOM content affects productive capacity under different environmental conditions. If more spatial data on farm management (such as tillage practices) comes available in the future, the effect on risk of SOM deficiency can also be included, thereby improving the risk indicator. Alternatively, a similar approach could be used at regional scale with country specific datasets at a finer spatial resolution (soil maps, digital elevation models and land use databases). In that case, a higher spatial accuracy could be achieved.

Part of this study depended on information provided by farmers. This was considered an excellent method to capitalize on practical know-how and tacit knowledge (Corbeels et al. 2000; Musinguzi et al. 2015). There are however uncertainties associated with analysing data from a farm survey, of which we discuss the most important ones. First, farmers were asked which percentage of their farmland had a certain class of slope and soil texture. Wherever possible we used common terms and indicated percentages, but national and cultural values might have had some influence. Following, farms were classified according to their dominant slope or soil texture, which meant loss of information, especially in areas with very heterogeneous environments. Finally, SOM contents were reported by farmers and not measured in the fields, which would have given a more accurate comparison. It is likely that these uncertainties increased the variation in our data. Further studies could expand our approach by including on-farm soil analyses.

Our study shows that farmers can perceive a certain level of SOM deficiency (very low, low, neutral, high or very high) along a wide range of SOM contents. In other words, 
farmers with a similar SOM content do not necessarily perceive the same degree of SOM deficiency, even under the same soil texture. It would be interesting to differentiate these intervals further for different slopes, climates and land uses. Unfortunately, the sample size of our farm survey was too small to allow for such an exercise.

Another explanation for the wide interval ranges of SOM content could perhaps be found in the roles different fractions of SOM play. There is recent evidence that specific SOM fractions play specific roles in improving aggregate stability of soils (Dexter et al. 2008). Organic inputs from straw, stubble or roots might have a proportionally large impact on stable aggregates compared to organic inputs from animal manures (Powlson et al. 2011; Watts et al. 2006). Evaluating total SOM content - the only information farmers have from ordinary soil analyses - lacks this type of detail. Future studies could explore the contributions from different SOM fractions further.

Last, in this study we only looked at benefits of SOM for productive capacity. Economic benefits are expected to follow from a higher productive capacity either direct through increased yields or indirect through improved workability of the soil which gives more flexibility in field operations. Besides economic benefits, SOM content also has environmental benefits such as supporting soil biodiversity or sequestering carbon (Chang et al. 2007; Freibauer et al. 2004). Integrating these different aspects fell however outside the scope of the current study objectives. Our findings could be used in a more broader analysis in which economic and environmental benefits are integrated. Besides a spatial, this could also include a temporal dimension.

\subsection{Conclusion}

This study used two very different approaches (developing a risk indicator and a farm survey) to assess SOM deficiency and has tried to link them. The risk indicator was based on increasing or decreasing risk of SOM deficiency along certain environmental (slope, soil texture, aridity) and land use gradients, based on a literature review. Remarkably similar patterns were observed between the findings from the literature review and perceived deficiency of SOM by farmers in the survey. In addition, a correlation was found between the risk indicator and farmers' perceptions of SOM deficiency. Large part of the variance in farmers' perceptions, however, could not be explained by the environmental factors or land use as investigated in this study. This is not surprising when one realizes the variation in other factors (nutrient management, irrigation, tillage), farmers' experience and land use history. Nonetheless, our findings 
provide some relevant insights (e.g. threshold intervals based on soil texture) and call for further investigations in which practical and expert knowledge are used complementary.

Currently, worldwide and in Europe specifically, policies are proposed to maintain or increase SOM content in agricultural fields (EC 2006, 2011b, 2013; Toth et al. 2008; UNFCCC 2012, 2015). Maintaining and in particular increasing SOM content can be a very costly effort, requiring many years of additional inputs. Based on differences in carbon sequestration potential, van Groenigen et al. (2017) argue for a spatially differentiated strategy for soil carbon sequestration. Our study argues likewise, yet based on spatial differences in contributions from SOM to productive capacity. If policies on SOM management want to include benefits for productive capacity, efforts should be focussed on areas with a higher risk of SOM deficiency (mainly Southern and Eastern Europe), more extreme environmental conditions (very dry or very wet climates, steep slopes, very sandy soils), cropping systems with larger shares of specialized or horticultural crops or with very low SOM contents (below the given threshold intervals).

\subsection{Acknowledgements}

First and foremost, our gratitude goes to all European farmers who spared some of their time to fill in the questionnaire. Setting up a large scale farm survey would have been impossible without numerous colleagues across different institutes. In Italy, we received support from universities of Ancona, Bari, Milano, Napoli Udine, Pisa, Teramo, Tuscia, Ancona and Perugia; provincial and regional officials; farmers unions (Coldiretti, Confagricoltura, Confederazione Italiana Agricoltori); CadirLab (Quargnento, AL); Consorzio Agrario di Siena; advisors of the Italian Farm Accountancy Data Network; Chiara Costamagna; students of the University of Torino and University of Milano. In Austria, main contacts were the provincial and regional officials of the chamber of agriculture in Lower Austria, Upper Austria and Tyrol. In Spain, data was collected and compiled through colleagues of the University of Córdoba, the Andalusian Institute of Agricultural and Fisheries Research and Training, the Institute for Sustainable Agriculture and farmers associations (ASAJA, AEAC-SV), with support from Ángela Portero (UCO). In Belgium, data was collected with the help of Greet Ruysschaert and Erwin Wauters (ILVO). In Germany, data was collected with the help of Janine Mallast (IGZ) and Isabell Raschke (UGOE). Joost Wolf, Hein ten Berge, Jan Verhagen and Igor Staritsky (WUR) helped with developing the initial farm typology on which the environmental and land use classifications are based, while Peter Verweij (WUR) 
assisted in constructing the European risk map. We thank all colleagues for their efforts and support. 


\section{Supplement Chapter 6}

Supplementary Tables

6.1 to 6.3

Supplementary Tables

6.4 to 6.6

Supplementary Table

6.7

Supplementary Table

6.8

Supplementary Table 6.9
Three options for combining slope and soil texture into a soil risk estimate of SOM deficiency

Three options for combining soil risk and aridity into an environmental risk estimate of SOM deficiency

Combining environmental risk and land use into a (total) risk estimate of SOM deficiency

Classification of crops cultivated by farmers participating in the survey

Characteristics of farmers included in the analysis 157

155

156

158 


\section{Three options for combining slope and soil texture into a soil risk estimate of SOM deficiency}

Supplementary Table 6.1: Low soil risk estimate (soil texture x slope).

\begin{tabular}{|c|c|c|c|c|c|}
\hline & $\begin{array}{l}\text { Level } \\
\left(0^{\circ}\right)\end{array}$ & $\begin{array}{l}\text { Nearly } \\
\text { level }\left(1^{\circ}\right)\end{array}$ & $\begin{array}{l}\text { Gentle } \\
\left(2-3^{\circ}\right)\end{array}$ & $\begin{array}{l}\text { Moderate } \\
\left(4-7^{\circ}\right)\end{array}$ & $\begin{array}{l}\text { Strong to } \\
\text { steep }\end{array}$ \\
\hline Coarse $(>65 \%$ sand,$<18 \%$ clay $)$ & 2 & 2 & 3 & 4 & 5 \\
\hline $\begin{array}{l}\text { Medium }(>15 \% \text { sand, } 18-35 \% \text { clay or } 15-65 \% \\
\text { sand, }<18 \% \text { clay })\end{array}$ & 1 & 1 & 2 & 3 & 4 \\
\hline Medium fine $(<15 \%$ sand, $<35 \%$ clay $)$ & 1 & 2 & 3 & 3 & 4 \\
\hline Fine $(35-60 \%$ clay $)$ & 2 & 2 & 3 & 4 & 5 \\
\hline Very fine ( $>60 \%$ clay) & 2 & 2 & 3 & 4 & 5 \\
\hline
\end{tabular}

Supplementary Table 6.2: Medium soil risk estimate (soil texture x slope).

\begin{tabular}{|c|c|c|c|c|c|}
\hline & $\begin{array}{l}\text { Level } \\
\left(0^{\circ}\right)\end{array}$ & $\begin{array}{l}\text { Nearly } \\
\text { level }\left(1^{\circ}\right)\end{array}$ & $\begin{array}{l}\text { Gentle } \\
\left(2-3^{\circ}\right)\end{array}$ & $\begin{array}{l}\text { Moderate } \\
\left(4-7^{\circ}\right)\end{array}$ & $\begin{array}{l}\text { Strong to } \\
\text { steep }\end{array}$ \\
\hline Coarse $(>65 \%$ sand,$<18 \%$ clay $)$ & 2 & 3 & 4 & 5 & 5 \\
\hline $\begin{array}{l}\text { Medium }(>15 \% \text { sand, } 18-35 \% \text { clay or } 15- \\
65 \% \text { sand, }<18 \% \text { clay })\end{array}$ & 1 & 1 & 2 & 3 & 4 \\
\hline Medium fine $(<15 \%$ sand, $<35 \%$ clay $)$ & 1 & 2 & 3 & 3 & 4 \\
\hline Fine $(35-60 \%$ clay $)$ & 2 & 2 & 3 & 4 & 5 \\
\hline Very fine ( $>60 \%$ clay) & 2 & 3 & 4 & 5 & 5 \\
\hline
\end{tabular}

Supplementary Table 6.3: High soil risk estimate (soil texture x slope).

\begin{tabular}{|c|c|c|c|c|c|}
\hline & $\begin{array}{l}\text { Level } \\
\left(0^{\circ}\right)\end{array}$ & $\begin{array}{l}\text { Nearly } \\
\text { level }\left(1^{\circ}\right)\end{array}$ & $\begin{array}{l}\text { Gentle } \\
\left(2-3^{\circ}\right)\end{array}$ & $\begin{array}{l}\text { Moderate } \\
\left(4-7^{\circ}\right)\end{array}$ & $\begin{array}{l}\text { Strong to } \\
\text { steep }\end{array}$ \\
\hline Coarse ( $>65 \%$ sand,$<18 \%$ clay) & 2 & 3 & 4 & 5 & 5 \\
\hline $\begin{array}{l}\text { Medium }(>15 \% \text { sand, } 18-35 \% \text { clay or } 15- \\
65 \% \text { sand, }<18 \% \text { clay })\end{array}$ & 1 & 2 & 3 & 4 & 5 \\
\hline Medium fine $(<15 \%$ sand, $<35 \%$ clay $)$ & 1 & 2 & 3 & 4 & 5 \\
\hline Fine $(35-60 \%$ clay $)$ & 2 & 3 & 4 & 5 & 5 \\
\hline Very fine $(>60 \%$ clay $)$ & 3 & 4 & 5 & 5 & 5 \\
\hline
\end{tabular}


Three options for combining soil risk and aridity into an environmental risk estimate of SOM deficiency

Supplementary Table 6.4: Low environmental risk estimate (soil risk $x$ aridity).

\begin{tabular}{lccccc}
$\begin{array}{l}\text { Very low } \\
\text { soil } \\
(1)\end{array}$ & $\begin{array}{l}\text { Low soil } \\
\text { risk (2) }\end{array}$ & $\begin{array}{l}\text { Average } \\
\text { soil } \\
(3)\end{array}$ & $\begin{array}{l}\text { High soil } \\
\text { risk (4) }\end{array}$ & $\begin{array}{l}\text { Very } \\
\text { high soil } \\
\text { risk (5) }\end{array}$ \\
\hline 2 & 3 & 4 & 5 & 5 \\
1 & 2 & 3 & 4 & 5 \\
1 & 1 & 2 & 3 & 4 \\
1 & 2 & 3 & 4 & 5 \\
2 & 3 & 4 & 5 & 5 \\
\hline
\end{tabular}

Supplementary Table 6.5: Medium environmental risk estimate (soil risk $x$ aridity).

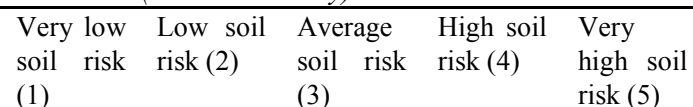

(1)

(3)

\begin{tabular}{llllll}
\hline Very dry $(0-0.4)$ & 2 & 3 & 4 & 5 & 5 \\
Dry $(0.4-0.6)$ & 1 & 2 & 3 & 4 & 5 \\
Intermediate $(0.6-0.7)$ & 1 & 2 & 3 & 4 & 5 \\
Wet $(0.7-0.8)$ & 1 & 2 & 3 & 4 & 5 \\
Very wet $(>0.8)$ & 2 & 3 & 4 & 5 & 5 \\
\hline
\end{tabular}

Supplementary Table 6.6: High environmental risk estimate (soil risk $x$ aridity).

\begin{tabular}{lcccccc}
\hline Supplementary Table 6.6: High environmental risk estimate (soil risk $x$ aridity). \\
& $\begin{array}{l}\text { Very low } \\
\text { soil risk } \\
(1)\end{array}$ & $\begin{array}{l}\text { Low soil } \\
\text { risk (2) }\end{array}$ & $\begin{array}{l}\text { Average } \\
\text { soil } \\
(3)\end{array}$ & $\begin{array}{l}\text { High soil } \\
\text { risk (4) }\end{array}$ & $\begin{array}{l}\text { Very } \\
\text { high soil } \\
\text { risk (5) }\end{array}$ \\
\hline Very dry (0-0.4) & 3 & 4 & 5 & 5 & 5 \\
Dry $(0.4-0.6)$ & 2 & 3 & 4 & 5 & 5 \\
Intermediate $(0.6-0.7)$ & 1 & 2 & 3 & 4 & 5 \\
Wet $(0.7-0.8)$ & 2 & 3 & 4 & 5 & 5 \\
Very wet $(>0.8)$ & 3 & 4 & 5 & 5 & 5 \\
\hline
\end{tabular}




\section{Combining environmental risk and land use into (total) risk of SOM deficiency}

Supplementary Table 6.7: (total) Risk of SOM deficiency estimate (environmental risk x land use).

$\begin{array}{lllll}\text { Very low } & \text { Low } & \text { Average } & \text { High } & \text { Very high } \\ \text { environment } & \text { environment } & \text { environment } & \text { environment } & \begin{array}{l}\text { environment } \\ \text { risk (1) }\end{array} \\ \text { risk (2) } & \text { risk (3) } & \text { risk(4) } & \text { risk (5) }\end{array}$

\begin{tabular}{|c|c|c|c|c|c|}
\hline $\begin{array}{l}\text { Permanent crops, grass and } \\
\text { cereals }\end{array}$ & 1 & 1 & 2 & 3 & 4 \\
\hline $\begin{array}{l}\text { Mixed crops: any other } \\
\text { crops or land independent }\end{array}$ & 1 & 2 & 3 & 4 & 5 \\
\hline $\begin{array}{l}\text { horticulture and specialized } \\
\text { crops }\end{array}$ & 2 & 3 & 4 & 5 & 5 \\
\hline Fallow land & 2 & 3 & 4 & 5 & 5 \\
\hline
\end{tabular}

\section{Classification of crops cultivated by farmers participating in the survey}

Supplementary Table 6.8: Classification of crops cultivated by farmers in the survey.

\begin{tabular}{|c|c|c|c|}
\hline Cereals and grass & \multicolumn{2}{|c|}{ Horticultural and specialized crops } & Other \\
\hline $\begin{array}{l}\text { barley } \\
\text { durum } \\
\text { grain maize } \\
\text { oat } \\
\text { rice } \\
\text { rye } \\
\text { sorghum } \\
\text { spelt } \\
\text { triticale } \\
\text { wheat } \\
\text { other cereals or grass }\end{array}$ & $\begin{array}{l}\text { aloe vera } \\
\text { asparagus } \\
\text { beans } \\
\text { beetroot } \\
\text { bitter vetch } \\
\text { cabbage } \\
\text { carrots } \\
\text { Cherries } \\
\text { chickpeas } \\
\text { Chicory } \\
\text { Cichorei } \\
\text { Cotton } \\
\text { cucumber } \\
\text { fave beans } \\
\text { Flax } \\
\text { flower seeds } \\
\text { Flowers } \\
\text { Garlics } \\
\text { grass seeds } \\
\text { green peppers } \\
\text { Lentils }\end{array}$ & $\begin{array}{l}\text { melons } \\
\text { mint } \\
\text { mustard } \\
\text { oil flax } \\
\text { oil seeds } \\
\text { onion } \\
\text { parsley } \\
\text { peas } \\
\text { potatoes } \\
\text { pumpkin } \\
\text { rhubarb } \\
\text { soy bean } \\
\text { strawberries } \\
\text { sugar beet } \\
\text { tobacco } \\
\text { tomatoes } \\
\text { turnip } \\
\text { vegetable seeds } \\
\text { other vegetables open air } \\
\text { other beets } \\
\text { other legumes }\end{array}$ & $\begin{array}{l}\text { buckwheat } \\
\text { energy maize } \\
\text { forage barley } \\
\text { forage ley } \\
\text { forage or silage maize } \\
\text { Italian rye grass } \\
\text { mint } \\
\text { silage rye } \\
\text { other forage or fodder } \\
\text { crops }\end{array}$ \\
\hline
\end{tabular}


Farmers' characteristics

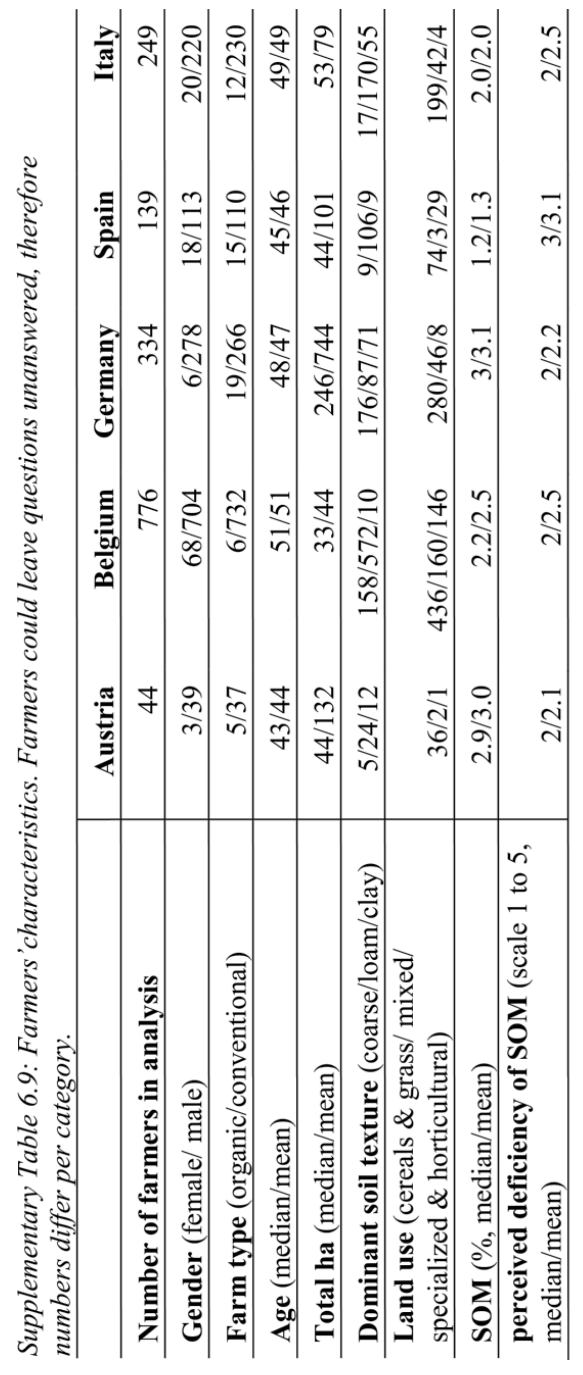




\section{Chapter 7. General discussion}

The aim of this thesis was to improve understanding of the role of organic inputs and SOM for crop production in contemporary arable farming in Europe. For this purpose, long-term experiments were analysed on the additional yield effect of organic inputs and savings in mineral fertiliser. In addition, a farm survey was conducted to find drivers and barriers for the use of organic inputs and to assess if farmers perceive a deficiency of SOM. In this chapter, the findings of this thesis are discussed along the following lines: general findings (Section 7.1); influence of environmental factors (Section 7.2); influence of crop types cultivated (Section 7.3); types of organic inputs (Section 7.4); synergies and trade-offs with other ecosystem services (Section 7.5); limitations of the study (Section 7.6) and implications of the findings (Section 7.7). A summary of the main findings is presented in Fig. 7.1.

\subsection{General findings}

This thesis set out to answer five main research questions (Section 1.6). Here the questions are listed together with a short answer based on the findings in each chapter.

\section{$Q$ 1: What is the additional yield effect of organic inputs for arable crops in Europe?}

Based on 20 long-term experiments, the mean additional yield effect of organic inputs for arable crops in Europe is not significantly different from zero $(1.4 \% \pm 1.6-95 \%$ Confidence Interval $[\mathrm{CI}]$ ). In specific cases however, especially for root and tuber crops, spring sown cereals, or for very sandy soils or wet climates, organic inputs did increase attainable yields (between 3 and 7\%). Initial SOM contents of the experiments were not related to the additional yield effect of organic inputs, but a correlation was found between increases in additional yield and increases in SOM content.

\section{Q2: Do mineral fertiliser savings from organic inputs depend on total $N$ supply?}

Based on eight long-term experiments, the use of FYM saves more mineral fertiliser $\mathrm{N}$ at high total $\mathrm{N}$ supply than at low total $\mathrm{N}$ supply. The nitrogen fertiliser replacement value (NFRV, based on equal yields) of FYM was 2.1 times larger at high than at low total $\mathrm{N}$ supply $(p=0.04)$. For the other types of organic inputs investigated (slurry, straw or a combination of straw and green manures), NFRV was also higher at high total N supply than at low total $\mathrm{N}$ supply. In these cases however, sample sizes were too small or variations too large to find significant differences. 
Q3: What are currently the main drivers and barriers for arable farmers to use organic inputs?

Using a farm survey in six agro-ecological zones in four countries, major drivers to use organic inputs (incorporation of straw, cultivation of green manures, FYM and compost) were perceived effects on soil quality (such as improved soil structure or reduced erosion) and the positive influence from social referents (such as fellow farmers or agricultural advisors). Major barriers to use organic inputs were financial (increased costs or foregone income) and perceived increases in pressures from weeds, pest and diseases.

\section{Q 4: How are farmers' beliefs on SOM related to their use of organic inputs?}

A case study in the Netherlands shows that arable farmers specifically value the effect of SOM content on soil structure, especially where it improves workability on clay soils and water holding capacity on sandy soils. Soil fungi were evaluated as a negative outcome of SOM. Among the different control factors, the long-term effect of SOM content was perceived as very strong and evaluated very positively. Advisors were considered to have the most positive view on SOM and fellow farmers were considered to be least positive. Farmers' beliefs were correlated weakly but significantly with their intention to increase SOM content. The large majority of Dutch farmers in the survey (91\%) had a high or very high intention to increase SOM content. A higher intention to increase SOM content was significantly correlated with the use of organic inputs as expressed in total and effective $\mathrm{C}$ inputs ( $\mathrm{C}$ remaining in the soil after one year).

\section{Q 5: Do farmers perceive a deficiency of SOM?}

Based on a farm survey in five countries (Austria, Belgium, Germany, Spain and Italy), $18 \%$ of 1452 farmers perceived a high to very high SOM deficiency. Perceived deficiency of SOM content was related to climate (aridity), slope, soil texture and land use. Based on farmers' perceptions threshold intervals for SOM content were established (sand: $1.2-4.7 \%$, loam: $0.6-2.6 \%$ and clay: $1.0-2.4 \%$ ). Below a threshold interval, a farmer will benefit from more SOM content, irrespective of other factors such as land use or management. Above a threshold interval, farmers do not expect production benefits from additional SOM. Some indication was found that being at the extreme end for one environmental factor gives a higher chance of perceiving a deficiency of SOM than having a combination of moderate environmental conditions. 


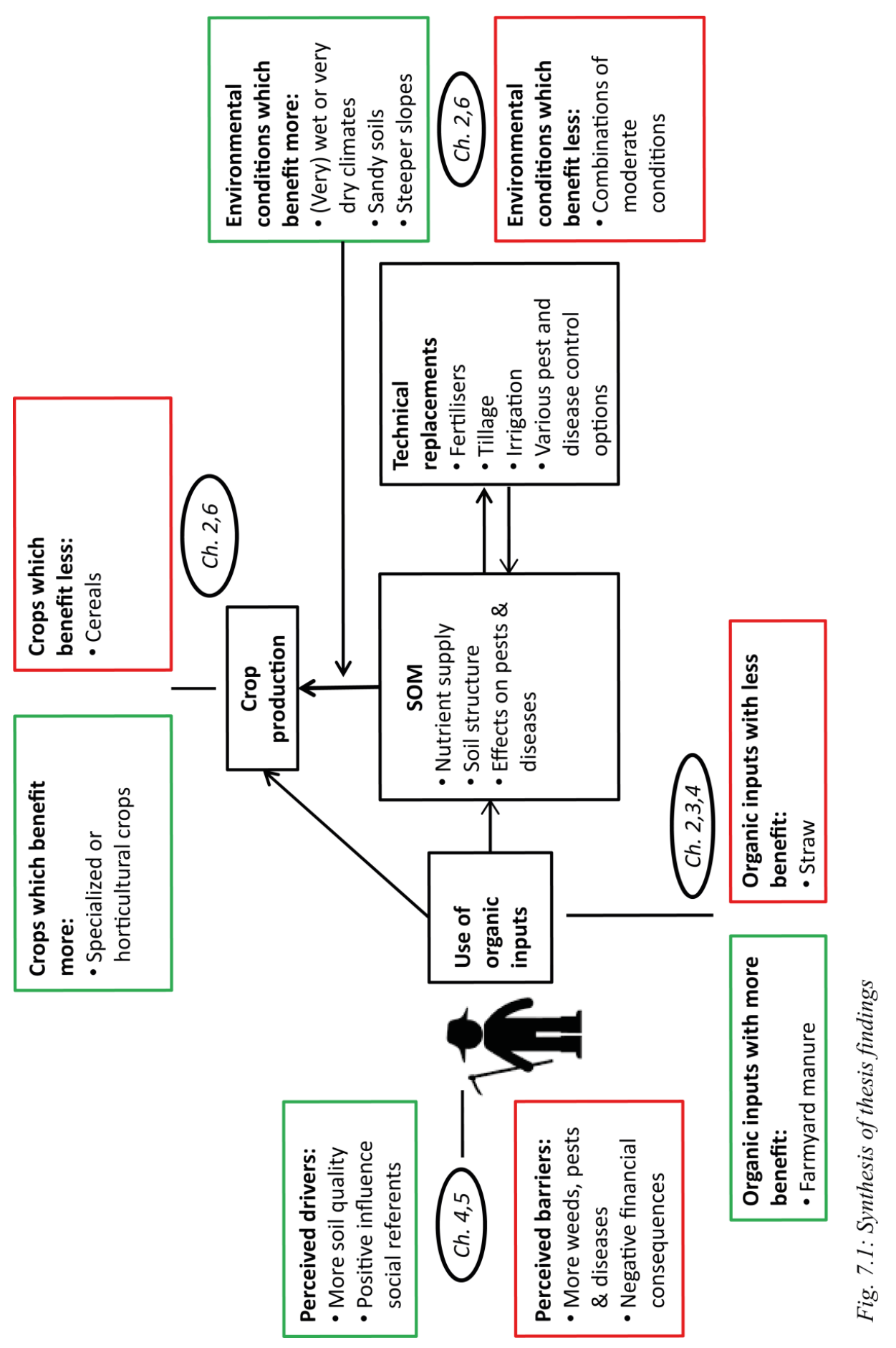




\subsection{Influence of environmental factors on the role of SOM for crop production}

In Chapters 2, 4, 5 and 6, environmental factors were included in data collection and analysis to assess their effects on the role of SOM for crop production (Table 1.3). Here findings are discussed per environmental factor.

\section{Climate}

The meta-analysis of 20 long-term experiments showed that in wet climates, the additional yield effect of organic inputs was larger than in more moderate or dry climates (Fig. 2.4c). This was probably related to an improved drainage and aeration and the prevention of soil compaction in wet climates (Soane 1990). This finding was reflected in the farm survey, as farmers in wet climates perceived a higher deficiency of SOM than those in dry climates.

Beforehand, it was rather expected that crops in dry climates would benefit more from organic inputs as SOM increases the water holding capacity of soils (Díaz-Zorita et al. 1999), but this was not confirmed in the meta-analysis. Possibly, crops were well irrigated in the experiments and therefore the water holding effect of SOM did not add any benefit to crop yields. If and how often experimental fields were irrigated was however not mentioned in the publications on which this analysis was based.

An alternative explanation is that the increase in SOM content did not increase water holding capacity sufficiently to affect crop yields. It has to be borne in mind however that even though some experiments were included with a dry sub-humid semi-arid climates, lower aridity indices are more common outside Europe. One indication that crop production benefits more from organic inputs or SOM in drier climates was found in the farm survey as farmers in very dry climates perceived a higher deficiency of SOM than those in between (Fig. 6.6c). Possibly, farmers operate in less controlled or more water limited settings than those found at the experimental sites.

\section{Land slope}

Land slope was only included as a co-variable in the farm survey. As expected, farmers on steeper slopes perceived a higher deficiency of SOM than those on less steep slopes (Fig. 6.6a). On steep slopes, SOM content was lower than on less steep slopes (probably due to soil erosion). In addition, SOM can promote infiltration rates (Rhoton et al. 2002), which is more appreciated on steeper slopes. 
When assessing drivers and barriers to use organic inputs, two agro-ecological zones were included with steeper slopes (AT1 and IT2-sloping; Table 4.5). In both agroecological zones, reduced erosion was evaluated as a driver for cultivating green manures or cover crops (Fig. 4.6a,d). It is however unclear if this is due to the increased SOM content or due to the reduction of bare soils when cultivating green manures or cover crops.

\section{Soil texture}

The meta-analysis of 20 long-term experiments showed that on soils with less clay content (i.e. more sandy soils), the additional yield effect of organic inputs was larger than on soils containing more clay content (Fig 2.4a). Probably, the organic inputs and increased SOM content improved the loose soil structure of the sandy soils (Tisdall \& Oades 1982).

The additional yield effect of organic inputs on sandy soils was reflected in the farm survey as perceived deficiency of SOM was higher on sandy soils (Fig. 6.6b). A priori, it was expected that farmers on very heavy clay soils would also perceive a higher SOM deficiency (Table 6.2). This could not be verified in the farm survey as no farmers were included with more than $35 \%$ clay content in their soils (and these very heavy clay soils are rare in Europe, EC \& ESBN 2004).

In the Dutch case study, farmers on sandy soils valued effects of SOM on productivity and water holding capacity the most, farmers on loam soils valued effects of SOM on soil structure and rooting the most and farmers and clay soils valued effects of SOM on soil structure and workability the most (Table 5.2).

\subsection{Influence of crop types cultivated on the role of SOM for crop production}

A previous analysis of two field experiments in the Netherlands (De Haan 1977) suggested that root and tuber crops will benefit more from organic inputs or SOM than cereals, even beyond the macro-nutrients supplied. This suggestion is supported for potatoes in the meta-analysis of 20 long-term experiments (Fig. 2.3b). The additional yield effect for potatoes was on average $7.0 \%( \pm 4.9-95 \% \mathrm{CI})$. This might be because root and tuber crops depend more on soil structure for their successful cultivation and harvesting. Spring sown cereals (including maize) also benefit (3.4 percent $\pm 2.6-95 \%$ CI.). Spring sown crops have a shorter time frame to develop their root system which is 
needed to acquire sufficient nutrients and water (Johnston et al. 2009). In addition, maize has a less developed root system than wheat or barley, which might be another explaining factor.

In the farm survey, land use classes were made comparing farmers cultivating more specialized or horticultural crops with farmers cultivating more grass and cereals or a mixture of crops. Among the specialized and horticultural crops cultivated by the farmers were root and tuber crops such as potatoes or sugar beets, but also beans and other vegetables (Supplementary Table 6.8). Farmers who cultivated more specialized or horticultural crops perceived a higher deficiency of SOM than farmers who cultivated more cereals (Fig. 6.6d). As crop rotations differed widely between farmers, it was not evident if there was a specific selection of specialized or horticultural crops causing this increase in perceived SOM deficiency. Further research would therefore be recommended looking into more details between specific crop types.

\subsection{Types of organic inputs}

It was found that the type of organic input used (e.g. FYM, compost, slurry) affects the relation between SOM and crop production. The additional yield effect of FYM is larger than that of slurry, straw or a combination of straw and green manures (even when compensating for the $\mathrm{N}$ immobilization by applying additional mineral fertiliser $\mathrm{N}$, Fig. 2.3a).

When assessing the mineral fertiliser $\mathrm{N}$ savings from organic inputs, straw has a varying effect on $\mathrm{N}$ supply, from negative to positive (Table 3.2). This was confirmed in the farm survey, in which farmers indicated that incorporation of straw sometimes saves the use of mineral fertiliser $\mathrm{N}$ whilst in other cases it needs mineral fertiliser $\mathrm{N}$ for decomposition (Fig. 4.5).

Based on data from eight long-term experiments, NFRV of FYM increases with total N supply (Table 3.2). This could suggest that NFRV of organic inputs is higher when combined with mineral fertiliser than without. If validated, this would open a new perspective on the advantage of distributing available organic inputs among many farmers in a given region: the region would require less fertiliser to produce the same yield output, than when organic inputs were concentrated in few farms.

The main drivers to use organic inputs were perceived effects on soil quality and influence from social referents (for all types of organic inputs). In addition, green 
manure was also perceived to have a positive effect on the environment. For all input types, perceived pressures from weeds, pests and diseases were evaluated as important barriers (Fig. 4.8). In addition, farmers perceived more negative financial consequences from FYM and compost than from the cultivation of green manures or incorporation of straw.

\subsection{Synergies and trade-offs with other ecosystem services}

SOM content in arable farms does not only affect crop production, but can also contribute to other ecosystem services. Ecosystem services which have been suggested positively or negatively affected by the use of organic inputs or SOM content in arable soils include climate change mitigation (soil carbon sequestration, greenhouse gas emissions), positive effects on crop protection, nutrient leaching and soil biodiversity conservation. Here effects of SOM on these ecosystem services will be discussed.

\section{Climate change mitigation}

Currently, much emphasis is placed on the carbon sequestration potential of SOM in agriculture. As SOM is known to improve soil quality, this is argued a win-win situation for climate change mitigation and food security (see for example Lal 2004a or the $4 / 1000$ initiative by the UNFCCC 2015). This thesis has shown that SOM can positively affect crop production, but only in specific situations, namely depending on environmental conditions, practices used to maintain or increase SOM content and crop types cultivated. In many other cases, no significant additional yield effect of SOM could be shown.

For soil carbon sequestration, there are a number of limitations. First, after some time under a specific management, SOM will reach an equilibrium state in which inputs balance outputs (Janssen 2002). In such a state, adding organic inputs does not sequester more carbon. This means by definition there is only a limited potential for soil carbon sequestration. This limited potential also exists due to the limited availability of organic resources and competition with other uses (such as feed for livestock, fibre or as fuel). Some studies have shown that bioenergy produced from straw might be a more effective climate change mitigation measure than storage in soil, especially when assessed over longer periods of time (Poeplau et al. 2015; Powlson et al. 2008). In addition, built up of organic carbon in soils must always accompanied by other elements such as N. This means that increasing SOM might need additional mineral fertiliser production (Kirkby et al. 2016; Richardson et al. 2014), with associated costs and environmental impacts. 
While the use of organic inputs can temporarily sequester carbon, there is a risk for increased greenhouse gas emissions, potentially offsetting any gains for climate change mitigation (Bos et al. 2017).

While this thesis shows that increasing SOM does not always increase crop production, the reverse relationship has a more general validity (i.e. higher crop production increases SOM). If, through any means, higher crop yields can be reached, this will lead to production of more aboveground biomass and roots and potentially a higher availability of crop residues which can be returned to the field (Fig. 2.5b, Yang \& Janssen 1997).

\section{Nutrient leaching}

In some cases, the use of organic inputs instead of mineral fertilisers has been suggested to reduce nutrient leaching (Leclerc et al. 1995). For example, during the 1980s, the Synchrony Hypothesis was formulated on nutrient supply from organic inputs (Swift (1985) as cited by Palm et al. 2001). The Synchrony Hypothesis states that the release of nutrients (N,P) from organic inputs can be synchronized with plant growth demands. In this manner, synchrony reduces leaching of nutrients while enhancing crop growth. Based on a multitude of studies, Palm et al. (2001) however conclude that there is no single or combination of organic material that releases $\mathrm{N}$ in perfect synchrony to crop demand. This means that some percentage of nutrients applied with organic inputs will always be prone to losses to the environment. Following, a number of studies have tried to compare nutrient losses applied with mineral fertilisers versus application with organic inputs. It has been suggested that over the long-term, if nutrients are applied attuned to crop requirements, there is no difference in nitrate leaching between using either organic inputs or mineral fertilisers (Maeda et al. 2003).

\section{Crop protection measures}

There is some evidence from field experiments that in certain cases the use of organic inputs might reduce the need for chemical crop protection. This is especially the case when they are rich in nitrogen (Bailey \& Lazarovits 2003) or enriched with specific soil microbes (Mehta et al. 2014). There are also findings pointing to the contrary. Incorporation of straw is for example known to spread diseases to subsequent cereals in crop rotations (Maiorano et al. 2008). In our farm survey, farmers consistently evaluated the effects of organic inputs on crop protection negatively (Fig. 4.8). There is therefore a need for more research on the relation between the use of various organic inputs and 
pressures from weeds, pests and diseases. Farmers need specific guidance on which combination of organic inputs and crops can increase or reduce the pressure of weeds, pests and diseases in a given environment.

\section{Soil biodiversity}

Soil is one of the most species-rich habitats of terrestrial ecosystems (Decaëns et al. 2006; Wolters 2001). In agricultural systems, most of the biodiversity resides in soils (Brussaard et al. 2007). In part due to these large number of soil species, most of the relationships between soil biodiversity and crop production remain unknown. There are close relations between SOM and soil life, but the precise mechanisms are not fully understood (Six et al. 2006). Losses of SOM might however lead to losses in soil biodiversity (Tibbet 2016) and agricultural intensification is known to affect biodiversity in agricultural soils (Tsiafouli et al. 2015). In this case, the 'precautionary' principle (Decaëns et al. 2006) could apply as we are not aware of the risks of losing soil biodiversity on the long term.

\subsection{Limitations of the study}

\section{Analysis of total SOM content instead of different SOM fractions}

In this thesis, the role of SOM for crop production was based on total $\mathrm{C}$ content in the soil (Fig. 2.4b, Fig. 2.5, Fig. 6.7 and Fig. 6.8) or total or effective $C$ content of organic inputs (Fig. 2.4d, Table 5.6 and Fig. 5.8). These numbers were either reported by farmers (Chapter 6), calculated using technical coefficients (Chapters 2 and 5) or based on soil analyses in experimental fields (Chapter 2). All these three methods (reports by farmers, using technical coefficients or soil analyses in experimental fields) might have caused some degree of error or variation in the data. This was however inevitable when relying on published data and farm surveys. Nonetheless some interesting relationships and patterns could be observed (as described in the previous sections).

There is recent evidence that specific SOM fractions play specific roles in improving aggregate stability of soils (Dexter et al. 2008). Organic inputs from straw, stubble or roots might have a proportionally larger impact on aggregate stability compared to organic inputs from animal manures (Powlson et al. 2011; Watts et al. 2006). In contrast, comparing effects from animal manure and crop residues on soil structure, Bhogal et al. (2009) found that animal manures increased topsoil porosity, plant available water capacity and decreased bulk density while crop residues did not. Evaluating total SOM 
content lacks this type of detail. Ordinary soil analyses (for field experiments or farmers) report only total SOC or SOM content. Taking into account specific fractions would therefore require introduction and acceptance of new soil analysis methods.

Which fractions of SOM play a larger role in aggregate stability is also important when considering possible trade-offs or synergies with soil carbon sequestration. If the contribution from SOM to soil fertility is mainly from fresh or active fractions, there is less synergy with soil carbon sequestration, which by default relies on very stable and inactive pools of carbon. If the correlation in Fig. 2.5a is a causal relation (meaning a relative increase in SOM content causes a relative increase in additional yield), then this thesis would support the first option. In that case the proportion of fresh or active SOM is more important for soil structural benefits to crop production than older fractions. This would explain the observation in Fig. 2.4b, in which there is no relation between SOM content at the start of each experiment and the additional yield effect of organic inputs. If large parts of these different SOM percentages are older SOM fractions (and if older SOM fractions are less beneficial for soil structural benefits to crop growth), then fields with both lower and higher SOM contents benefit equally from fresh organic inputs.

\section{Study area}

The objective of this thesis was to cover large parts of Europe. Per chapter however, study areas differed. The meta-analysis of Chapter 2 was based on long-term experiments in nine countries (Germany, Italy, Romania, Czech Republic, Hungary, Spain, Serbia, Estonia and Austria), while a subset of these was taken in Chapter 3 (Italy, Romania, Hungary, Czech Republic and Germany), depending on data availability. Chapter 4 was based on a farm survey in four countries (the Netherlands, Belgium, Austria and Italy), whilst Chapter 5 was a case study in the Netherlands. Finally, Chapter 6 was based on a farm survey in five countries, again differing in composition (Germany, Italy, Belgium, Austria and Spain).

The data used in each chapter depended on available publications (Chapters 2 and 3 ) or inclusion of arable farmers and incorporation of questions in the farm survey of the CATCH-C project (Chapters 4, 5 and 6). Therefore, study areas differed between chapters and datasets were sometimes unbalanced with regard to spread of farmers across climates and soil textures and practices included. In addition, response rates to questionnaires were sometimes low, which might have given a bias in the type of 
farmers filling in the questionnaire. Nonetheless, ranges of environmental conditions and spread of locations does seem to justify more general conclusions.

As this study only focussed on Europe, very weathered soils, mostly occurring in tropical regions, were not included. Weathered soils often have very low cation exchange capacity (Palm et al. 1997) and lack a number of micro nutrients necessary for crop growth (Gupta et al. 2008). On weathered soils therefore, additional yield effects of organic inputs and perceived deficiency of SOM could be larger. In tropical regions however, soil analyses by farmers are often less common. In addition, a recent global database suggests experimental set-ups as used in our meta-analysis do not exist outside temperate regions (ISCN 2015), establishment of such long term experiments would therefore be recommended.

\section{Focus on mineral soils only}

This study is limited to mineral soils, organic (peat) soils were excluded (besides a small percentage of Dutch farmers in Chapter 4). Peat soils have very high contents of SOM, but because of their organic nature, their structure and response to organic inputs is very different from mineral soils (Lucas 1982). Peat soils are especially important when considering climate change mitigation as, globally, peat soils contain approximately 455 Pg of carbon, which is twice the amount found in the world's forest biomass (Dunn \& Freeman 2011). Often, peat soils are drained to make them suitable for cultivation, which causes substantial amounts of greenhouse gas emissions (Erkens et al. 2016). These dynamics were however outside the scope of this study.

\subsection{Implications of the findings}

The findings in this thesis indicate that at least on the shorter term, on average, there seems to be no immediate threat from a deficiency of SOM to crop production in arable farming in Europe. The long-term experiments showed that with sufficient use of only mineral fertilisers, similar yields could be attained over multiple years as with the combined use of organic inputs and mineral fertiliser. This result was independent from SOM content in the experimental fields (Chapter 2). Similarly, the large majority of the farmers interviewed (82\%) did not perceive a high or very high deficiency of SOM for productive capacity (Chapter 6). Likewise, a major barrier identified for the use of organic inputs are the financial consequences at farm level (either increased costs or reduced income, Chapters 4,5). This suggests that at least on the short term, on average, European arable farmers do not benefit financially from increasing SOM content. 
These findings differ when looking in more detail at specific environmental conditions, types of crops cultivated and types of organic inputs used (Fig 7.1). SOM and organic inputs give more benefits to crop production in wet climates, on very sandy soils and on steep slopes. It seems that while the functions of SOM can be replaced with technical means to a large extent (e.g. tillage, use of mineral fertilisers), there are limits to this technical potential when environmental conditions are more extreme or crops are more demanding.

Specialized crops (such as root and tuber crops) benefit more from organic inputs than cereals. Even though additional yield effects of organic inputs were small, they do exist for potatoes (Fig. 2.3b). More in general, farmers who cultivate a larger share of their land with specialized or horticultural crops (such as sugar beets, onions, carrots or other vegetables) perceived a higher deficiency of SOM (Fig. 6.6d). Often, such crops are the cash crops on which the income of a farmer relies, more than on cereals. Small changes in yields of these crops might therefore have a relatively large impact on the long-term viability of a farm.

This thesis has found that - for the current degree of intensification in European arable farming - the contribution of SOM to crop production in European arable farming depends on a number of environmental factors, types of organic inputs used and crop types cultivated. If policies on SOM management aim to include benefits for crop production, it would therefore be advisable to focus on areas with more extreme environmental conditions.

In his thesis on the on-farm benefits of SOM for England and Wales, Verheijen (2005b) calls for a paradigm change in which SOM's importance for crop production shifts from a primary function to a secondary, or buffer, function. In this proposed new paradigm: "SOM still contributes to most agro-production sub-functions, but its magnitude is relatively low and in many cases only (measurably) occurring in 'extreme' climatic years" (Verheijen 2005b). The findings in this thesis support his suggestion and give reason to in include besides 'more extreme climatic years' also 'more extreme environmental conditions' and possibly 'more demanding crops'. 


\section{List of references}

Ajzen I. 1991. The theory of planned behavior. Organizational Behavior and Human Decision Processes 50: 179-211.

Albert E. and Grunert M. 2013. Wirkung einer langjährig differenzierten mineralischorganischen Düngung auf Ertrag, Humusgehalt, N-Bilanz und Nährstoffgehalte des Bodens. Archives of Agronomy and Soil Science 59: 1073-1098.

Allison F.E. 1973. Developments in soil science 3; Soil organic matter and its role in crop production. Elsevier scientific publishing company, Amsterdam.

Andersen E., Elbersen B., Godeschalk F. and Verhoog D. 2007. Farm management indicators and farm typologies as a basis for assessments in a changing policy environment. Journal of Environmental Management 82: 353-362.

Aune J. and Lal R. 1997. Agricultural productivity in the tropics and critical limits of properties of Oxisols, Ultisols, and Alfisols. Tropical Agriculture 74: 96-103.

Bailey K.L. and Lazarovits G. 2003. Suppressing soil-borne diseases with residue management and organic amendments. Soil and Tillage Research 72: 169-180.

Baker J.M., Ochsner T.E., Venterea R.T. and Griffis T.J. 2007. Tillage and soil carbon sequestration - What do we really know? Agriculture, Ecosystems \& Environment 118: $1-5$.

Baldock J., Oades J., Waters A., Peng X., Vassallo A. and Wilson M. 1992. Aspects of the chemical structure of soil organic materials as revealed by solid-state $13 \mathrm{C} \mathrm{NMR}$ spectroscopy. Biogeochemistry 16: 1-42.

Barkusky D. 2009. Müncheberger Nährstoffsteigerungsversuch. Dauerfeldversuche in Brandenburg und Berlin. Beiträge für eine nachhaltige landwirtschaftliche Nutzung. Hrsg. Ministerium für ländliche Entwicklung, Umwelt und Verbraucherschutz des Landes Brandenburg (MLUV), pp. 103-108.

Barton K. 2015. Package 'MuMIn'. Multi-model interference The Comprehensive R Archive Network, p. Software package.

Barzegar A.R., Yousefi A. and Daryashenas A. 2002. The effect of addition of different amounts and types of organic materials on soil physical properties and yield of wheat. Plant and Soil 247: 295-301.

Basso B. and Ritchie J.T. 2005. Impact of compost, manure and inorganic fertilizer on nitrate leaching and yield for a 6-year maize-alfalfa rotation in Michigan. Agriculture, Ecosystems \& Environment 108: 329-341.

Bauder J. 2000. Cereal Crop Residues and Plant Nutrients. Montana State University.

Beedell J. and Rehman T. 2000. Using social-psychology models to understand farmers' conservation behaviour. Journal of rural studies 16: 117-127. 
Benito E. and Diaz-Fierros F. 1992. Effects of cropping on the structural stability of soils rich in organic matter. Soil and Tillage Research 23: 153-161.

Bhogal A., Nicholson F.A., Rollett A. and Chambers B.J. 2009. Best practice for managing soil organic matter in agriculture. Manual of methods for 'lowland' agriculture. ADAS Gleadthorpe.

Birkmose T.S. 2009. Nitrogen recovery from organic manures: improved slurry application techniques and treatment - the Danish scenario. International Fertiliser Society, York, p. 24 pp.

Bischoff R. 1995. Der Internationale Organische Stickstoffdauerdüngungsversuch (IOSDV) Speyer. Archives of Agronomy and Soil Science 39: 461-471.

Blandino M., Haidukowski M., Pascale M., Plizzari L., Scudellari D. and Reyneri A. 2012. Integrated strategies for the control of Fusarium head blight and deoxynivalenol contamination in winter wheat. Field crops research 133: 139-149.

Bodner G. 2013. Hydrologische Effekte des Zwischenfruchtanbaus im Trockengebiet. Innovation Universität für Bodenkultur Wien, Austria.

Bodner G., Summerer H., Ecker F. and Rosner J. 2011. Zwischenfruchtbau ist auch im Trockengebiet machbar Ländlicher Raum.Online-Fachzeitschrift des Bundesministeriums für Land- und Forstwirtschaft, Umwelt und Wasserwirtschaft.

Bos J.F.F.P., ten Berge H.F.M., Verhagen J. and van Ittersum M.K. 2017. Trade-offs in soil fertility management on arable farms. Agricultural Systems.

Bozdogan H. 1987. Model selection and Akaike's Information Criterion (AIC): The general theory and its analytical extensions. Psychometrika 52: 345-370.

Brussaard L., de Ruiter P.C. and Brown G.G. 2007. Soil biodiversity for agricultural sustainability. Agriculture, Ecosystems \& Environment 121: 233-244.

Burke I.C., Yonker C.M., Parton W.J., Cole C.V., Schimel D.S. and Flach K. 1989. Texture, Climate, and Cultivation Effects on Soil Organic Matter Content in U.S. Grassland Soils. Soil Science Society of America Journal 53: 800-805.

Burton R.J.F. 2004. Reconceptualising the 'behavioural approach' in agricultural studies: a socio-psychological perspective. Journal of rural studies 20: 359-371.

Capriel P. 2013. Trends in organic carbon and nitrogen contents in agricultural soils in Bavaria (south Germany) between 1986 and 2007. European Journal of Soil Science 64: 445-454.

Case S.D.C., Oelofse M., Hou Y., Oenema O. and Jensen L.S. 2017. Farmer perceptions and use of organic waste products as fertilisers - A survey study of potential benefits and barriers. Agricultural Systems 151: 84-95. 
CBAV. 2017. Handboek Bodem en Bemesting. Praktijkonderzoek Plant en Omgeving (PPO) Wageningen University and Research, p. Dutch web page on soils and nutrients run by the committee for fertilization for arable and vegetable crops (CBAV).

CBS. 2012. Agricultural Census 2012. Statistics Netherlands.

CBS. 2017. Statline. Electronic databank of Statistics Netherlands. Statistics Netherlands, http://statline.cbs.nl/statweb/.

Cerrato M. and Blackmer A. 1990. Comparison of models for describing; corn yield response to nitrogen fertilizer. Agronomy Journal 82: 138-143.

Chaney K. and Swift R.S. 1986. Studies on aggregate stability. 11. The effect of humic substances on the stability of re-formed soil aggregates. Journal of Soil Science 37: 337343.

Chang E.-H., Chung R.-S. and Tsai Y.-H. 2007. Effect of different application rates of organic fertilizer on soil enzyme activity and microbial population. Soil Science and Plant Nutrition 53: 132-140.

Chapman S.J., Bell J.S., Campbell C.D., Hudson G., Lilly A., Nolan A.J., Robertson A.H.J., Potts J.M. and Towers W. 2013. Comparison of soil carbon stocks in Scottish soils between 1978 and 2009. European Journal of Soil Science 64: 455-465.

Chivenge P.P., Murwira H.K., Giller K.E., Mapfumo P. and Six J. 2007. Long-term impact of reduced tillage and residue management on soil carbon stabilization: Implications for conservation agriculture on contrasting soils. Soil and Tillage Research 94: 328-337.

Christensen B.T. and Johnston A.E. 1997. Chapter 18 Soil organic matter and soil quality-Lessons learned from long-term experiments at Askov and Rothamsted. Developments in Soil Science 25: 399-430.

Ciais P., Sabine C., Bala G., Bopp L., Brovkin V., Canadell J., Chhabra A., DeFries R., Galloway J., Heimann M., Jones C., Le Quéré C., Myneni R.B., Piao S. and Thornton P. 2013. Carbon and other biogeochemical cycles. In: Stocker T. F., Qin D., Plattner G.K., Tignor M., Allen S. K., Boschung J., Nauels A., Xia Y., Bex V. and Midgley P. M. (eds), Climate change 2013: the physical science basis. Contribution of Working Group I to the Fifth Assessment Report of the Intergovernmental Panel on Climate Change. Cambridge University Press, Cambridge, United Kingdom and New York, NY, USA, pp. 465-570.

Conover W.J. 1971. Practical nonparametric statistics. John Wiley \& Sons.

Corbeels M., Shiferaw A. and Haile M. 2000. Farmers' knowledge of soil fertility and local management strategies in Tigray, Ethiopia. IIED-Drylands Programme.

Dalgaard T., Hansen B., Hasler B., Hertel O., Hutchings N.J., Jacobsen B.H., Jensen L.S., Kronvang B., Olesen J.E. and Schjørring J.K. 2014. Policies for agricultural 
nitrogen management - trends, challenges and prospects for improved efficiency in Denmark. Environmental Research Letters 9: 115002.

Dawe D., Dobermann A., Ladha J., Yadav R., Bao L., Gupta R., Lal P., Panaullah G., Sariam O. and Singh Y. 2003. Do organic amendments improve yield trends and profitability in intensive rice systems? Field crops research 83: 191-213.

De Haan S. 1977. Humus, its formation, its relation with the mineral part of the soil, and its significance for soil productivity. Soil Organic Matter Studies; Proceedings of a Symposium.

de Vries J. 2014. From animals to crops: environmental consequences of current and future strategies for manure management. Wageningen Universiteit (Wageningen University).

De Vries J., Vinken T., Hamelin L. and De Boer I. 2012. Comparing environmental consequences of anaerobic mono-and co-digestion of pig manure to produce bioenergy-a life cycle perspective. Bioresource technology 125: 239-248.

Decaëns T., Jiménez J.J., Gioia C., Measey G.J. and Lavelle P. 2006. The values of soil animals for conservation biology. European Journal of Soil Biology 42: S23-S38.

Dekker P., van Dam A.-M. and Pronk A. 2004. Data supplement to "Rapportage bemesting 2004. Telen met toekomst".

Delin S., Stenberg B., Nyberg A. and Brohede L. 2012. Potential methods for estimating nitrogen fertilizer value of organic residues. Soil Use and Management 28: 283-291.

Dersch G. 2015. Die Humusgehalte der heimischen Ackerböden haben sich positiv entwickelt. BauernZeitung, p. 6.

Dexter A.R., Richard G., Arrouays D., Czyż E.A., Jolivet C. and Duval O. 2008. Complexed organic matter controls soil physical properties. Geoderma 144: 620-627.

Díaz-Zorita M., Buschiazzo D.E. and Peinemann N. 1999. Soil Organic Matter and Wheat Productivity in the Semiarid Argentine Pampas. Agronomy Journal 91: 276-279.

Diekmann K.H., De Datta S.K. and Ottow J.C.G. 1993. Nitrogen uptake and recovery from urea and green manure in lowland rice measured by $15 \mathrm{~N}$ and non-isotope techniques. Plant and Soil 148: 91-99.

Dlugokencky E. and Tans P. 2017. Trends in Atmospheric Carbon Dioxide. Recent Global CO2. NOAA/ESRL Global Monitoring Division. Earth System Research Laboratory.

Dungait J.A.J., Hopkins D.W., Gregory A.S. and Whitmore A.P. 2012. Soil organic matter turnover is governed by accessibility not recalcitrance. Global Change Biology 18: 1781-1796.

Dunn C. and Freeman C. 2011. Peatlands: our greatest source of carbon credits? Carbon Management 2: 289-301. 
EC. 2006. Proposal for a Directive of the European Parliament and of the Council establishing a framework for the protection of soil and amending Directive 2004/35/EC. COM (2006) 232 final. Brussels.

EC. 2011a. Commission staff working paper. Analysis associated with the Roadmap to a Resource Efficient Europe. Part II. Brussels.

EC. 2011b. Roadmap to a resource efficient Europe. COM(2011) 571 final. EUR-Lex, Brussels, p. 25.

EC. 2013. Annex II, rules on cross-compliance pursuant to article 93. Regulation (EU) No 1306/2013 of the European parliament and of the council on the financing, management and monitoring of the common agricultural policy. Official Journal of the Europan Union, Brussels.

EC and ESBN. 2004. The European Soil Database distribution version 2.0, CD-ROM, EUR 19945 EN. European Commission and the European Soil Bureau Network.

EEC. 1991. Council Directive 91/676/EEC of 12 December 1991 concerning the protection of waters against pollution caused by nitrates from agricultural sources. official Journal 1 375: 12.

Eggleton T. 2013. A short introduction to climate change. Cambridge University Press, New York.

Eich D., Körschens M. and Pfefferkorn A. 2013. 100 Jahre Agrar-und Umweltforschung Bad Lauchstädt: Geschichte der Forschungsstätte von 1895 bis 1995. Springer-Verlag.

Eriksen J. 2009. Chapter 2 Soil Sulfur Cycling in Temperate Agricultural Systems. Advances in agronomy. Academic Press, pp. 55-89.

Erkens G., van der Meulen M.J. and Middelkoop H. 2016. Double trouble: subsidence and $\mathrm{CO} 2$ respiration due to 1,000 years of Dutch coastal peatlands cultivation. Hydrogeology Journal 24: 551-568.

Eurostat. 2012. Agri-environmental indicator - mineral fertiliser consumption. European Commission, Statistical office of the European Union

Eurostat. 2013. Standard output coefficients. European Commission, Statistical office of the European Union

Falkowski P., Scholes R., Boyle E., Canadell J., Canfield D., Elser J., Gruber N., Hibbard K., Högberg P. and Linder S. 2000. The global carbon cycle: a test of our knowledge of earth as a system. Science 290: 291-296.

Fantappiè M., L'Abate G. and Costantini E.A.C. 2011. The influence of climate change on the soil organic carbon content in Italy from 1961 to 2008. Geomorphology 135: 343352. 
Feller C. 1995. La matière organique du sol et la recherche d'indicateurs de la durabilité des systèmes de culture dans les régions tropicales semi-arides et subhumides d'Afrique de l'Ouest.

Feller C. and Beare M.H. 1997. Physical control of soil organic matter dynamics in the tropics. Geoderma 79: 69-116.

Flavel T.C. and Murphy D.V. 2006. Carbon and Nitrogen Mineralization Rates after Application of Organic Amendments to Soil. Journal of Environmental Quality 35: 183193.

Fleischer J., Barnes A., Awumbila B., Amaning-Kwarteng K. and Tieku C. 1989. Grain Yield and nutritive value of crop residues from three varieties of maize (Zea Mays L) crop. Overcoming Constraints to Efficient Utilization of Agricultural By-Products as Animal Feed (eds. Said, AN and Dzowela, BH). Proceedings of the African Research Network for Agricultural By-products (ARNAB). Bamenda, Cameroun, Addis Ababa, Ethiopia: 239-255.

Florentín M.A. 2011. Green manure/cover crops and crop rotation in conservation agriculture on small farms. Plant Production and Protection Division, Food and Agriculture Organization of the United Nations.

Fox D.M. and Bryan R.B. 2000. The relationship of soil loss by interrill erosion to slope gradient. Catena 38: 211-222.

Freibauer A., Rounsevell M.D., Smith P. and Verhagen J. 2004. Carbon sequestration in the agricultural soils of Europe. Geoderma 122: 1-23.

Frelih-Larsen A., Bowyer C., Albrecht S., Keenleyside C., Kemper M., Nanni S., Naumann S., Mottershead D., Landgrebe R., Andersen E., Banfi P., Bell S., Brémere I., Cools J., Herbert S., Iles A., Kampa E., Kettunen M., Lukacova Z., Moreira G., Kiresiewa Z., Rouillard J., Okx J., Pantzar M., Paquel K., Pederson R., Peepson A., Pelsy F., Petrovic D., Psaila E., Šarapatka B., Sobocka J., Stan A.-C., Tarpey J. and Vidaurre R. 2016. Updated Inventory and Assessment of Soil Protection Policy Instruments in EU Member States. Ecologic Institute, Berlin.

Frigge M., Hoaglin D.C. and Iglewicz B. 1989. Some implementations of the boxplot. The American Statistician 43: 50-54.

Gardner K. and Barrows R. 1985. The Impact of Soil Conservation Investments on Land Prices. American Journal of Agricultural Economics 67: 943-947.

Gent U. 2010. Ontwikkelen van een expertsysteem voor het adviseren van het koolstofbeheer in de landbouwbodems. Universiteit Gent, Vakgroep Bodembeheer en bodemhygiëne.

George B. 1984. Design and interpretation of nitrogen response experiments. Nitrogen requirement of cereals: proceedings of a conference organised by the Agricultural Development and Advisory Service, September 1982. London: HMSO, 1984. 
Giordani G., Comellini F., Triberti L. and Nastri A. 2010. Dopo 15 anni di residui interrati al grano non serve più l'azoto. l'informatore agrario. Edizioni l'informatore agrario S.p.A.

Glendining M. and Powlson D. 1995. The effects of long continued applications of inorganic nitrogen fertilizer on soil organic nitrogen-a review. Soil Management. Experimental Basis for Sustainability and Environmental Quality, Lewis Publishers, Boca Raton-London-Tokyo: 385-446.

Glenk K., Shrestha S., Topp C.F., Sánchez B., Iglesias A., Dibari C. and Merante P. 2017. A farm level approach to explore farm gross margin effects of soil organic carbon management. Agricultural Systems 151: 33-46.

Goidts E. and van Wesemael B. 2007. Regional assessment of soil organic carbon changes under agriculture in Southern Belgium (1955-2005). Geoderma 141: 341-354.

Gonçalves J.L.M. and Carlyle J.C. 1994. Modelling the influence of moisture and temperature on net nitrogen mineralization in a forested sandy soil. Soil Biology and Biochemistry 26: 1557-1564.

Govaerts* B., Verhulst* N., Castellanos-Navarrete A., Sayre K., Dixon J. and Dendooven L. 2009. Conservation agriculture and soil carbon sequestration: between myth and farmer reality. Critical Reviews in Plant Science 28: 97-122.

Greenland D., Rimmer D. and Payne D. 1975. Determination of the structural stability class of English and Welsh soils, using a water coherence test. Journal of Soil Science 26: 294-303.

Gregorich E.G., Greer K.J., Anderson D.W. and Liang B.C. 1998. Carbon distribution and losses: erosion and deposition effects. Soil and Tillage Research 47: 291-302.

Gregorich E.G., Monreal C.M., Carter M.R., Angers D.A. and Ellert B.H. 1994. Towards a minimum data set to assess soil organic matter quality in agricultural soils. Canadian Journal of Soil Science 74: 367-385.

Günther A., Van Den Eeckhaut M., Malet J.-P., Reichenbach P. and Hervás J. 2014. Climate-physiographically differentiated Pan-European landslide susceptibility assessment using spatial multi-criteria evaluation and transnational landslide information. Geomorphology 224: 69-85.

Gupta U.C., Wu K. and Liang S. 2008. Micronutrients in Soils, Crops, and Livestock. Earth Science Frontiers 15: 110-125.

Gurevitch J. and Hedges L.V. 1999. Statistical issues in ecological meta-analyses. Ecology 80: 1142-1149.

Gutser R., Ebertseder T., Weber A., Schraml M. and Schmidhalter U. 2005. Short-term and residual availability of nitrogen after long-term application of organic fertilizers on arable land. Journal of Plant Nutrition and Soil Science 168: 439-446. 
Hamza M.A. and Anderson W.K. 2005. Soil compaction in cropping systems: A review of the nature, causes and possible solutions. Soil and Tillage Research 82: 121-145.

Haynes R.J. and Naidu R. 1998. Influence of lime, fertilizer and manure applications on soil organic matter content and soil physical conditions: a review. Nutrient Cycling in Agroecosystems 51: 123-137.

Hedges J.I., Eglinton G., Hatcher P.G., Kirchman D.L., Arnosti C., Derenne S., Evershed R.P., Kögel-Knabner I., De Leeuw J. and Littke R. 2000. The molecularlyuncharacterized component of nonliving organic matter in natural environments. Organic geochemistry 31: 945-958.

Hege U. and Offenberger K. 2006. Effect of differentiated mineral fertilization and organic manuring on yield, product quality and $\mathrm{N}$ balances in the international permanent organic nitrogen experiment (IOSDV) Puch. Archives of Agronomy and Soil Science 52: 535-550.

Heikkinen J., Ketoja E., Nuutinen V. and Regina K. 2013. Declining trend of carbon in Finnish cropland soils in 1974-2009. Global Change Biology 19: 1456-1469.

Hendrickx G., Boon W. and Bries J. 1992. De chemische bodemvruchtbaarheid van het Vlaamse akkerbouw-en weilandareaal, 1989-1991. Bodemkundige Dienst van Belgie.

Hernández D., Polo A. and Plaza C. 2013. Long-term effects of pig slurry on barley yield and $\mathrm{N}$ use efficiency under semiarid Mediterranean conditions. European Journal of Agronomy 44: 78-86.

Herron G. and Erhart A. 1965. Value of manure on an irrigated calcareous soil. Soil Science Society of America Journal 29: 278-281.

Hideborn Alm K. and Dahlin S. 2007. Success Stories of Agricultural Long-term Experiments. Ake Barklund, KSLA, Royal Swedish Academy of Agriculture and Forestry.

Hijbeek R., van Ittersum M.K., ten Berge H.F.M., Gort G., Spiegel H. and Whitmore A.P. 2017. Do organic inputs matter - a meta-analysis of additional yield effects for arable crops in Europe. Plant and Soil 411: 293-303.

Hijbeek R., Wolf J. and Van ittersum M.K. 2013. A typology of farming systems, related soil management and soil degradation in eight European countries. D2.242. CATCH-C report. Wageningen University and Research Centre, Wageningen, p. 226.

Hoffmann S., Kismányoky T. and Balázs J. 1997. Der Internationale Organische Stickstoffdauerdüngungsversuch (IOSDV) Keszthely nach 12 Versuchsjahren. Archives of Agronomy and Soil Science 41: 123-132.

Hoogsteen M.J.J., Lantinga E.A., Bakker E.J., Groot J.C.J. and Tittonell P.A. 2015. Estimating soil organic carbon through loss on ignition: effects of ignition conditions and structural water loss. European Journal of Soil Science 66: 320-328. 
Hösch J. and Dersch G. 2002. The International Organic Nitrogen Long-term Fertilization Experiment (IOSDV) at Vienna. Archives of Agronomy and Soil Science 48: 471-484.

Houšková B. and Montanarella L. 2008. The natural susceptibility of european soils to compaction. Threats to Soil Quality in Europe: 23.

Hudson B.D. 1994. Soil organic matter and available water capacity. Journal of Soil and Water Conservation 49: 189-194.

IGBP T.C.W.G. 1998. The Terrestrial Carbon Cycle: Implications for the Kyoto Protocol. Science 280: 1393-1394.

Ingram J.S.I. and Fernandes E. 2001. Managing carbon sequestration in soils: concepts and terminology. Agriculture, Ecosystems \& Environment 87: 111-117.

Ingram J., Mills, J., Frelih-Larsen, A., Davis, M., Merante, P., Ringrose, S., Molnar, A., Sanchez, B., Ghaley, B.B. and Karaczub, Z. 2014. Managing Soil Carbon: A Farm perspective. Eurochoices, 13:12-19.

ISCN. 2015. ISCN Database, International Soil Carbon Network, available at http://iscn.fluxdata.org/Data/Pages/AccessData.aspx.

Janssen B.H. 2002. Organic matter and soil fertility. Wageningen Agricultural University. Department of Environmental Sciences. Sub-department of Soil quality, Wageningen, p. 248.

Janssen B.H. and De Willigen P. 2006. Ideal and saturated soil fertility as bench marks in nutrient management: 1. Outline of the framework. Agriculture, Ecosystems \& Environment 116: 132-146.

Janssen B.H. and van der Weert R. 1977. The influence of fertilizers, soil organic matter and soil compaction on maize yields on the Surinam 'Zanderij'soils. Plant and Soil 46: 445-458.

Janssen S., Andersen E., Athanasiadis I.N. and van Ittersum M.K. 2009. A database for integrated assessment of European agricultural systems. Environmental Science \& Policy 12: 573-587.

Janzen H. 2004. Carbon cycling in earth systems - a soil science perspective. Agriculture, Ecosystems \& Environment 104: 399-417.

Janzen H.H., Bole J.B., Biederbeck V.O. and Slinkard A.E. 1990. Fate of N applied as green manure or ammonium fertilizer to soil subsequently cropped with spring wheat at three sites in Western Canada. Canadian Journal of Soil Science 70: 313-323.

Jensen L.S. 2013. Animal manure fertiliser value, crop utilisation and soil quality impacts. Animal Manure Recycling: Treatment and Management: 295-328.

Johnston A.E., Poulton P.R. and Coleman K. 2009. Soil organic matter: its importance in sustainable agriculture and carbon dioxide fluxes. Advances in agronomy 101: 1-57. 
Jonckheere A.R. 1954. A distribution-free k-sample test against ordered alternatives. Biometrika 41: 133-145.

Kanal A., Kautz T., Ellmer F. and Rühlmann J. 2003. Einfluss langjährig differenzierter Düngungsmassnahmen auf die Schwefel-und Stickstoffversorgung von Sommergerste in Berlin-Dahlem (D) und Tartu (Est). Archives of Agronomy and Soil Science 49: 543553.

Karlen D., Andrews S. and Doran J. 2001. Soil quality: current concepts and applications. Advances in agronomy 74: 1-40.

Káš M., Haberle J. and Matějková S. 2010. Crop productivity under increasing nitrogen rates and different organic fertilization systems in a long-term IOSDV experiment in the Czech Republic. Archives of Agronomy and Soil Science 56: 451-461.

Kätterer T., Reichstein M., Andrén O. and Lomander A. 1998. Temperature dependence of organic matter decomposition: a critical review using literature data analyzed with different models. Biology and fertility of soils 27: 258-262.

Katyal J. 1993. Integrated nitrogen management and supply: an overview. Proceedings -Indian National Science Academy Part B 59: 161-161.

Kemper W.D. and Koch E. 1966. Aggregate stability of soils from western United States and Canada. Measurement procedure, correlation with soil constituents. Technical Bulletin. United States Department of Agriculture, Agricultural Research Service.

Kendall M.G. 1948. Rank correlation methods. C. Griffin.

Kimetu J.M., Lehmann J., Ngoze S.O., Mugendi D.N., Kinyangi J.M., Riha S., Verchot L., Recha J.W. and Pell A.N. 2008. Reversibility of Soil Productivity Decline with Organic Matter of Differing Quality Along a Degradation Gradient. Ecosystems 11: 726-739.

Kirkby C.A., Richardson A.E., Wade L.J., Conyers M. and Kirkegaard J.A. 2016. Inorganic Nutrients Increase Humification Efficiency and C-Sequestration in an Annually Cropped Soil. PLoS ONE 11: e0153698.

Kirkby M.J., Jones R.J.A., Irvine B., Gobin A., Govers G., Cerdan O., Van Rompaey A.J.J., Le Bissonnais Y., Daroussin J., King D., Montanarella L., Grimm M., Vieillefont V., Puigdefabregas J., Boer M., Kosmas C., Yassoglou N., Tsara M., Mantel S., Van Lynden G.J. and Huting J. 2004. Pan-European Soil Erosion Risk Assessment: The PESERA Map, Version 1 October 2003. Explanation of Special Publication Ispra 2004 No.73 (S.P.I.04.73). European Soil Bureau Research Report Luxembourg, p. 18 pp.

Kismányoky T. and Tóth Z. 2012. Effect of mineral and organic fertilization on soil organic carbon content as well as on grain production of cereals in the IOSDV (ILTE) long-term field experiment, Keszthely, Hungary. Archives of Agronomy and Soil Science 59: 1121-1131. 
Klasink A. and Steffens G. 1995. Der Internationale Organische Stickstoffdauerdüngungsversuch (IOSDV) Oldenburg nach Neun Versuchs-jahren. Archives of Agronomy and Soil Science 39: 449-460.

Knapp E.B., Elliott L.F. and Campbell G.S. 1983. Carbon, nitrogen and microbial biomass interrelationships during the decomposition of wheat straw: A mechanistic simulation model. Soil Biology and Biochemistry 15: 455-461.

Konstantopoulos S. 2011. Fixed effects and variance components estimation in threelevel meta-analysis. Research Synthesis Methods 2: 61-76.

Körschens M., Albert E., Armbruster M., Barkusky D., Baumecker M., Behle-Schalk L., Bischoff R., Čergan Z., Ellmer F. and Herbst F. 2013. Effect of mineral and organic fertilization on crop yield, nitrogen uptake, carbon and nitrogen balances, as well as soil organic carbon content and dynamics: results from 20 European long-term field experiments of the twenty-first century. Archives of Agronomy and Soil Science 59: 1017-1040.

Körschens M., Albert E., Baumecker M., Ellmer F., Grunert M., Hoffmann S., Kismanyoky T., Kubat J., Kunzova E., Marx M., Rogasik J., Rinklebe J., Rühlmann J., Schilli C., Schröter H., Schroetter S., Schweizer K., Toth Z., Zimmer J. and Zorn W. 2014. Humus and climate change - results of 15 long-term experiments. Archives of Agronomy and Soil Science 60: 1485-1517.

Körschens M., Weigel A. and Schulz E. 1998. Turnover of soil organic matter (SOM) and long-term balances - tools for evaluating sustainable productivity of soils. Zeitschrift für Pflanzenernährung und Bodenkunde 161: 409-424.

Krull E., Baldock J. and Skjemstad J. 2001. Soil texture effects on decomposition and soil carbon storage. Net Ecosystem Exchange CRC Workshop Proceedings. Citeseer, pp. 103-110.

Kuldkepp P., Teesalu T. and Liiva I. 1996. Einfluss mineralischer und organischer Ndüngung auf Ertrag, Qualitätsmerkmale und auf die N-Bilanz im IOSDV Tartu/Estland. Archives of Agronomy and Soil Science 40: 97-105.

Kundler P., Steinbrenner K., Smukalski M., Kunze A., Quast J. and Roth D. 1989. Erhöhung der Bodenfruchtbarkeit. VEB Deutscher Landwirtschaftsverlag.

KWIN A. 2015. Kwantitatieve Informatie Akkerbouw en Vollegrondsgroenteteelt 2015. Praktijkonderzoek Plant en Omgeving (PPO) Wageningen University and Research.

Lal R. 1995. The role of residues management in sustainable agricultural systems. Journal of Sustainable Agriculture 5: 51-78.

Lal R. 2004a. Soil Carbon Sequestration Impacts on Global Climate Change and Food Security. Science 304: 1623-1627.

Lal R. 2004b. Soil carbon sequestration to mitigate climate change. Geoderma 123: 122. 
Lang H., Dressel J. and Bleiholder H. 1995. Langzeitwirkung der Stickstoffdüngung IOSDV - Standort Limburgerhof (Deutschland) in der Reihe 'Internationale Organische Stickstoffdauerdüngungsversuche'. Archives of Agronomy and Soil Science 39: 429448.

Langmeier M., Frossard E., Kreuzer M., Mäder P., Dubois D. and Oberson A. 2002. Nitrogen fertilizer value of cattle manure applied on soils originating from organic and conventional farming systems. Agronomie 22: 789-800.

Lantz B. 2013. The large sample size fallacy. Scandinavian Journal of Caring Sciences 27: 487-492.

Le Quéré C., Andres R.J., Boden T., Conway T., Houghton R.A., House J.I., Marland G., Peters G.P., van der Werf G., Ahlström A., Andrew R.M., Bopp L., Canadell J.G., Ciais P., Doney S.C., Enright C., Friedlingstein P., Huntingford C., Jain A.K., Jourdain C., Kato E., Keeling R.F., Klein Goldewijk K., Levis S., Levy P., Lomas M., Poulter B., Raupach M.R., Schwinger J., Sitch S., Stocker B.D., Viovy N., Zaehle S. and Zeng N. 2012. The global carbon budget 1959-2011. Earth System Science Data 5: 1107-1157.

Leclerc B., Georges P., Cauwel B. and Lairon D. 1995. A Five Year Study on Nitrate Leaching under Crops Fertilised with Mineral and Organic Fertilisers in Lysimeters. Biological Agriculture \& Horticulture 11: 301-308.

Lehmann J. and Kleber M. 2015. The contentious nature of soil organic matter. Nature 528: 60-68.

Leiros M., Trasar-Cepeda C., Seoane S. and Gil-Sotres F. 1999. Dependence of mineralization of soil organic matter on temperature and moisture. Soil Biology and Biochemistry 31: 327-335.

Lenth R.V. 2015. Using lsmeans. The Comprehensive R Archive Network. University of Iowa, p. Software package.

LNE. 2009. Organische stof in de bodem: sleutel tot bodemvruchtbaarheid. Brussel.

López-Fando C. and Pardo Fernández M.T. 2008. Long-term effect of organic and inorganic nitrogen Fertilizers on soil $\mathrm{N}$ balance and crop productivity.

López-Fando C., Fernandez M.T.P. and Wegener H.R. 1999. Erträge und N-Bilanzen im IOSDV Madrid im Laufe von vier Rotationen. Archives of Agronomy and Soil Science 44: 489-505.

Lory J.A., Russelle M.P. and Peterson T.A. 1995. A comparison of two nitrogen credit methods: traditional vs. difference. Agronomy Journal 87: 648-651.

Loveland P. and Webb J. 2003. Is there a critical level of organic matter in the agricultural soils of temperate regions: a review. Soil and Tillage Research 70: 1-18.

Lucas R.E. 1982. Organic soils (Histosols) : formation, distribution, physical and chemical properties and management for crop production. Michigan State University, East Lansing. 
Luo Z., Wang E. and Sun O.J. 2010. Can no-tillage stimulate carbon sequestration in agricultural soils? A meta-analysis of paired experiments. Agriculture, Ecosystems \& Environment 139: 224-231.

Lynne G.D., Shonkwiler J.S. and Rola L.R. 1988. Attitudes and farmer conservation behavior. American Journal of Agricultural Economics 70: 12-19.

MacCarthy P. 2001. The principles of humic substances: An introduction to the first principle. Special publication - Royal Society of Chemistry 273: 19-30.

Maeda M., Zhao B., Ozaki Y. and Yoneyama T. 2003. Nitrate leaching in an Andisol treated with different types of fertilizers. Environmental Pollution 121: 477-487.

Magdoff F. and Weil R.R. 2004. Soil organic matter management strategies. Soil organic matter in sustainable agriculture. CRC Press.

Maiorano A., Blandino M., Reyneri A. and Vanara F. 2008. Effects of maize residues on the Fusarium spp. infection and deoxynivalenol (DON) contamination of wheat grain. Crop Protection 27: 182-188.

Malinda D. 1995. Factors in conservation farming that reduce erosion. Australian Journal of Experimental Agriculture 35: 969-978.

Mandryk M. 2016. Integrated assessment of farm level adaptation to climate change in agriculture. Wageningen University.

Mandryk M., Reidsma P., Kanellopoulos A., Groot J.C. and van Ittersum M.K. 2014. The role of farmers' objectives in current farm practices and adaptation preferences: a case study in Flevoland, the Netherlands. Regional environmental change 14: 14631478 .

McDonald J.H. 2009. Handbook of biological statistics. Sparky House Publishing Baltimore, MD.

McGill R., Tukey J.W. and Larsen W.A. 1978. Variations of box plots. The American Statistician 32: 12-16.

Mehta C.M., Palni U., Franke-Whittle I.H. and Sharma A.K. 2014. Compost: Its role, mechanism and impact on reducing soil-borne plant diseases. Waste management 34: 607-622.

Meiyappan P. and Jain A.K. 2012. Three distinct global estimates of historical landcover change and land-use conversions for over 200 years. Frontiers of Earth Science 6: 122-139.

Metzger M.J., Bunce R.G.H., Jongman R.H.G., Mücher C.A. and Watkins J.W. 2005. A climatic stratification of the environment of Europe. Global Ecology and Biogeography 14: 549-563.

Meyer-Kohlstock D., Schmitz T. and Kraft E. 2015. Organic Waste for Compost and Biochar in the EU: Mobilizing the Potential. Resources 4: 457. 
Miller A.J., Amundson R., Burke I. and Yonker C. 2004. The effect of climate and cultivation on soil organic $\mathrm{C}$ and N. Biogeochemistry 67: 57-72.

Mogârzan A., Vasilica C., Axinte M., Zaharia M., Slabu C. and Robu T. 2007. The effect of organic-mineral fertilization on the yield and quality of sugar beet in a long term experiment at Ezăreni-Iasi. Lucrări Ştiinţifice 50.

Monreal C.M., Zentner R.P. and Robertson J.A. 1997. An analysis of soil organic matter dynamics in relation to management, erosion and yield of wheat in long-term crop rotation plots. Canadian Journal of Soil Science 77: 553-563.

Morari F., Panagos P. and Bampa F. 2016. Decline in organic matter in mineral soils. In: Stolte J., Tesfai M., Øygarden L., Kværnø S., Keizer J., Verheijen F., Panagos P., Ballabio C. and Hessel R. (eds), Soil threats in Europe. JRC, Luxembourg, pp. 39-52.

Motavalli P., Palm C., Parton W., Elliott E. and Frey S. 1995. Soil pH and organic C dynamics in tropical forest soils: evidence from laboratory and simulation studies. Soil Biology and Biochemistry 27: 1589-1599.

Murphy B. 2014. Soil organic matter and soil function-review of the literature and underlying data. Department of the Environment, Canberra, Australia.

Musinguzi P., Ebanyat P., Tenywa J., Basamba T., Tenywa M. and Mubiru D. 2015. Precision of farmer-based fertility ratings and soil organic carbon for crop production on a Ferralsol. Solid Earth 6: 1063.

Musinguzi P., Ebanyat P., Tenywa J.S., Basamba T.A., Tenywa M.M. and Mubiru D.N. 2016. Critical Soil Organic carbon range for optimal crop response to mineral fertiliser nitrogen on a Ferralsol. Experimental Agriculture: 1-19.

Nicholson F., Bhogal A., Chadwick D., Gill E., Gooday R., Lord E., Misselbrook T., Rollett A., Sagoo E. and Smith K. 2013. An enhanced software tool to support better use of manure nutrients: MANNER-NPK. Soil Use and Management 29: 473-484.

Nicholson F., Kindred D., Bhogal A., Roques S., Kerley J., Twining S., Brassington T., Gladders P., Balshaw H. and Cook S. 2014. Research Review No. 81. Straw incorporation review.

Oades J. 1988. The retention of organic matter in soils. Biogeochemistry 5: 35-70.

Oades J.M. 1984. Soil organic matter and structural stability: mechanisms and implications for management. Plant and Soil 76: 319-337.

Oehlert G.W. 1992. A note on the delta method. The American Statistician 46: 27-29.

Oelofse M., Markussen B., Knudsen L., Schelde K., Olesen J.E., Jensen L.S. and Bruun S. 2015. Do soil organic carbon levels affect potential yields and nitrogen use efficiency? An analysis of winter wheat and spring barley field trials. European Journal of Agronomy 66: 62-73. 
Oenema O. and Berentsen P. 2004. Manure policy and MINAS: regulating nitrogen and phosphorus surpluses in agriculture of the Netherlands. OECD.

Palm C.A., Giller K.E., Mafongoya P.L. and Swift M. 2001. Management of organic matter in the tropics: translating theory into practice. Managing Organic Matter in Tropical Soils: Scope and Limitations. Springer, pp. 63-75.

Palm C.A., Myers R.J. and Nandwa S.M. 1997. Combined use of organic and inorganic nutrient sources for soil fertility maintenance and replenishment. Replenishing soil fertility in Africa: 193-217.

Pan G., Smith P. and Pan W. 2009. The role of soil organic matter in maintaining the productivity and yield stability of cereals in China. Agriculture, Ecosystems \&amp; Environment 129: 344-348.

Panagos P., Borrelli P., Meusburger K., Alewell C., Lugato E. and Montanarella L. 2015. Estimating the soil erosion cover-management factor at the European scale. Land Use Policy 48: 38-50.

Pfefferkorn A. and Körschens M. 1995. Der Internationale Organische Stickstoffdauerdüngungsversuch (IOSDV) Bad Lauchstädt nach 16 Jahren. Archives of Agronomy and Soil Science 39: 413-427.

Pikula D., Berge H., Goedhart P. and Schröder J. 2016. Apparent nitrogen fertilizer replacement value of grass-clover leys and of farmyard manure in an arable rotation. Part II: farmyard manure. Soil Use and Management 32: 20-31.

Pinheiro J., Bates D., DebRoy S., Sarkar D. and Team R.C. 2015. Nlme: Linear and Nonlinear Mixed Effects Models. The Comprehensive R Archive Network, p. Software package.

Poeplau C. and Don A. 2015. Carbon sequestration in agricultural soils via cultivation of cover crops - A meta-analysis. Agriculture, Ecosystems \& Environment 200: 33-41.

Poeplau C., Kätterer T., Bolinder M.A., Börjesson G., Berti A. and Lugato E. 2015. Low stabilization of aboveground crop residue carbon in sandy soils of Swedish long-term experiments. Geoderma 237: 246-255.

Pohlert T. 2014. The pairwise multiple comparison of mean ranks package (PMCMR). The Comprehensive R Archive Network, Software package.

Potter P., Ramankutty N., Bennett E.M. and Donner S.D. 2010. Characterizing the Spatial Patterns of Global Fertilizer Application and Manure Production. Earth Interactions 14: 1-22.

Powlson D.S., Glendining M.J., Coleman K. and Whitmore A.P. 2011. Implications for Soil Properties of Removing Cereal Straw: Results from Long-Term Studies. Agronomy Journal 103: 279-287. 
Powlson D.S., Riche A.B., Coleman K., Glendining M.J. and Whitmore A.P. 2008. Carbon sequestration in European soils through straw incorporation: Limitations and alternatives. Waste management 28: 741-746.

Pribyl D.W. 2010. A critical review of the conventional SOC to SOM conversion factor. Geoderma 156: 75-83.

Pronk A.A. and Korevaar H. 2008. Possibilities to increase organic matter in arable production systems. Plant Research International, Wageningen.

Pronk A.A., Rijk B. and Hijbeek R. 2014. Compatibility of agricultural management practices and types of farming in the EU to enhance climate change mitigation and soil health. Task 4.2 Farm survey country report: The Netherlands., CATCH-C report. Wageningen University and Research Centre, Wageningen, p. 262.

Rawls W.J., Pachepsky Y.A., Ritchie J.C., Sobecki T.M. and Bloodworth H. 2003. Effect of soil organic carbon on soil water retention. Geoderma 116: 61-76.

RB I.W.G. 1998. World reference base for soil resources. Atlas. ISRIC-FAO-ISSSAcco, Leuven.

Reeves D. 1997. The role of soil organic matter in maintaining soil quality in continuous cropping systems. Soil and Tillage Research 43: 131-167.

Reijneveld A., van Wensem J. and Oenema O. 2009. Soil organic carbon contents of agricultural land in the Netherlands between 1984 and 2004. Geoderma 152: 231-238.

Reijneveld J. A. 2013. Unravelling changes in soil fertility of agricultural land in the Netherlands. Wageningen University, Wageningen, p. 240.

Reynolds B., Chamberlain P.M., Poskitt J., Woods C., Scott W.A., Rowe E.C., Robinson D.A., Frogbrook Z.L., Keith A.M., Henrys P.A., Black H.I.J. and Emmett B.A. 2013. Countryside Survey: National "Soil Change" 1978-2007 for Topsoils in Great Britain-Acidity, Carbon, and Total Nitrogen Status. Vadose Zone Journal 12.

Rhoton F.E., Shipitalo M.J. and Lindbo D.L. 2002. Runoff and soil loss from midwestern and southeastern US silt loam soils as affected by tillage practice and soil organic matter content. Soil and Tillage Research 66: 1-11.

Rice J.A. and MacCarthy P. 1991. Statistical evaluation of the elemental composition of humic substances. Organic geochemistry 17: 635-648.

Richards M., van Ittersum M., Mamo T., Stirling C., Vanlauwe B. and Zougmoré R. 2016. Fertilizers and low emission development in sub-Saharan Africa. CCAFS Policy Brief no. 11. . CGIAR Research Program on Climate Change, Agriculture and Food Security (CCAFS), Copenhagen, Denmark.

Richardson A.E., Kirkby C.A., Banerjee S. and Kirkegaard J.A. 2014. The inorganic nutrient cost of building soil carbon. Carbon Management 5: 265-268. 
RVO. 2014. Tabel 3 Werkingscoëfficiënt dierlijke en andere organische meststoffen 2014-2017. Mestbeleid 2014 - 2017 Tabellen. Netherlands Enterprise Agency (RVO.nl)

Sachs L. 1997. Angewandte Statistik, 1997. Springer, Berlin, Heidelberg.

Scharlemann J.P., Tanner E.V., Hiederer R. and Kapos V. 2014. Global soil carbon: understanding and managing the largest terrestrial carbon pool. Carbon Management 5: 81-91.

Schilling G. 1987. Pflanzenernährung und Düngung. Teil 2 Düngung.

Schröder J. 2005a. Revisiting the agronomic benefits of manure: a correct assessment and exploitation of its fertilizer value spares the environment. Bioresource technology 96: 253-261.

Schröder J. and Neeteson J. 2008. Nutrient management regulations in The Netherlands. Geoderma 144: 418-425.

Schröder J.J. 2005b. Manure as a suitable component of precise nitrogen nutrition.

Schulten H.-R., Plage B. and Schnitzer M. 1991. A chemical structure for humic substances. The Science of Nature 78: 311-312.

Scrimgeour F.G. and Shepherd T.G. 1998. The economics of soil structural degradation under cropping: some empirical estimates from New Zealand. Soil Research 36: 831840 .

Seshan V. 2012. clinfun: Clinical Trial Design and Data Analysis Functions. R package version 1.0.3.

Shibu M., Leffelaar P., Van Keulen H. and Aggarwal P. 2006. Quantitative description of soil organic matter dynamics - a review of approaches with reference to rice-based cropping systems. Geoderma 137: 1-18.

Silgram M. and Chambers B.J. 2002. Effects of long-term straw management and fertilizer nitrogen additions on soil nitrogen supply and crop yields at two sites in eastern England. The Journal of Agricultural Science 139: 115-127.

Six J., Conant R.T., Paul E.A. and Paustian K. 2002. Stabilization mechanisms of soil organic matter: Implications for C-saturation of soils. Plant and Soil 241: 155-176.

Six J., Frey S., Thiet R. and Batten K. 2006. Bacterial and fungal contributions to carbon sequestration in agroecosystems. Soil Science Society of America Journal 70: 555-569.

Smith P. 2004. Soils as carbon sinks: the global context. Soil Use and Management 20: 212-218.

Smith P. 2016. Soil carbon sequestration and biochar as negative emission technologies. Global Change Biology 22: 1315-1324.

Smith P., Smith J.U., Powlson D.S., McGill W.B., Arah J.R.M., Chertov O.G., Coleman K., Franko U., Frolking S., Jenkinson D.S., Jensen L.S., Kelly R.H., Klein-Gunnewiek H., Komarov A.S., Li C., Molina J.A.E., Mueller T., Parton W.J., Thornley J.H.M. and 
Whitmore A.P. 1997. A comparison of the performance of nine soil organic matter models using datasets from seven long-term experiments. Geoderma 81: 153-225.

Soane B.D. 1990. The role of organic matter in soil compactibility: A review of some practical aspects. Soil and Tillage Research 16: 179-201.

Sparling G., Parfitt R., Hewitt A. and Schipper L. 2003. Three approaches to define desired soil organic matter contents. Journal of Environmental Quality 32: 760-766.

Spiegel H., Dersch G., Baumgarten A. and Hösch J. 2010. The International organic nitrogen long-term fertilisation experiment (IOSDV) at Vienna after 21 years. Archives of Agronomy and Soil Science 56: 405-420.

Spink J., Hackett R., Forristal D. and Creamer R. 2010. Soil Organic Carbon: A review of 'critical'levels and practices to increase levels in tillage land in Ireland. Teagasc, Oak Park Crops Research Centre, Co. Carlow.

Starčević L., Latković D. and Malešević M. 2005. Dependence of corn yield on weather conditions and nitrogen fertilization in IOSDV Novi Sad. Archives of Agronomy and Soil Science 51: 513-522.

Starčević L., Malesević M., Marinković B. and Crnobarać J. 1997. Der Internationale Organische Stickstoffdauerdüngungsversuch (IOSDV) Novi Sad nach 12 Jahren. Archives of Agronomy and Soil Science 41: 155-166.

Stevenson F.J. 1994. Humus chemistry: genesis, composition, reactions. John Wiley \& Sons.

Stockmann U., Adams M.A., Crawford J.W., Field D.J., Henakaarchchi N., Jenkins M., Minasny B., McBratney A.B., Courcelles V.d.R.d., Singh K., Wheeler I., Abbott L., Angers D.A., Baldock J., Bird M., Brookes P.C., Chenu C., Jastrow J.D., Lal R., Lehmann J., O'Donnell A.G., Parton W.J., Whitehead D. and Zimmermann M. 2013. The knowns, known unknowns and unknowns of sequestration of soil organic carbon. Agriculture, Ecosystems \& Environment 164: 80-99.

Stolbovoy V. and Montanarella L. 2008. Application of Soil Oganic Carbon Status Indicators for policy-decision making in the EU. In: Toth G., Montanarella L. and Rusco E. (eds), Threats to Soil Quality in Europe. Office for Official Publication of the European Communities, Luxembourg.

Stolte J., Tesfai M., Øygarden L., Kværnø S., Keizer J., Verheijen F., Panagos P., Ballabio C. and Hessel R. 2015. Soil threats in Europe. Status, methods, drivers and effects on ecosystem services. deliverable 2.1 of the RECARE project. EUR $27607 \mathrm{EN}$. JRC Technical Reports. JRC, Luxembourg, p. 207.

Taghizadeh-Toosi A., Olesen J.E., Kristensen K., Elsgaard L., Østergaard H.S., Lægdsmand M., Greve M.H. and Christensen B.T. 2014. Changes in carbon stocks of Danish agricultural mineral soils between 1986 and 2009. European Journal of Soil Science 65: 730-740. 
ten Berge H.F.M., Schröder J.J., Olesen J.E. and Giráldez Cervera J.V. 2017. Preserving agricultural soils in the EU. Research for AGRI Committee European Parliament, Policy Department for Structural and Cohesion Policies, Brussels.

Tibbet. 2016. Decline in soil biodiversity. In: Jannes S., Tesfai M., Øygarden L., Kværnø S., Keizer J., Verheijen F., Panagos P., Ballabio C. and Hessel R. (eds), Soil threats in Europe: status, methods, drivers and effects on ecosystem services. European Union, Luxembourg.

Timmer R.D., Korthals G.W. and Molendijk L.P.G. 2004. Teelthandleiding groenbemesters. Kennisakker.nl. Productschap Akkerbouw, PPO-AGV.

Tisdall J.M. and Oades J.M. 1982. Organic matter and water-stable aggregates in soils. Journal of Soil Science 33: 141-163.

Toth G., Montanarella L. and Rusco E. 2008. Threats to soil quality in Europe. EUR 23438 EN - 2008. JRC Scientific and Technical Reports. JRC, Luxembourg.

Trabucco A. and Zomer R.J. 2009. Global Potential Evapo-Transpiration (Global-PET) and Global Aridity Index (Global-Aridity). available from the CGIAR-CSI GeoPortal at: http://www.csi.cgiar.org.

Triberti L., Nastri A., Giordani G., Comellini F., Baldoni G. and Toderi G. 2008. Can mineral and organic fertilization help sequestrate carbon dioxide in cropland? European Journal of Agronomy 29: 13-20.

Tsiafouli M.A., Thébault E., Sgardelis S.P., Ruiter P.C., Putten W.H., Birkhofer K., Hemerik L., Vries F.T., Bardgett R.D. and Brady M.V. 2015. Intensive agriculture reduces soil biodiversity across Europe. Global Change Biology 21: 973-985.

UK. 2015. The Nitrate Pollution Prevention Regulations 2015. The National Archives.

UNFCCC. 2012. Report of the Conference of the Parties on its seventeenth session, held in Durban from 28 November to 11 December 2011. Part Two: Action taken by the Conference of the Parties at its seventeenth session. Decisions adopted by the Conference of the Parties.

UNFCCC. 2015. Join the 4/1000 Initiative. Soils for Food Security and Climate. LimaParis Action Agenda

USGS. 1996. Global 30 Arc-Second Elevation (GTOPO30).

Van den Putte A., Govers G., Diels J., Gillijns K. and Demuzere M. 2010. Assessing the effect of soil tillage on crop growth: A meta-regression analysis on European crop yields under conservation agriculture. European Journal of Agronomy 33: 231-241.

van der Kolk J. and Zwart K. 2013. Pyrolysis in the Countries of the North Sea Region: Potentially available quantities of biomass waste for biochar production. Interreg IVB project Biochar. 
van Groenigen J.W., van Kessel C., Hungate B.A., Oenema O., Powlson D.S. and van Groenigen K.J. 2017. Sequestering Soil Organic Carbon: A Nitrogen Dilemma. Environmental science \& technology.

van Ittersum M.K. and Rabbinge R. 1997. Concepts in production ecology for analysis and quantification of agricultural input-output combinations. Field crops research 52: 197-208.

van Noordwijk M., Cerri C., Woomer P.L., Nugroho K. and Bernoux M. 1997. Soil carbon dynamics in the humid tropical forest zone. Geoderma 79: 187-225.

Vanlauwe B., Bationo A., Chianu J., Giller K.E., Merckx R., Mokwunye U., Ohiokpehai O., Pypers P., Tabo R. and Shepherd K.D. 2010. Integrated soil fertility management operational definition and consequences for implementation and dissemination. Outlook on agriculture 39: 17-24.

Vasilica C., Mogârzan A., Axinte M. and Chetrone M. 1997. Einfluss veschiedener Formen der organischen Düngung in Kombination mit mineralischem Stickstoff auf die Ertragsleistung von Zuckerrüben, Winterweizen und Mais und auf die Nährstoffbilanzen im Boden. Archives of Agronomy and Soil Science 41: 133-142.

Verheijen F.G.A., Bellamy P., Kibblewhite M.G. and Gaunt J. 2005. Organic carbon ranges in arable soils of England and Wales. Soil Use and Management 21:2-9.

Verheijen F.G.A. 2005a. Chapter 6. Arable field performance for different soil organic levels, measures, and management. On-farm benefits for SOM. Cranfield University.

Verheijen F.G.A. 2005b. On-farm benefits from soil organic matter in England and Wales. Faculty of Environment. Cranfield University, p. 238.

Verweij P., Janssen S., Braat L., van Eupen M., Soba M.P., Winograd M., de Winter W. and Cormont A. 2016. QUICKScan as a quick and participatory methodology for problem identification and scoping in policy processes. Environmental Science \& Policy 66: 47-61.

Von Boguslawski E. 1995. Das Zusammenwirken der mineralischen Düngung mit verschiedenen Formen der organischen Düngung im IOSDV Rauischholzhausen. Archives of Agronomy and Soil Science 39: 403-411.

Voskuilen M., Berkhout P., van Everdingen W., Jukema G., Luijt J., Van der Meulen H., Silvis H. and Wisman A. 2013. Structuur land- en tuinbouw. Landbouw Economisch Bericht 2013.

Vrkoc F., Skala J. and Suskevic M. 1996. Neunjährige Ertragsergebnisse der Internationalen Organischen Stickstoffdauerdüngungsversuche in der Tschechischen Republik. Archives of Agronomy and Soil Science 40: 115-132.

Vrkoč F., Vach M., Veleta V. and Košner J. 2002. Influence of different organic mineral fertilization on the yield structure and on changes of soil properties. Rostlinná Výroba 48: 216-221. 
Wadman W., Sluijsmans C. and Cremer L.D.L.L. 1987. Value of animal manures: changes in perception. Animal Manure on Grassland and Fodder Crops. Fertilizer or Waste? Springer, pp. 1-16.

Waksman S.A. and Stevens K.R. 1930. A critical study of the methods for determining the nature and abundance of soil organic matter. Soil Science 30: 97-116.

Wander M. 2004. Soil organic matter fractions and their relevance to soil function. Soil organic matter in sustainable agriculture. CRC Press.

Watts C.W., Clark L.J., Poulton P.R., Powlson D.S. and Whitmore A.P. 2006. The role of clay, organic carbon and long-term management on mouldboard plough draught measured on the Broadbalk wheat experiment at Rothamsted. Soil Use and Management 22: $334-341$.

Watts C.W. and Dexter A.R. 1997. The influence of organic matter in reducing the destabilization of soil by simulated tillage. Soil and Tillage Research 42: 253-275.

Wauters E. and Mathijs E. 2014. The adoption of farm level soil conservation practices in developed countries: a meta-analytic review. International Journal of Agricultural Resources, Governance and Ecology 10: 78-102.

Webb J., Sørensen P., Velthof G., Amon B., Pinto M., Rodhe L., Salomon E., Hutchings N., Burczyk P. and Reid J. 2013. An assessment of the variation of manure nitrogen efficiency throughout Europe and an appraisal of means to increase manure-N efficiency. Advances in agronomy 119: 371-442.

Wei W., Yan Y., Cao J., Christie P., Zhang F. and Fan M. 2016. Effects of combined application of organic amendments and fertilizers on crop yield and soil organic matter: An integrated analysis of long-term experiments. Agriculture, Ecosystems \& Environment 225: 86-92.

Werner M., Wauters E., Bijttebier J., Steinmann H.-H., Ruysschaert G. and Knierim A. 2017. Farm level implementation of soil conservation measures: farmers' beliefs and intentions. Renewable Agriculture and Food Systems: 1-14.

Wiersum L. 1957. The relationship of the size and structural rigidity of pores to their penetration by roots. Plant and Soil 9: 75-85.

Wolf J. and Janssen L. 1991. Effects of changing land use in The Netherlands on net carbon fixation. Netherlands Journal of Agricultural Science 39: 237-246.

Wolters V. 2001. Biodiversity of soil animals and its function. European Journal of Soil Biology 37: 221-227.

Wood S. and Cowie A. 2004. A review of greenhouse gas emission factors for fertiliser production. IEA bioenergy task, pp. 1-20.

Yang H. and Janssen B. 1997. Analysis of impact of farming practices on dynamics of soil organic matter in northern China. European Journal of Agronomy 7: 211-219. 
Zimmermann M., Leifeld J., Schmidt M.W.I., Smith P. and Fuhrer J. 2007. Measured soil organic matter fractions can be related to pools in the RothC model. European Journal of Soil Science 58: 658-667.

Zwart K., Kikkert A., Wolfs A., Termorshuizen A. and Van der Burgt G.J. 2013. De organische stof balans met de te verwachten stikstoflevering per teeltrotatie. Opzet en gebruikswijze van een rekenmodule. HLB, Wijster. the Netherlands, p. 17. 


\section{Summary}

Soil organic matter (SOM) is often considered the most important indicator of soil fertility. It contributes to each of fertility's three dimensions: the physical (structure, aeration, water retention), the biological (biomass, biodiversity, nutrient mineralisation, disease suppression) and the chemical (nutrient supply) dimension. Yet there is currently little scientific consensus on the precise relation between SOM and crop production.

Recently, concerns have been raised that SOM is declining in European soils and that SOM content should be maintained above a certain threshold to (among others) protect productive capacity of soils. It is currently unclear whether these concerns are justified. The aim of this thesis was to improve understanding of the role of organic inputs and SOM for crop production in contemporary arable farming in Europe. On a given arable field, a farmer can increase SOM content by increasing organic inputs, reducing tillage or reducing drainage. In this thesis, the research focus was on using organic inputs to increase SOM contents. Types of organic inputs investigated were application of farmyard manure (FYM), slurry or compost, incorporation of straw and the cultivation of green manures. The hypothesis was that the contribution of SOM to crop production on arable farms depends on environmental conditions and crop types cultivated.

The following research questions were addressed: (1) What is the additional yield effect of organic inputs for arable crops in Europe? (2) Do mineral fertiliser savings from organic inputs depend on total $\mathrm{N}$ supply? (3) What are currently the main drivers and barriers for arable farmers to use organic inputs? (4) How are farmers' beliefs on SOM related to their use of organic inputs? (5) Do farmers perceive a deficiency of SOM? Data from field and farm level were used to answer the research questions. To answer the first two research questions, data from long-term experiments were analysed. To answer the last three research questions, a large farm survey was conducted in six European countries (the Netherlands, Belgium, Austria, Spain, Italy and Germany).

Previous studies assessing the effects of organic inputs and SOM on crop yields have shown mixed results. Some studies have found positive effects while others found none. One cause for this variation may be found in mixing the effects of nutrient supply from organic inputs or SOM and other effects such as improved soil structure or soil life. To circumvent this limitation, in this thesis effects of organic inputs on crop yields were assessed in a system without macro-nutrient limitation. Any effect found on crop yields was called the 'additional yield effect'. 
To find the additional yield effect of organic inputs, a meta-analysis was performed of 20 long-term experiments (Chapter 2).Yield response curves to mineral fertiliser-N were calculated, with and without organic inputs (with sufficient $\mathrm{P}$ and $\mathrm{K}$ supply). The additional yield effect of organic inputs was calculated by taking the difference between the maxima ('attainable yield') of the yield response curves. Across all experiments, the mean additional yield effect of organic inputs was not significant $(+1.4$ percent \pm 1.6 $95 \%$ Confidence Interval). In specific cases however (i.e. for root and tuber crops, spring sown cereals, or for very sandy soils or wet climates), organic inputs did increase attainable yields (depending on the co-variable, additional yield effects varied mostly between 3-7\%). A significant correlation was found between increase in attainable yields and increase in SOM content.

The use of organic inputs can save mineral fertiliser N. Factors known to affect savings of mineral fertiliser include the form of $\mathrm{N}$ in the organic input, crop type cultivated, soil type, method of application, time of application and the manuring history which may govern $\mathrm{N}$ retention and losses. In this thesis, an additional factor on mineral fertiliser $\mathrm{N}$ savings was assessed which is currently not taken into account: the total $\mathrm{N}$ supply itself.

In Chapter 3, a subset of eight experiments was taken from Chapter 2 in which $\mathrm{N}$ contents of organic inputs were reported. Mineral fertiliser savings were compared at low and high total N supply. Results show that FYM saves significantly more mineral fertiliser $\mathrm{N}$ at high total $\mathrm{N}$ supply than at low total $\mathrm{N}$ supply (Nitrogen Fertiliser Replacement Value (NFRV) of 1.12 vs $0.53, p=0.04$ ). The other organic input types investigated also saved more mineral fertiliser $\mathrm{N}$ at high total $\mathrm{N}$ supply than at low total $\mathrm{N}$ supply, but sample sizes were too small or variations too large to find significant differences.

Besides effects on yield or savings of mineral fertilisers, farmers can have a wide array of drivers and barriers to use organic inputs or increase SOM content on their farm. According to the theory of planned behaviour, people base their behaviour on three main constructs: (1) their attitude (based on outcomes), 2) their subjective norm (based on social referents) and 3) the degree of perceived behavioural control (based on control factors). These three constructs are based on underlying beliefs of farmers and together lead to an intention, which might lead to a certain behaviour.

To find drivers and barriers for the use of organic inputs (Chapter 4), semi-structured interviews were held with arable farmers in six agro-ecological zones in four European countries (the Netherlands, Belgium, Austria and Italy). These semi-structured 
interviews were used to identify outcomes, referents and control factors relevant to the use of four types of organic inputs (incorporation of straw, cultivation of green manures, application of FYM and application of compost). Following, a large farm survey was held among 1180 arable farmers to quantify the outcomes, referents and control factors as either drivers or barriers. Drivers and barriers were classified into nine main categories (soil type \& climate, soil quality, crop protection, land use, technical, financial, environmental impact, legal and social).

Major drivers to use organic inputs were perceived effects on soil quality (such as improved soil structure or reduced erosion) and the positive influence from social referents (such as fellow farmers or agricultural advisors). Major barriers to use organic inputs were financial (increased costs or foregone income) and perceived effects on crop protection (such as increased weeds, pest and diseases or increased pesticide use). These findings show that farmers perceive a trade-off between improved soil quality on the one hand and increased pressures from weeds, pests and diseases and financial consequences on the other hand when using organic inputs.

A case study among 435 arable farmers in the Netherlands (Chapter 5), showed that farmers specifically value the effect of SOM content on soil structure, especially where it improves workability on clay soils and water holding capacity on sandy soils. Soil fungi were evaluated as a negative outcome of SOM. Among the different control factors, the long-term effect of SOM content was perceived as very strong and evaluated very positively. Advisors were considered to have the most positive view on SOM and fellow farmers were considered to be least positive. Farmers' beliefs were correlated weakly but significantly with their intention to increase SOM content. The large majority $(91 \%)$ of the farmers in the survey had a high or very high intention to increase SOM content. A higher intention to increase SOM content was significantly correlated with the use of organic inputs as expressed in total and effective $\mathrm{C}$ inputs.

In total 1452 farmers in five European countries (Belgium, Germany, Austria, Spain and Italy) were asked if they perceive a deficiency of SOM (Chapter 6). Results show that $18 \%$ perceived a high or very high SOM deficiency, $53 \%$ perceived a very low or low SOM deficiency and $29 \%$ giving an indication in the middle. Perceived deficiency of SOM content was related to climate (aridity), slope, soil texture and land use. Based on farmers' perceptions threshold intervals for SOM content were established (sand: 1.24.7\%, loam: $0.6-2.6 \%$ and clay: $1.0-2.4 \%$ ). Below a threshold interval, a farmer will benefit from more SOM content, irrespective of other factors such as land use or 
management. Above a threshold interval, more SOM content will not be beneficial for productive capacity from a farmers' point of view. Some indication was found that being at the extreme end for one environmental factor gives a higher chance of perceiving a deficiency of SOM than having a combination of moderate environmental conditions.

The findings in this thesis indicate that at least on the shorter term, on average, there seems to be no immediate threat from a deficiency of SOM to crop production in arable farming in Europe. The long-term experiments showed that with sufficient use of only mineral fertilisers, on average, similar yields could be attained over multiple years as with the combined use of organic inputs and mineral fertiliser. This result was independent from SOM content in the experimental fields.

Effect of organic inputs and SOM differ when taking into account specific environmental conditions, types of crops cultivated and types of organic inputs used. Long-term experiments show that organic inputs give more benefits to crop production in wet climates and on sandy soils. In addition, farmers perceive more benefits from SOM on steep slopes, sandy soils, wet or very dry climates. The additional yield effect of organic inputs is larger for potatoes than for cereals and more in general, farmers who cultivate larger shares of their land with specialized crops (including potatoes, sugar beets, onions and other vegetables) perceive more benefit from SOM. Using FYM has more benefits to crop production than using straw (even when compensating for the $\mathrm{N}$ immobilization by applying additional mineral fertiliser N). It seems that while the functions of SOM can be replaced with technical means to a large extent (tillage, use of mineral fertilisers), there are limits to this technical potential when environmental conditions are more extreme and crops are more demanding.

Indications were found that more mineral fertiliser $\mathrm{N}$ can be saved when using farmyard manure at high $\mathrm{N}$ rates (with mineral fertiliser application) than at low $\mathrm{N}$ rates (without mineral fertiliser application), based on comparisons at 'equal yield'. If further validated, this could imply an advantage of distributing available farmyard manure (and possibly other types of organic input) among many farmers in a given region: the region would require less mineral fertiliser to produce the same yield output, than when organic inputs were concentrated in few farms. Main drivers for farmers to use organic inputs are the perceived effects on soil quality, while the main barriers are the perceived financial consequences and increased pressures from weeds, pests and diseases.

If policies aim to stimulate the maintenance or increase of SOM, more insight is needed under which conditions the use of organic inputs increases or reduces pressures of 
weeds, pests and diseases. Financial consequences (at least on the short term) should also be accounted for. More importantly however, benefits from SOM for crop production cannot be taken for granted. Only in specific situations does this assumption hold. If European policies on SOM want to align benefits for the larger society (such as soil carbon sequestration, biodiversity conservation) with benefits for crop production, focus should be on areas with more extreme environmental conditions (very dry or very wet climates, steep slopes, very sandy soils), or cropping systems with more specialized or horticultural crops and less cereals. 


\section{Samenvatting}

Organische stof (OS) in de bodem wordt vaak gezien als de belangrijkste indicator voor bodemvruchtbaarheid. OS draagt namelijk bij aan elk van de drie dimensies van bodemvruchtbaarheid: de fysische (structuur, beluchting, infiltratie, watervasthoudend vermogen), de biologische (biomassa, biodiversiteit, mineralisatie van nutriënten, ziektewering) en de chemische (retentie en levering van nutriënten) dimensie. Desalniettemin is er momenteel weinig wetenschappelijke consensus over de precieze relatie tussen OS en gewasproductie.

De afgelopen jaren zijn meerdere zorgen geuit over een mogelijke daling van OS in Europese bodems. Dit heeft geleid tot verschillende voorstellen om te streven naar een bepaald percentage OS om (onder andere) de productiecapaciteit van bodems te waarborgen. Het is momenteel onduidelijk of deze zorgen gerechtvaardigd zijn. Het doel van dit proefschrift was om de rol van organische meststoffen en OS voor gewasproductie in hedendaagse Europese akkerbouw beter te begrijpen. Op een bepaald perceel akkerbouwgrond kan een boer het percentage OS verhogen door meer organische meststoffen aan te voeren, het ploegen te verminderen of door drainage te verminderen. In dit proefschrift ligt de nadruk op het toedienen van meer organische meststoffen om OS te verhogen of te behouden. De volgende soorten organische meststoffen ${ }^{1}$ zijn daarbij in acht genomen: vaste mest, drijfmest, compost, het inwerken van stro en het telen van groenbemesters. De hypothese van dit onderzoek was dat de bijdrage van OS aan gewasproductie in de akkerbouw afhangt van milieufactoren en de gewassen die geteeld worden.

De volgende onderzoeksvragen zijn gesteld: (1) Wat is het specifieke effect van organische meststoffen op de gewasopbrengst van akkerbouwgewassen in Europa? (2) Is de besparing van kunstmest door gebruik te maken van organische meststoffen afhankelijk van de totale stikstof (N) gift? (3) Wat zijn momenteel de belangrijkste motivaties en belemmeringen voor boeren om organische meststoffen te gebruiken? (4) Hoe zijn overtuigingen van boeren over OS gerelateerd aan hun daadwerkelijk gebruik van organische meststoffen? (5) Ervaren boeren een tekort aan OS? Analyse van data vond plaats op zowel veld- als bedrijfsniveau. De eerste twee onderzoeksvragen zijn beantwoord met behulp van lange-termijn experimenten. De laatste drie

\footnotetext{
${ }^{1}$ Bij gebrek aan een eenduidige alomvattende Nederlandse term wordt het woord organische meststof hier gebruikt voor zowel dierlijke mest als plantaardig materiaal (zoals compost of gewasresten).
} 
onderzoeksvragen zijn beantwoord met behulp van een grootschalige enquête, gehouden in zes Europese landen (Nederland, België, Oostenrijk, Spanje, Italië en Duitsland).

Eerdere studies naar het effect van organische meststoffen en OS op gewasopbrengsten lieten wisselende resultaten zien. Sommige studies vonden positieve effecten op de gewasopbrengst, terwijl andere studies geen effect aantoonden. Het verschil in bevindingen kan mogelijk verklaard worden doordat in sommige studies bepaalde effecten van OS, zoals een verbeterde bodemstructuur of een gewijzigd bodemleven, verward worden met een verhoogde beschikbaarheid van nutriënten. Om deze koppeling uit te sluiten, is in dit proefschrift het effect van organische meststoffen en OS op de gewasopbrengst geanalyseerd in een situatie waarbij macronutriënten niet limiterend zijn voor de gewasgroei. In deze situatie wordt een effect van OS op gewasopbrengst het 'specifieke effect' van OS genoemd, ook wel eerder het 'rest-effect' genoemd, maar niet te verwarren met de Engelse term 'residual effect' wat in deze context een andere betekenis heeft.

Om het specifieke effect van organische meststoffen te achterhalen is een meta-analyse gedaan van 20 lange termijn experimenten (Hoofdstuk.2). Curves van gewasopbrengst in relatie tot de toediening van kunstmest-N zijn berekend, met en zonder toevoeging van organische meststoffen (en met toediening van voldoende fosfor $(\mathrm{P})$ en kalium $(\mathrm{K})$ ). Het specifieke effect van organische meststoffen is uitgedrukt als het verschil tussen de maxima (de haalbare gewasopbrengsten) van de beide curves. Gemiddeld over de 20 lange termijn experimenten was het specifieke effect van organische meststoffen niet significant verschillend van nul ( +1.4 procent $\pm 1.6-95 \%$ betrouwbaarheidsinterval). Echter, onder bepaalde omstandigheden (bij het telen van wortel- en knolgewassen of zomergranen, of op erg zandige gronden of in een nat klimaat), verhoogde het gebruik van organische meststoffen de haalbare opbrengst wel. Het positieve effect varieerde hierbij, afhankelijk van de situatie, tussen de 3 en $7 \%$. Daarnaast werd er een significante correlatie vastgesteld tussen een verhoging van de haalbare gewasopbrengst en de toename van het percentage OS in de bodem.

Het gebruik van organische meststoffen kan een besparing opleveren in het gebruik van kunstmest-N. Hoeveel kunstmest er precies bespaard wordt hangt af van de samenstelling van de organische meststof, het gewas dat geteeld wordt, bodemtype, moment en manier van toediening en de voorgeschiedenis van een perceel dat zorgt voor behoud of verlies van $\mathrm{N}$ in de bodem. In dit proefschrift is een bijkomende factor 
onderzocht, die tot heden niet is meegenomen in eerdere studies: de totale hoeveelheid $\mathrm{N}$ die toegediend wordt.

In Hoofdstuk 3 is een deelverzameling genomen van de experimenten uit Hoofdstuk 2. In deze deelverzameling van acht experimenten was bekend hoeveel $\mathrm{N}$ toegediend is met organische meststoffen. Besparingen van kunstmest (door gebruik te maken van organische meststoffen) zijn vergeleken bij een lage en hoge $\mathrm{N}$ gift. Resultaten laten zien dat om een bepaalde gewasopbrengst te halen, het gebruik van vaste mest significant meer kunstmest bespaart bij een hoge dan bij een lage $\mathrm{N}$ gift (stikstofwerkingscoefficiënt van $1.12 \mathrm{ipv} 0.53, p=0.04$ ). Ook de andere soorten organische meststoffen bespaarden meer kunstmest- $\mathrm{N}$ bij een hoge dan een lage $\mathrm{N}$ gift, maar de steekproefomvang was daar te klein of de variatie in de uitkomsten te groot om een significant verschil te kunnen aantonen.

Naast effecten op gewasopbrengst of het besparen van kunstmest kunnen boeren een breed scala hebben van motivaties en belemmeringen om organische meststoffen te gebruiken of OS te verhogen in hun bodem. Volgens de 'Theorie van Gepland Gedrag' baseren mensen hun gedrag op drie belangrijke factoren: (1) hun attitude (gebaseerd op overtuigingen over 'gevolgen' van gedrag), (2) hun sociale norm (gebaseerd op overtuigingen met betrekking tot 'sociale referenten') en (3) ervaren gedragscontrole (gebaseerd op overtuigingen over 'controle factoren'). Gezamenlijk leiden ze tot een intentie, die kan leiden tot een bepaald gedrag of keuzes in management.

Om de motivaties en belemmeringen te vinden voor het gebruiken van organische meststoffen (Hoofdstuk 4), zijn semi-gestructureerde interviews gehouden met akkerbouwers in zes agro-ecologische zones in vier Europese landen (Nederland, België, Oostenrijk en Italië). Door middel van deze interviews zijn relevante gevolgen, sociale referenten en controle factoren voor het gebruik van vier soorten organische meststoffen (stro, groenbemesters, vaste mest en compost) in kaart gebracht. Vervolgens is een grootschalige enquête gehouden onder 1180 boeren om de attitudes, sociale normen en gedragscontrole te kwantificeren als motiverende factoren of belemmeringen. Motiverende factoren en belemmeringen zijn vervolgens geclassificeerd in negen categorieën (bodemtype \& klimaat, bodemkwaliteit, gewasbescherming, landgebruik, technisch, financieel, milieu-impact, juridisch en sociaal).

Belangrijke motiverende factoren voor boeren om organische meststoffen te gebruiken bleken waargenomen effecten op bodemkwaliteit (zoals een verbeterde bodemstructuur 
of verminderde erosie) en de positieve invloed van sociale referenten (zoals andere boeren of adviseurs). Belangrijke belemmeringen waren financieel gerelateerd (zoals hogere kosten of lagere inkomsten) en te verwachten effecten op gewasbescherming (zoals verhoogde onkruid- of ziektedruk, meer plagen of meer noodzaak om pesticiden te gebruiken). Deze bevindingen laten zien dat boeren een dilemma ervaren tussen een verbeterde bodemkwaliteit aan de ene kant en een hogere druk van onkruid, ziekten en/of plagen en financiële consequenties aan de andere kant bij het gebruiken van organische meststoffen.

Meer gedetailleerd onderzoek onder 435 akkerbouwers in Nederland (Hoofdstuk 5) laat zien dat boeren OS vooral waarderen vanwege het positieve effect op de bodemstructuur. Op kleigronden heeft dit voornamelijk te maken met een verbetering in de bewerkbaarheid van de bodem, terwijl op zandgronden de bijdrage aan het watervasthoudend vermogen gewaardeerd wordt. De Nederlandse boeren evalueerden het effect van OS op bodemschimmels als een negatieve uitkomst.

Het lange-termijn effect van OS werd erg sterk geacht en positief gewaardeerd door de Nederlandse akkerbouwers. Van de verschillende sociale referenten werden adviseurs gezien als degenen met de meest waardering voor OS en andere boeren als degenen met de minst positieve waardering van OS. Overtuigingen van boeren waren zwak maar significant gerelateerd met hun intentie om OS te verhogen. Het merendeel van de Nederlandse boeren (91\%) had een sterke of erg sterke intentie om OS te verhogen. Een sterkere intentie om OS te verhogen was significant gerelateerd met een hoger daadwerkelijk gebruik van organische meststoffen (uitgedrukt in totale of effectieve C die jaarlijks werd toegediend) door de respondenten.

In Hoofdstuk 6 is ingegaan op de vraag of akkerbouwers in vijf Europese landen (België, Duitsland, Oostenrijk, Spanje en Italië) een tekort ervaren aan OS. Van de 1452 geïnterviewden ervaarde $18 \%$ een groot of erg groot tekort aan OS, 53\% een klein of erg klein tekort en $29 \%$ van de akkerbouwers gaf een neutrale indicatie. Ervaren tekort aan OS was gerelateerd aan klimaat (droog of nat), helling, bodemtextuur en landgebruik. Gebaseerd op de percepties van de boeren zijn ranges van grenswaarden voor OS vastgesteld (zand: 1.2-4.7\%, zavel 0.6-2.6\% en klei: 1.0-2.4\%). Beneden de gegeven ranges ervoeren de boeren een voordeel van OS, ongeacht andere factoren zoals landgebruik of management. Boven de gegeven ranges ervoeren boeren een toename in OS niet als een voordeel voor de productie capaciteit van de bodem. Er was enige indicatie dat een extreme waarde van één factor (zoals helling, bodemtextuur, of 
landgebruik) een grotere kans geeft op een tekort aan OS dan een combinatie van gemiddelde factoren.

De resultaten in dit proefschrift laten zien dat op de korte termijn, gemiddeld genomen, er geen sprake is van een onmiddellijk risico van een tekort aan OS voor gewasproductie op akkerbouwgrond in Europa. De lange-termijn experimenten laten zien dat met voldoende gebruik van alleen kunstmest er, gemiddeld genomen over meerdere jaren, dezelfde gewasopbrengsten kunnen worden behaald als met een combinatie van kunstmest en organische meststoffen. Dit resultaat was onafhankelijk van het OSgehalte in de betreffende experimenten.

Effecten van organische meststoffen op gewasopbrengsten verschillen echter afhankelijk van omgevingsfactoren, type gewassen die geteeld worden en het soort organisch meststof dat gebruikt wordt. Lange-termijn experimenten laten zien dat organische meststoffen meer voordeel opleveren voor gewasproductie in nattere klimaten en op zandige gronden. Daarnaast ervaren boeren meer voordeel van OS op steilere hellingen, op zandige gronden en in natte of erg droge klimaten. Het specifieke effect van organische meststoffen is groter voor aardappels en meer in het algemeen ervaren boeren die meer gespecialiseerde gewassen telen (zoals aardappels, suikerbieten, uien en andere groentegewassen) meer voordeel van OS. Het gebruik van vaste mest heeft meer voordelen voor de gewasproductie dan het inwerken van stro (zelfs als er gecompenseerd wordt voor $\mathrm{N}$-immobilisatie door meer kunstmest-N toe te dienen). Het lijkt erop dat alhoewel de functies van OS merendeels vervangen kunnen worden door technische middelen (zoals door te ploegen of door gebruik te maken van kunstmest), dit vervangingspotentieel beperkter is wanneer milieufactoren extremer zijn en er meer veeleisende gewassen geteeld worden.

Het gebruik van vaste mest bespaart (per eenheid vaste mest) meer kunstmest als het toegediend wordt in combinatie met een relatief hoge kunstmest-N gift dan in combinatie met een relatief lage kunstmest-N gift of zonder kunstmest-N. Dit zou kunnen impliceren dat met de beschikbare hoeveelheid vaste mest in een regio meer kunstmest bespaard wordt indien deze verdeeld wordt over meerdere bedrijven, in plaats van geconcentreerd wordt toegediend op enkele bedrijven. Dit zou mogelijk ook kunnen gelden voor andere soorten organische meststoffen.

Belangrijke motivaties voor boeren om organische meststoffen te gebruiken zijn positieve effecten op bodemkwaliteit, terwijl de belangrijkste belemmeringen liggen in de financiële consequenties en een verhoogde druk van onkruiden, ziekten en plagen. 
Als beleidsmakers een stimulans wil geven om OS in akkerbouwgronden te behouden of te verhogen, dan zal er meer inzicht nodig zijn waarom en onder welke omstandigheden het gebruik van organische meststoffen leidt tot een verhoogde druk van onkruiden, ziekten en plagen. Financiële consequenties (ten minste die op de korte termijn spelen) zouden hierbij ook betrokken kunnen worden. Belangrijker nog is het om te beseffen dat voordelen van OS voor de gewasopbrengst zich niet altijd voordoen. Alleen in specifieke situaties treedt dit voordeel op. Als Europees beleid omtrent OS in landbouwgronden maatschappelijke voordelen (zoals koolstofopslag of behoud van biodiversiteit) wil afstemmen met voordelen voor gewasproductie, dan zal de nadruk moeten liggen op gebieden met extremere milieus (erg droge of natte klimaten, steilere hellingen, zandige gronden), of op regio's met meer gespecialiseerde gewassen en een laag aandeel granen. 


\section{Acknowledgements}

Like any other scientific work, this work would not have been possible without support of numerous colleagues, friends and family. First and foremost, I would like to thank my promotor Martin van Ittersum, whose patience almost seemed endless. Thanks, Martin!! I also want to thank Hein ten Berge, project leader of CATCH-C and my copromotor. Thanks for your enthusiasm, Hein and - when in Wageningen - for creating time for discussions and the occasional coffee.

One of the most cherished parts of my $\mathrm{PhD}$ journey was spending time at Rothamsted Research. I still vividly remember the lunch sessions and Friday tea with cookies. Right in a very difficult time of my $\mathrm{PhD}$ I found a great inspiration in my supervisor abroad Andy Whitmore. Thanks for hosting me, Andy. I wish I could have stayed longer.

In Wageningen, on the very first day of my PhD journey, I met Anouk Cormont whom proved to be a very strong ally in sharing both work and the latest baby pictures :-). Not much later I met her colleague Gerard Hazeu who brought up the idea of soil organic matter deficiency as a concept. Thanks to both of you for the pleasant collaboration. I also cherish the collaboration with Annette Pronk who shared her wealth of practical knowledge and - together with Bert Rijk - kept the Dutch farm survey running when I was on leave. In addition, both Jan Verhagen and Peter Leffelaar were very helpful in sharing their old boxes of literature on soil organic matter with me. This was an oldfashioned but handy manner to get started. At the end of my PhD, Jaap Schröder proved to be a useful sparring partner.

Within the CATCH-C project, I found many many nice collaborations with Carlo Grignani, Laura Zavattaro, Luca Bechini, Chiara Costamagna, Magdalena Werner, Janine Krüger, Juan Vicente Giráldez, Gema Guzmán, Tom Vanwalleghem, Karl Vanderlinden, Greet Ruysschaert, Jo Bijttebier, Tommy D'Hose, Heide Spiegel, Norman Schlatter, Taru Lehtinen, Nadine Turpin, Alina Syp and many others. Thanks to all of you for making the project not only successful but also fun!

The fun part in my $\mathrm{PhD}$ also benefitted from numerous office mates at the Plant Production Systems group to share lunch, coffee or a Friday afternoon drink with. Charles Bagura, Guillaume Ezui, Edouard Rurangwa, Jairos Rurinda, Godfrey Taulya, Wilson Leonardo, Gatien Falconnier, Lotte Klapwijk, Esther Ronner, Greta van den Brand, Ilse de Jager, Wytze Marinus, Lenny van Bussel, Argyris Kanellopoulos, Sheida Sattari, Jiska van Vliet, Jannicke Wichern, Pytrick Reidsma, Tom Schut, Katrien 
Deschaemaker, Juliana Gil, Gerrie van de Ven, Maja Slingerland, Beyene Melisse, Anne de Valença, Marieke Sassen, Madeleine Florin, Sander de Vries, Christiaan Biemond, Bob Douma, Joost van Heerwaarden, Petra Rietberg and many many others: thanks a lot! With a special thanks to Ria van Dijk, Linda Kaster, Charlotte Schilt and Alex-Jan de Leeuw for keeping the office running! When times became less fun and more difficult I also found support from many colleagues, especially Esther was often willing to share some $\mathrm{PhD}$-sorrow, thanks for the friendship offered.

At Rothamsted I was lucky to find Shibu Muhammed, Lindsay Todman, Gordon Dailey, Kevin Coleman, Margaret Glendining and Tom Sizmur as my temporary colleagues: Thanks for making me feel welcome. The last few months of my PhD I spent - together with colleagues in crime Joao da Silva and Lotte Woittiez - writing at the temporal housing of Agrosystems Research. Thanks for hosting us, Raymond! And thanks to all the other AGRO-colleagues for sharing much-appreciated coffee breaks in the B-Bar or outside in the sun.

Almost coming to the end, I would like show my gratitude to Ken Giller for introducing me to Martin and sharing his views on soils and farming systems. Another major influence has been Bert Janssen. Thanks, Bert, for sharing your piles of knowledge and critical mind.

Finally, in retrospect, my life choices benefitted much from my (grand) parental influences. I want to thank my mother Ineke Ginjaar, who taught me the essential lesson that there is no better man for a job than a woman. Thanks to my father Gerrit Hijbeek for sharing his love for nature with his children. I want to thank my grandmother Nell Ginjaar-Maas for motivating young Dutch girls to choose a technical study and take the future in their own hands, I surely benefitted from her efforts. I thank my grandfather Leendert Ginjaar for teaching me that solid arguments matter more than authority does. I thank my grandparents Roel and Maartje Hijbeek for brightening up the day with jokes and laughter. I want to thank my brother and sister for being there. I thank Eric for sharing the journey with me. Finally, I want to thank Jason for being such a beautiful shining light. May all your dreams be bright and passionate. 


\section{About the author}

Renske Hijbeek was born on the $14^{\text {th }}$ of July 1983 in Rotterdam, the Netherlands. After secondary school she travelled for some time through North America and studied for one year Physics at the Rijksuniversiteit Groningen before landing in Wageningen. In Wageningen she obtained a BSc degree in Environmental Science. She conducted an internship in Sierra Leone with a local youth organisation and wrote her BSc thesis on the relation between environmental degradation and violent conflict. During this time she was board member of the study association for environmental students and student assistant at the department for Environmental Science.

Following her BSc degree, she completed an MSc degree in Human Ecology at the Vrije Universiteit Brussel. She conducted her MSc thesis at the Laboratory of Plant Biology and Nature Management. The subject of her thesis was the use of plotless vegetation sampling methods in mangrove forests. This included a period of field work in Kenya and resulted in a scientific publication. After graduation she worked at the Dutch ministry of Agriculture and Economic Affairs on topics related to sustainable agriculture. During this time, she was seconded for half a year to the taskforce on resource use efficiency of DG Environment at the European Commission in Brussels.

Between 2012 and 2017, Renske worked at the Plant Production Systems Group of Wageningen University, mainly in the European FP7 project CATCH-C. In this project she collaborated with researchers from different institutes across eight European countries, developed a farm typology and helped to set up a farm survey among more than 3000 farmers. This $\mathrm{PhD}$ thesis is in part based on data collected in this project. During her PhD, she went for an exchange period of six months to Rothamsted Research in the UK. 


\section{Publications}

\section{Refereed scientific journals}

Hijbeek, R., van Ittersum, M. K., ten Berge, H. F. M., Gort, G., Spiegel, H. \& Whitmore, A. P. 2017. Do organic inputs matter - a meta-analysis of additional yield effects for arable crops in Europe. Plant and Soil 411: 293-303

Hijbeek R., Cormont A., Hazeu G.W., Bechini L., Zavattaro L., Janssen B.H., Werner M., Schlatter N., Guzmán G., Bijttebier J., Pronk A.A., van Eupen M. \& van Ittersum, M.K. 2017. Do farmers perceive a deficiency of soil organic matter? A European and farm level analysis. Ecological Indicators 83: 390-403

Hijbeek R., ten Berge H.F.M., Whitmore A.P., Barkusky D., Schröder, J.J. \& van Ittersum, M.K. 2017. Apparent Nitrogen fertiliser replacement values for organic amendments appear to increase with $\mathrm{N}$ application rates. Nutrient Cycling in Agroecosystems DOI 10.1007/s10705-017-9875-5

Hijbeek, R.,Pronk, A.A., van Ittersum, M.K., ten Berge, H.F.M., Bijttebier, J. \& Verhagen, A. 2017 (in press) What drives farmers to increase soil organic matter? A case study in The Netherlands. Soil Use and Management

Khan, M. N. I., Hijbeek, R., Berger, U., Koedam, N., Grueters, U., Islam, S. Z., Hasan, M. A. \& Dahdouh-Guebas, F. 2016. An Evaluation of the Plant Density Estimator the PointCentred Quarter Method (PCQM) Using Monte Carlo Simulation. PLoS ONE 11(6): e0157985.

Hijbeek, R., Koedam, N., Khan, M. N. I., Kairo, J. G., Schoukens, J. \& Dahdouh-Guebas, F. 2013. An Evaluation of Plotless Sampling Using Vegetation Simulations and Field Data from a Mangrove Forest. PLoS ONE, 8 (6): e67201.

\section{Conference proceedings}

Ruysschaert, G., Bijttebier, J. Bechini, L., Zavattaro, L., Werner, M., Hijbeek, R, Pronk, A., Ten Berge, H. 2017. Barriers and drivers for adoption of non-inversion tillage in four European countries. 1st World conference Soil and Water Conservation under Global change. Lleida, Spain 12-16 June 2017

ten Berge, H., Hijbeek, R., van Ittersum, M., Gort, G. \& Whitmore, A. 2016. Apparent longterm fertilizer replacement value of arganic amendments depends on mineral fertilizer $\mathrm{N}$ range itself. Efficient use of different sources of nitrogen in agriculture-from theory to practice Skara, Sweden 27 June-29 June 2016, 438.

Hijbeek, R., Ten Berge, H., Van Ittersum, M. \& Whitmore, A. 2015. Effects of organic matter on attainable yields across Europe. In: Book of Abstracts Wageningen Soil Conference 2015 'Soil Science in a Changing World'. Wageningen. 
Bijttebier, J., Ruysschaert, G., Marchand, F., Hijbeek, R., Pronk, A., Schlatter, N., Guzmán, G., Syp, A., Werner, M., Bechini, L., Guiffant, N. \& Wauters, E. 2014. Assessing farmers' intention to adopt soil conservation practices across Europe. In: 11th European IFSA Symposium, Farming Systems Facing Global Challenges: Capacities and Strategies, Proceedings, Berlin, Germany, 1-4 April 2014. International Farming Systems Association (IFSA) Europe, pp. 1903-1910.

Hijbeek, R., Pronk, A., ten Berge, H., van Ittersum, M., Ruysschaert, G. \& Verhagen, A. 2014. Barriers to adopting best management practices aiming at soil fertility and GHG mitigation across dairy farmers in The Netherlands. In: 11th European IFSA Symposium, Farming Systems Facing Global Challenges: Capacities and Strategies, Proceedings, Berlin, Germany, 1-4 April 2014. International Farming Systems Association (IFSA) Europe, pp. 1903-1910.

\section{Scientific reports}

Bijttebier, J., Ruysschaert, G., Hijbeek, R., Rijk, B., Werner, M., Raschke, I., Steinmann, H., Zylowska, K., Pronk, A., Schlatter, N., Guzmán, G., Syp, A., Bechini, L., Turpin, N., Guiffant, N., Perret, E., Mauhe, N., Toque, C., Zavattaro, L., Costamagna, C., Grignani, C., Lehninen, A. B., A., Spiegel, H., Portero, A., Van Walleghem, T., Pedrera, A., Lahguna, A., Vanderlinden, K. \& Giraldez, V. 2015. Farmers review of Best Management Practices: drivers and barriers as seen by adopters and non-adopters. D4.422. CATCH-C report. p. 171

Pronk, A., Bijttebier, J., ten Berge, H., Ruysschaert, G., Hijbeek, R., Rijk, B., Werner, J., Raschke, I., Steinmann, H. \& Zylowska, K. 2015. List of drivers and barriers governing soil management by farmers, including cost aspects: D4.434. CATCH-C report. p. 180

Pronk A.A., Rijk B. and Hijbeek R. 2014. Task 4.2 Farm survey country report: The Netherlands., CATCH-C report. Wageningen University and Research Centre, Wageningen, p. 262.

Hijbeek R., Wolf J. and Van ittersum M.K. 2013. A typology of farming systems, related soil management and soil degradation in eight European countries. D2.242. CATCH-C report. Wageningen University and Research Centre, Wageningen, p. 226.

\section{Other}

Hijbeek, R. 2017. Relatie organische stof en gewasopbrengsten is niet zo simpel. Boerderij, http://www.boerderij.nl/Home/Blogs/2017/2/Relatie-organische-stof-engewasopbrengsten-is-niet-zo-simpel-96207E/

Hijbeek, R. 2016 Organic matter in European soils: Solution for food security and climate change mitigation? Website of the Global Research Alliance on agricultural greenhouse gas emissions.

Pronk, A. \& Hijbeek, R. 2015. Bodemverbetering: vooral traditioneel. Boerderij, 100, A14A15. 


\section{PE\&RC Training and Education Statement}

With the training and education activities listed below the $\mathrm{PhD}$ candidate has complied with the requirements set by the C.T. de Wit Graduate School for Production Ecology and Resource Conservation (PE\&RC) which comprises of a minimum total of 32 ECTS (= 22 weeks of activities)

\section{Review of literature (4.5 ECTS)}

The role of soil organic matter for arable farming in Europe

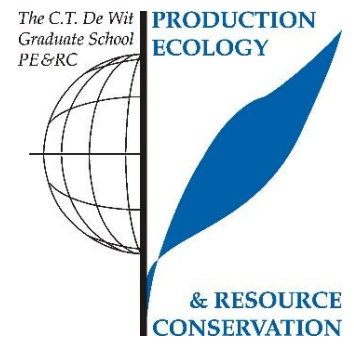

\section{Writing of project proposal (4.5 ECTS)}

Raising soil organic matter content in European arable lands: a viable option at field, farm or regional level?

\section{Post-graduate courses (4.2 ECTS)}

Theoretical ecology; Rijksuniversiteit Groningen (2012)

Linear models, generalized linear models and mixed linear models; PE\&RC (2014)

Introduction to R for statistical analysis; PE\&RC (2014)

\section{Laboratory training and working visits (0.6 ECTS)}

Workshop on the theory of planned behaviour and on how to conduct semi-structured interviews with farmers; ILVO, BE (2013)

\section{Invited review of (unpublished) journal manuscript (5 ECTS)}

European journal of agronomy: crop residue management and wheat productivity (2016)

Agronomy journal: straw management, tillage options and maize yields (2016)

Nutrient cycling in agroecosystems: comparison of nitrogen flow indicators for dairy farms (2017)

Ecological Indicators: effects of organic and mineral fertilisers on soil indicators and crop production (2017)

Soil Use and Management: effect of different organic inputs in conventional and organic cropping systems (2017) 
Deficiency, refresh, brush-up courses (4.5 ECTS)

Geo-information tools; WUR (2012)

Basic statistics; PE\&RC (2014)

\section{Competence strengthening / skills courses (2.7 ECTS)}

Project and time management; WGS (2013)

Techniques for writing and presenting a scientific paper; WGS (2013)

PE\& RC Annual meetings, seminars and the PE\&RC weekend (2.1 ECTS)

PE\&RC Weekend $(2012,2016)$

PE\&RC Carousel (2016)

Wageningen PhD symposium (2017)

Discussion groups / local seminars / other scientific meetings (8 ECTS)

$\mathrm{PhD}$ Discussion group Sustainable Intensification of Agricultural Systems (SIAS) (2013-2016)

Annual meetings of the European research project CATCH-C; in the Netherlands, Italy and Poland (2012-2015)

Presentation of $\mathrm{PhD}$ research at a lunch meeting of the Conservation Science group of Cambridge University, UK (2016)

Presentation of $\mathrm{PhD}$ research at a foodFirst Vijverberg session on the precarious balance between science and policy making (2016)

International symposia, workshops and conferences (6.6 ECTS)

International conference Soil Carbon Sequestration; Reykjavik, Iceland (2013)

Wageningen Soil Conference; Wageningen, the Netherlands (2015)

Ecosummit; Montpellier, France (2016)

Lecturing / supervision of practicals / tutorials (4.2 ECTS)

Modelling Biological Systems

Analysing Sustainability of Farming Systems

Supervision of a MSc student (3 ECT)

Organic matter inputs and nitrate leaching 
Renske Hijbeek was financially supported by the European Commission, Directorate General for Research \& Innovation, within the 7th Framework Programme of RTD, Theme 2 - Biotechnologies, Agriculture \& Food (Grant Agreement $N^{\circ}$ 289782). The views and opinions expressed in this thesis are purely those of the writers and may not in any circumstances be regarded as stating an official position of the European Commission.

Financial support from Wageningen university for printing this thesis is gratefully acknowledged

Cover design by Arjan Hijbeek (www.arjanhijbeek.com)

Printed by Gildeprint Drukkerijen 



\section{Propositions}

1. More soil organic matter does not necessarily imply more soil fertility. (this thesis)

2. The potential to replace functions of soil organic matter for arable crop production by technical means is more limited under extreme environmental conditions.

(this thesis)

3. Sequestering carbon in agricultural soils is at best a short-term, not a sustainable solution to mitigate climate change.

4. The need for economic quantification of ecosystem services is a defeat of the rule of law by the rule of the market.

5. The large volume of literature available on any given topic makes it easy to transform opinions into facts and facts into opinions.

6. It is better to evaluate research proposals on questions asked and methodologies proposed, rather than on promised impacts and innovations.

7. Societal valorisation of life science research does not only need clear policy recommendations from scientists, it also requires expert policy makers to capture underlying scientific principles.

8. Without an obligatory and state-paid paternity leave equal in length to the current obligatory and state paid maternity leave, all attempts to achieve professional gender equality will be futile.

Propositions belonging to the thesis, entitled

On the role of soil organic matter for crop production in European arable farming Renske Hijbeek

Wageningen, 4 October 2017 
